\title{
Functional traits and diversity of intertidal seaweeds: from individuals to communities
}

\author{
Laura Cappelatti, MSc \\ Department of Biosciences \\ Swansea University
}

Submitted to Swansea University in fulfilment of the requirements for the Degree of Doctor of Philosophy

2020

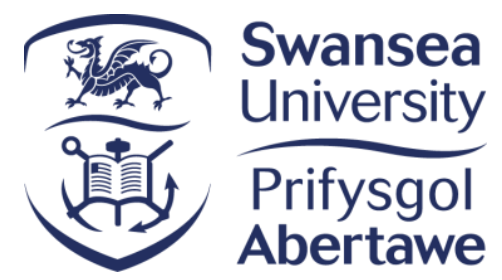




\section{Thesis Summary}

Marine producers such as seaweeds and seagrasses support a wide range of coastal ecosystem functions and services worldwide. As marine assemblages face accelerating environmental change, there is a growing need to understand and predict ecosystem-level consequences from changes in community composition and diversity. Functional traits facilitate the link between species identity and ecosystem processes and functions.

My research aimed to elucidate patterns, processes, and possible ecosystem effects of community assembly of seaweeds. More specifically, I investigated how multiple aspects of the functional diversity of seaweeds vary across an environmental gradient, from low to high shore. With collaborators, I developed an extensive database of functional traits. I then applied this trait data to community surveys across intertidal rocky shores in south Wales, UK. Scaling from individuals to communities, I investigated the taxonomic, functional, and phylogenetic structure of assemblages.

Among the main findings are that 1) within morpho-functional groups - the most common approach in seaweed functional ecology - there is substantial variation in traits, which demonstrates how much information is gained by moving from grouping approaches to measured traits; 2) functional diversity of seaweeds declines alongside species richness across the intertidal gradient in a scale-dependent way; 3) changes in dominant traits between intertidal zones represent shifts in ecological functions; and 4) phylogenetic diversity of the largest algae clade (Rhodophyta) did not accurately describe how functionally different species are, although it provided additional insights into their ecology. Collectively, results show that seaweed traits can improve our understanding of the assembly of these highly diverse marine producers, while bringing a new perspective to the well-studied seaweed intertidal zonation. 


\section{Declarations and statements}

\section{Declaration}

This work has not previously been accepted in substance for any degree and is not being concurrently submitted in candidature for any degree.

Signed .

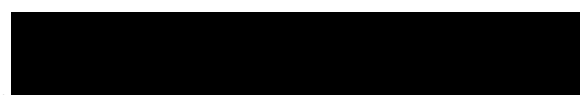
(candidate)

Date: $21^{\text {st }}$ July 2020

\section{Statement 1}

This thesis is the result of my own investigations, except where otherwise stated. Where correction services have been used, the extent and nature of the correction is clearly marked in a footnote(s). Other sources are acknowledged by footnotes giving explicit references. A bibliography is appended.

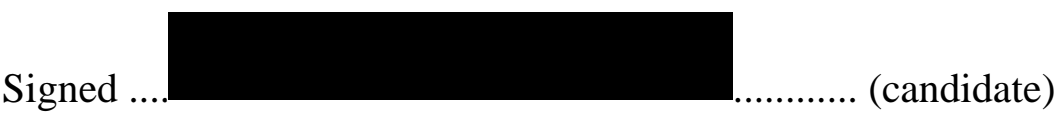

Date: $21^{\text {st }}$ July 2020

\section{Statement 2}

I hereby give consent for my thesis, if accepted, to be available for photocopying and for inter-library loan, and for the title and summary to be made available to outside organisations.

Signed (candidate)

Date: $21^{\text {st }}$ July 2020

This research has been funded by the Brazilian National Council for Scientific and Technological Development (CNPq - Science Without Borders grant 202032/2015-9). 


\section{Table of Contents}

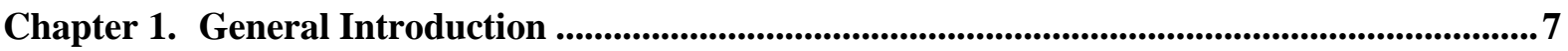

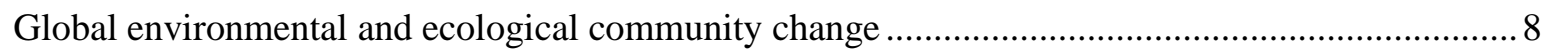

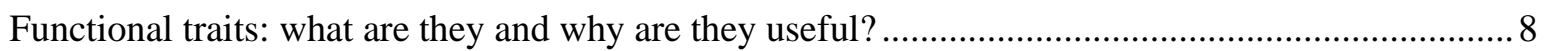

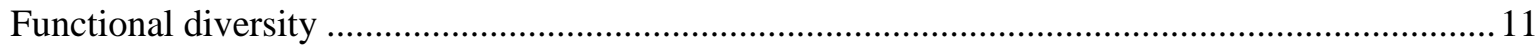

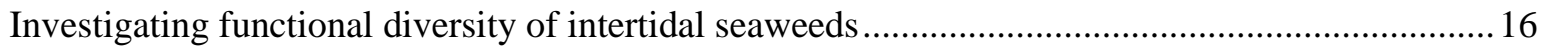

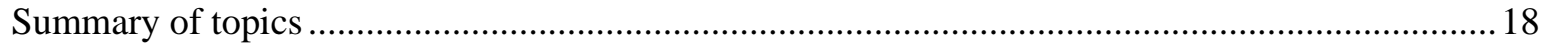

Chapter 2. Applying continuous functional traits to large brown macroalgae: variation across

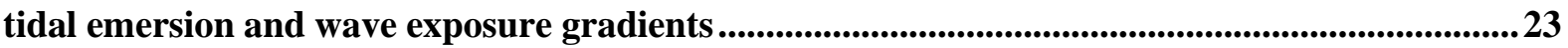

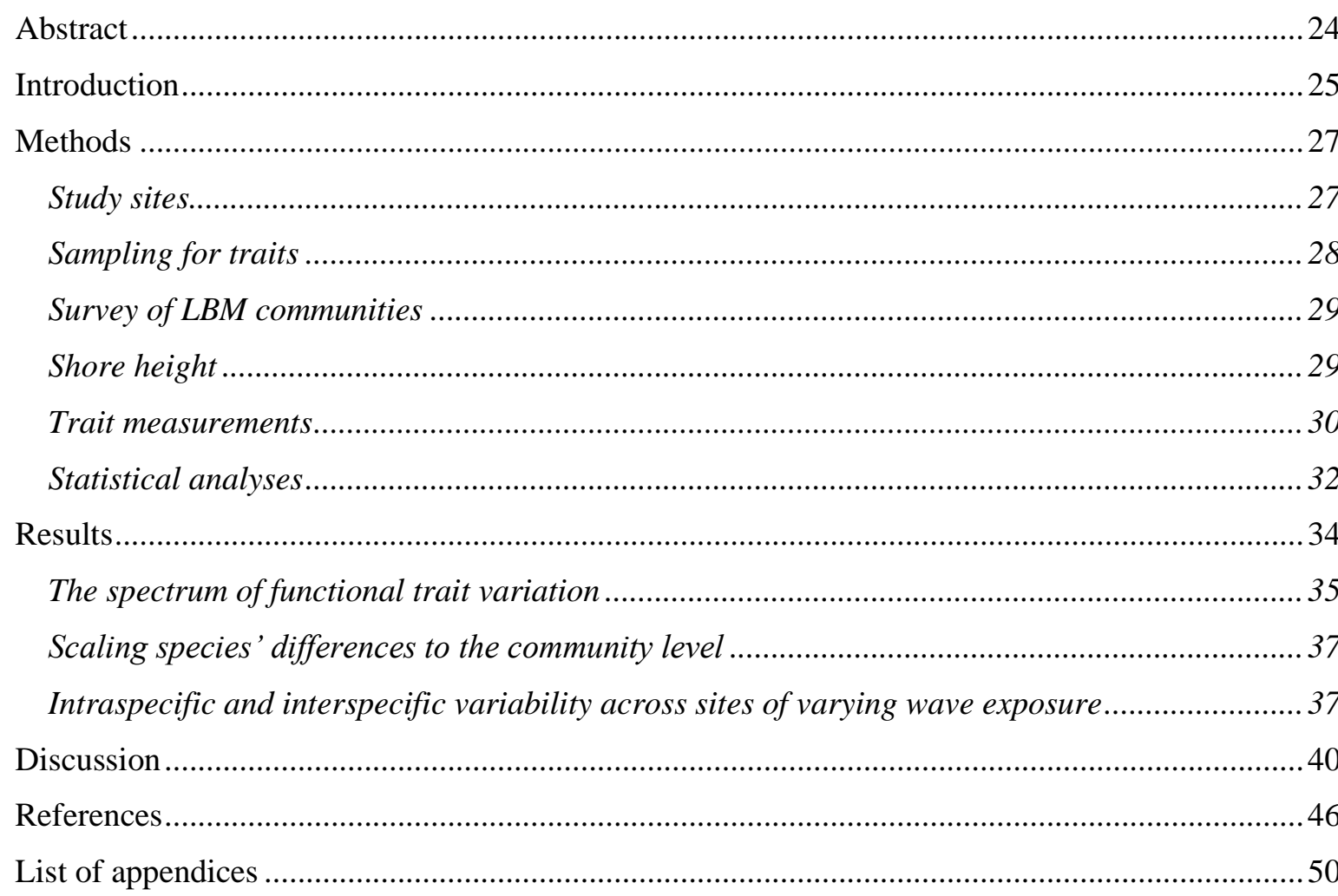

Chapter 3. Functional diversity of seaweeds declines scale-dependently across an environmental stress gradient..........................................................................................................51

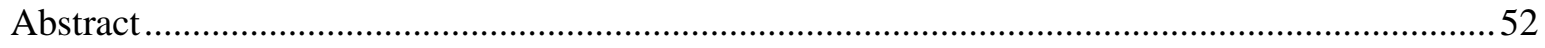

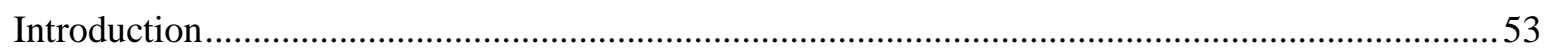

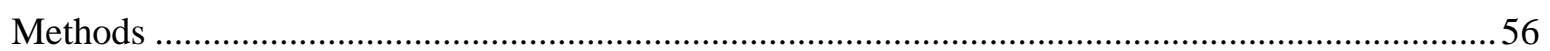

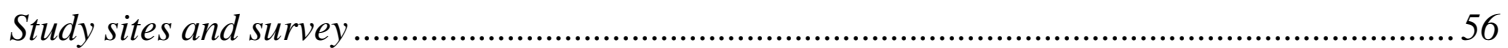

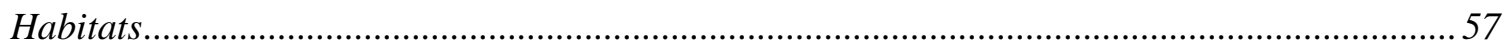

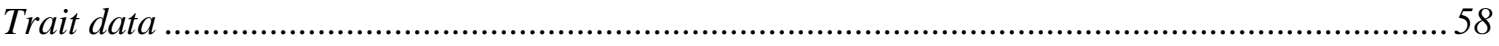

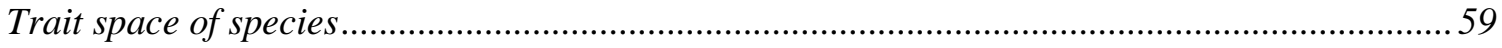

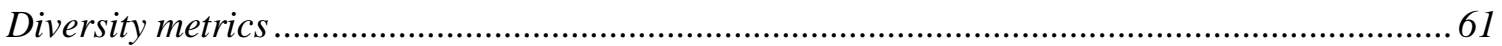

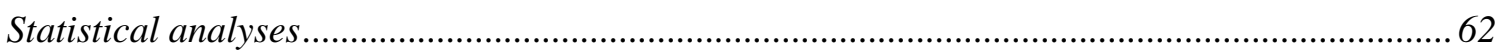

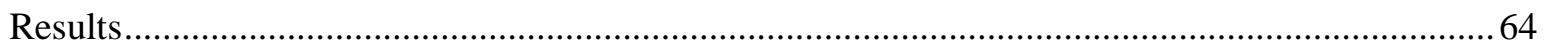




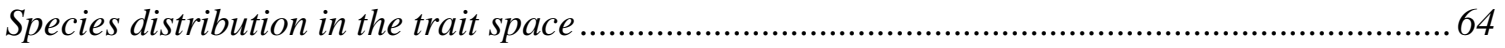

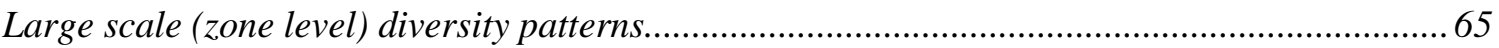

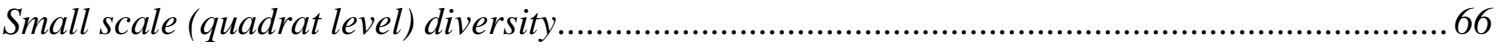

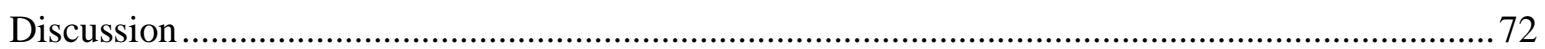

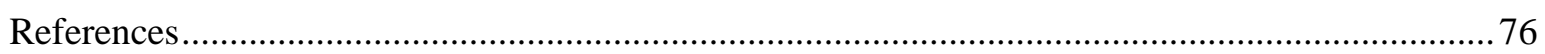

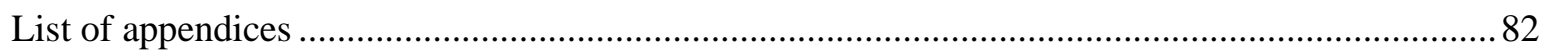

Chapter 4. A phylogenetic perspective to the functional diversity of red seaweeds ......................83

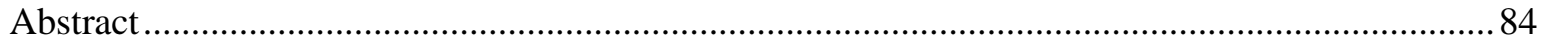

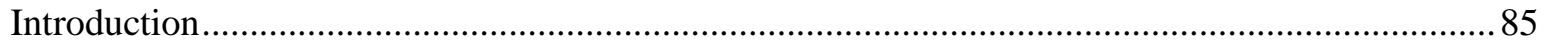

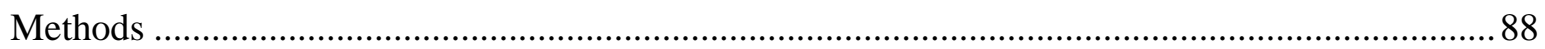

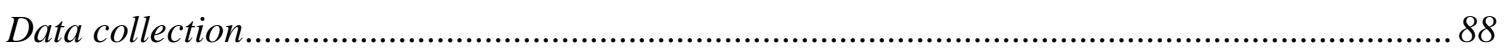

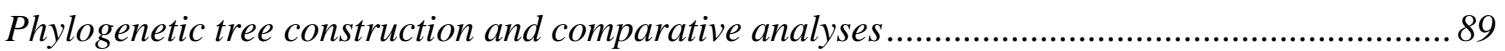

Testing the application of a phylogenetic approach to a macroalgal community ......................... 91

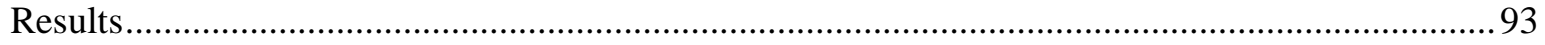

Do traits related to photosynthesis, structure and space use have a phylogenetic signal? .......... 93

How well does phylogenetic diversity capture functional trait diversity? ..................................... 95

Can phylogenetic diversity reveal hidden trait-environment relationships in macroalgae? ........ 98

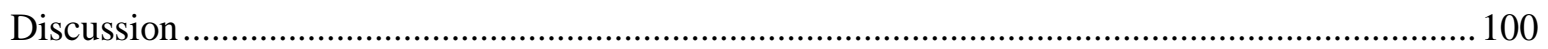

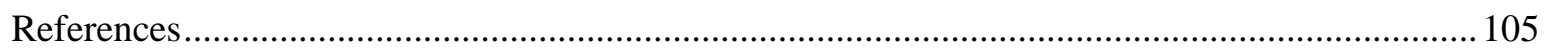

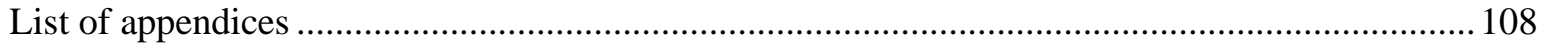

Chapter 5. Functional diversity of seaweeds revisited: confronting traditional groups with quantitative traits.............................................................................................................................................109

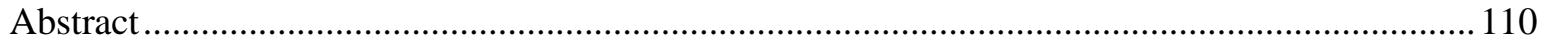

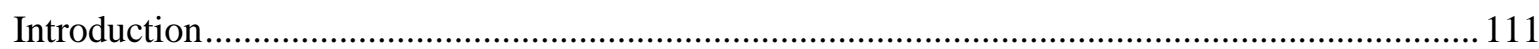

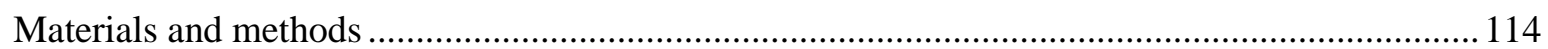

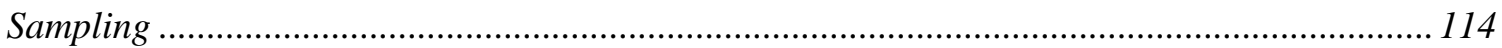

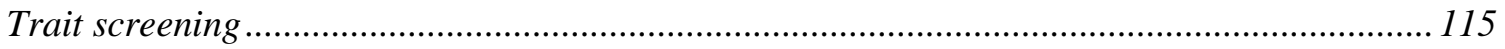

Categorisation of species into functional groups..................................................................... 118

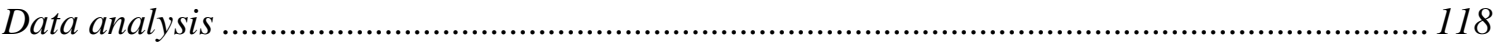

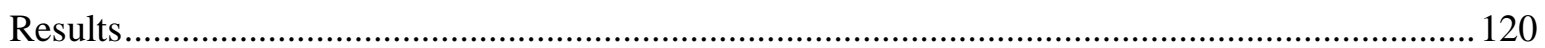

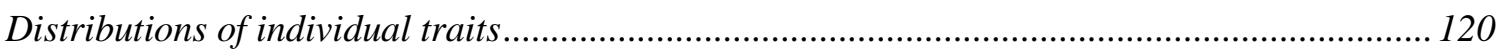

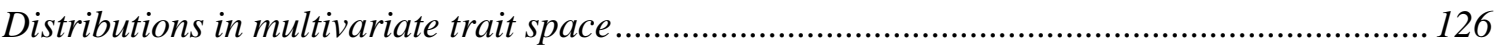

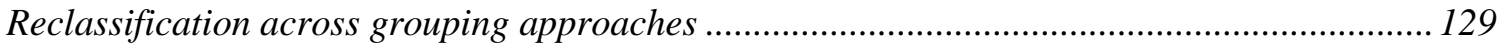

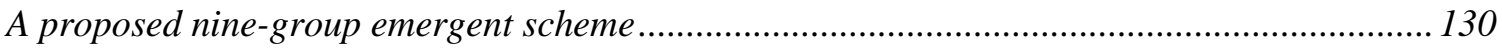

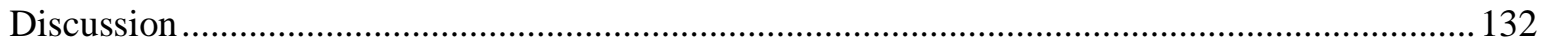

Traditional groups are incomplete representatives of underlying physiological and ecological

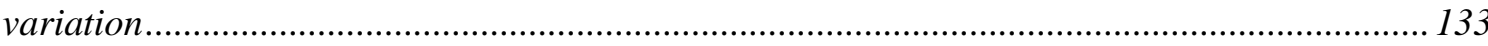


Common categorisations of vertical space use provide coarse assessments of the ecological impacts of fast-paced changes in macroalgal assemblages

Functional traits and emergent groups offer more ecologically informative alternatives to traditional macroalgal groups...

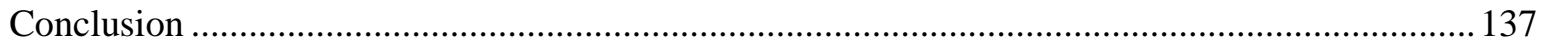

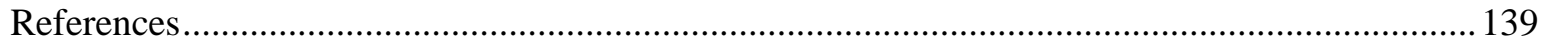

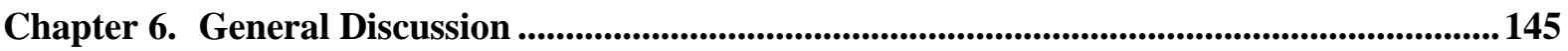

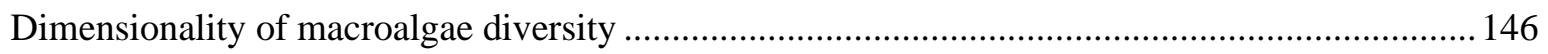

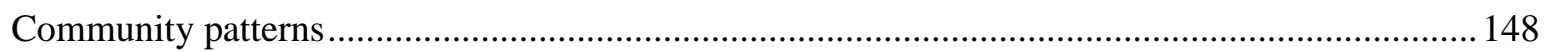

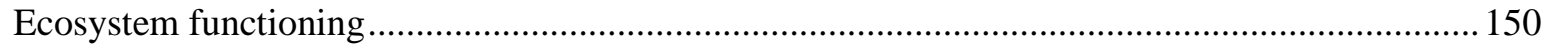

Applying phylogeny to the study of functional diversity of macroalgae ......................................... 151

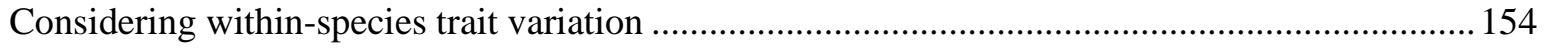

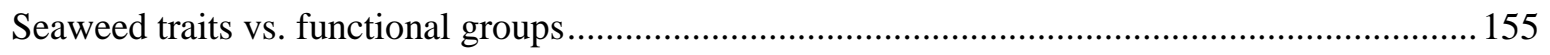

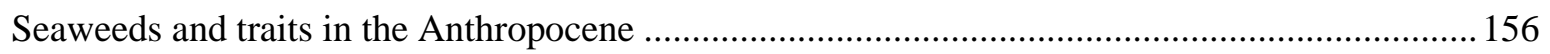

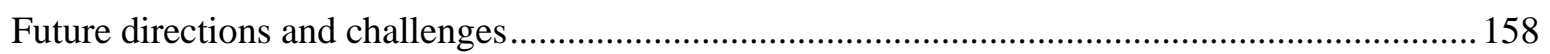

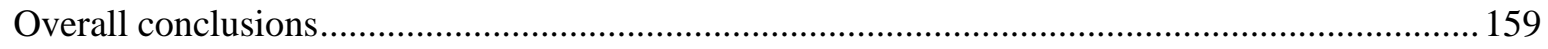

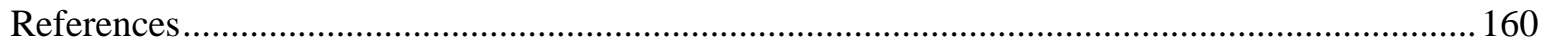

Chapter 7. Supplementary material .......................................................................................................164

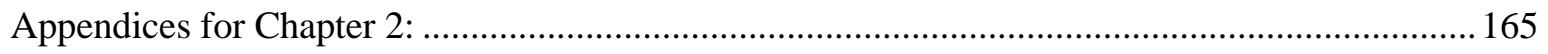

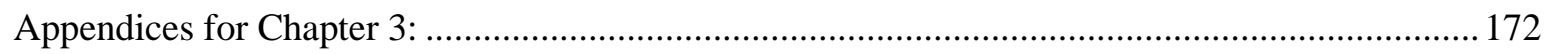

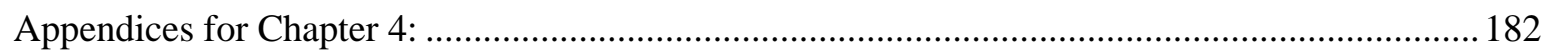

Appendix for Chapter 5: "Functional diversity of seaweeds revisited: confronting traditional groups

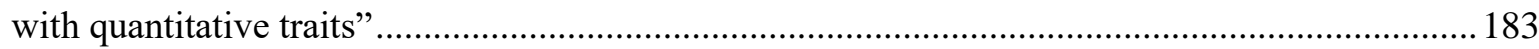

Chapter 8. Glossary ....................................................................................................................................... 186 


\section{Acknowledgements}

I would first like to thank my supervisor John Griffin, for his support and friendship throughout my $\mathrm{PhD}$. I am forever grateful for his guidance since before I started, giving positive feedback, being understanding of my limitations and providing the necessary tools I needed to go through this four-year process.

I cannot thank my husband Igor Pessi enough for being by my side during all my $\mathrm{PhD}$, even when living in different countries for most of the time. His love and companionship are more than I could ever ask for. I could have done this without him, but it would have been much harder.

I also thank my family, without whom I would not have gotten this far in my academic career. Their incentive for science and nature since I was a child has certainly played a big role in my development, not only professional, but also personal. I love nature because I was thought to appreciate it and respect it all my life. Ewerton (dad), Lisete (mom) and Amanda (sister), it has been hard living apart for years, but I never felt distant from them.

I am thankful for all the amazing people I have met during my $\mathrm{PhD}$, who have helped me and thought me so much, at work and in life. My office friends, Alizée, Davide, Kate, Tom, Sanaa: I have missed your company; working (and partying) with you was such a joy. My friends along the hallway, the list is long but I want to highlight a few that made a huge difference: Suzana, Jessica, Ben, Waldir, Frances, Dania, Marta, Teja, Sara, just remembering meeting them on the hall brings a smile to my face. Other dear friends that Swansea gave me: Pietro, Pipo, Josh, Larissa, Dimitra, André, Deiene, David, Raul and Mike, who are all awesome. I thank each one of them for being part of this adventure with me.

Finally, I also want to thank some friends from Brazil, who have remained closed to me an ocean apart and whose support have helped me get this far. Vinicius, for the help with statistics and the honest friendship filled with silliness. Anelise, Natália, for their unconditional friendship, always bringing me joy (and more silliness). Ana Lúcia and Gabriel, for the support and the sincere friendship I got since we first met (and an extra dose of silliness). I also thank my husband's family, for the love and support.

Thank you.

Laura 


\section{Chapter 1}

\section{General Introduction}

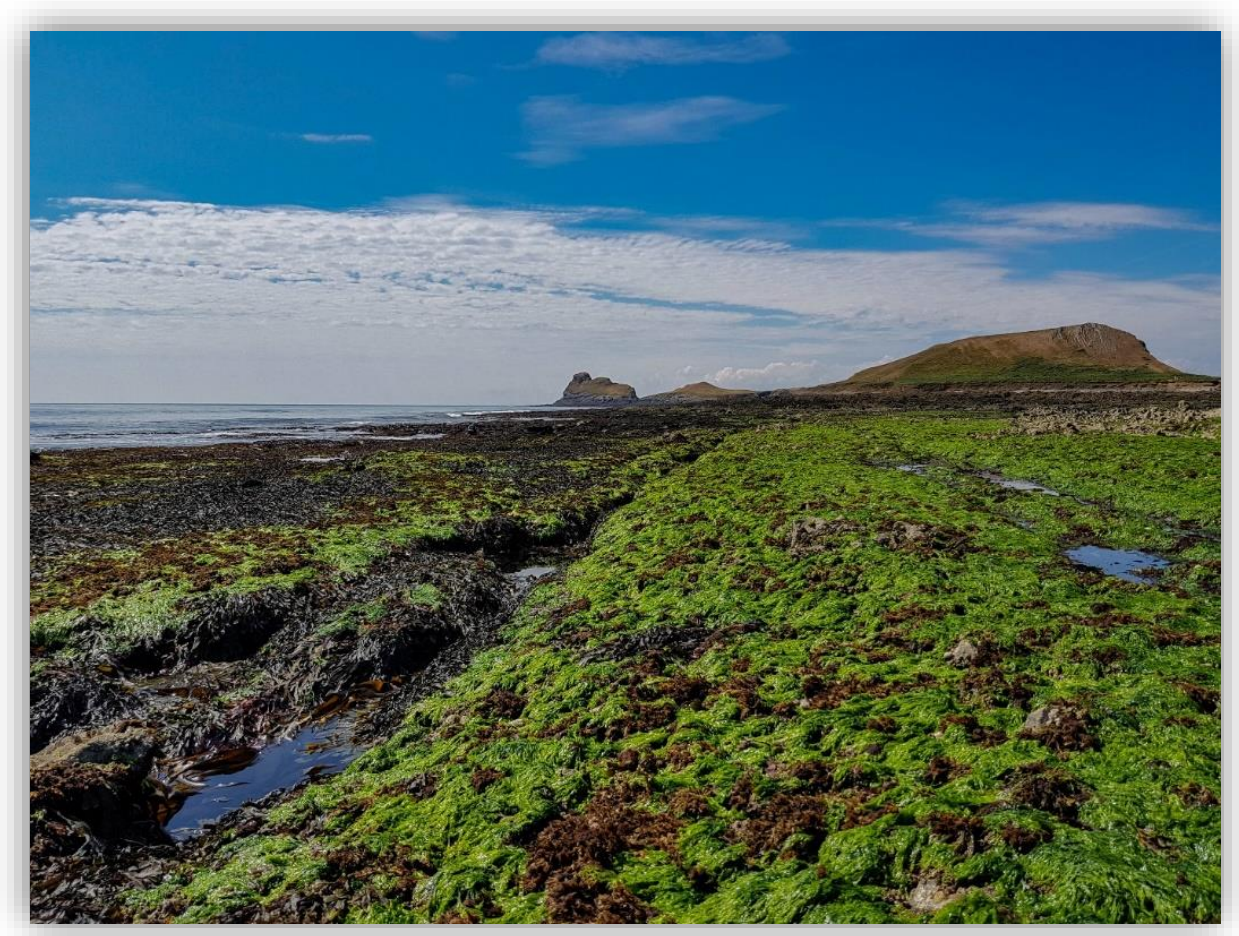

(C) Tom Fairchild 


\section{Global environmental and ecological community change}

The accelerating human impact on coastal and marine environments is causing global changes such as ocean acidification, warming and coastal urbanization. These impacts are reorganizing biological communities worldwide, both directly via environmental tolerances and indirectly via changes in species interactions (Wernberg et al. 2011; Harley 2011; Harley et al. 2012). There is a growing need to understand and predict how species invasions and extinctions affect ecosystem processes, so we can prevent or mitigate consequences. A fundamental challenge is how to best capture relationships between species and ecosystem functions, since taxonomic identity (or richness) does not show how species differ in their contribution to the community. Functional traits such as body size and leaf morphology determine an organism's capacity to process resources and how it interacts with its environment. Therefore, traits provide a practical, mechanistic link between organism (or species) and environment. The diversity of such traits - functional diversity - captures variation in the ecological roles of species (e.g. Tilman 2001; Violle et al. 2007).

\section{Functional traits: what are they and why are they useful?}

Long before the term "functional trait" came to be used, naturalists were classifying species based on their general characteristics, such as "shrubs", "herbs" and "trees", during ancient Greece, or on their life forms (Plant life forms by Raunkiaer in early 20th century). Over the past few decades, a variety of functional group approaches have been used to summarise species' diversity and categorise them according to characters such as gross morphology, anatomy, growth form or life history. Currently, the most widely used and reliable way to describe species' ecological differences is via trait-based approaches. Functional traits are any morphological, physiological or phenological characteristics of individuals that influence their response to the environment and/or effect on ecosystem properties (Díaz et al. 
2013). By characterizing organisms, traits allow us to establish the link between individuals and the environment and help elucidate mechanisms behind species coexistence (Garnier et al. 2016; Kunstler et al. 2016). They can be categorical or continuous, but the choice of traits should be carefully considered within the context of the research questions and systems (Petchey and Gaston 2006). Due to the many ecological similarities between macrophytes, macroalgal functional ecology has largely relied on the established trait framework of vascular plants (Cornelissen 2003, Díaz et al. 2016). One of these similarities is the trade-off producers often face between allocating energy for resistance or for growth (Littler and Littler 1980). Traits can therefore be "functional markers", by serving as indicators of eco-physiological functions rather than direct measurements of them (Garnier et al. 2004).

Regardless of the focus organism, trait-based approaches hold the promise of more predictive ecology that goes beyond taxonomy, towards a more mechanistic understanding of biodiversity (Mcgill et al. 2006). Traits can reflect species' adaptations or ecological strategies while also helping to predict ecosystem functions (Lavorel and Garnier 2002). For example, specific leaf area responds to soil nutrient availability (environmental response), relates to photosynthetic capacity (eco-physiological strategy) and predicts primary productivity (ecosystem function) (Cunningham et al. 1999; Reich et al. 2014). Similarly, leaf dry matter content varies with canopy light availability, suggests a resource-conservative strategy and negatively affects decomposition (Niinemets et al. 1999; Westoby et al. 2002).

Using a suite of traits in ecological studies is more likely to capture functional relationships between species and environment than one or two traits, especially when hypotheses are multifaceted (Lefcheck et al. 2015). Incorporating multiple, continuous, functional traits allows the description of a multidimensional trait space (= functional space) filled by species across communities (Petchey and Gaston 2006). Changes in this 
multidimensional space can reveal how different niche-based processes operate across environments (Mcgill et al. 2006). For example, a seminal work by Díaz et al. (2016) set the groundwork for the description of a plant multidimensional trait space, using six traits from the scale of organ to whole individual, on around 45000 species. The two main dimensions (described by principal component axes) described two strategic gradients: one in plant size and one from fast-growing (resource acquisitive) to conservative species, i.e. the leaf economics spectrum (Wright 2004). Although similarities between plants and seaweeds are expected as to what individual traits capture (e.g. plant height $=$ competitive ability; thickness = structural integrity), an analogue for macroalgae "thallus economics spectrum" has not been explored so far; neither has the dimensionality of continuous traits across a variety of seaweed species.

For simplicity, or when traits are not available, researchers have used the functional group approach, which classifies species into groups, unrelated to phylogeny, based on their morphological or ecological similarities. For example, studies have linked functional group richness to enhancement of above and belowground productivity (Tilman 1997; Lanta and Lepš 2006). However, despite the practicality of the grouping approach, it carries limitations that may compromise our ability to capture underlying trait variation among species. One limitation is that groups do not consider within-group trait variability, which includes both inter- and intra-specific variation. Overlooking within-group variability hides potentially important facets of functional diversity such as redundancy, which can indicate the buffering capacity against species loss (Micheli and Halpern 2005; Mouillot et al. 2014; McWilliam et al. 2018). Additionally, because species can only belong to one group, their allocation is often subjective and may be erroneous, given the number of implicit traits which are overlooked (Chapin et al. 1996; Díaz and Cabido 2001). 


\section{Functional diversity}

Under the functional lens, it is possible to quantify and express biological diversity beyond the number and abundance of species. There are several ways to measure the functional facet of biodiversity, i.e. functional diversity. In essence, functional diversity will describe the value and range of species traits and thus express the diversity of functions organisms can potentially perform in a community (Petchey and Gaston 2006). Functional diversity therefore provides a link between community structure and ecosystem function in more detail than taxonomic diversity (Díaz and Cabido 2001). Using community surveys (presence/absence or abundance), and trait data (individual- and species-level), one can explore the functional structure of communities and scale to ecosystem functioning (Fig. 1).

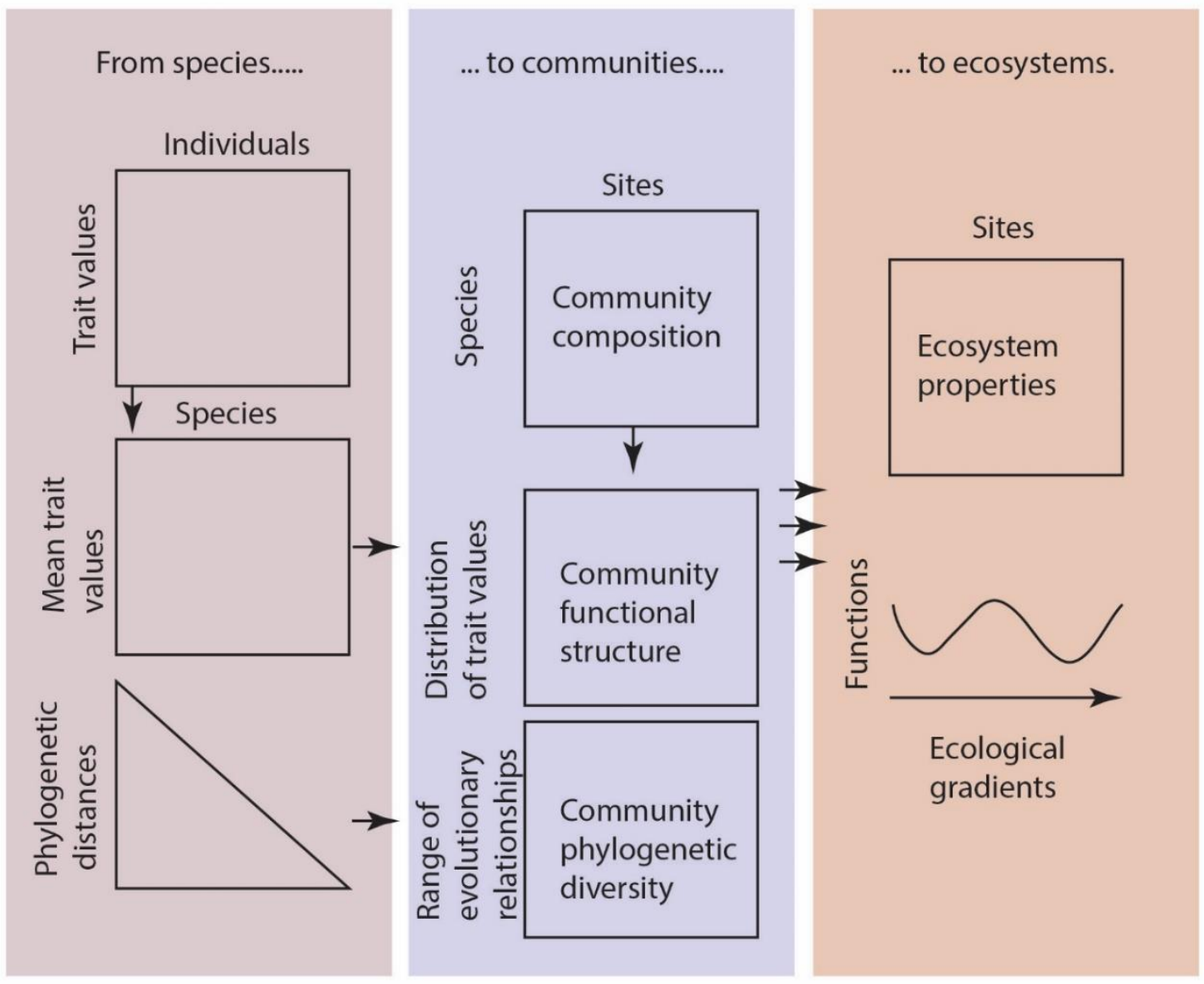


Figure 1. Schematic figure of data used to address main questions of my thesis, which range from individuals to ecosystems. Functions across ecological gradients (third panel) is depicted for context, as a research goal, but is not tested on my thesis.

Functional diversity can be measured with multiple traits, at different spatial and temporal scales, and it can reveal how ecological processes act along environmental gradients (Mcgill et al. 2006). For example, since traits vary across axes of niche specialization (Díaz et al 2004; 2016), two opposing processes driving community trait structure - habitat filtering and niche differentiation - can simultaneously act on different trait axes: plants can converge in stature to reach the limiting amount of light, while differentiation in soil resource use traits allows them to coexist (Maire et al. 2012). Consequently, a stronger habitat filtering will decrease functional diversity along one axis, while niche differentiation will increase functional diversity along another axis.

The functional characterization of communities can be divided into two major aspects: the description of the trait values in the assemblage - functional identity - and the overall range and distribution of traits - functional diversity per se (Fig. 2). Functional identity relates to the functional traits in the community and the processes and functions they perform, usually incorporating species abundances (e.g. community weighted means, CWM, where the species' traits are given weights proportionally to their abundances in communities). Therefore, this aspect linked to the biomass ratio hypothesis, where properties of ecosystems depend on the local contribution of species' identities, relative abundances, and traits of the community (Grime 1998). This relationship between dominant species and ecosystem properties is often mediated by the environment. For example, in vascular plant communities, leaf traits (e.g. specific leaf area and dry matter content) of dominant species have been shown to correlate to net primary productivity and litter decomposition (Garnier et al. 2004), while varying across 
environmental soil gradients (e.g. Bernard-Verdier et al. 2012). This dynamic is illustrated in Figure 2, where community assembly - species taxonomic and identities - across an environmental gradient drives trait values; then, a different ecological function will be provided by each trait value dominating both ends of the gradient.

The second main aspect, functional diversity per se, better encompasses the complementarity and redundancy of species in the assemblage. A greater range of traits should provide more opportunities for the use of resources and therefore increase niche complementarity (Tilman 1997; Díaz and Cabido 2001; Zhang et al. 2012), which is also illustrated on Figure 2. The diversity of a community based on multiple traits can be described by a n-dimensional functional (trait) space, derived from a species distance matrix. There are different metrics which capture distinct facets of functional diversity based on this trait space, including: functional richness, which defines its size (Villéger et al. 2008), and functional dispersion, which is the mean distance of the species to its overall centroid (Laliberté and Legendre 2010). While functional richness will increase with the addition of species with extreme trait values, functional dispersion will be enhanced when these new species are also more abundant. However, although the number of species is somewhat correlated to functional richness, the strength of this correlation depends on how much species overlap in functional trait space; therefore, the use of species richness is not a good substitute of functional richness (Cadotte et al. 2011). There have been many efforts to relate species diversity to ecosystem functioning, but experiments have consistently shown that functional diversity is a better predictor of ecosystem functions (Griffin et al. 2009; Flynn et al. 2011; Gagic et al. 2015; Lefcheck and Duffy 2015).

When functional traits are not available or possible to measure, and we need a more complete assessment of functional diversity or specific functions than that provided by 
functional groups, we may be able to use phylogenetic relationships as a proxy for species' morphological and physiological similarities. However, this approach has a limitation which is that relatedness does not necessarily mean similarity; in fact, divergent traits are commonly reported, which can disrupt the linear relationship between phylogenetic and functional similarity (Swenson 2019). However, testing a priori whether traits have evolved as expected across lineages could validate this phylogeny-as-proxy approach. Comparing how much trait variance is captured by different taxonomic levels (e.g. species, genus, family) can also provide practical information for the use of other hierarchies when species-level traits are not available (Fig. 1). 


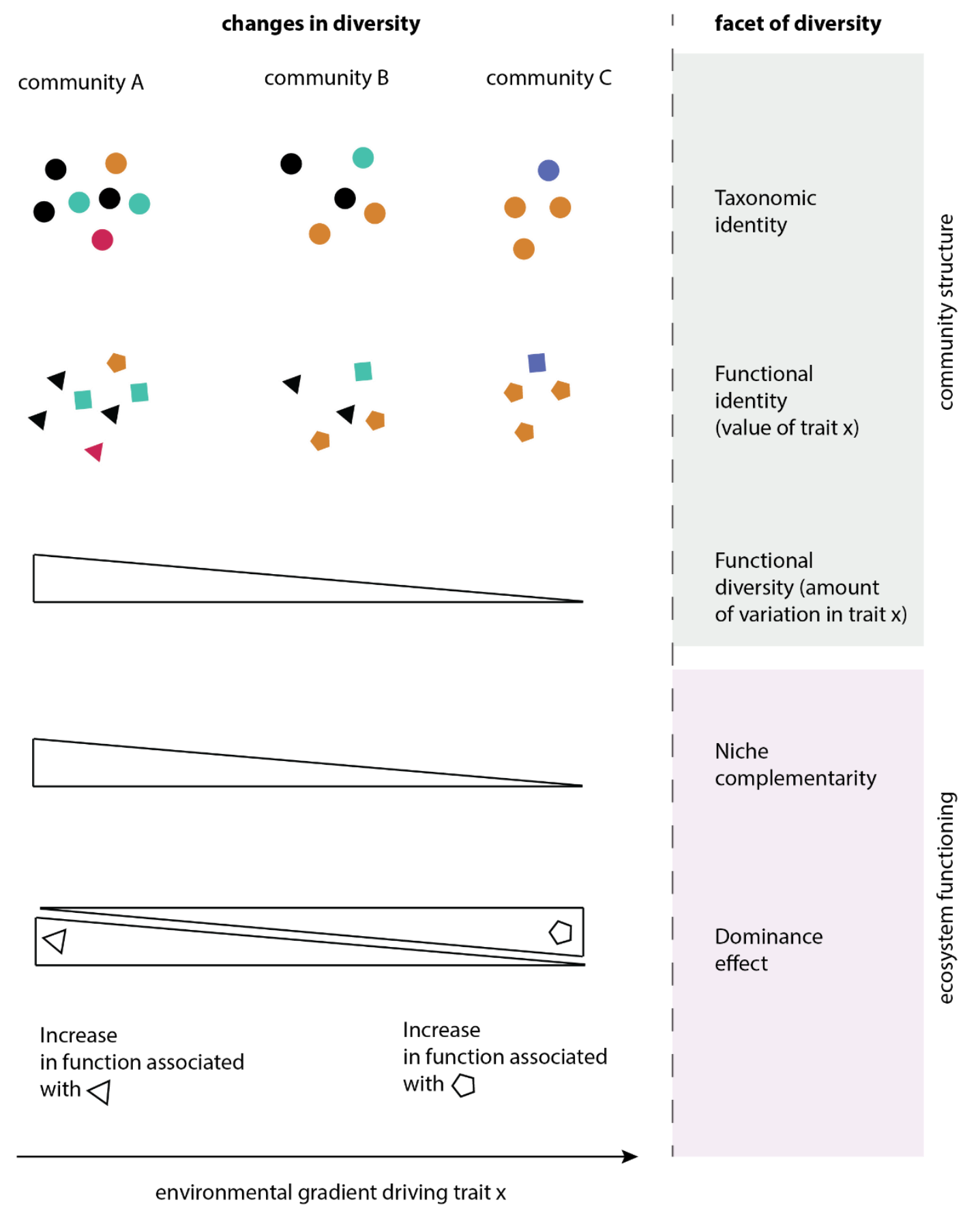

Figure 2. Conceptual representation of the links between community assembly and ecosystem functioning, using a fictional trait (trait "x"). Trait values are given as different polygons, whereas colour represents species identity. Trait values are dominant when associated to higher abundance of species; the dominance hypothesis states that dominant traits will influence ecosystem functions. An alternative, but not exclusive, hypothesis stipulates that having species with different trait values should use resources - and therefore drive functions - in a complementary manner. 
There is also a lot to be gained from incorporating phylogenies into functional ecology. One reason is that phylogenies are expected to contain all the information on species' features - i.e. besides measured traits (Webb 2000). Because of that, phylogenetic diversity (how evolutionarily distant species are in the assemblage) and originality (species which contribute proportionally more to phylogenetic diversity) have been considered aspects of biodiversity of priority for conservation (Isaac et al. 2007). Moreover, phylogenetic diversity has been shown to predict productivity in plants better than species diversity (Cadotte et al. 2009; Flynn et al. 2011), suggesting the potential value of the phylogeny-as-proxy approach. Phylogenetic relationships among species may also offer complementary information on species' ecological differences. For example, integrating phylogenetic information can improve the ability to detect how the environment has historically selected traits in the present communities (Cadotte et al. 2013). Finally, decoupling traits from phylogeny may reveal additional information which could link species assembly with the environment (Bello et al. 2017), stimulating a search for more functional traits to explain the ecological pattern of interest (Li et al. 2017).

\section{Investigating functional diversity of intertidal seaweeds}

In temperate marine and coastal systems, seaweeds are major contributors to primary productivity, and support diverse ecosystem services including fisheries, coastal protection and carbon storage (Chung et al. 2011; Smale et al. 2013). Pronounced changes in species composition and diversity, from the low subtidal to the upper intertidal limit of seaweed distribution, form species zonation patterns in communities. Zonation in seaweeds has been studied in rocky shores in several parts of the world: from the North West Atlantic (Lubchenco 1980), to high latitudes of Alaska and the Magellanic region (Ingólfsson 2005). However, the corresponding functional aspects of the distribution and diversity of species remain poorly addressed. In the intertidal zone, the emersion period associated with the tides represents a 
stress gradient, where we can expect traits will vary according to species' adaptations to different levels of emersion, with a potential habitat filter on the range of possible trait values. The accessibility and steepness of abiotic changes of the intertidal make these seaweed assemblages a model system to investigate changes in trait values (functional identity) and range (functional diversity) across an environment gradient.

The first developments in seaweed functional ecology date back to 1958 by Odum and collaborators, with attempts to relate form (surface : volume) to function (productivity). Later, Littler and Murray (1974) used growth form (e.g. sheet-like, branched) to predict productivity. In the following decade, Littler and Littler (1980) proposed a "functional form model" based on gross morphology. A new classification was later proposed by Steneck and Dethier (1994), using more finely defined characters based on branching pattern, anatomy, and degree of cortication. Additionally, a broad characterization of space use (canopy vs. turf forms) has been employed in studies observing major changes in community structure (e.g. Filbee-Dexter and Wernberg (2018)). To date, macroalgal functional ecology has remained largely focused on categorizing species into functional groups (Arenas et al. 2006; Gómez and Huovinen 2011). These traditional grouping schemes, however, are coarse representations of seaweed functional diversity and, unlike among plant functional types (Thomas et al. 2019), the assumption that they capture underlying trait variation between seaweed species has not been explored yet.

Although applying continuous measures of traits is the basis of modern functional ecology, this approach is underdeveloped for seaweeds, compared to vascular plants. Studies of seaweed assemblages have already demonstrated the utility of functional traits in predicting ecosystem functioning and explaining environmental drivers of community assembly. For example, both CWM of thallus traits (analogous to leaf traits) and functional diversity had effects on primary productivity in algal experimental mixtures (Griffin et al. 2009; Rodriguez 
et al. 2016), while light absorbance traits are more related to zonation than light stress tolerance traits in southern Chile (Gómez and Huovinen 2011). The further exploration of multiple, continuously measured traits across several species will deepen the knowledge of the functional dimensionality of seaweeds and help untangle the effects of environmental filters and biotic interactions on intertidal functional assembly. Additionally, there is a growing need to predict the functional consequences of environmental change on seaweed communities and their environment, as species shift/contract range distributions (Wernberg et al. 2011, Riera et al. 2015, Straub et al. 2016) or alter their physiology (Harley et al. 2012).

\section{Summary of topics}

In my thesis I aimed at understanding the relationships between seaweed species and their environments, via functional traits. Using complementary functional and phylogenetic metrics, I explored the diversity of macroalgae across intertidal assemblages, with a special focus on the typical species zonation patterns. This approach allowed me to describe seaweed diversity from different perspectives and therefore have a more complete view of their contributions and responses to their environment.

In chapter 2, I looked at the taxonomic and functional diversity of large brown algae (i.e. kelp and fucoids) along the intertidal gradient. I asked what drives the changes in community composition and investigated if wave exposure drives variation in trait values within species. In Chapter 3, I used a similar approach for all macroalgal species, aiming to shed a new light on the typical zonation patterns we commonly see in rocky shores. Using species-level traits on 50 species, I asked how the functional structures of communities changes with increasing height, expecting this factor to act as an environmental filter. In Chapter 4, I incorporated a phylogenetic approach to red algae on intertidal communities, to compare how traits and phylogeny help explain community assembly. I also explored the phylogeny-as- 
proxy of individual trait and multi-trait diversity. In Chapter 5, I collaborated on a study addressing how well traditional functional groups explain species differences in functional traits. Finally, in Chapter 6, I discuss the findings of my $\mathrm{PhD}$ and outstanding questions and challenges.

\section{References}

Arenas F, Sánchez I, Hawkins SJ, Jenkins SR (2006) the invasibility of marine algal assemblages: role of functional diversity and identity. Ecology 87:2851-2861. https://doi.org/10.1890/00129658(2006)87[2851:TIOMAA]2.0.CO;2

Bello F, Šmilauer P, Diniz-Filho JAF, et al (2017) Decoupling phylogenetic and functional diversity to reveal hidden signals in community assembly. Methods Ecol Evol 8:1200-1211. https://doi.org/10.1111/2041-210X.12735

Bernard-Verdier M, Navas M-L, Vellend M, et al (2012) Community assembly along a soil depth gradient: contrasting patterns of plant trait convergence and divergence in a Mediterranean rangeland. J Ecol 100:1422-1433. https://doi.org/10.1111/1365-2745.12003

Cadotte M, Albert CH, Walker SC (2013) The ecology of differences: assessing community assembly with trait and evolutionary distances. Ecol Lett 16:1234-1244. https://doi.org/10.1111/ele.12161

Cadotte MW, Carscadden K, Mirotchnick N (2011) Beyond species: functional diversity and the maintenance of ecological processes and services: Functional diversity in ecology and conservation. Journal of Applied Ecology 48:1079-1087. https://doi.org/10.1111/j.1365-2664.2011.02048.x

Cadotte MW, Cavender-Bares J, Tilman D, Oakley TH (2009) Using Phylogenetic, Functional and Trait Diversity to Understand Patterns of Plant Community Productivity. PLoS ONE 4:e5695. https://doi.org/10.1371/journal.pone.0005695

Chapin FS, Bret-Harte MS, Hobbie SE, Zhong H (1996) Plant functional types as predictors of transient responses of arctic vegetation to global change. Journal of Vegetation Science 7:347-358. https://doi.org/10.2307/3236278

Chung IK, Beardall J, Mehta S, et al (2011) Using marine macroalgae for carbon sequestration: a critical appraisal. J Appl Phycol 23:877-886. https://doi.org/10.1007/s10811-010-9604-9

Cornelissen JHC, Lavorel S, Garnier E et al. (2003) Handbook of protocols for standardised and easy measurement of plant functional traits worldwide. Australian J. of Botany, 51(4), 335-380. doi:10.1071/BT02124

Cunningham SA, Summerhayes B, Westoby M. (1999) Evolutionary divergences in leaf structure and chemistry, comparing rainfall and soil nutrient gradients. Ecological Monographs 69(4): 569-588

Díaz S, Purvis A, Cornelissen JHC, et al (2013) Functional traits, the phylogeny of function, and ecosystem service vulnerability. Ecol Evol 3:2958-2975. https://doi.org/10.1002/ece3.601

Díaz S, Cabido M (2001) Vive la différence: plant functional diversity matters to ecosystem processes. Trends in Ecology \& Evolution 16:646-655. https://doi.org/10.1016/S0169-5347(01)02283-2 
Filbee-Dexter, K., \& Wernberg, T. (2018). Rise of Turfs: A New Battlefront for Globally Declining Kelp Forests. BioScience, 68(2), 64-76. doi: 10.1093/biosci/bix147

Flynn DFB, Mirotchnick N, Jain M, et al (2011) Functional and phylogenetic diversity as predictors of biodiversity-ecosystem-function relationships. Ecology 92:1573-1581. https://doi.org/10.1890/101245.1

Gagic V, Bartomeus I, Jonsson T, et al (2015) Functional identity and diversity of animals predict ecosystem functioning better than species-based indices. Proc R Soc B 282:20142620. https://doi.org/10.1098/rspb.2014.2620

Garnier E, Cortez J, Billès G, et al (2004) plant functional markers capture ecosystem properties during secondary succession. Ecology 85:2630-2637. https://doi.org/10.1890/03-0799

Garnier E, Navas M, Grigulis K (2016) Plant Functional Diversity: Organism traits, community structure and ecosystem properties. Oxford University Press.

Gómez I, Huovinen P (2011) Morpho-functional patterns and zonation of South Chilean seaweeds: the importance of photosynthetic and bio-optical traits. Mar Ecol Prog Ser 422:77-91. https://doi.org/10.3354/meps08937

Griffin JN, Méndez V, Johnson AF, et al (2009) Functional diversity predicts overyielding effect of species combination on primary productivity. Oikos 118:37-44. https://doi.org/10.1111/j.16000706.2008.16960.x

Grime J (1998). Benefits of plant diversity to ecosystems: Immediate, filter and founder effects. Journal of Ecology, 86, 902-910. https://doi.org/10.1046/j.1365-2745.1998.00306.x

Harley CDG (2011) Climate Change, Keystone Predation, and Biodiversity Loss. Science 334:11241127. https://doi.org/10.1126/science.1210199

Harley CDG, Anderson KM, Demes KW, et al (2012) effects of climate change on global seaweed communities. Journal of Phycology 48:1064-1078. https://doi.org/10.1111/j.1529-8817.2012.01224.x

Ingólfsson A (2004) Community structure and zonation patterns of rocky shores at high latitudes: an interocean comparison: Rocky shore communities at high latitudes. J Biogeogr 32:169-182. doi: 10.1111/j.1365-2699.2004.01150.x

Isaac NJB, Turvey ST, Collen B, et al (2007) Mammals on the EDGE: Conservation Priorities Based on Threat and Phylogeny. PLoS ONE 2:e296. https://doi.org/10.1371/journal.pone.0000296

Kunstler G, Falster D, Coomes D. et al. (2016) Plant functional traits have globally consistent effects on competition. Nature 529: 204-207. doi: 10.1038/nature16476

Laliberté E, Legendre P (2010) A distance-based framework for measuring functional diversity from multiple traits. Ecology 91:299-305. https://doi.org/10.1890/08-2244.1

Lanta V, Lepš J (2006) Effect of functional group richness and species richness in manipulated productivity-diversity studies: a glasshouse pot experiment. Acta Oecologica 29:85-96. https://doi.org/10.1016/j.actao.2005.08.003

Lavorel S, Garnier E (2002) Predicting changes in community composition and ecosystem functioning from plant traits: revisiting the Holy Grail. Funct Ecology 16:545-556. https://doi.org/10.1046/j.13652435.2002.00664.x 
Lefcheck JS, Bastazini VAG, Griffin JN (2015) Choosing and using multiple traits in functional diversity research. Envir Conserv 42:104-107. https://doi.org/10.1017/S0376892914000307

Lefcheck JS, Duffy JE (2015) Multitrophic functional diversity predicts ecosystem functioning in experimental assemblages of estuarine consumers. Ecology 96:2973-2983. https://doi.org/10.1890/141977.1

Li D, Ives AR, Waller DM (2017) Can functional traits account for phylogenetic signal in community composition? New Phytol 214:607-618. https://doi.org/10.1111/nph.14397

Littler MM, Littler DS (1980) The Evolution of Thallus Form and Survival Strategies in Benthic Marine Macroalgae: Field and Laboratory Tests of a Functional Form Model. The American Naturalist 116:2544. https://doi.org/10.1086/283610

Lubchenco J (1980) Algal Zonation in the New England Rocky Intertidal Community: An Experimental Analysis. Ecology 61:333-344 doi: 10.2307/1935192

Maire V, Gross N, Börger L, et al (2012) Habitat filtering and niche differentiation jointly explain species relative abundance within grassland communities along fertility and disturbance gradients. New Phytol 196:497-509. https://doi.org/10.1111/j.1469-8137.2012.04287.x

Mcgill B, Enquist B, Weiher E, Westoby M (2006) Rebuilding community ecology from functional traits. Trends in Ecology \& Evolution 21:178-185. https://doi.org/10.1016/j.tree.2006.02.002

McWilliam M, Hoogenboom MO, Baird AH, et al (2018) Biogeographical disparity in the functional diversity and redundancy of corals. Proc Natl Acad Sci USA 115:3084-3089. https://doi.org/10.1073/pnas.1716643115

Micheli F, Halpern BS (2005) Low functional redundancy in coastal marine assemblages. Ecology Letters 8:391-400. https://doi.org/10.1111/j.1461-0248.2005.00731.x

Mouillot D, Villeger S, Parravicini V, et al (2014) Functional over-redundancy and high functional vulnerability in global fish faunas on tropical reefs. Proceedings of the National Academy of Sciences 111:13757-13762. https://doi.org/10.1073/pnas.1317625111

Niinemets U. (1999) Research review. Components of leaf dry mass per area-thickness and densityalter leaf photosynthetic capacity in reverse directions in woody plants. New Phytologist 144:35-57.

Odum EP, Kuenzler EJ and Blunt MX (1958). Uptake of P32 and primary productivity in marine benthic algae. Limnol. Oceanogr. 3: 240-345

Petchey OL, Gaston KJ (2006) Functional diversity: back to basics and looking forward. Ecol Letters 9:741-758. https://doi.org/10.1111/j.1461-0248.2006.00924.x

Reich PB (2014) The world-wide "fast-slow" plant economics spectrum: A traits manifesto. J. of Ecology, 102(2), 275-301. doi:10.1111/1365-2745.12211

Riera R, Sangil C, Sanson M (2015) Long-term herbarium data reveal the decline of a temperate-water algae at its southern range. Estuarine, Coastal and Shelf Science 165: 159-165

Rodriguez S, Martín A, Sousa-Pinto I, Arenas F (2016) Biodiversity effects on macroalgal productivity: exploring the roles of richness, evenness and species traits. Mar Ecol Prog Ser 562:79-91. https://doi.org/10.3354/meps11948 
Smale DA, Burrows MT, Moore P, et al (2013) Threats and knowledge gaps for ecosystem services provided by kelp forests: a northeast Atlantic perspective. Ecol Evol 3:4016-4038. https://doi.org/10.1002/ece3.774

Steneck RS, Dethier MN (1994) A functional group approach to the structure of algal-dominated communities. Oikos, 69, 476-498.

Straub, S., Thomsen, M. \& Wernberg, T. (2016). The dynamic biogeography of the Anthropocene: the speed of recent range shifts in seaweeds. In Seaweed Phylogeography (Hu, Z.-M. \& Fraser, C., editors), 63-93. Springer, Amsterdam

Swenson NG (2019) Phylogenetic Ecology A History, Critique, and Remodeling. The University of Chicago Press

Thomas HJD, Myers-Smith IH, Bjorkman AD, et al. (2019). Traditional plant functional groups explain variation in economic but not size-related traits across the tundra biome. Global Ecology and Biogeography, 28(2), 78-95. doi: 10.1111/geb.12783.

Tilman D (1997) The Influence of Functional Diversity and Composition on Ecosystem Processes. Science 277:1300-1302. https://doi.org/10.1126/science.277.5330.1300

Tilman D (2001) Functional diversity. Encyclopaedia of biodiversity. Academic Press, San Diego, 109120

Villéger S, Mason NWH, Mouillot D (2008) New Multidimensional Functional Diversity Indices for a Multifaceted Framework in Functional Ecology. Ecology 89:2290-2301

Violle C, Navas ML, Vile, D et al. (2007). Let the concept of trait be functional! Oikos 116, 882-892

Webb CO (2000) Exploring the Phylogenetic Structure of Ecological Communities: An Example for Rain Forest Trees. The American Naturalist 156:145-155. https://doi.org/10.1086/303378

Wernberg T, Russell BD, Thomsen MS, et al (2011) Seaweed Communities in Retreat from Ocean Warming. Current Biology 21:1828-1832. https://doi.org/10.1016/j.cub.2011.09.028

Westoby M, Falster DS, Moles AT, Vesk PA, Wright IJ (2002) Plant ecological strategies: some leading dimensions of variation between species. Annual Review of Ecology and Systematics, 33, 125-159

Wright I J, Reich PB, Westoby M, et al. (2004) The worldwide leaf economics spectrum. Nature 428, $821-827$.

Zhang J-T, Lihong F, Min L (2012) Functional diversity in plant communities: Theory and analysis methods. Afr J Biotechnol 11:1014-1022. https://doi.org/10.5897/AJB11.3122 


\section{Chapter 2}

\section{Applying continuous functional traits to large brown macroalgae: variation across tidal emersion and wave exposure gradients}

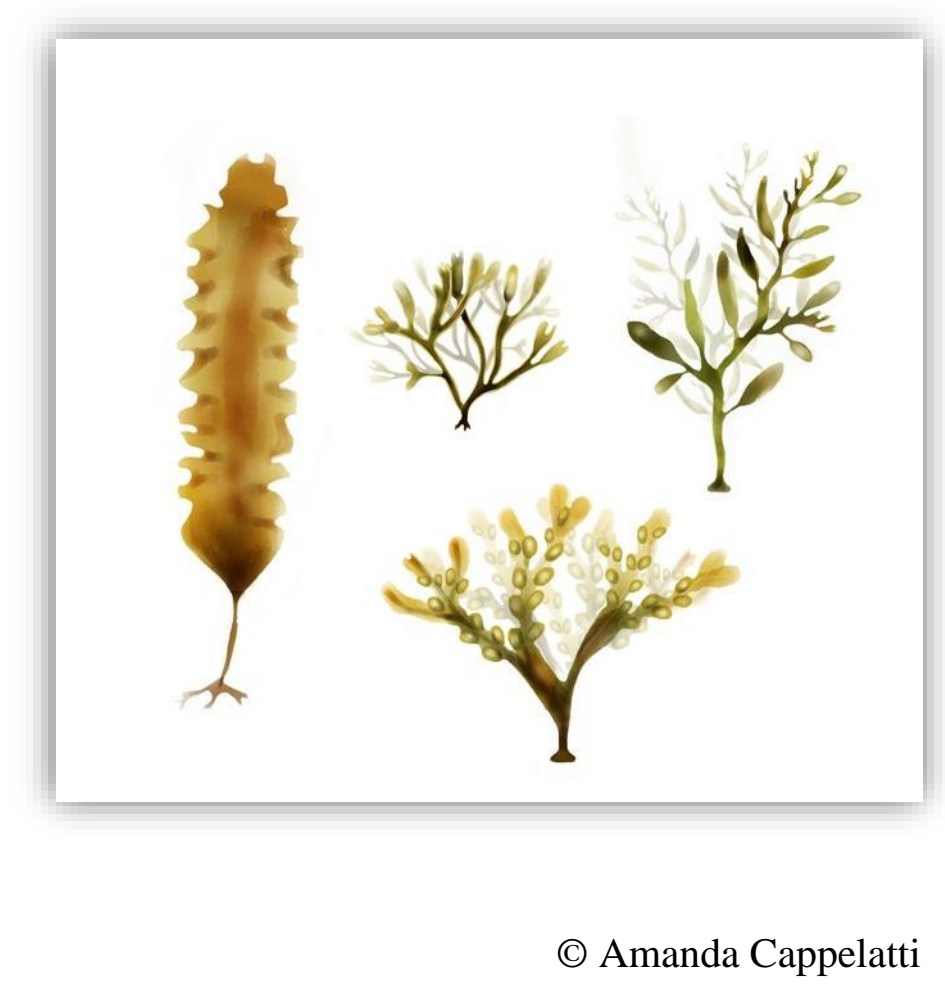

Disclaimer: This chapter is published, with Open Access, by the journal Marine Biology (doi: 10.1007/s00227-019-3574-5). It was developed with the collaboration of Alizée Mauffrey and John Griffin. It is presented here as published. 


\begin{abstract}
Ecologists use a functional trait-based approach to seek a general understanding of organism environment interactions, but, among primary producers, the empirical basis rests on vascular plants. We hypothesised that with increasing intertidal elevation, traits of large brown macroalgae would reflect a resource-acquisition vs. conservation (stress tolerance) trade-off at species and community levels. Across the elevation gradient at four UK sites of varying wave exposure, we: i) screened species' relevant morphological traits, using principal component analysis to reduce dimensionality; and ii) up-scaled species' traits using community weighted trait means (CWMs). The first principal component (PC1) strongly related to specific thallus area and thallus dry matter content, representing an acquisition - conservation trade-off. Although species generally shifted to the conservative end of this axis as elevation increased, mid-shore Ascophyllum nodosum sat at the extreme conservative end. PC2 related to holdfast ratio, thickness and length, with $A$. nodosum scoring higher than other mid-shore species. CWMs of PC1 decreased with elevation at two sites indicating a shift from 'fast' to 'slow' ecosystem functioning, but this relationship was disrupted by A. nodosum at the sheltered site, and by the up-shore extent of Laminaria digitata at the most exposed site. The anomalous traits of A. nodosum reflect its unique competitive strategy (slow, persistent growth) in the relatively stressful mid-shore. Seaweed functional traits show promise in linking species' identities to their strategies and ecosystem contributions. However, because resource conservation traits can be related to competitive as well as stress tolerance strategies, predicting seaweed trait responses to environmental stress gradients is challenging.
\end{abstract}

Key-words: functional group, functional trait, rocky intertidal, seaweeds, intraspecific variation 


\section{Introduction}

Characterising how organisms' functional traits vary along environmental gradients can reveal species' ecological strategies (Cornwell and Ackerly 2009), the extent of intraspecific variability (Fajardo and Piper 2011), and the adaptive significance of traits (Kraft et al. 2007). Doing so also elucidates how the environment affects trait values at the community level, and therefore the consequences of spatial and temporal variation in the environment for ecosystem functioning (Suding et al. 2008). However, modern functional ecology, a science based on multiple continuous traits measured at the level of individuals, has largely been focused on vascular plants (e.g., Bloomfield et al. 2018) and rarely applied to other groups of primary producers such as macroalgae or seaweeds.

Here, we adopt approaches of functional ecology to study 'large brown macroalgae' (LBM), a seaweed group including kelps and rockweeds, that dominate standing biomass along temperate rocky intertidal and shallow subtidal zones worldwide (Dayton 1985). These foundation species are major contributors to near-shore primary productivity, and support diverse ecosystem services including fisheries, coastal protection and carbon storage (e.g., Smale et al. 2013). Classic studies in the rocky intertidal point towards functional differences between species of LBM and show the effects of environmental gradients - especially tidal emersion period (represented by height on the shore) and wave exposure (commonly represented by wave fetch) - on their distribution (Southward 1959; Ballantine 1961). Furthermore, recent work illustrates how these factors affect the morphology and fitness of individual species (Hepburn et al. 2007). However, categorisation of species into coarse functional groups remains the usual approach in macroalgal ecology (Steneck and Dethier 1994; Arenas et al. 2006; Gómez and Huovinen 2011), and assemblages of LBM have not previously been investigated using a range of continuous functional traits. Therefore, 
fundamental questions such as the extent to which gradients such as shore height and wave exposure are associated with functional traits at individual, species and community levels, have remained unexplored.

Like vascular plants, LBM are sedentary, multicellular and differentiated photosynthesising organisms (Hurd et al. 2014). Accordingly, we expect the functional ecology of vascular plants to inform macroalgal functional ecology. Plant ecological strategies range from resource conservative, stress-tolerant and long-lived - so-called "slow" species - to resource acquisitive, competitive and short-lived - "fast" species (Grime 1974, Reich 2014). This spectrum reflects the inevitable trade-off between traits that are advantageous in resourcerich environments (e.g., rapid rates of resource acquisition and loss and high rates of tissue turnover), and the more conservative strategy prevailing in resource-poor or stressful environments (Díaz et al. 2004). For LBM in the intertidal, tidal emersion represents a gradient where these shifts in functional traits should be visible. A stress tolerant, resource conservative strategy (e.g., low specific thallus ['leaf'] area) should be beneficial at the upper shore, where exposure to air for long periods leads to desiccation and slows photosynthesis (Chapman 1995). Meanwhile, a resource acquisitive strategy (e.g., high specific thallus area) should prevail on the more light-competitive lower shore (Littler and Littler 1980). Following plant ecology, we expect strategies and associated trade-offs to manifest as coordinated changes across functional traits (Díaz et al. 2004). Across shore locations, however, gradients of wave exposure, known to be associated with changes in community structure (Ballantine 1961; Burrows et al. 2008) and individual traits (Cousens 1982; Bäck 1993; Blanchette 1997), may disrupt associations between species' and community-level trait values and tidal emersion. Finally, variability within species threatens to undermine application of traits at the species level; although plant ecologists have addressed its contribution in many systems (Siefert et al. 2015), how 
intraspecific compares to interspecific variation in functional trait space is still not known for macroalgae.

Here we evaluate variability in the functional traits of LBM across gradients of shore height and wave exposure. The choice of focusing on this group of seaweed is mainly because they are the dominant species in the intertidal and because a small group of species allowed us to explore within-species trait variability. We conducted surveys and screened individuals for functional traits related to the resource acquisition - stress tolerance trade-offs, along the intertidal at four sites of varying wave exposure in south Wales (UK). Specifically, we investigated: 1) how species of LBM that span shore heights differ in their position in functional trait space; 2) how this interspecific variability scales to the community level along shore heights at sites of varying wave exposure; and 3) given expected intraspecific variability, the extent to which species maintain functional differences across a wave exposure gradient. We hypothesised that, across shore heights, species traits will reflect adaptations to the emersion period in an overall more conservative, stress tolerant, strategy. Although we examined the robustness of these relationships across sites of varying wave exposure, our main focus was on shore height. Table 1 outlines our predictions for how traits would change with shore height, and the mechanisms underlying this variation.

\section{Methods}

Study sites

The study was conducted on four rocky shores in south Wales (UK), during the summers of 2017 and 2018. Shores in this region experience large tidal ranges, and typically host stands of LBM characteristic of northeastern Atlantic rocky shores. We selected accessible sites covering a wide range of wave exposures and with extensive carboniferous limestone intertidal platforms. Three of the sites span ca. $20 \mathrm{~km}$ of the Gower Peninsula (tidal range of 
10.37 m): Rhossili (exposed; 51.56 N, 4.32 W), Bracelet Bay (semi-exposed; 51.57 N, 3.98 W), and Oxwich (sheltered; $51.55 \mathrm{~N}, 4.15 \mathrm{~W}$ ). Since very sheltered sites could not be found on the Gower, we selected an additional site ca. $50 \mathrm{~km}$ west, located in a ria (Milford Haven, Pembrokeshire, tidal range of $7.89 \mathrm{~m})$ : Angle Bay $(51.68 \mathrm{~N}, 5.08 \mathrm{~W})$. As an index of wave exposure, we calculated the average wave fetch for each site, which provides good explanatory power for UK rocky shore communities (Burrows 2008; 2012). We used the R packages (R Development Core Team, 2014) rgdal (Bivand et al. 2018), to get the spatial points, and fetchR (Seers 2017), to obtain the fetch distances of 9 directions, to a maximum distance of $300 \mathrm{~km}$, as default. Average fetch values were $1.95 \mathrm{~km}$ at Angle Bay, $16.43 \mathrm{~km}$ at Oxwich, $24.79 \mathrm{~km}$ at Bracelet Bay, and $67.17 \mathrm{~km}$ at Rhossili. We also conducted rapid assessments of water parameters (salinity, temperature, and nutrient levels) and found minimal differences between sites (see Appendix 1 and Table S1 in Supplementary material for details). Accordingly, and in line with a long history of phycological studies (Ballantine 1961; Hepburn et al. 2007), we expected wave exposure to be a key driver of any trait differences between sites.

\section{Sampling for traits}

We assessed morphological traits of LBM at the individual level (within species). Across the intertidal and during low tide, at each site, we haphazardly positioned nine replicate $1 \times 1 \mathrm{~m}$ quadrats, at least $5 \mathrm{~m}$ apart (spread equally among the lower, middle and upper parts of the shore), providing 36 quadrats in total. Individuals were sampled from each replicate quadrat. Due to the effort necessary to measure traits at this scale, we collected a maximum of three samples per species, per quadrat, adding to a total of $n=167$ individuals. Samples were stored in bags with seawater, and kept in coolers until returning to the laboratory, where they were immediately transferred to a freezer $\left(-18^{\circ} \mathrm{C}\right)$. Sampling took place in summer 2017 (June and July). 


\section{Survey of LBM communities}

In order to fully capture the dominant species of intertidal LBM and the assemblages that they form in the study region, we went back to survey the study sites in the summer of 2018 (July- August). A thorough census allowed us to scale traits to the community level and observe how they change with the environmental gradients (shore height and wave exposure). Along four transects at each shore, spanning the whole intertidal zone, we placed $1 \mathrm{x} 1 \mathrm{~m}$ quadrats every $10 \mathrm{~m}$. This also allowed us to accurately quantify the mean shore height distribution of each LBM species for the species-level analyses. Abundance was estimated by counting how many of the 25 string squares inside the quadrat were covered, then transforming that into percentage values (Dethier et al. 1993). Since the study species share similar gross morphologies, cover provides an appropriate, as well as quick, assessment of abundance (Edmunds and Carpenter 2001, Aquilino et al. 2009)

\section{Shore height}

The position of each quadrat for both surveys was marked using GPS (Garmin 62 ST, Garmin Ltd., Olathe, KS, US) and its height (above chart datum) ascertained using publicly available LIDAR data (lle.gov.wales). To account for differences in tidal range among sites so they are comparable, we used 'relative height' $(\mathrm{RH})$ as a measure of the shore height of replicate quadrats, calculated as:

$$
\mathrm{RH}=(\mathrm{HQ}-\mathrm{LAT}) / \mathrm{TTR}
$$

where HQ is the height of the quadrat, LAT is the lowest astronomical tidal height of the specific shore and TTR is the total tidal range of the region (www.ntslf.org). The range of RH spanning the sampled transects varied among sites: Angle bay: 0.22 - 0.70; Oxwich: 0.07 - 
0.78; Bracelet Bay: 0.07 to 0.75 ; and Rhossili: 0.15 to 0.73 , possibly owing to differences in exposure, aspect, or shore topography.

\section{Trait measurements}

We assessed six morphological traits that were either known or expected to relate to the ability of individual LBM to cope with the environmental stressors shore height (tidal emersion) and wave exposure (see Table 1 for rationale and supporting references). Most of these traits have been measured previously in macroalgae, although not systematically, and have analogous traits that are routinely measured in terrestrial plant ecology (Cornelissen et al. 2003). To allow efficient screening across individuals, the functional traits served as indicators of physiological or physical functions, rather than being direct measurements of them, i.e., 'functional markers' (sensu Garnier et al. 2004). Before trait measurement, samples were thawed, cleaned of epibiota, and large fucoid individuals with many fronds were cut in half, longitudinally. Traits were considered at the whole individual or blade-only level (Table 1) and are described below.

The first three traits (1-3) were specific thallus area (STA), surface area to volume ratio (SAV) and thallus thickness. (1) STA and (2) SAV, similarly to specific leaf area (SLA) in plants, capture the ratio between photosynthetically active surface tissues and structural compounds (Wilson et al. 1999). These traits are expected to be related to (3) thallus thickness, because at constant density a thicker thallus (or leaf) will decrease surface area to mass or volume ratios (Reich et al. 1999). High values of STA or SAV, are associated with higher productivity (Rodriguez et al. 2016; Sakanishi et al. 2017) and nutrient uptake (Hein et al. 1995), but favour water loss and are associated with a weaker physical structure (Littler 1980). Meanwhile, thicker thalli provide structural strength, conferring resistance to frond breakage in wave-exposed conditions (e.g., Wing et al. 2007), but are associated with reduced 
productivity (Markager and Sand-Jensen 1996) and increase in drag forces. We measured surface area (SA) with software ImageJ (Schneider et al. 2012) from images of samples, cut into thallus parts, spread on an A1 light pad (MiniSun, Manchester, UK). STA was calculated by dividing the blade SA by its dry mass and is expressed as $\mathrm{cm}^{2} \mathrm{~g}^{-1}$. SAV (given as $\mathrm{cm}^{2} \mathrm{~mL}^{-}$ ${ }^{1}$ ) was obtained from dividing whole SA by total volume, which was measured through water displacement in a graduated cylinder $(0.1 \mathrm{~mL}$ resolution $)$. For large individuals such as kelp we used a larger cylinder with $1 \mathrm{~mL}$ resolution. Thickness is given in $\mathrm{cm}$ and was averaged from ten measurements along the blades, using a digital thickness gauge with $0.001 \mathrm{~mm}$ precision (Digital Micrometers Ltd., Sheffield, UK).

Three further traits were included: (4) total length, (5) holdfast ratio and (6) thallus dry matter content (TDMC). Total length should determine an individual's position in the water column, influencing light availability to the thallus (Littler and Littler 1980) and, analogously to plant height (Hodgson et al. 1999), relate to competitive dominance. Total length is the maximum length of the whole individual, and it was measured in centimetres. Holdfast ratio reflects the trade-off macroalgae face between preferentially allocating resources to the fronds to maximise photosynthetic rates and investing in anchoring structures under harsher conditions to prevent dislodgment (Sjøtun and Fredriksen 1995). This trait consists of the ratio of holdfast dry mass to the dry mass of the remaining thallus parts. Dry matter content captures the ratio between structural compounds and water-filled, nutrient-rich photosynthetically active tissues (Wilson et al. 1999). A high thallus dry matter content (TDMC) should strengthen macroalgae against wave damage and, by reducing the rate of - and tolerance to - water loss, increase desiccation tolerance (Schonbeck and Norton 1979). 
Table 1. Functional traits measured, their functional relevance, expected variation along the gradients of shore height, and the mechanisms that explain them. Arrows indicate whether trait values are expected to increase, decrease or remain unchanged. "Part" refers to the part of the macroalgae used to measure the trait in this study. "Mechanism" refers to the hypothesised mechanism through which the trait response (rather than the trait itself) is associated with the environmental driver. "Slow" or "fast" indicates the association between the trait and the rate of physiological and ecological processes (see e.g., Reich 2014). Example references supporting each function and shown in superscript numbers are: 1 . Wilson et al. (1999); 2. Markager and Sand-Jensen (1996); 3. Littler (1980); 4. Hodgson et al. (1999); 5. Sjøtun and Fredriksen (1995). See Methods for explanation of traits and hypothesised responses.

\begin{tabular}{|c|c|c|c|c|c|}
\hline \multirow[b]{2}{*}{ Trait } & \multirow{2}{*}{$\begin{array}{c}\text { Plant } \\
\text { analogue }\end{array}$} & \multirow{2}{*}{ Part } & \multirow{2}{*}{$\begin{array}{l}\text { Function and } \\
\text { reference }\end{array}$} & \multicolumn{2}{|r|}{ Shore height } \\
\hline & & & & $\begin{array}{c}\text { Trait } \\
\text { response }\end{array}$ & Mechanism \\
\hline $\begin{array}{l}\text { Specific thallus } \\
\text { area (STA) }\end{array}$ & $\begin{array}{l}\text { Specific leaf } \\
\text { area }\end{array}$ & Blade & $\begin{array}{l}\text { Light capture } \\
\text { ("fast") }\end{array}$ & $\boldsymbol{K}$ & Slows water loss \\
\hline Thickness & Leaf thickness & Blade & $\begin{array}{l}\text { Physical } \\
\text { structure } \\
(\text { "slow") }\end{array}$ & $\pi$ & Slows water loss \\
\hline $\begin{array}{l}\text { Surface area: } \\
\text { volume ratio } \\
(\mathrm{SAV})\end{array}$ & Leaf SAV & Whole & $\begin{array}{l}\text { Nutrient } \\
\text { capture } \\
\text { ("fast") }\end{array}$ & $\boldsymbol{k}$ & Slows water loss \\
\hline $\begin{array}{l}\text { Thallus dry matter } \\
\text { content (TDMC) }\end{array}$ & $\begin{array}{l}\text { Dry matter } \\
\text { content (DMC) }\end{array}$ & Whole & $\begin{array}{l}\text { Physical } \\
\text { structure } \\
\text { ("slow") }\end{array}$ & $\pi$ & $\begin{array}{l}\text { Increases tolerance to } \\
\text { desiccation }\end{array}$ \\
\hline Total length & $\begin{array}{l}\text { Total length/ } \\
\text { height }\end{array}$ & Whole & $\begin{array}{l}\text { Competition } \\
\text { for light } \\
\text { ("fast") } 4\end{array}$ & $k$ & $\begin{array}{l}\text { Economic: reduced } \\
\text { requirement to compete } \\
\text { for light }\end{array}$ \\
\hline Holdfast ratio & $\begin{array}{l}\text { Root : shoot } \\
\text { ratio }\end{array}$ & Whole & $\begin{array}{l}\text { Anchoring to } \\
\text { substrate } \\
\text { ("slow") } 5\end{array}$ & $\boldsymbol{k}$ & $\begin{array}{l}\text { Economic: reduced } \\
\text { requirement for strong } \\
\text { attachment }\end{array}$ \\
\hline
\end{tabular}

Statistical analyses

All analyses were performed in R. To explore how LBM species vary in functional trait space, we performed a principal component analysis (PCA) using package ade4 (Dray and Dufour 2007). We used a Euclidean distance matrix based on the six traits, using scaled, individual values. Prior to the PCA, we log-transformed the traits and visually checked the 
linearity of trait-trait relationships. A pair of traits was moderately correlated (SAV and STA, $r=0.76$ ), so to make sure that would not influence the outcome of the PCA, we performed the same ordination removing SAV. This had only negligible effects on the species axes coordinates or the correlation between traits and axes (Appendix 2). Because of human error during sampling, 58 individual trait measures (representing 6\% of all trait values) were absent from our dataset. We therefore conducted analyses with these missing values imputed using the package mice (multiple imputations with chain equations; van Buuren and GroothuisOudshoorn 2011) and this did not appreciably affect species position relative to each other or trait loadings on axes (see Appendix 2, Table S2, Fig. S2).

To evaluate how this interspecific variability scales to the community level along the shore height gradient and across sites, we examined how community weighted means (CWMs) of loadings from PC1 and PC2 varied with RH at each site. CWM uses species means and assigns proportional weight to the traits according to the abundance of each species, therefore making it possible to relate traits to ecosystem functioning, as has been done in plant communities (e.g., Vile et al. 2006). Moreover, because this approach assigns trait values at the species level, it assumes that species identity (rather than site $\mathrm{x}$ species interactions) is the most important source of trait variation. CWMs express the dominant traits in a community (Mokany et al. 2008), so to focus our analyses on communities dominated by LBM we selected communities where the total cover of these species was of at least one third (33\% of quadrat area). We used the data from the survey and calculated CWMs for each quadrat using package "FD" (Laliberté et al. 2014). Then we plotted the CWMs of each axis for all sites individually to observe their distribution along the relative heights. Because they were not linear, we used Kendall's rank correlation (which also allows ties) to statistically test the relationship between relative heights and traits for each site. We show the data distribution along with pie charts of 
species' relative abundances at each point to highlight the species that were driving any trends or patterns.

We next evaluated the degree of intraspecific variability across sites of varying wave exposure, and the extent to which species maintain functional trait differences under this variability. We ran a linear mixed model using lme4 in R (Bates et al. 2015), fitting species by site as predictors of PCs 1 and 2. To account for the possible non-independence of samples collected from the same quadrat, we fitted quadrat identity as a random effect, but this did not improve the model fit (by AIC comparison) and so we report the results of the linear model (site $*$ species; function anova on stats $\mathrm{R}$ package). Note that we expected the distribution of species to be strongly related to RH due to the obvious zonation, so we did not plan analyses including both species and RH as simultaneous predictors. However, we did test whether residual variance from the above models could be attributed to RH (Appendix 3, Table S3). To integrate multiple traits, we performed the same species by site model using PERMANOVA based on Euclidean distances using adonis in the package vegan (Oksanen et al. 2018), with the scaled trait scores (Table S4). Two species (S. latissima and H. siliquosa) were removed from these analyses because they were found at only one site and in less than five quadrats. Of those included, A. nodosum and L. digitata were both missing from a single site (Oxwich and Angle Bay, respectively); the remaining four species occurred at all four sites.

\section{Results}

We found 8 species belonging to three families. The total number of samples for trait measurement was 14 for Ascophyllum nodosum, 27 for Fucus spiralis, 45 for Fucus serratus, 31 for Fucus vesiculosus, 22 for Pelvetia canaliculata (family Fucaceae), 3 for Halidrys siliquosa (family Sargassaceae), 17 for Laminaria digitata, and 8 for Saccharina latissima 
(family Laminariaceae). Species' mean relative heights and ranges for both surveys are given Table S5.

The spectrum of functional trait variation

Across sites and shore heights, PC1 captured $46.1 \%$ and PC2 captured $21.5 \%$ of variation in function trait space (Fig. 1). The traits that most contributed to the first and second axes of variation were STA, SAV and TDMC (on PC1) and holdfast ratio, blade thickness and total length (on PC2). PC3 captured an additional 16.7\% variation and was driven mostly by length and holdfast ratio (Table S2). Despite intraspecific variability, and the notable overlapping positions of species in the Fucus genus, most species occupied distinct regions of trait space (Fig. 1; Table 2 (ANOVA), species effect: PC 1 and 2: partial $\mathrm{R}^{2}=0.72, \mathrm{P}<0.001$ ) and could be associated with traits or axes, illustrating the nature of their functional differences. STA was positively and strongly associated with $S$. latissima, a kelp species found at low shore and restricted to the most sheltered site. Length and holdfast ratio were associated with $L$. digitata, a kelp species of the low shore which is absent from the most sheltered site. TDMC was associated with $P$. canaliculata, the species highest on the shore at all sites. Thickness was associated with the mid shore species $A$. nodosum, which was distinct from other mid shore species $F$. vesiculosus and F. serratus. Among the LBM, these Fucus species and the upper shore $F$. spiralis shared the most similarity. Trait means and variance for each species are shown on Fig. S1.

We can observe how species differentiate in PCs 1 and 2 with increasing shore height (Fig. 1, bottom panel). In general, species' values on both PC1 and PC2 declined with their average shore height. However, A. nodosum was a clear outlier, occupying the mid-shore while scoring lower on PC1 than high shore species, and scoring similarly to low shore species on 
PC2. Taking all species together, there was a clear relationship between all trait values and the predictors of shore height and site (Table S4; PERMANOVA).
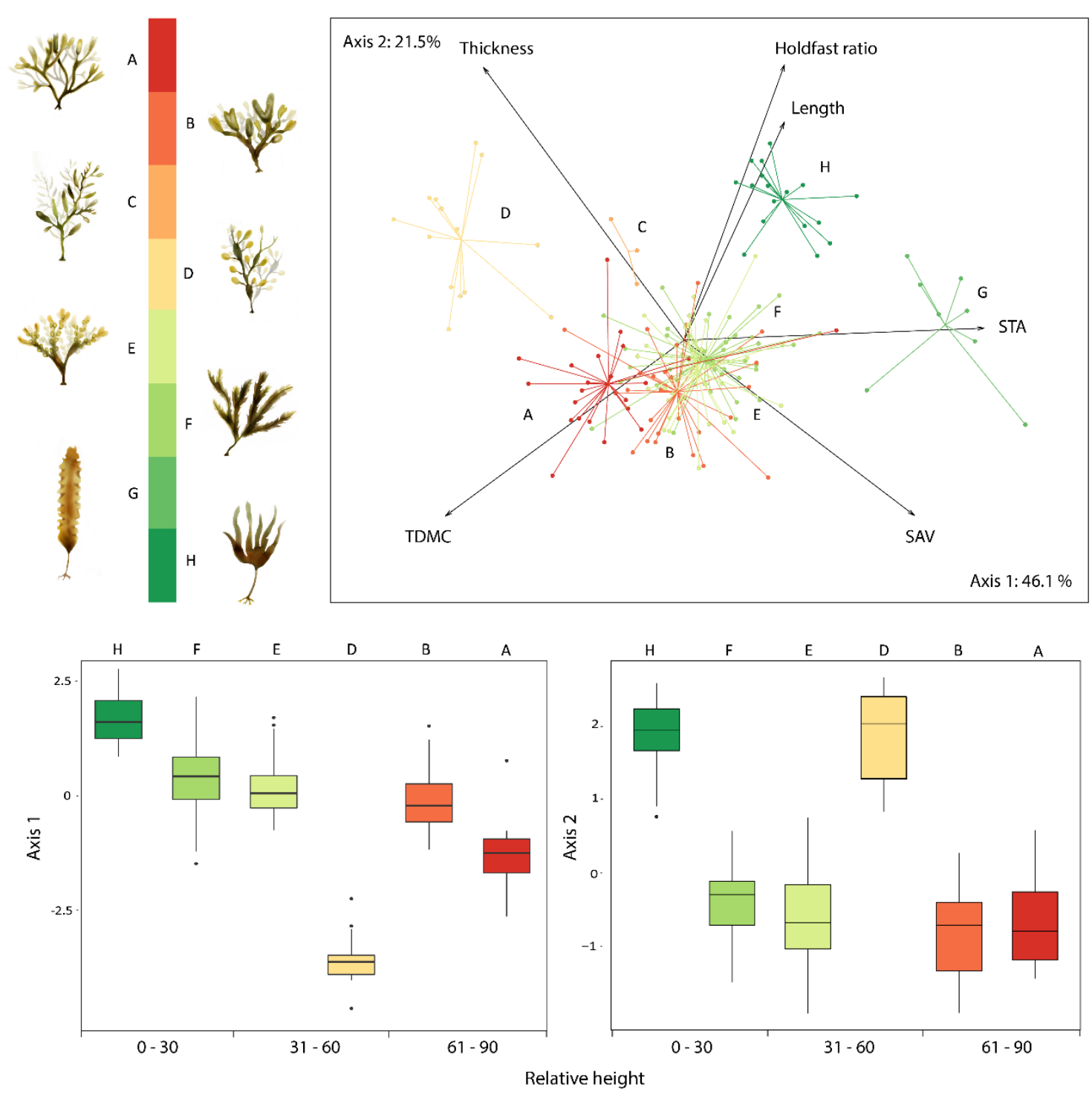

Figure 1. First two PCA axes of large brown macroalgae, based on trait survey from 2017. The top panel shows the distribution of individuals and species in trait space, together with the relationships between functional traits and PC axes. All eight sampled species are included, colour-coded by order of height distribution (top left). Species legend: A, Pelvetia canaliculata; B, Fucus spiralis; C, Halidrys siliquosa; D, Ascophyllum nodosum; E, F. vesiculosus; F, F. serratus; G, Saccharina latissima; and H, Laminaria digitata. Lower panels show species variation in PC scores, with species sorted by relative height (RH, as proportion, relative to the total tidal variation; full description in Methods). Two species were removed from the boxplots due to their low occurrences: H. siliquosa and S. latissima. Contributions of each trait to the PCA axes are given in Table S2. 


\section{Scaling species' differences to the community level}

The relationships between increasing shore height and CWMs based on PC1 and 2 varied across sites (Figures 2 and 3). PC1 significantly decreased with relative height at the two sites in the middle of the exposure gradient, Bracelet Bay and Oxwich $(\tau=-0.72 ; \mathrm{p}<0.001$, and $\tau=-0.75 ; \mathrm{p}<0.001$, respectively). Accordingly, at these two sites, higher on the shore, dominant species exhibited lower STA and SAV, and higher TDMC. There was also a decrease in PC2 with increasing height at Oxwich $(\tau=-0.75)$, indicating that at this site, higher on the shore dominant species were shorter, thicker and with a lower holdfast ratio. There were no clear relationships between height and CWMs of PCs at either the very sheltered Angle Bay or the exposed Rhosilli. At Angle, this can be explained by the dominance and relatively low shore extent of A. nodosum (Figures 2 and 3), with its anomalous traits (see above). At Rhosilli, this can be explained by the up-shore extent of the otherwise lower shore L. digitata.

Intraspecific and interspecific variability across sites of varying wave exposure

Species' traits and differences in trait space among them varied with site, to some extent. Although there was no clear evidence of a site - species interaction for PC1 (partial $\mathrm{R}^{2}$ $=0.03 ; \mathrm{p}=0.07 ;$ Table 2 ) there was an interaction between site and species for PC2 (partial $\mathrm{R}^{2}$ $=0.05 ; \mathrm{p}=0.001)$. However, these interactions and the main effects of site were much weaker than those of species (PC1: site 8\% vs. species 72\%; PC2: site 2\% vs. species $72 \%$ ), indicating that the readjustments of species' relative trait values at different sites are much smaller than the overall differences between them. Still, we can observe changes in the trait means across sites for some species, although not clearly continuous along the exposure gradient (except for F. vesiculosus, which increased in thickness consistently and positively with exposure; Fig. 
S1). Residual intraspecific variability could not be attributed to variation in the relative height of collected samples (Appendix 3, Table S3).

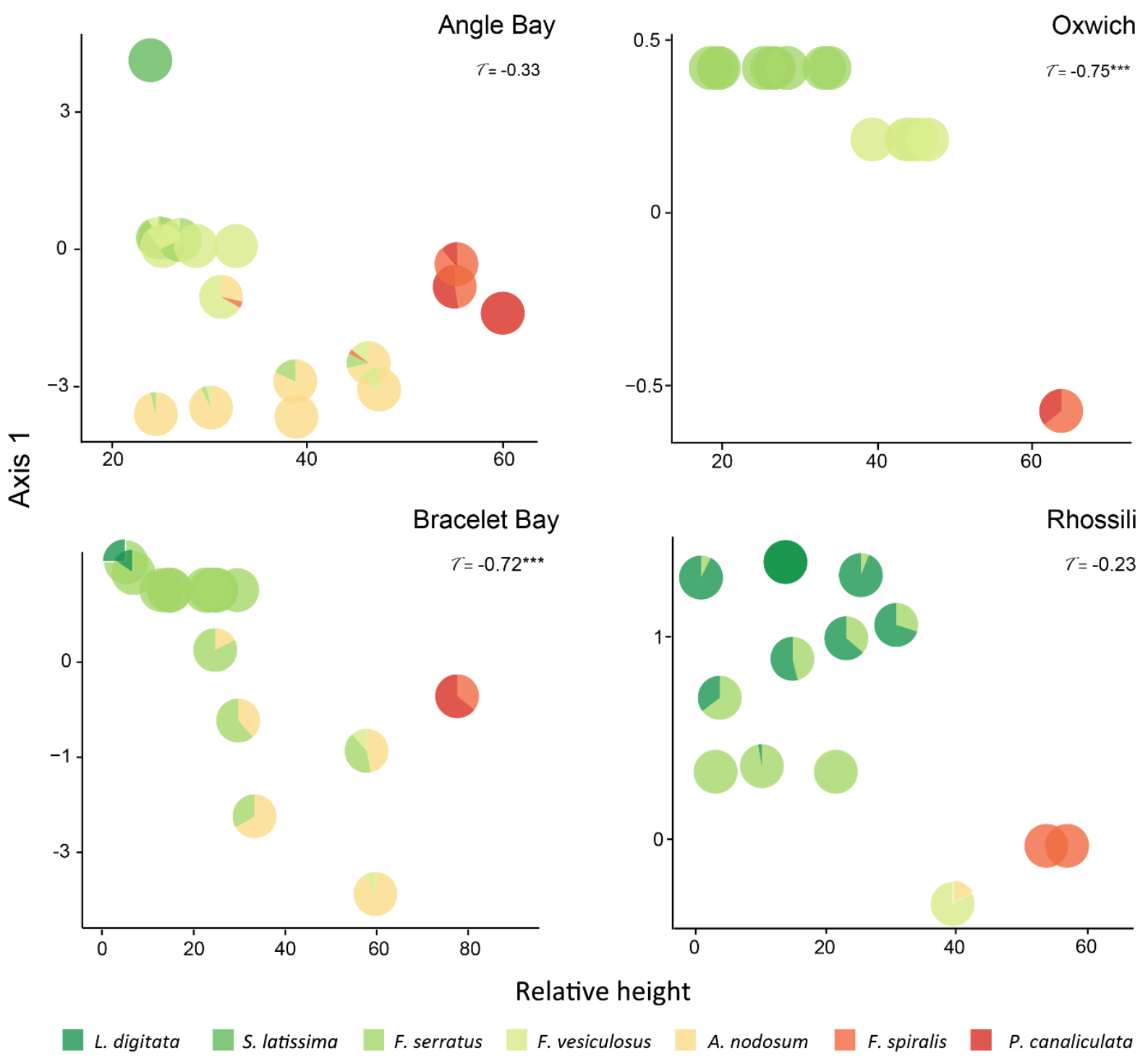

Figure 2. Community weighted means (CWMs) of the first PCA axis along relative heights (as proportion, relative to the total tidal variation). Full description for calculation of relative heights in Methods. Note that sites differ in range). Pie charts represent species relative abundances for each point (quadrat) and Kendal's tau is given for each site, with significant values $(\mathrm{p}<0.01)$ shown with asterisks. 

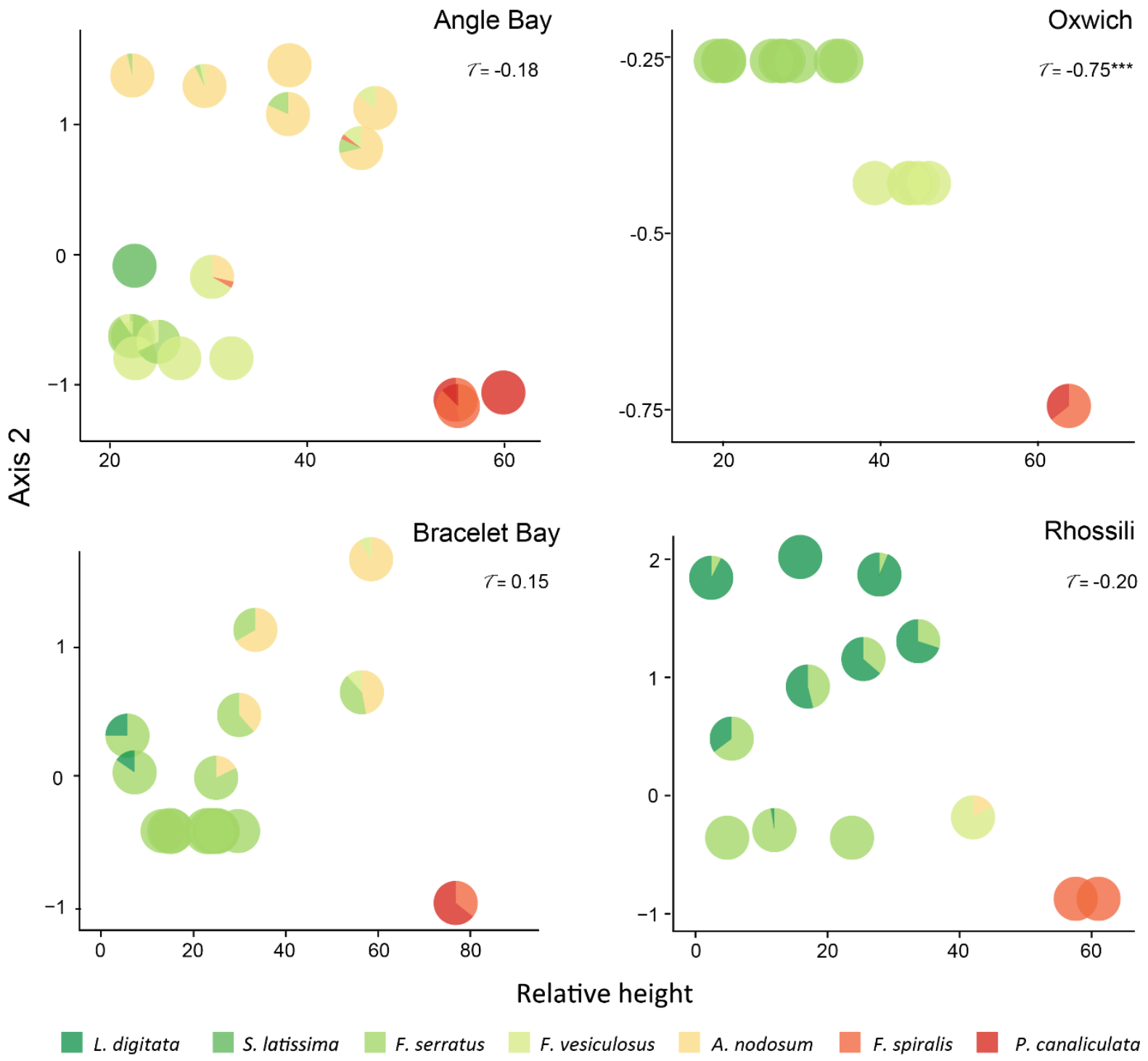

Figure 3. Community weighted means (CWMs) of the second PCA axis along relative heights (as proportion, relative to the total tidal variation). Full description for calculation of relative heights in Methods. Note that sites differ in range). Pie charts represent species relative abundances for each point (quadrat) and Kendal's tau is given for each site, with significant values $(\mathrm{p}<0.01)$ shown with asterisks. 
Table 2. Result of ANOVAs examining the effect of species and site on individual traits loaded onto the first two PCA axes. Degrees of freedom (df), and test statistics (sum of squared differences, mean of squared differences, F-value and $\mathrm{P}$ value) are given, as well as an estimated variance explained (Partial $\mathrm{R}^{2}$ ).

\begin{tabular}{lrrrrrr}
\hline & df & Sum Sq & Mean Sq & F value & P value & Partial R $^{\mathbf{2}}$ \\
\hline Axis $1-\mathrm{R}^{2}: 0.82$ & & & & & & \\
Site & 3 & 30.859 & 10.286 & 20.1006 & $<\mathbf{0 . 0 0 1}$ & 0.080 \\
Species & 5 & 276.483 & 55.297 & 108.0572 & $<\mathbf{0 . 0 0 1}$ & 0.716 \\
Site * Species & 13 & 11.111 & 0.855 & 1.6702 & 0.074 & 0.029 \\
Residuals & 134 & 67.5 & 0.508 & & & \\
\hline Axis 2- $\mathrm{R}^{2}: 0.79$ & & & & & & \\
Site & 3 & 4.183 & 1.394 & 3.6491 & $<\mathbf{0 . 0 5}$ & 0.017 \\
Species & 5 & 176.168 & 35.234 & 92.2094 & $<\mathbf{0 . 0 0 1}$ & 0.719 \\
Site * Species & 13 & 13.372 & 1.029 & 2.7773 & $\mathbf{0 . 0 0 1}$ & 0.055 \\
Residuals & 134 & 51.202 & 0.382 & & & \\
\hline
\end{tabular}

\section{Discussion}

Addressing trait variability at both within and between species levels provides insights to inform the study of functional diversity in macroalgal communities (Demes and Pruitt 2019). We investigated a group of dominant macroalgae in rocky intertidal shores, the "large brown macroalgae" (LBM) to reveal the levels of morphological trait variability and how these relate to environmental gradients and ecological strategies. We therefore bring a new perspective to the study of macroalgal functional ecology, which has so far remained largely restricted to classifying species into - and comparing - functional groups.

Trait variability among LBM was largely captured by two key axes and could be related to species' position on the shore and ecological strategies. The existence of two major axes of variation (at least based on the suite of traits measured here) is consistent with studies of vascular plants (Pescador et al. 2015; Díaz et al. 2016). The first, analogous to the 'leaf economics' axis in plants, is representative of resource acquisition vs. conservation/stress tolerance trade-offs. That is, LBM will either have high STA and SAV, and therefore high 
productivity, or have a high TDMC and more resistance to mechanical or desiccation stress. The second axis requires more interpretation, but we argue that it relates to competitive dominance. Longer LBM have higher canopies that are competitively dominant for light, while a greater proportional investment in anchoring holdfasts and thicker blades provide physical resistance to the increased drag associated with larger fronds (Wernberg and Thomsen 2005). With the exception of Ascophyllum, species' positions on these axes broadly reflect their position on the shore, as we hypothesised, with species higher on the shore scoring lower on PC1 and 2. The outlying traits of the mid-shore Ascophyllum appear to reflect its unique strategy among mid-shore species: slow and persistent growth, resisting physical and biological stressors over a long lifespan (10-15 years; Sundene 1973), to eventually dominate latesuccessional assemblages at sheltered sites (Topinka et al. 1981, Vadas et al. 1990). This strategy appears to require traits that are more conservative than other mid-shore species and also shifts it higher on the second axis reflecting greater thallus thickness (especially) and length. The case of Ascophyllum suggests that the first trait dimension can relate to both stress tolerance and competitive strategy, which can blur the relationship between traits and environmental stress gradients, such as that represented by shore height.

Although we examined species' trait values in relation to their mean shore position, these species often exist in mixed assemblages. Community weighted means allow integration across species in these mixed assemblages (most strongly reflecting the dominants) and indicate consequences for ecosystem functioning ("mass-ratio hypothesis", Grime 1998). It should be noted here that, although a simplification, the use of species' level mean trait values in CWMs was validated by our analysis showing species identity as the dominant source of trait variability. At Bracelet Bay and Oxwich, both at the middle of the exposure gradient, we observed a decline in CWMs of $\mathrm{PC1}$. This means that communities in the more environmentally stressful higher shore were dominated by species with a more conservative 
thallus structure (low STA/high TDMC). This is consistent with our expectation, with species dominating the higher shore needing to conserve resources (especially water). At Oxwich, there was also a decline in PC2, illustrating that upper shore communities invested proportionally less in holdfasts and were shorter (less competitive). The implications are a slowing of ecosystem functions towards higher on the shore, such as primary productivity (Reich 2014), potentially affecting ecosystem services by reducing the volume of material available to biomass harvesting or fisheries, as well as decreasing the potential for wave attenuation (Smale et al. 2013). Nevertheless, these higher shore communities may still provide valuable functions. For instance, they support and shade faunal assemblages where the threat of desiccation and excessive heat is most extreme. Additionally, their more recalcitrant tissue should persist longer in the environment, driving long-term carbon sequestration (Chung et al. 2011).

However, at sites located at the extremes of the wave exposure gradient, there was no clear relationship between shore height and CWMs for either PCs. At the very exposed Rhossili, low-shore L. digitata appeared to benefit from the level of exposure, as well as the presence of rockpools, and expanded to almost $30 \%$ of the shore height, raising CWMs through the mid-shore. At sheltered Angle Bay, the dominance of the outlier A. nodosum in many of the quadrats throughout the mid-shore depressed PC1 and elevated PC2. Together, these results show that the correspondence between shore height and CWMs can be disrupted where species show diffuse zonation and shifts in vertical position, or where species possess unusual traits relative to their shore height $-A$. nodosum in this case.

We also aimed to compare within- to between-species variability. Among individuals of the same species, trait adjustments across sites was proportionally small (relative to interspecific variability). It was also not present for all species and traits and it did not vary in a consistent manner across the wave exposure gradient, thus indicating that either other 
environmental factors might be driving this intraspecific variation, or that our scale was not large enough to detect the expected influence of wave exposure (or a combination of both). Still, this intraspecific variation in traits at such a small spatial scale supports previous studies in LBM (Sjøtun and Fredriksen 1995; Blanchette 1997; Wing et al. 2007) and exemplifies the potential for these species to change their morphology to match environmental conditions, which can be attributed to both adaptive variation and phenotypic plasticity (King et al. 2017). At the interspecific level, we show that considering LBM as a single "functional group", and therefore ecologically similar, can obscure and underestimate functional diversity. Using multiple continuous functional traits, as demonstrated in this study, provides a solution by allowing individuals and species to be positioned in continuous trait space. Following efforts in terrestrial plants (Díaz et al. 2016), the functional diversity of seaweeds should be resolved more generally by expanding this approach to other species of LBM worldwide through coordinated trait screening initiatives. This could shed new light on topics in seaweed ecology, such as their functional biogeography and response to global change drivers (Harley et al. 2012; Violle et al. 2014). Our finding that interspecific trait variability overwhelmed intraspecific variability in LBM supports an initial application of these traits at the species level. Nevertheless, the prevalent, albeit relatively weak, species-site interactions we found here indicate more accurate estimations of functional diversity could ultimately be gained by integrating intraspecific variation.

Our approach has some limitations associated with the scope and focus of our study. We pragmatically used indirect measurements of the gradients of wave exposure (wave fetch of different sites) and tidal emersion (relative shore height), and did not consider direct mediators of stress on individuals such as drag forces or evaporation potential. This is a first step towards understanding spatial variation in seaweed functional traits and is analogous, for example, to using altitude in terrestrial studies of plant functional diversity. We also chose traits 
as functional markers (sensu Garnier et al. 2004), which provided an efficient way to screen multiple dimensions of variability at the cost of fine-scale mechanistic insight. The addition of other traits may offer more detail in studies such as ours. For example, positive buoyancy and the presence of pneumatocysts, which can enhance competitive dominance in the water column, and phenolic compound content, which can help the persistence and dominance of resource-conservative species by granting protection against grazers (Amsler 2008). Finally, we focused on the trait rather than phylogenetic differences among species. We recognise that these differences have an evolutionary basis such that close relatives are likely to share similar shore heights and traits (e.g., lower shore kelps with high STA vs. mid-shore fucoids with lower STA). However, in light of our a priori hypotheses linking traits to shore height, the mechanistic and ecologically important connections between species' identities, traits and shore heights stand to be complemented - but not undermined by - an understanding of their evolutionary basis (de Bello et al. 2015).

In conclusion, we have reported the first attempt to position species of large brown macroalgae in a continuous, multidimensional, trait space. Reminiscent of findings from terrestrial plants, species were concentrated along a two-dimensional plane defined by axes of resource acquisition and competitive dominance. We found that predicting seaweed trait responses to intertidal (stress) emersion gradient is challenging because 1) resource conservation traits can be related to competitive as well as stress-tolerance strategies, and 2) community zonation patterns can be modified by wave exposure. Overall, our study demonstrates the potential for functional traits to reveal new dimensions of diversity among macroalgae and unify ecological methods and perspectives across ecosystems and evolutionarily divergent producer groups. 


\section{Acknowledgements}

We thank Andrew J. King for the contributions to the manuscript; Tom P. Fairchild for the technical help; Mike Burrows for the help obtaining the fetch data; Olga Koppel and Josh Mutter for their help in the field and the lab; Igor S. Pessi for the help with the images; and Amanda Cappelatti for the illustrations. We also thank the anonymous reviewers for their suggestions. 


\section{References}

Amsler CD (2008) Algal Chemical Ecology. Springer-Verlag, Berlin.

Arenas F, Sánchez I, Hawkins SJ, Jenkins SR (2016) The invasibility of marine algal assemblages: role of functional diversity and identity. Ecology, 87(11), 2851-61.

Aquilino K, Bracken M, Faubel M, Stachowicz J (2009) Local-scale nutrient regeneration facilitates seaweed growth on wave-exposed rocky shores in an upwelling system. Limnol. Oceanogr., 54(1), 309317

Bäck S (1993) Morphological variation of northern Baltic Fucus vesiculosus along the exposure gradient. Ann. Bot. Fennici. 30, 275-283

Ballantine W J (1961) A biologically-defined exposure scale for the comparative description of rocky shores. Field Studies Council, 19p.

Bates D, Maechler M, Bolker B, Walker S (2015) Fitting linear mixed-effects models using lme4. Journal of Statistical Software, 67(1), 1-48. doi:10.18637/jss.v067.i01.

Bivand R, Keitt T, Rowlingson B (2018) rgdal: Bindings for the 'Geospatial' Data Abstraction Library. $\mathrm{R}$ package version 1.2-18.

Blanchette CA (1997) Size and survival of intertidal plants in response to wave action: A case study with Fucus gardneri. Ecology, 78(5), 1563-1578. doi:10.2307/2266149

Bloomfield KJ, Cernusak LA, Eamus D et al. (2018) A continental- scale assessment of variability in leaf traits: Within species, across sites and between seasons. Func. Ecol., 32, 1492-1506. doi: $10.1111 / 1365-2435.13097$

Burrows MT, Harvey R, Robb L (2008) Wave exposure indices from digital coastlines and the prediction of rocky shore community structure. Mar. Ecol. Prog. Ser., 353:1-12. doi: 10.3354/meps07284

Burrows MT (2012) Influences of wave fetch, tidal flow and ocean colour on subtidal rocky communities. Mar. Ecol. Prog. Ser, 445, 193-207. doi:10.3354/meps09422

van Buuren S, Groothuis-Oudshoorn K (2011) mice: Multivariate Imputation by Chained Equations in R. J. of Stat. Software, 45(3), 1-67.

Chapman ARO (1995) Functional ecology of fucoid algae: twenty-three years of progress. Phycologia, 34 (1), 1-32. doi:10.2216/i0031-8884-34-1-1.1

Chung IK, Beardall J, Mehta S, Sahoo D, Stojkovic S (2011) Using marine macroalgae for carbon sequestration: a critical appraisal. J. Appl. Phycol., 23, 877-886. doi: 10.1007/s10811-010-9604-9

Cornelissen JHC, Lavorel S, Garnier E et al. (2003) Handbook of protocols for standardised and easy measurement of plant functional traits worldwide. Australian J. of Botany, 51(4), 335-380. doi:10.1071/BT02124

Cornwell WK, Ackerly DD (2009) Community assembly and shifts in plant trait distributions across an environmental gradient in coastal California. Ecol. Monographs, 79(1), 109-126. doi:10.1890/071134.1

Cousens R (1982) The effect of exposure to wave action on the morphology and pigmentation of Ascophyllum nodosum (L.) Le Jolis in South-Eastern Canada. Bot. Mar. 25, 191-195. 
Dayton PK (1985) Ecology of kelp communities. Ann. Rev. Ecol. Syst., 16, 215-245.

de Bello F, Berg M, Dias A, Diniz-Filho J et al. (2015) On the need for phylogenetic 'corrections' in functional trait-based approaches. Fol. Geobot., 50(3). doi:10.1007/s12224-015-9228-6

Dethier MN, Graham ES, Cohen S, Tear M (1993) Visual versus random-point percent cover estimations: 'objective' is not always better. Mar. Ecol. Prog. Ser., 96, 93-100.

Demes KW, Pruitt JN (2019) Individuality in seaweeds and why we need to care. J Phycol., 55(2), 247256. doi: 10.1111/jpy.12845.

Díaz S, Hodgson JG, Thompson K et al. (2004) The plant traits that drive ecosystems: Evidence from three continents. J. of Veg. Sci., 15(3), 295-304. doi:10.1111/j.1654-1103.2004.tb02266.x

Díaz S, Kattge J, Cornelissen J et al. (2016) The global spectrum of plant form and function. Nature, 529, 167-177. doi: 10.1038/nature16489

Dray S, Dufour AB (2007) The ade4 Package: implementing the duality diagram for ecologists. J. of Stat. Software, 22, 1-20.

Edmunds E, Carpenter R (2001) Recovery of Diadema antillarum reduces macroalgal cover and increases abundance of juvenile corals on a Caribbean reef. PNAS 98 (9), 5067-5071

Fajardo A, Piper F (2011) Intraspecific trait variation and covariation in a widespread tree species (Nothofagus pumilio) in southern Chile. New Phytol., 189, 259-271. doi: 10.1111/j.14698137.2010.03468.x

Garnier E, Cortez J, Billè, G et al. (2004) Plant functional markers capture ecosystem properties during secondary succession. Ecology, 85(9), 2630-2637. doi:10.1890/03-0799

Gómez I, Huovinen P (2011) Morpho-functional patterns and zonation of south Chilean seaweeds: The importance of photosynthetic and bio-optical traits. Mar. Ecol. Prog. Ser., 422, 7791. doi:10.3354/meps08937

Grime JP (1974) Vegetation classification by reference to strategies. Nature, 250, 36-31. doi:10.1038/250026a0

Grime JP (1998) Benefits of plant diversity to ecosystems: Immediate, filter and founder effects. J. of Ecol., 86, 902-910.

Harley CDG, Anderson KM, Demes KW et al. (2012) Effects of climate change on global seaweed communities. J. Phycol., 48, 1064-78.

Hein M, Pedersen MF, Sand-Jensen K (1995) Size-dependent nitrogen uptake in micro- and macroalgae. Mar. Ecol. Prog. Ser., 118, 247-253.

Hepburn CD, Holborow JD, Wing SR, Frew RD, Hurd CL (2007) Exposure to waves enhances the growth rate and nitrogen status of the giant kelp Macrocystis pyrifera. Mar. Ecol. Prog. Ser., 339, 99108. doi:10.3354/meps339099.

Hodgson JG, Wilson PJ, Hunt R, Grime JP, Thompson K (1999) Allocating C-S-R plant functional types: a soft approach to a hard problem. Oikos, 85, 282-296.

Hurd C, Harrison P, Bischof K, Lobban C (2014) Seaweed Ecology and Physiology. Cambridge: Cambridge University Press. doi:10.1017/CBO9781139192637 
King NG, McKeown NJ, Smale DA, Moore PJ (2017) The importance of phenotypic plasticity and local adaptation in driving intraspecific variability in thermal niches of marine macrophytes. Ecography 40, 001-014. doi: 10.1111/ecog.03186

Kraft NJB, Cornwell WK, Webb CO, Ackerly DD (2007) Trait Evolution, Community Assembly, and the Phylogenetic Structure of Ecological Communities. The American Naturalist, 170(2), 271-283. doi:10.1086/519400

Laliberté E, Legendre P, Shipley B (2014) FD: measuring functional diversity from multiple traits, and other tools for functional ecology. R package version 1.0-12.

Littler MM (1980) Morphological Form and Photosynthetic Performances of Marine Macroalgae: Tests of a Functional/Form Hypothesis. Botanica Marina, 23, 161-165. doi:10.1515/botm.1980.23.3.161

Littler MM, Littler DS (1980) The Evolution of Thallus Form and Survival Strategies in Benthic Marine Macroalgae: Field and Laboratory Tests of a Functional Form Model. The American Naturalist, 116(1), 25-44. doi:10.1086/283610

Markager S, Sand-Jensen K (1996) Implications of thallus thickness for growth-irradiance relationships of marine macroalgae. European J. of Phycology, 31(1), 79-87. doi:10.1080/09670269600651231

Mokany K, Ash J, Roxburgh S (2008) Functional identity is more important than diversity in influencing ecosystem processes in a temperate native grassland. J. of Ecol., 96(5), 884-893. doi:10.1111/j.1365-2745.2008.01395.x

Oksanen J, Blanchet F, Friendly M, Kindt R et al. (2018) vegan: Community Ecology Package. R package version 2.4-6.

Pescador D, de Bello F, Valladares F, Escudero A (2015) Plant Trait Variation along an Altitudinal Gradient in Mediterranean High Mountain Grasslands: Controlling the Species Turnover Effect. Plos One, 10 (3), 1-16. doi: 10.1371/journal.pone.0118876

Reich PB, Ellsworth DS, Walters MB et al. (1999) Generality of leaf trait relationships: a test across six biomes. Ecology, 80(6), 1955-1969

Reich PB (2014) The world-wide "fast-slow" plant economics spectrum: A traits manifesto. J. of Ecology, 102(2), 275-301. doi:10.1111/1365-2745.12211

Rodriguez S, Martín AP, Sousa-Pinto I, Arenas F (2016) Biodiversity effects on macroalgal productivity: Exploring the roles of richness, evenness and species traits. Mar. Ecol. Prog. Ser., 562, 79-91. doi:10.3354/meps11948

Sakanishi Y, Kasai H, Enomoto K, Toda M, Tanaka J (2017) Productivity and thallus toughness tradeoff relationship in marine macroalgae from the Japan Sea. Phycol. Research, 65 (2), 103-110. doi:10.1111/pre.12168

Schneider CA, Rasband WS, Eliceiri KW (2012) "NIH Image to ImageJ: 25 years of image analysis". Nature Methods, 9(7), 671-675.

Schonbeck M, Norton, TA (1979) Drought-Hardening in the Upper-Shore Seaweeds Fucus spiralis and Pelvetia canaliculata. J. of Ecol., 67(2), 687-696.

Seers B. (2017) fetchR: Calculate Wind Fetch. R package version 2.1-0

Siefert A, Violle C, Chalmandrier L et al. (2015) A global meta-analysis of the relative extent of intraspecific trait variation in plant communities. Ecol. Letters, 18, 1406-1419. doi: 10.1111/ele.12508. 
Sjøtun K, Fredriksen S (1995) Growth allocation in Laminaria hyperborea (Laminariales, Phaeophyceae) in relation to age and wave exposure. Mar. Ecol. Prog. Ser., 126, 213-222.

Smale DA, Burrows MT, Moore P, O’Connor N, Hawkins SJ (2013) Threats and knowledge gaps for ecosystem services provided by kelp forests: A northeast Atlantic perspective. Ecol. and Evol., 3(11), 4016- 4038 doi:10.1002/ece3.774.

Southward AJ (1959) The zonation of plants and animals on rocky sea shores. Bio. Rev., 33,137-177.

Steneck RS, Dethier MN (1994) A functional group approach to the structure of algal-dominated communities. Oikos, 69, 476-498.

Suding KN, Lavorel S, Chapin FS et al. (2008) Scaling environmental change through the communitylevel: A trait-based response-and-effect framework for plants. Global Change Biology, 14(5), 11251140. doi:10.1111/j.1365-2486.2008.01557.x.

Sundene O (1973) Growth and reproduction in Ascophyllum nodosum (Phaeophyceae). Norwegian J. of Botany, 20, 249-255.

Topinka J, Tucker L, Korjeff W (1981) The Distribution of Fucoid Macroalgal Biomass Along Central Coastal Maine. Botanica Marina, 24 (6), 311-320. doi:10.1515/botm.1981.24.6.311

Vadas RL, Wright WA, Miller SL (1990) Recruitment of Ascophyllum nodosum: wave action as a source of mortality. Mar. Ecol. Prog. Ser., 61, 263-272.

Vile D, Shipley B, Garnier E (2006) Ecosystem productivity can be predicted from potential relative growth rate and species abundance. Ecol. Letters, 9, 1061-1067. doi:10.1111/j.14610248.2006.00958.x.

Violle C, Reich PB, Pacala SW, Enquist BJ, Kattge J. (2014) The Emergence and promise of functional biogeography. PNAS 111(38), 13690-96. doi: 10.1073/pnas.1415442111.

Wernberg T, Thomsen MS (2005) The effect of wave exposure on the morphology of Ecklonia radiata. Aquatic Botany 83, 61-70.

Wilson PJ, Thompson K, Hodgson JG (1999) Specific leaf area and leaf dry matter content as alternative predictors of plant strategies. New Phytologist, 143, 155- 162. doi: 10.1046/j.1469-8137.1999.00427.x.

Wing SR, Leichter JJ, Perrin C, Rutger SM, Bowman MH, Cornelisen CD (2007) Topographic shading and wave exposure influence morphology and ecophysiology of Ecklonia radiata (C. Agardh 1817) in Fiordland, New Zealand. Limnology and Oceanography, 52(5), 1853-1864. doi:10.4319/ lo.2007.52.5.1853. 


\section{List of appendices (given at the end of the thesis)}

Figure S1. Boxplots of species traits (log-transformed) across the four study sites.

Appendix 1 and Table S1. Description and results of water analysis of the study sites.

Appendix 2, Table S2 and Figure S2. Comparing PCA methods of removing missing values vs. imputing missing values, with a PCA plot of the former. Also, the effect of removing the trait SAV of the ordination due to a correlation with STA.

Appendix 3 and Table S3. Description and summary of residual analysis to test for the effect of tidal height on species' traits.

Table S4. PERMANOVA including all six traits, with species*site for the species found at more than one site.

Table S5. Mean and standard deviation of relative height where each species was found. 


\section{Chapter 3}

\section{Functional diversity of seaweeds declines scale-dependently across an environmental stress gradient}

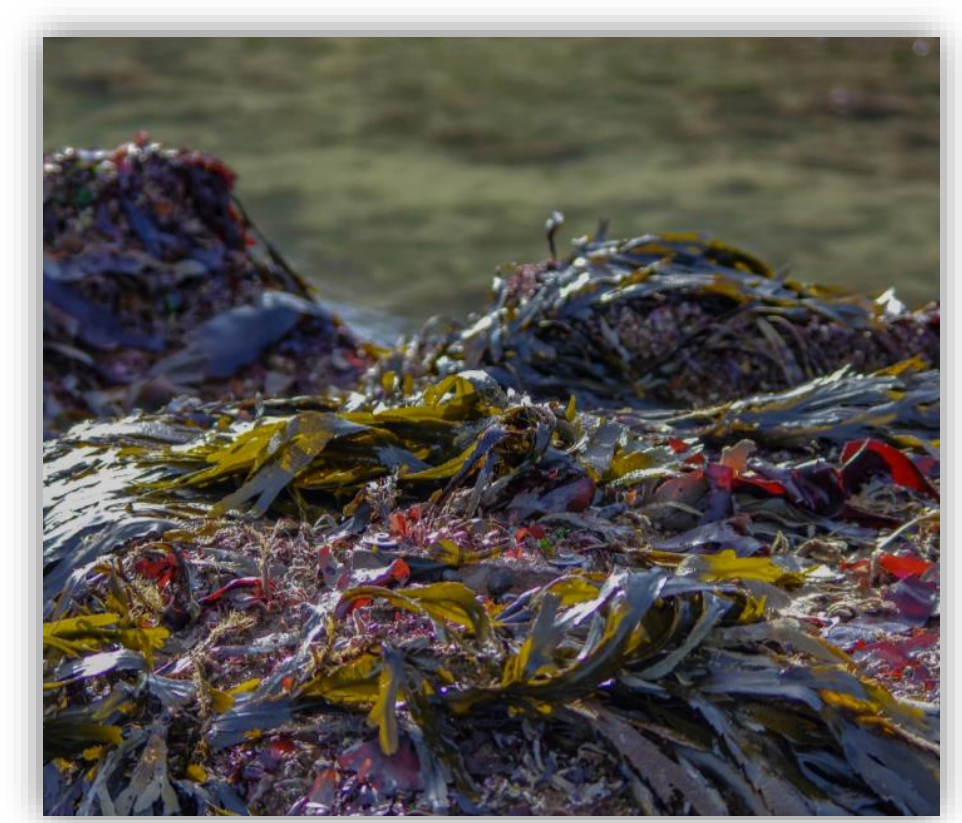

(C) Tom Fairchild

Disclaimer: This chapter is under review at the journal Oecologia. It was developed with the collaboration of Alizée Mauffrey and John Griffin. 


\section{Abstract}

Marine habitat formers such as seaweeds and corals are lynchpins of coastal ecosystems, but their functional diversity and how it varies with scale and context remains poorly studied. Here we investigate the functional diversity of seaweed assemblages across the rocky intertidal stress gradient at large (zones) and small (quadrat) scales. We quantified complementary metrics of emergent group richness, functional richness (functional space occupied) and functional dispersion (trait complementarity of dominant species). With increasing shore height, under species loss and turnover, responses of functional diversity were scale- and metric-dependent. At the large scale, functional richness contracted while - notwithstanding a decline in redundancy - emergent group richness and functional dispersion were both invariant. At the small scale, all measures declined, with the strongest responses evident for functional and emergent group richness. Comparisons of observed versus expected values based on null models revealed that functional richness and dispersion were greater than expected in the low shore but converged with expected values higher on the shore. These results show that functional diversity of assemblages of marine habitat formers can be especially responsive to environmental stress gradients at small scales and for richness measures. Furthermore, nichebased processes at the small - neighbourhood - scale can favour co-occurrence of functionally distinctive species under low, but not high, stress, magnifying differences in functional diversity across environmental gradients. As assemblages of marine habitat formers face accelerating environmental change, studies using trait databases are needed to elucidate patterns, processes, and ecosystem consequences of community (dis-)assembly across diverse groups.

Key-words: emersion gradient, seaweed, functional traits, emergent groups, assembly patterns. 


\section{Introduction}

Biodiversity is increasingly recognised as multidimensional, including taxonomic, phylogenetic, and functional components (Cadotte et al. 2009; Devictor et al. 2010; Stevens and Gavilanez 2015). Functional traits such as body size, mouthpart- or leaf- morphology determine an organism's capacity to process resources and how it experiences and interacts with its environment. The diversity of such traits - functional diversity - captures variation in the ecological roles of species (Tilman 2001; Violle et al. 2007; Díaz et al. 2020). Although ecologists have traditionally focused on taxonomy-based metrics of biodiversity, incorporating functional diversity allows a more complete view of how communities respond to environmental gradients and human pressures (Mouillot et al. 2013; Teixidó et al. 2018; Sol et al. 2020; Muguerza et al. 2020), elucidates the relationships between biodiversity and ecosystem functioning (e.g. Griffin et al. 2009; Lefcheck and Duffy 2015), and reveals the operation of niche-based processes during community assembly (Mcgill et al. 2006). Functional diversity approaches have been widely tested and applied in terrestrial ecosystems structured by primary producers and habitat formers such as trees, grasses, and climbing plants (Roderick et al. 2000; Mokany and Ash 2008; Seger et al. 2017). There is now growing interest in applying functional diversity approaches to assemblages of habitat formers in marine and coastal ecosystems as they rapidly reorganise under global change (Blowes et al. 2019; Antão et al. 2020).

Habitat-forming organisms such as corals, seagrasses, and seaweeds form diverse assemblages and support associated biodiversity and ecosystem functioning in many coastal environments worldwide (Stachowicz et al. 2007; Teagle et al. 2017; Thomsen et al. 2010; Vergés et al. 2019). In temperate nearshore systems, macroalgae (seaweeds) often dominate standing biomass and contribute to services from carbon sequestration to coastal defence and 
fisheries support (Smale et al. 2013). Global changes including ocean warming and acidification, invasive non-native species and coastal urbanisation are driving marked shifts in seaweed assemblages (Wernberg et al. 2011; Harley et al. 2012). Functional approaches to seaweed assemblages predominantly involve grouping species based on position in the canopy (e.g. Tait et al. 2014) or general morphology (e.g. Steneck and Dethier 1994). Yet the functionality of species and assemblages is determined by multiple, often continuous, traits, challenging coarse a priori grouping (Chapin et al. 1996; Mauffrey et al. 2019). Here, we use the rocky intertidal as a test case for applying a suite of continuous traits to seaweeds to understand patterns of functional diversity across environmental gradients.

Multiple, complementary, metrics are required to describe how functional diversity changes along gradients of disturbance or stress (Villéger et al. 2008; Mouillot et al. 2013). Functional diversity can be quantitatively defined as the distribution of species in a functional space where the axes represent combinations of traits (Rosenfeld 2002; Mason et al. 2005; Villéger et al. 2008). Metrics used to describe functional diversity include functional richness - the total extent of species in trait space - and functional dispersion - the distinctness of dominant species (Laliberté and Legendre 2010). Functional richness and dispersion indicate the potential for species complementarity, respectively emphasising differences between extreme and abundant species (Mason et al. 2013; Kuebbing et al. 2018). Although declines in species richness along environmental gradients are expected to erode redundancy and particularly affect functional richness, these changes can be buffered in systems with high redundancy (Micheli and Halpern 2005; but see Mouillot et al. 2014). Contrarily, strong environmental constraints on the viable traits (environmental filtering) can drive greater-than expected declines in functional richness (Mouillot et al. 2013; Valdivia et al. 2017; Teixidó et al. 2018) and may reduce dispersion of dominant species (Schellenberger Costa et al. 2017). Investigating changes in multiple facets of functional diversity across environmental gradients 
can therefore add to the traditional taxonomic focus and provide a complementary lens to understand community structure and potential consequences for ecosystem functioning (Díaz and Cabido 2001; Zhang et al. 2012).

The rocky intertidal has long served as a proving ground for ecological ideas due to its accessible marine communities and provides a model system to examine functional diversity of seaweeds along an environmental stress gradient. The intertidal rocky shore is characterised by a vertical pattern of community turnover (or 'zonation') and decreasing species richness, driven by an interplay between biotic interactions, and species' tolerances to tidal emersion period and associated stressors of desiccation, temperature extremes and nutrient scarcity (e.g. Schonbeck and Norton 1979; Underwood and Jernakoff 1984; Scrosati and Heaven 2007). These gradients can be mitigated by rock pools which create habitat heterogeneity on beds of emergent rock and commonly host different suites of less desiccation-tolerant species (Araújo et al. 2006; Firth et al. 2014). The rocky shore and attendant community gradients remain a classic research and teaching system in ecology and are prominent in contemporary ecological textbooks (Begon et al. 1996; Singer 2016). Zonation patterns in seaweed communities have been studied in rocky shores in several parts of the world: from the North Atlantic (Lubchenco 1980; Dring and Brown 1982) to high latitudes of Alaska and the Magellanic region (Ingólfsson 2005). However, beyond studies of the traits of dominant species (Gómez and Huovinen 2011; Cappelatti et al. 2019), the corresponding responses of functional diversity in these assemblages remain poorly appreciated.

Here we revisit the classical pattern of intertidal seaweed zonation from a functional perspective. With information on community composition and species' traits across four rocky shores in Wales (UK), we investigated the functional structure of seaweed assemblages along the emersion gradient (shore height). First, we hypothesised that the increasing stress towards 
the upper intertidal would act as an environmental filter, constraining viable trait values and resulting in a disproportionate loss of functional diversity relative to species loss. Second, we hypothesised that a turnover in species composition would lead to a functional turnover in communities, as trait values reflect different adaptations to the upper shore environment. To address these hypotheses, we examined changes in diversity across the shore height gradient at the scale of entire zones (total species lists) and local communities (replicate quadrats). We further investigated the role of rock pools in modifying diversity gradients via habitat heterogeneity and explored functional redundancy across zones by assigning species to clusters in trait space (i.e. emergent groups).

\section{Methods}

Study sites and survey

We studied macroalgal communities along the intertidal gradient across four rocky shores in the Gower peninsula, south Wales (UK). The carboniferous limestone shores span ca. $25 \mathrm{~km}$, and have a tidal variation of approximately $10.4 \mathrm{~m}$ : Oxwich (sheltered; $51.55 \mathrm{~N}$, 4.15 W), Bracelet Bay (semi-exposed; 51.57 N, $3.98 \mathrm{~W}$ ), Overton (exposed; 51.53 N, 4.21 W) and Rhossili (exposed; $51.56 \mathrm{~N}, 4.32 \mathrm{~W}$ ).

Surveys were conducted during the summer of 2018, by identifying and quantifying all living macroalgal species within 1 x $1 \mathrm{~m}$ quadrats, placed $10 \mathrm{~m}$ apart along four transects. Each transect crossed the whole intertidal from the kelp zone in the lower shore to the end of seaweed distribution in the upper shore. We sampled the low shore at low tides only during spring tides $(0-0.5 \mathrm{~m}$ above chart datum). Cover was estimated within quadrats with the help of strings which divided the quadrat into 25 sub-units (each unit $=4 \%$ cover). Individuals were thoroughly manipulated to ensure inclusion of small, understory seaweeds, therefore the multilayered communities could surpass $100 \%$ cover. 
To address the intertidal emersion gradient, we used commonly defined zones of the low, middle, and upper shore (Fig. 1). In agreement with previous studies (Stephenson and Stephenson 1949; Ballantine 1961; Johnson et al. 1998; Chappuis et al. 2014), these zones were defined by their relative position in the intertidal combined with the identity of dominant Phaeophytes (fucoids and kelp). Specifically, zones were delimited where the following species alone or together comprised in excess of $80 \%$ of the total macroalgal cover: low shore Laminaria digitata and Fucus serratus; mid-shore - Ascophyllum nodosum and F. vesiculosus; upper shore - Pelvetia canaliculata and F. spiralis. To obtain a clearer distinction between zones, we excluded quadrats falling in the transition between zones as defined above; accordingly, zones were separated by at least $20 \mathrm{~m}$. Although zone serves as an indicator of shore height, and thus emersion period, the exact position of these zones along shore height gradients depends on additional factors such as wave exposure and disturbance history (Ballantine 1961). These three main zones are thus conceptualised as 'community types' positioned sequentially with respect to shore height rather than communities occurring at precise shore heights. In our study, the characteristic fucoids or kelps in each zone comprise a minority of the assemblage (low shore: 5\%; mid-shore: 6\%; upper shore: 11\%) and our findings are robust to exclusion of these species (Appendix 1, ESM). Details on the sampling effort across zones are in Appendix 2, ESM.

\section{Habitats}

We distinguish between two simple habitat types on the rocky shore: emergent rock and rock pool. During the survey, we recorded the percentage cover of these two habitat types. Preliminary analyses revealed that the distribution of rock pool cover was highly uneven, with half of the quadrats having zero cover. Furthermore, the relationship between rock pool cover on seaweed species richness was complex and mostly realised within the first $5 \%$ of cover. 
Accordingly, for simplicity, we treat rock pools as a binary presence ( $\geq 5 \%$ cover $)$ or absence $(<5 \%)$ variable. Quadrats that landed at least partially on gullies or deep rock pools $(>50 \mathrm{~cm}$ depth) were not considered, since the projected area would be much larger than the other quadrats.

After sampling all shores, we randomly selected a subset of quadrats to obtain an equal representation of combinations of shore zone (low, middle, and upper shore) and habitat (presence/absence of rock pools). The final analysed community data comprised 84 quadrats, 14 for each zone and habitat category combination. Of the selected quadrats, 15 were from Bracelet Bay, and 22, 23, and 24 from the remaining sites.

\section{Trait data}

Traits were obtained from a dataset in development since 2016 (see Mauffrey et al. 2020). For the creation of this trait database, we conducted frequent summer sampling trips predominantly in south Wales; all but two of the species in this study were sampled for trait screening from the same sites as the survey data used here. We collected a minimum of 3 individuals per species (mean and mode $=6, \min =3$, $\max =45$ ). This wide range in replicates is due to the varying abundance of species, and to our efforts to sample abundant species at different sites to capture their intraspecific variation (Cappelatti et al. 2019). To obtain comparable traits, we restricted our study to erect macroalgae only (i.e. not encrusting forms).

The traits we chose are "functional markers" (sensu Garnier et al. 2004) and thus are proxies for physiological or physical functions. We summarise the traits in Table 1 and describe methods for their collection as well as ecological relevance in Appendix 3 (ESM). Prior to analyses, all traits were log-transformed and scaled to zero mean and unit variance, to approach normal distributions and have the same range of variation. Traits were always measured at the species level; however, some species require laboratory identification, so they were only 
identified at the genus level. In the case of Ulva, this genus was further divided into two groups related to obvious phenotypic differences. For the artificial taxa "green sheet", we used trait averages from $U$. linza and $U$. lactuca; for "green tubular" we used trait averages from $U$. intestinalis and U. compressa.

\section{Trait space of species}

Species' functional trait differences were characterised based on a Gower distance matrix, at the whole study scale. Traits were weighted to ensure that all three aspects of functionality considered here (photosynthesis, physical structure, complexity) were equally represented (Table 1). To visualise species' functional diversity as captured in the Gower distance matrix, we used principal coordinate analysis (PCoA) and displayed the first two axes, which explained $61 \%$ of inertia (Fig. 2; see Appendix 3, ESM, for further details of the quality of functional space representation).

To examine species' contributions to functional diversity and redundancy across zones, we also addressed species' occupancy of parts of the trait space via emergent groups. Because emergent groups are based on measured traits, they should be a more accurate representation of species' differences than the traditional functional groups (Mauffrey et al. 2019). In our study communities, emergent groups allowed us to observe redundancy (species within groups share similar trait values) and how parts of the trait space (as occupied by different groups) change across zones. Species were grouped based on the Gower distance matrix, using the $k$ medoids clustering method (Reynolds et al. 2006) applied with pam in package cluster (Maechler et al. 2019). We tested increasing numbers of groups and selected the highest number of groups (i.e. 6) where all pairwise contrasts using PERMANOVA were significant at $\alpha=0.05$ (Hervé 2020; Mauffrey et al. 2019). 
Table 1. Summary of traits used in this study. Traits are divided into three groups, according to the eco-physiological aspects of macroalgae and the respective ecological significance. Proposed mechanisms linking traits to ecophysiology are provided. Each trait was assigned a weight for functional diversity metrics so that each of the three aspects of eco-physiology were equally represented. References: ${ }^{\mathrm{a}}$ Carpenter (1990); ${ }^{\mathrm{b}}$ Littler and Littler (1980); ${ }^{\mathrm{c}}$ Roderick et al. (2000); ${ }^{\mathrm{d}}$ Reich et al. (1999); ${ }^{\mathrm{e}}$ Cornelissen et al. (2003); ${ }^{\mathrm{f}}$ Elger and Willby (2003); ${ }_{\mathrm{g}}^{\mathrm{g}}$ Weykam et al. (1996); ${ }^{\mathrm{h}}$ Rodriguez et al. (2016); ${ }^{\text {I }}$ Steneck and Dethier (1994); ${ }^{\mathrm{j}}$ Starko et al. (2015); ${ }^{\mathrm{k}}$ Dromgoole (1981); ${ }^{1}$ Stewart and Carpenter (2003); ${ }^{\mathrm{m}}$ Hay (1981); ${ }^{\mathrm{n}}$ Taylor and Hay (1984).

\begin{tabular}{|c|c|c|c|c|}
\hline $\begin{array}{l}\text { Eco- } \\
\text { physiological } \\
\text { aspect }\end{array}$ & $\begin{array}{l}\text { Ecological } \\
\text { significance }\end{array}$ & Trait and unit & Related mechanism & Weight \\
\hline \multirow{3}{*}{$\begin{array}{l}\text { Photosynthetic } \\
\text { ability }\end{array}$} & \multirow{3}{*}{$\begin{array}{c}\text { Investment in } \\
\text { photosynthesising } \\
\text { structure } \\
\text { maximises light } \\
\text { capture, increasing } \\
\text { productivity. } \\
\text { Trade-off: lower } \\
\text { investment in } \\
\text { structural } \\
\text { compounds affects } \\
\text { integrity a,b }\end{array}$} & $\begin{array}{l}\text { Specific thallus } \\
\text { area - STA } \\
\left(\mathrm{cm}^{2} \mathrm{~g}^{-1}\right)\end{array}$ & $\begin{array}{l}\text { High STA increases the } \\
\text { proportion of light-absorbing } \\
\text { surface. }^{c}\end{array}$ & 0.33 \\
\hline & & $\begin{array}{l}\text { Surface area to } \\
\text { volume ratio - } \\
\mathrm{SA}: \mathrm{V}\left(\mathrm{cm}^{2} \mathrm{~mL}^{-}\right. \\
\left.{ }^{1}\right)\end{array}$ & $\begin{array}{l}\text { High SAV increases the } \\
\text { proportion of nutrient- and } \\
\text { gas- exchange surface. }{ }^{\mathrm{b}}\end{array}$ & 0.33 \\
\hline & & Thickness (cm) & $\begin{array}{l}\text { Thicker fronds allow } \\
\text { survival and draught } \\
\text { resistance. }{ }^{\mathrm{d} ; \mathrm{a}}\end{array}$ & 0.33 \\
\hline \multirow{3}{*}{ Structure } & \multirow{3}{*}{$\begin{array}{l}\text { High ratios of hard } \\
\text { structural to soft } \\
\text { palatable tissue } \\
\text { protects against } \\
\text { desiccation and } \\
\text { increases } \\
\text { recalcitrance, } \\
\text { contributing to } \\
\text { carbon storage. } \\
\text { Trade-off: slows } \\
\text { productivity. }\end{array}$} & $\begin{array}{l}\text { Thallus dry } \\
\text { matter content } \\
\text { - TDMC } \\
\text { (ratio) }\end{array}$ & $\begin{array}{l}\text { High TDMC confers } \\
\text { structural integrity. } \mathrm{e} ; \mathrm{f}\end{array}$ & 0.50 \\
\hline & & & & \\
\hline & & $\begin{array}{c}\text { Carbon to } \\
\text { Nitrogen ratio } \\
\text { - C:N }\end{array}$ & $\begin{array}{c}\text { High C:N confers structural } \\
\text { integrity. }{ }^{e, g}\end{array}$ & 0.50 \\
\hline \multirow{4}{*}{ Space use } & \multirow{4}{*}{$\begin{array}{l}\text { Exploration of } \\
\text { space, linked to } \\
\text { competitive } \\
\text { dominance, } \\
\text { resource } \\
\text { acquisition and } \\
\text { habitat provision }{ }^{\mathrm{i}} \text {. } \\
\text { Trade-off: } \\
\text { potentially } \\
\text { increases water } \\
\text { drag }^{\mathrm{j}}\end{array}$} & Length $(\mathrm{cm})$ & $\begin{array}{l}\text { Holds seaweed high in water } \\
\text { column, facilitates access to } \\
\text { light. }^{\text {a, b }}\end{array}$ & 0.25 \\
\hline & & $\begin{array}{l}\text { Pneumatocysts } \\
\text { (yes/no) }\end{array}$ & $\begin{array}{l}\text { Holds seaweed upwards in } \\
\text { water column, facilitates } \\
\text { access to light. }{ }^{k}\end{array}$ & 0.25 \\
\hline & & $\begin{array}{l}\text { Branching } \\
\text { order (integer) }\end{array}$ & $\begin{array}{l}\text { Increases complexity, may } \\
\text { maximise light exposure }{ }^{1} \\
\text { and delays desiccation. }^{\mathrm{m}, \mathrm{n}}\end{array}$ & 0.25 \\
\hline & & $\begin{array}{l}\text { Surface area to } \\
\text { perimeter ratio } \\
\quad-\text { SA:P }\end{array}$ & $\begin{array}{l}\text { Reversely related to } \\
\text { branching order; higher SAP } \\
\text { decreases complexity }\end{array}$ & 0.25 \\
\hline
\end{tabular}




\section{Diversity metrics}

We calculated species and functional diversity metrics at both the large (zone) and small (quadrat) scales (Fig. 1). The larger scale includes all quadrats within a zone across the four study sites and provides the most complete estimate of the species occupying the specific zone in the area/region. This scale of diversity includes large-scale heterogeneity across sites and represents species that may contribute to ecosystem functionality over larger spatial and temporal scales (Isbell et al. 2017). The smaller scale of the $1 \times 1 \mathrm{~m}$ quadrat (the local or "neighbourhood" scale) represents the scale at which direct biotic interactions occur between seaweeds (e.g. Edwards and Connell 2012). Seaweeds respond to the stresses associated with shore height at both scales, but community composition also varies at the quadrat scale due to differences in local factors such as the presence of rock pools.

We calculated four complementary $\alpha$-diversity metrics: species richness, emergent group richness, functional richness, and functional dispersion (Fig. 1). Species and emergent group richness are simply the total number of species or emergent groups present at a focal scale. While species richness is a standard metric of biodiversity in rocky shore assemblages (e.g. Scrosati et al. 2011) and treats all species equally, emergent group richness is based on species' relative positions in trait space and only declines when entire regions of trait space (emergent groups) have been vacated. Functional richness is the size of the functional space filled by the community, based on the convex hull delimited by the most extreme points in functional space (Cornwell et al. 2006; Villéger et al. 2008). We scaled functional richness to a hypothetical community with all species in the study pool, to benchmark values relative to the potential maximum. Functional dispersion is the mean abundance-weighted distance in multidimensional space of individual species to their overall centroid, thus measuring species' distribution in trait space (Laliberté and Legendre 2010). To calculate functional richness and 
dispersion, we selected PCoA axes from the Gower distance matrix among communities (details on the PCoA are in Appendix 3, ESM). As the above-described metrics quantify diversity for individual communities, they are measures of $\alpha$-diversity. All $\alpha$-diversity indices were calculated using function $d b F D$ on package $F D$ (Laliberté and Legendre 2010).

Patterns of $\beta$-diversity reveal underlying changes in community structure along environmental gradients (Legendre 2014). While taxonomic $\beta$-diversity captures the changes in the identities of the species, functional $\beta$-diversity captures changes in the locations of species in trait space. To examine $\beta$-diversity across zones, we used the Sorensen index, which measures the ratio of shared species (or overlapping volume of convex hull) among assemblages to the mean number of species (or mean convex hull volume) occurring in a single assemblage (Gotelli and Chao 2013). The returned index is a measure of the multiple site dissimilarity among communities (Baselga 2010). At both species and functional levels, $\beta$ diversity was partitioned between nestedness and turnover components (Fig. 1). These indices were calculated with functions beta.multi (species incidences) and functional.beta.multi (based on the PCoA) in package Betapart (Baselga and Orme 2012).

\section{Statistical analyses}

To investigate if the observed functional diversity metrics of local - small scale communities were lower or higher than expected based on the number of species within a community, we used a null model approach. Null communities (999 in each case) were constructed by shuffling species' position on the trait matrix, thus holding constant the overall functional structure of seaweeds and species richness within each observed community (quadrat), while randomizing the identities of species in each null community (Swenson 2014). We then calculated the standardized effect sizes (SES) of functional richness and functional dispersion, which compares observed to null values (Cadotte and Tucker 2017). For each focal 
aspect of functional diversity (richness, divergence) and each community $(n=84)$ a single SES value was generated. We used one-sample t-tests (or Wilcoxon rank tests, when data distribution was not normal) to compare observed SES values against null SES values.

We used linear models to investigate the additive and interacting effect of shore height (zone) and habitat heterogeneity (presence/absence of rock pool) on species and functional $\alpha-$ diversity metrics, and on SES values. We also examined the observed $\alpha$-diversity metrics across sites and found no significant differences in their means; site was then dropped from the analysis as our focus was on general effects of zone (Appendix 4, ESM).

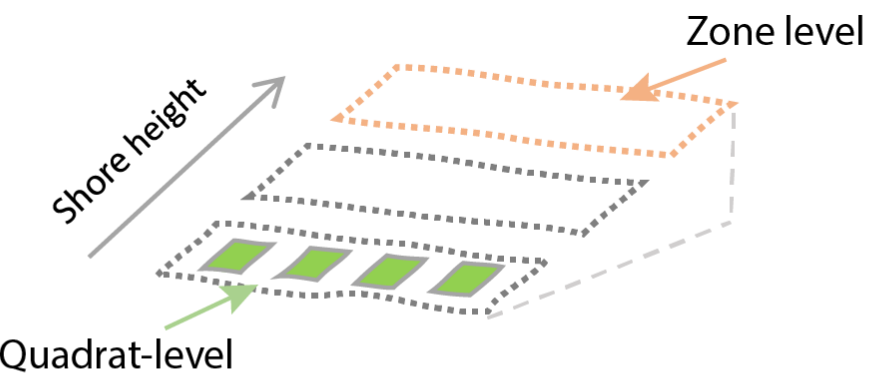

\section{a-diversity}

Species richness

Number of species

Emergent group richness

Number of groups

Functional richness

Proportion of the maximum convex hull of whole assembly

Functional dispersion

Mean distance of species

to the centroid of trait space

scale $\Delta$ null model

\section{$\beta$-diversity}

Species nestedness

Communities with fewer species are subsets of communities with more species

\section{Functional nestedness}

Functional space of some communities are subsets of other communities

\section{Species turnover}

Replacement of species between communities

\section{Functional turnover}

Replacement of parts of functional space between communities

Figure 1. Conceptual illustration of study scales and description of diversity metrics. Colours represent either small (quadrat) or large (zone) scale, therefore flags next to each 
metric indicate at which scale they were measured. Triangles indicates cases where we also compared observed to null values.

\section{Results}

Species distribution in the trait space

Fifty taxa (referred to as species hereafter) were found in the survey: 43 identified at the species level, and seven at genus level (including the two artificial groups of Ulva). The majority $(\mathrm{n}=33$ ) were red algae (phylum Rhodophyta), followed by brown algae $(\mathrm{n}=10$, class Phaeophyceae) and green algae ( $\mathrm{n}=7$, phylum Chlorophyta).

The first PCo axis was most strongly related to traits linked to photosynthesis: species with higher PCo 1 values tended to display reduced specific thallus area (STA), reduced surface area to volume ratio (SAV) and have thicker thalli (Fig. 2; Table 1). The second axis mainly related to traits representing space use and structure: species with higher PCo 2 values tended to have lower thallus dry matter content (TDMC) and branching order, and higher surface area to perimeter ratio (SAP). Generally, PCo 1 translates into a trade-off between resource acquisition and conservation (i.e. an "economic" trade-off) and PCo 2 into a complexity / structural gradient. All trait-axis and trait-trait correlations are shown in Appendix 3, ESM. Overall, species were distributed unevenly across the functional space and therefore emergent groups had varying numbers of species (from 3 to 22, Figs. 2 and 4). The large richness observed within groups 1 and 4 shows they hold a high degree of redundancy. 


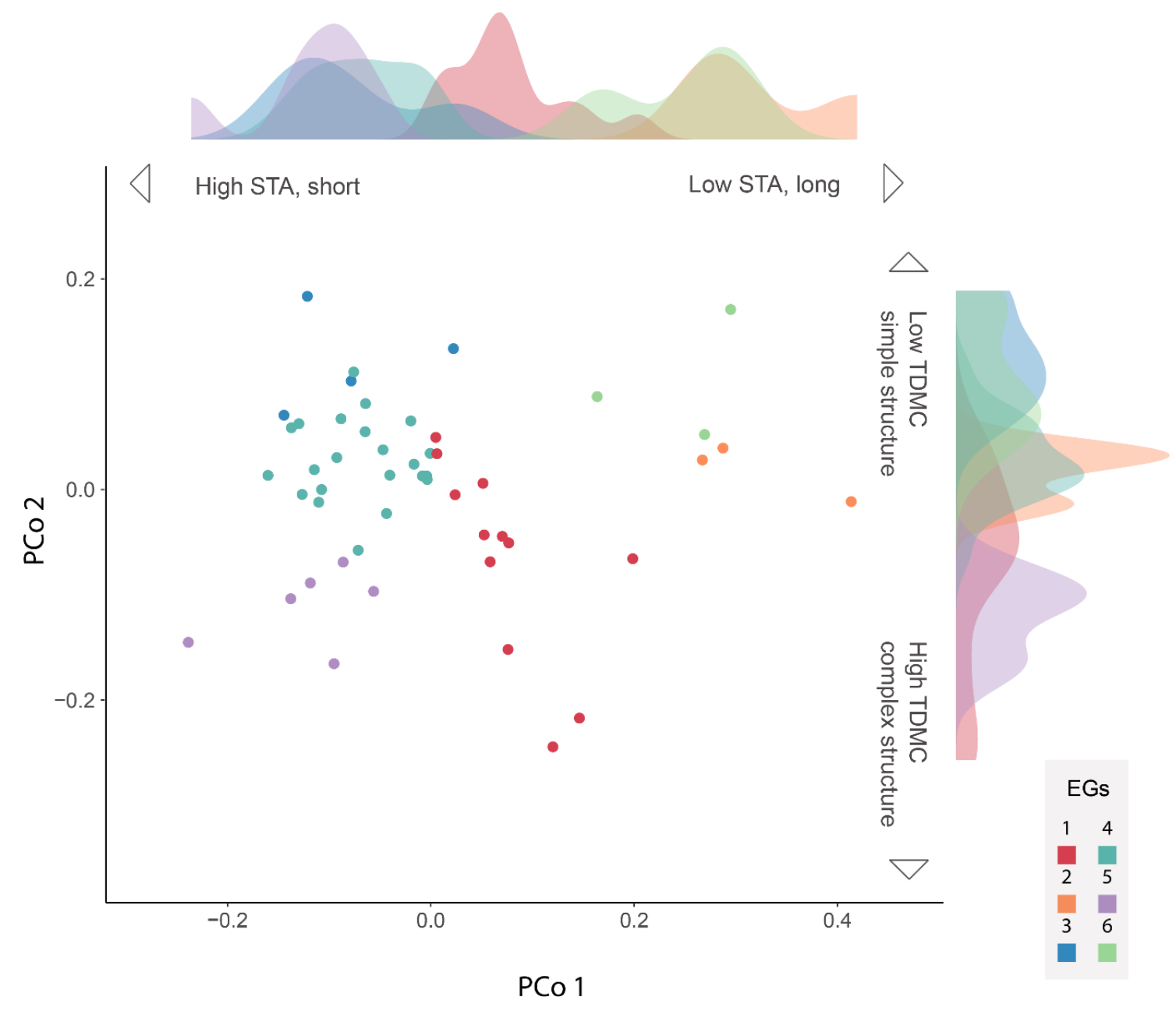

Figure 2. Principal Coordinates of study species based on 9 traits. Each point represents a species, coloured by emergent group. Emergent groups were created from on a trait-based Gower distance, and therefore may not be fully represented in this two-dimensional plot. Density plots show the distribution of emergent groups along each PCo axis. Summary of traits correlated to each axis are indicated with the arrows.

Large scale (zone level) diversity patterns

With increasing shore height, the number of species in each zone declined (Fig. 3a). Changes in the taxonomic composition between zones ( $\beta$-diversity) were divided relatively evenly between nestedness and turnover, regardless of rock pool presence or absence (Fig. 3b). How this taxonomic loss and turnover translated into changes at the functional level depended on the metric. Functional richness peaked in the mid-shore, despite a continuous decline in 
species richness (Fig. 3c). Meanwhile, functional dispersion did not vary strongly across shore levels, notwithstanding a slight increase towards higher zones (Fig. 3c). In addition to changes in the size of the functional space, there were also subtle changes in the relative location of the space, i.e. functional $\beta$-diversity (Fig. 3d-e). Unlike at the taxonomic level, these changes were dominated by nestedness rather than turnover (Fig. 3d-f). Indeed, the only observable functional turnover is with the expansion driven by Ascophyllum nodosum in the mid shore (Fig. 3e), while the rest of the changes are clearly via loss of parts of the trait space, especially in the absence of rock pools (Fig. 3f). Despite losses in functional richness, the presence of all emergent groups across zones illustrates the persistence of the overall 'framework' of functional space (Fig. 4a). A further look into emergent group richness between zones indicates that species loss was stronger within some groups than others (Fig. 4b), thus unevenly eroding functional redundancy. Overall, across zones, taxonomic diversity and composition changed more strongly than their functional counterparts.

\section{Small scale (quadrat level) diversity}

Contrary to the zone scale, all $\alpha$-diversity metrics decreased towards higher shore at the small-scale (Table 2; Fig. 5a-d). Overall, the negative effect of height on diversity was stronger for species and functional richness than for emergent group richness and functional dispersion. Changes in local communities across zones were not constant: while species richness continuously decreased (Fig. 5a), the functional metrics only changed from middle to upper shore (Fig. 5b-d). Emergent group richness was strongly related to species richness $(\mathrm{R} 2=0.83$; see Appendix 5, ESM, for relationships between functional diversity metrics and species richness). Moreover, the presence of rock pools had an additive effect on all diversity metrics (Table 2). Generally, at the small scale, we observed further declines in functional diversity metrics with height, which were not evident at the large scale. 
The standardised effect size (SES; comparing observed to null communities) showed different patterns for functional richness and dispersion (Table 2; Fig. 5e-f). Greater-thanexpected values (over-dispersion of trait values) were observed for functional richness at the low shore with rock pools (Fig. 5e) and for functional dispersion in both low shore communities and middle shore with rock pools (Fig. 5f). The presence of rock pools had an additive effect on the SES of functional dispersion $(\mathrm{F}=7.174, \mathrm{p}<0.01)$ but not on the SES of functional richness $(\mathrm{F}=0.175, \mathrm{p}=0.7$; Table 2). After obtaining these results, we ran the null models again, constraining the randomisations within zones, so that we could isolate the local effects from the whole-intertidal gradient effects. The over-dispersion was still observed, with patterns largely unchanged (Fig. S6, Appendix 6), indicating the role of small-scale (local) species interactions in driving functional over-dispersion. Overall, in low shore communities, species exhibited a greater total spread in trait space (functional richness) and abundant species were more distant to the centroid (functional dispersion) than expected, and this was further boosted in environments with rock pools. Contrary to our hypothesis there was no evidence that functional diversity was being limited due to environmental filtering at the upper shore (no under-dispersion). 
Table 2. Summary of main effects from (generalised) linear models ((G)LMs) with diversity dimensions ( $\alpha$-diversity), shore zone and presence of rock pool (RP). For species and emergent group richness we used generalised linear models (family: quasipoisson); for functional richness and dispersion we used general linear models. Significant values are in bold. $\mathrm{RPa}=\mathrm{RP}$ absent; $\mathrm{RPp}=\mathrm{RP}$ present.

\begin{tabular}{|c|c|c|c|c|c|}
\hline & GLMs & Deviance & Res. deviance & F value & P value \\
\hline \multicolumn{6}{|c|}{ Species richness } \\
\hline Zone & & 96.333 & 105.873 & 40.618 & $<0.001$ \\
\hline $\mathrm{RP}$ & & 13.117 & 92.756 & 11.061 & $<0.001$ \\
\hline Zone * RP & & 0.006 & 92.749 & 0.002 & 0.99 \\
\hline \multicolumn{6}{|c|}{ Emergent group richness } \\
\hline Zone & & 14.3734 & 33.648 & 18.411 & $<0.001$ \\
\hline $\mathrm{RP}$ & & 1.9221 & 31.725 & 4.9239 & $<0.05$ \\
\hline Zone * RP & & 0.1243 & 31.601 & 0.1592 & 0.85 \\
\hline & LMs & Sum of Squares & Mean SSq & F value & P value \\
\hline \multicolumn{6}{|c|}{ Functional richness } \\
\hline Zone & & 70355 & 35177 & 39.325 & $<0.001$ \\
\hline $\mathrm{RP}$ & & 11249 & 11249 & 12.575 & $<0.001$ \\
\hline Zone * RP & & 2327 & 1164 & 1.301 & 0.278 \\
\hline \multicolumn{6}{|c|}{ Functional dispersion } \\
\hline Zone & & 94.67 & 47.34 & 13.955 & $<0.001$ \\
\hline $\mathrm{RP}$ & & 38.39 & 38.39 & 11.317 & 0.001 \\
\hline Zone * RP & & 2.47 & 1.24 & 0.365 & 0.695 \\
\hline \multicolumn{6}{|c|}{ SES Functional richness } \\
\hline Zone & & 1.59 & 0.7951 & 1.211 & 0.304 \\
\hline $\mathrm{RP}$ & & 0.11 & 0.1147 & 0.175 & 0.677 \\
\hline Zone * RP & & 0.27 & 0.1328 & 0.202 & 0.817 \\
\hline \multicolumn{6}{|c|}{$\begin{array}{l}\text { SES Functional } \\
\text { dispersion }\end{array}$} \\
\hline Zone & & 4.778 & 2.3891 & 6.733 & 0.002 \\
\hline RP & & 2.546 & 2.5457 & 7.174 & 0.009 \\
\hline Zone * RP & & 1.33 & 0.6652 & 1.875 & 0.160 \\
\hline
\end{tabular}




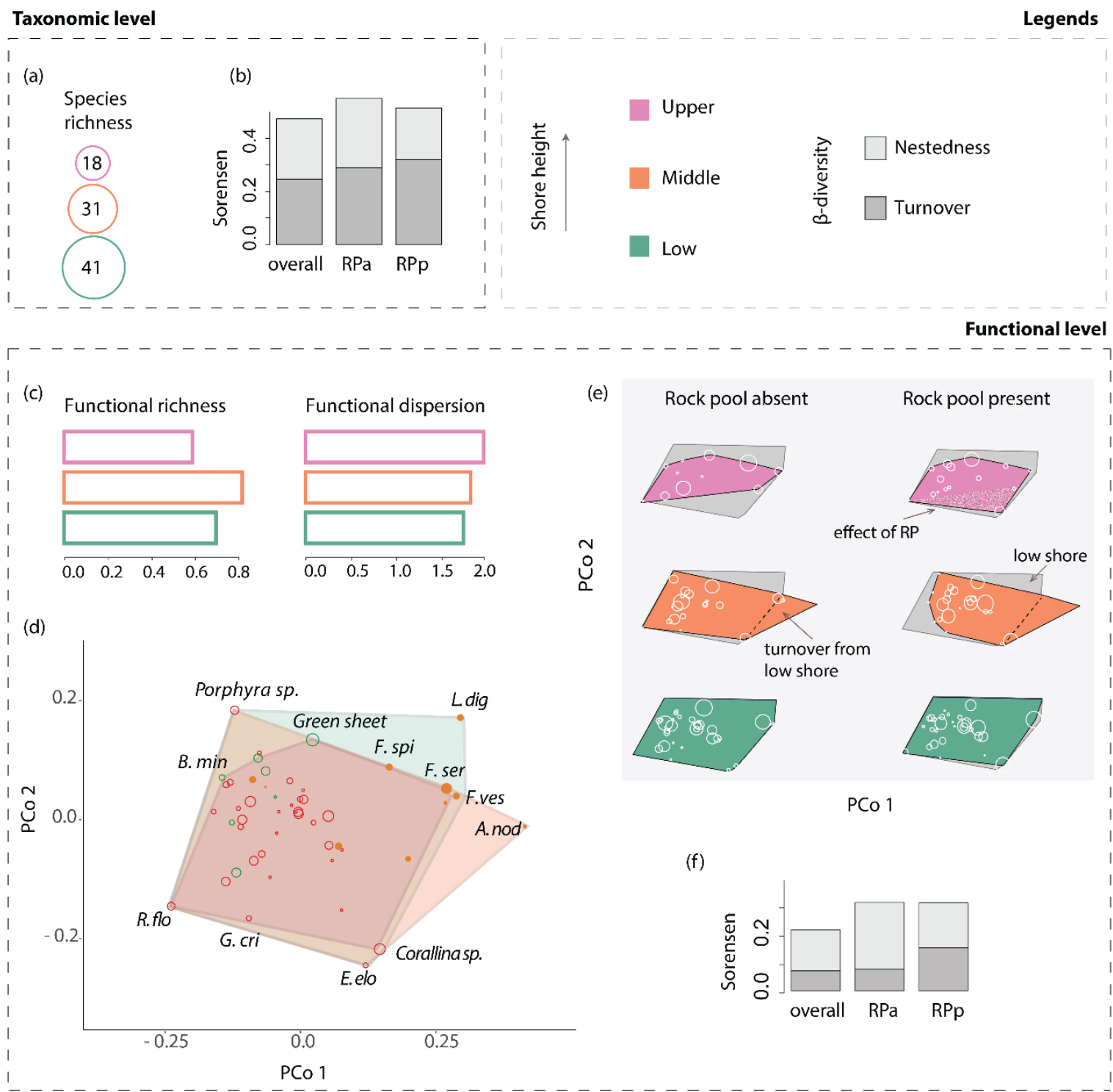

Figure 3. Seaweed functional $\alpha$ - and $\beta$-diversity across intertidal zones (large scale), separated between the taxonomic and functional level. Panels $a-b$ show species richness across zones and taxonomic $\beta$-diversity (divided into nestedness and turnover; for all communities and those with and without rock pools - RP). Panel $c$ shows indices of functional richness (scaled to the potential maximum; details in Methods) and functional dispersion at each zone (all quadrats together). Panel $d$ contains a representation the two-dimensional trait space of the species pool (PCoA biplot), indicating the zones with a coloured polygon. Species abbreviations are shown for those at the edges of the trait space at each height (complete names are given in Fig. 4). Panel e shows the same functional space, but separately for each zone and habitat type. Circle sizes on $d$ represent five frequency categories $(<10,<20,<30,<40$ and $<50$ ), with circle colours referring to the algae group (brown algae: filled orange, green algae: hollow green, and red algae: hollow red); circle sizes on $e$ are proportional to species local frequency. Nestedness is observed when a polygon is inside a larger one (represented in grey on panel $e$ ), while turnover is an expansion of a polygon (indicated in dashed line). Although we did not address $\beta$-diversity between habitats, we indicate the addition to the functional space with the presence of rock pools at the upper shore (pixelated pink). Barplots in panel $f$ show the partition of functional $\beta$-diversity components, overall and for the two habitat categories. 


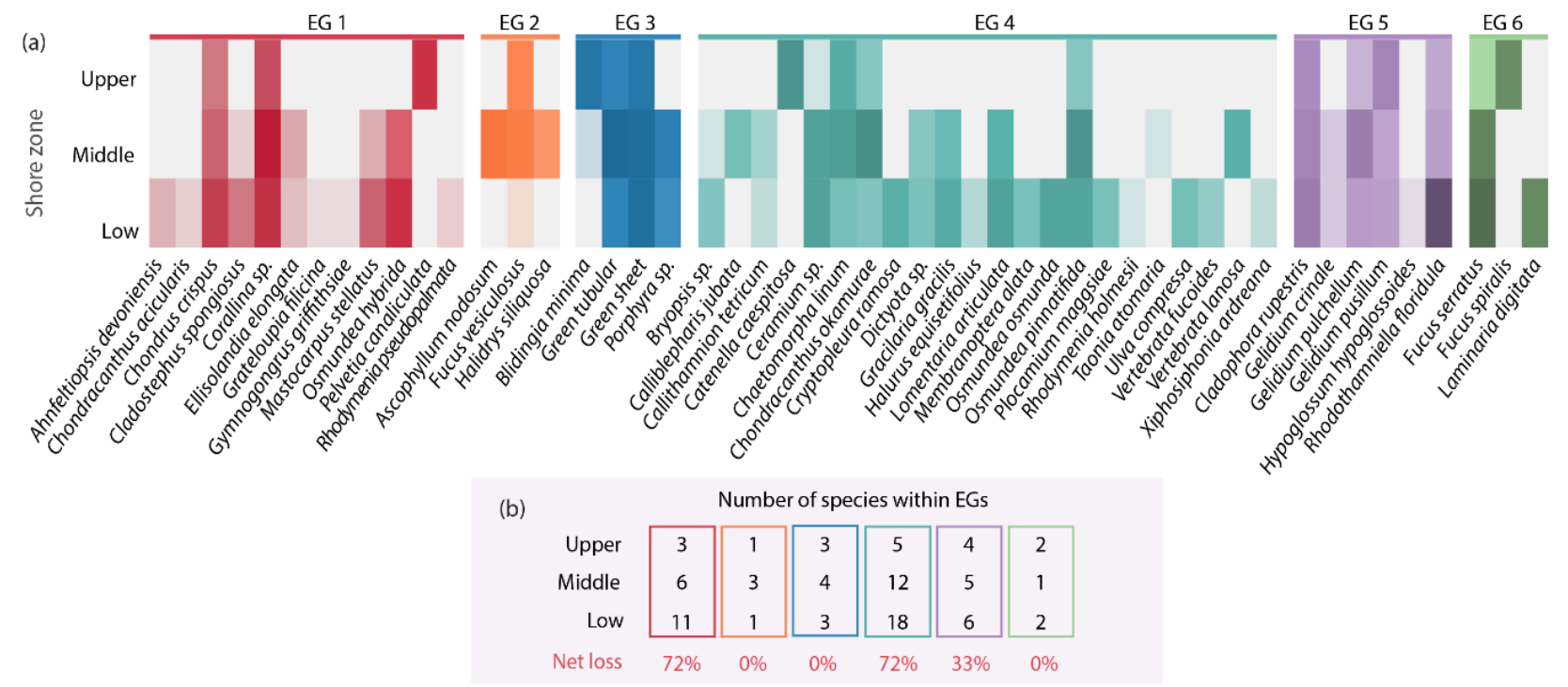

Figure 4. Species' abundances and their assembly across the intertidal zones. a) Species are sorted by emergent groups and abundance at each zone is log-transformed (values from 0 white - to 6 - dark). b) Number of species from each emergent group found at each zone, and percentage net loss from low to upper shore. Both panels are colour coded by emergent group (EG). 

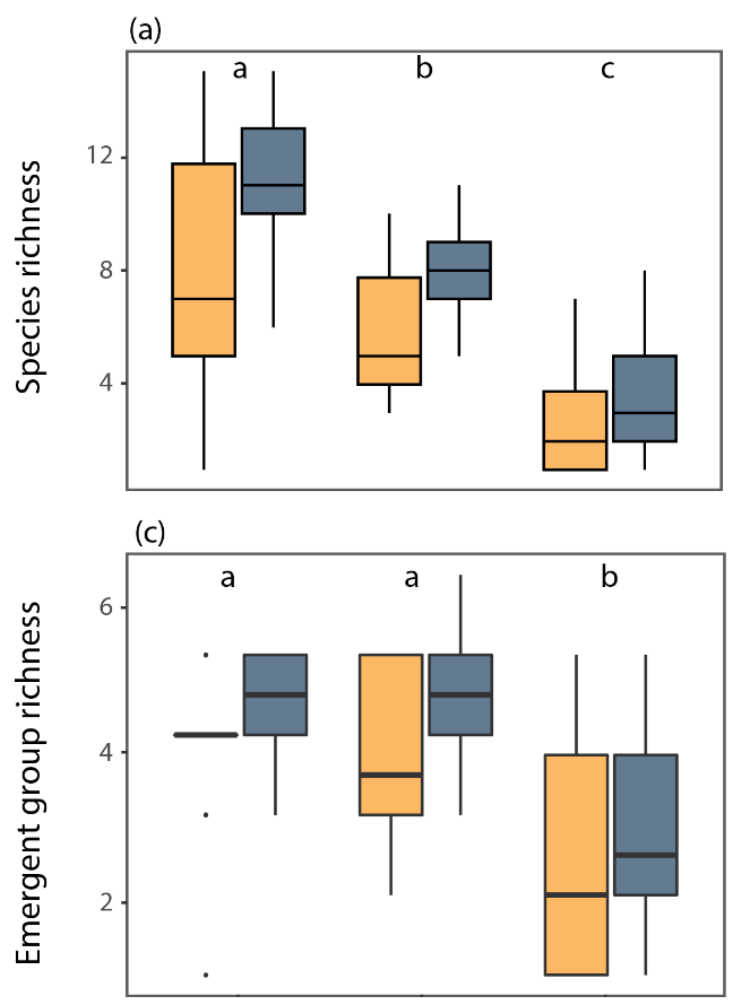

(e)

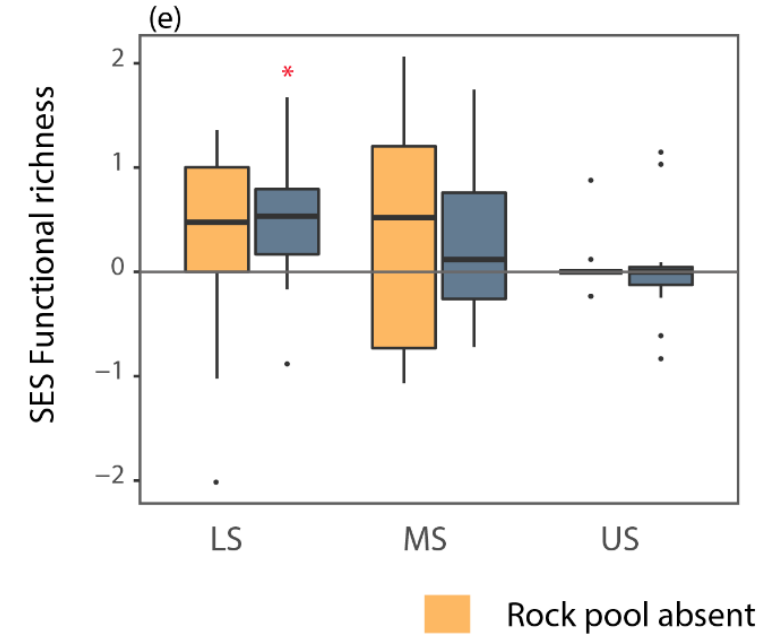

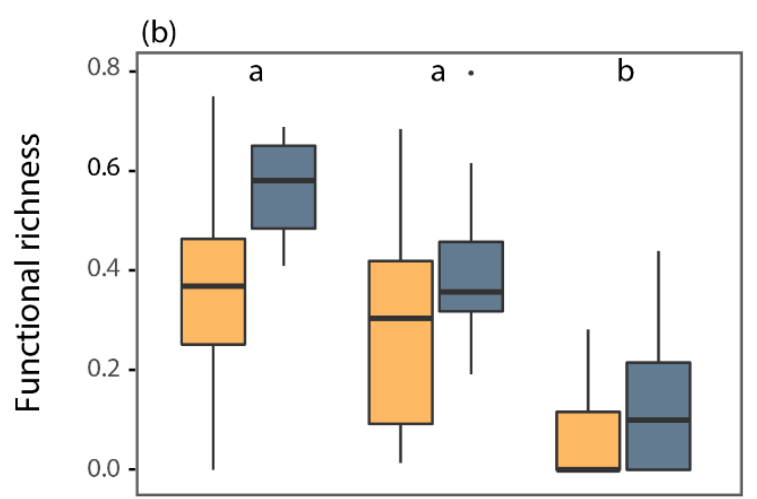

(d)
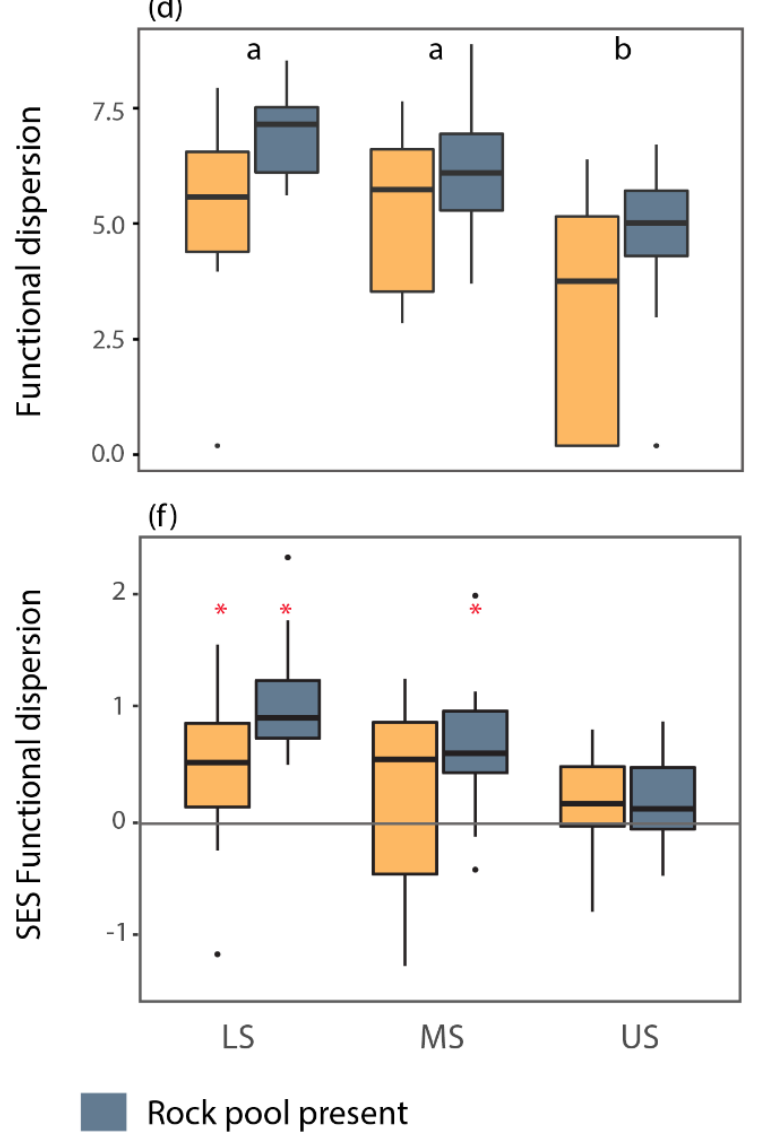

Figure 5. Observed and SES values of species' and functional $\boldsymbol{\alpha}$-diversity. Boxplots show values across shore zones (LS = low shore, MS = middle shore, and US = upper shore), in quadrats with and without rock pools. Functional richness is scaled to the potential maximum (details in Methods). For observed values, different letters on top of boxes indicate zones are significantly different. For SES, values above or below the lines indicate deviance from null models, i.e. greater or lower than expected at random (asterisks indicate significance of difference, obtained from one-sample t test, or Wilcoxon rank test when data distribution was not normal). Constrained randomizations are given in Fig. S6; SES without the zone-defining Phaeophytes are given in Fig. S1. 


\section{Discussion}

Our results show how the species and functional diversity of seaweed assemblages - as an example of marine habitat formers - change over the intertidal gradient. With the loss and turnover of species across the gradient, functional diversity declines in a metric- and scaledependent fashion. This study demonstrates the use of modern functional diversity approaches in seaweed assemblages and illustrates how functional diversity can deepen our understanding of changes in marine habitat former communities under environmental stress.

Consistent with expectations, functional diversity decreased with shore height, although metric- and scale-dependently. Functional diversity often varies as a function of the facets and spatial scale considered, which may yield varying responses to environmental gradients (Smith et al. 2013). At the large scale, functional richness was the only metric to respond, illustrating its greater sensitivity to species-level changes and reflecting a decline in species with extreme functional traits in the upper shore. Further, the persistence of all emergent functional groups in the face of species loss can be attributed to the presence of redundant species within each group; although it is notable that certain emergent groups and upper shore assemblages have low redundancy and are thus vulnerable to future species loss. The finding that upper shore communities are nested within lower shore communities, rather than occupying a different part of trait space, illustrates a maintenance of the "core" functional structure, despite declines in functional richness. Together, the functional metrics reveal that, at large scales, the upper shore assemblages contain less functionally distinct species, but retain a similar functional framework.

At the small scale, all metrics responded to the height gradient, although more strongly from middle to upper shore. For functional and emergent group richness, this pattern - changes only from middle to upper shore - can be explained by their non-linear responses to species 
richness (Appendix 5). From middle to upper shore, where species richness reaches low levels at the small scale, declines in richness are occurring closer to the first - steep - section of the curve (few species). In contrast, from the lower to middle shore, declines in species richness take place further along the curves, so they cause smaller changes in functional and emergent group richness. However, explanation for the similar response of functional dispersion is not as simple because, in theory, this metric is invariant to species richness (Laliberté and Legendre 2010). Besides a species richness mediated scale-dependency, scale is also expected to determine the relative importance of environmental filtering and biotic interactions (Smith et al. 2013). Thus, species interactions may also help explain scale-dependent functional diversity changes across the intertidal gradient.

Indeed, functional over-dispersion, points towards a key role of species interactions in the assembly of functionally diverse seaweeds. In particular, two biotic mechanisms may be largely responsible. First, interspecific competition, which has been widely documented in seaweeds (Hawkins and Hartnoll 1985; Edwards and Connell 2012), may result in the exclusion of functionally similar species from local communities (Macarthur and Levins 1967; Adler et al. 2013), promoting dissimilarity in traits of co-occurring species. The stronger overdispersion in the more favourable lower shore further indicates a key role of competition (Bertness and Callaway 1994) and is consistent with a study using categorical traits across seaweeds and invertebrates on Chilean rocky shores (Valdivia et al. 2017). Second, positive interactions such as facilitation and associational defences could also support species with contrasting traits (Teagle et al. 2017). The co-occurrence of functionally distinct species may be further promoted by small-scale environmental heterogeneity, as indicated by the enhancement of all observed functional diversity and over-dispersion in the presence of rock pools. Overall, it seems that local scale processes - likely involving species interactions - drove over-dispersion and effectively boosted functional diversity in the low shore and may help 
explain scale-dependent functional diversity responses to shore height. Our finding that overdispersion patterns were maintained even when null models were restricted to species occurring within each respective zone further strengthens this conclusion. Nevertheless, although observational studies such as ours describe naturally-occurring patterns of functional diversity and can show where functional diversity deviates from that expected under random assembly, only experiments can attempt to pin-down the relative and individual roles of the environment and species interactions in driving these patterns (Adler et al. 2013; Kraft et al. 2015).

Functional diversity approaches directly address the trait differences between species and therefore provide more insight than species-based measures into the potential consequences for ecosystem functioning (e.g. Le Bagousse-Pinguet et al. 2019). In our study, at the small scale, declines in functional richness and dispersion with increasing shore height reflect a reduction in both the total range of available traits and the distinctness of abundant species, potentially diminishing niche complementarity between co-occurring species (Cardinale et al. 2007; Stachowicz et al. 2008; Gamfeldt et al. 2015) and consequently ecosystem functioning (Griffin et al. 2009; Cadotte et al. 2011; Cadotte 2017). At the large scale, the smaller and nested functional space of upper shore communities, together with their lower redundancy, collectively indicate that these communities exhibit a reduced capacity to exploit environmental niches (Cardinale et al. 2000) and an impaired ability to withstand environmental changes (Loreau et al. 2003). Nevertheless, the persistence at this large scale of both functional dispersion and emergent group richness, as well as the maintenance of subset of core trait space, suggests resistance of some aspects of ecosystem functioning to the environmental gradient.

In conclusion, our results show that distinct aspects of seaweed functional diversity decline alongside species richness across the intertidal gradient. Yet patterns of change in 
functional diversity are scale-dependent: declines are stronger at the smaller scale, where both lower species richness and species interactions appear to be shaping functional diversity. These results bring a new perspective to the well-studied pattern of seaweed intertidal zonation, while pointing towards the role of local, biotic factors in shaping seaweed community assembly and resulting functional diversity. Our study also demonstrates the importance of considering different spatial scales in studies of changes in biodiversity across communities (Chase et al. 2018). Functional diversity studies in marine species have traditionally been limited by a lack of appropriate trait data. However, these are now emerging for corals (Madin et al. 2016), seagrasses (de los Santos et al. 2016) and seaweeds (Mauffrey et al. 2019). Applying these newly available functional traits to assemblages of marine habitat formers across temporal - or as we did, spatial - gradients allows the characterisation of context-dependent functional structure (e.g., redundancy) as well as insights into potential sensitivity to environmental change and attendant species loss. Future studies could use similar approaches along gradients such as coastal development, ocean acidification (volcanic vents), and climate change-driven species loss or turnover (see Teixidó et al. 2018; Hall-Spencer et al. 2008; Wernberg et al. 2011; Pessarrodona et al. 2019).

Acknowledgements: We thank the reviewers for the comments that helped improve the manuscript; we thank Josh Mutter, Olga Koppel and other Swansea University students for their valuable help in the field and lab work; we also thank Igor S. Pessi for his help throughout the study. 


\section{References}

Antão LH, Bates AE, Blowes SA et al. (2020) Temperature-related biodiversity change across temperate marine and terrestrial systems. Nat Ecol Evol. doi:10.1038/s41559-020-1185-7

Adler PB, Fajardo A, Kleinhesselink AR, Kraft NJB (2013) Trait-based tests of coexistence mechanisms. Ecol Lett 16:1294-1306 doi: 10.1111/ele.12157

Araújo R, Sousa-Pinto I, Bárbara I, Quintino V (2006) Macroalgal communities of intertidal rock pools in the northwest coast of Portugal. Acta Oecologica 30:192-202 doi: 10.1016/j.actao.2006.04.002

Ballantine WJ (1961) A biologically-defined exposure scale for the comparative description of rocky shores. Field Stud 1: 1-19

Baselga A (2010) Partitioning the turnover and nestedness components of beta diversity: Partitioning beta diversity. Glob Ecol Biogeogr 19:134-143 doi: 10.1111/j.1466-8238.2009.00490.x

Baselga A, Orme CDL (2012) betapart: an R package for the study of beta diversity: Betapart package. Methods Ecol Evol 3:808-812 doi: 10.1111/j.2041-210X.2012.00224.x

Begon M, Harper JL, Townsend CR (1996) Ecology: individuals, populations and communities. Oxford, Blackwell.

Bertness MD, Callaway R (1994) Positive interactions in communities. Trends Ecol Evol 9:191-19310 doi: 1016/0169-5347(94)90088-4

Blowes SA, Supp SR, Antão LH, et al (2019) The geography of biodiversity change in marine and terrestrial assemblages. Science 366:339-345 doi: 10.1126/science.aaw1620

Cadotte MW, Cavender-Bares J, Tilman D, Oakley TH (2009) Using Phylogenetic, Functional and Trait Diversity to Understand Patterns of Plant Community Productivity. PLoS ONE 4:e5695. doi:10.1371/journal.pone.0005695

Cadotte MW (2017) Functional traits explain ecosystem function through opposing mechanisms. Ecol Lett 20:989-996 doi: 10.1111/ele.12796

Cadotte MW, Carscadden K, Mirotchnick N (2011) Beyond species: functional diversity and the maintenance of ecological processes and services: Functional diversity in ecology and conservation. J Appl Ecol 48:1079-1087 doi: 10.1111/j.1365-2664.2011.02048.x

Cadotte MW, Tucker CM (2017) Should Environmental Filtering be Abandoned? Trends Ecol Evol 32:429-437 doi: 10.1016/j.tree.2017.03.004

Cappelatti L, Mauffrey ARL, Griffin JN (2019) Applying continuous functional traits to large brown macroalgae: variation across tidal emersion and wave exposure gradients. Mar Biol 166:145 doi: $10.1007 / \mathrm{s} 00227-019-3574-5$

Cardinale BJ, Nelson K, Palmer MA (2000) Linking species diversity to the functioning of ecosystems: on the importance of environmental context. Oikos 91:175-183 doi: 10.1034/j.16000706.2000.910117.x

Cardinale BJ, Wright JP, Cadotte MW, et al (2007) Impacts of plant diversity on biomass production increase through time because of species complementarity. Proc Natl Acad Sci 104:18123-18128. doi: 10.1073/pnas.0709069104 
Carpenter RC (1990) Competition Among Marine Macroalgae: A Physiological Perspective. Journal of Phycology, 26(1), 6-12. doi: 10.1111/j.0022-3646.1990.00006.x

Chapin FS, Bret-Harte MS, Hobbie SE, Zhong H (1996) Plant functional types as predictors of transient responses of arctic vegetation to global change. J Veg Sci 7:347-358. doi: 10.2307/3236278

Chappuis E, Terradas M, Cefalì ME, et al (2014) Vertical zonation is the main distribution pattern of littoral assemblages on rocky shores at a regional scale. Estuar Coast Shelf Sci 147:113-122. doi: 10.1016/j.ecss.2014.05.031

Chase JM, McGill BJ, McGlinn DJ, et al (2018) Embracing scale-dependence to achieve a deeper understanding of biodiversity and its change across communities. Ecol Lett 21:1737-1751. doi:10.1111/ele.13151

Cornelissen JHC, Lavorel S, Garnier E, Díaz S et al. (2003) A handbook of protocols for standardised and easy measurement of plant functional traits worldwide. Australian Journal of Botany, 51, 335-380.

Cornwell WK, Schwilk DW, Ackerly DD (2006) A trait-based test for habitat filtering: convex hull volume. Ecology 87:1465-1471 doi: 10.1890/0012-9658(2006)87[1465:ATTFHF]2.0.CO;2

Díaz S, Cabido M (2001) Vive la différence: plant functional diversity matters to ecosystem processes. Trends in Ecology \& Evolution 16:646-655. doi: 10.1016/S0169-5347(01)02283-2

Díaz S, Settele J, Brondízio E et al (2020) Summary for policymakers of the global assessment report on biodiversity and ecosystem services of the Intergovernmental Science-Policy Platform on Biodiversity and Ecosystem Services. In: Global Assessment Report on Biodiversity and Ecosystem Services, IPBES.

Devictor V, Mouillot D, Meynard C, et al (2010) Spatial mismatch and congruence between taxonomic, phylogenetic and functional diversity: the need for integrative conservation strategies in a changing world: Spatial mismatch between diversity facets. Ecology Letters 13:1030-1040. doi: 10.1111/j.14610248.2010.01493.x

Dring MJ, Brown FA. (1982) Photosynthesis of intertidal brown algae during and after periods of emersion: a renewed search for physiological causes of zonation. Mar Ecol Prog Ser 8: 301-308. doi: 10.3354/meps008301

Dromgoole FI (1981) Form and Function of the Pneumatocysts of Marine Algae. I. Variations in the Pressure and Composition of Internal Gases. Botanica Marina, 24, 257-266. doi: 10.1515/botm.1981.24.5.257

Edwards MS, Connell SD (2012) Competition, a Major Factor Structuring Seaweed Communities. In: Wiencke C, Bischof K (eds) Seaweed Biology. Springer Berlin Heidelberg, Berlin, Heidelberg, pp 135156

Elger A and Willby NJ (2003) Leaf dry matter content as an integrative expression of plant palatability: the case of freshwater macrophytes. Functional Ecology, 17, 58-65

Firth LB, Schofield M, White FJ, et al (2014) Biodiversity in intertidal rock pools: Informing engineering criteria for artificial habitat enhancement in the built environment. Mar Environ Res 102:122-130 doi: 10.1016/j.marenvres.2014.03.016

Gamfeldt L, Lefcheck JS, Byrnes JEK, et al (2015) Marine biodiversity and ecosystem functioning: what's known and what's next? Oikos 124:252-265 doi: 10.1111/oik.01549

Garnier E, Cortez J, Billès G, et al (2004) Plant functional markers capture ecosystem properties during secondary succession. Ecology 85:2630-2637 doi: 10.1890/03-0799 
Gómez I, Huovinen P (2011) Morpho-functional patterns and zonation of South Chilean seaweeds: the importance of photosynthetic and bio-optical traits. Mar Ecol Prog Ser 422:77-91. doi: 10.3354/meps08937

Gotelli NJ, Chao A (2013) Measuring and Estimating Species Richness, Species Diversity, and Biotic Similarity from Sampling Data. In: Encyclopedia of Biodiversity. Elsevier, pp 195-211

Griffin JN, Jenkins SR, Gamfeldt L, et al (2009) Spatial heterogeneity increases the importance of species richness for an ecosystem process. Oikos 118:1335-1342 doi: 10.1111/j.16000706.2009.17572.x

Gustafsson C, Boström C (2011) Biodiversity influences ecosystem functioning in aquatic angiosperm communities. Oikos 120:1037-1046 doi: 10.1111/j.1600-0706.2010.19008.x

Hall-Spencer JM, Rodolfo-Metalpa R, Martin S, et al (2008) Volcanic carbon dioxide vents show ecosystem effects of ocean acidification. 454:4

Harley CDG, Anderson KM, Demes KW, et al (2012) Effects of climate change on global seaweed communities. J Phycol 48:1064-1078 doi: 10.1111/j.1529-8817.2012.01224.x

Hawkins S, Hartnoll R (1985) Factors determining the upper limits of intertidal canopy-forming algae. Mar Ecol Prog Ser 20:265-271 doi: 10.3354/meps020265

Hay ME (1981). The functional morphology of turf forming seaweeds: persistence in stressful marine habitats. Ecology, 62, 739-750.

Hervé M (2020). RVAideMemoire: Testing and Plotting Procedures for Biostatistics. R package version 0.9-74. https://CRAN.R-project.org/package=RVAideMemoire

Ingólfsson A (2005) Community structure and zonation patterns of rocky shores at high latitudes: an interocean comparison: Rocky shore communities at high latitudes. J Biogeogr 32:169-182. doi: 10.1111/j.1365-2699.2004.01150.x

Isbell F, Gonzalez A, Loreau M, et al (2017) Linking the influence and dependence of people on biodiversity across scales. Nature 546:65-72 doi: 10.1038/nature22899

Johnson MP, Hawkins SJ, Hartnoll RG, Norton TA (1998) The establishment of fucoid zonation on algaldominated rocky shores: hypotheses derived from a simulation model. Funct Ecol 12:259-269. doi: 10.1046/j.1365-2435.1998.00185.x

Kraft NJB, Adler PB, Godoy O, et al (2015) Community assembly, coexistence and the environmental filtering metaphor. Funct Ecol 29:592-599 doi: 10.1111/1365-2435.12345

Kuebbing SE, Maynard DS, Bradford MA (2018) Linking functional diversity and ecosystem processes: A framework for using functional diversity metrics to predict the ecosystem impact of functionally unique species. J Ecol 106:687-698 doi: 10.1111/1365-2745.12835

Laliberté $E$, Legendre P (2010) A distance-based framework for measuring functional diversity from multiple traits. Ecology 91:299-305 doi: 10.1890/08-2244.1

Le Bagousse-Pinguet Y, Soliveres S, Gross N, et al (2019) Phylogenetic, functional, and taxonomic richness have both positive and negative effects on ecosystem multifunctionality. Proceedings of the National Academy of Sciences 201815727. doi: 10.1073/pnas.1815727116

Lefcheck JS, Duffy JE (2015) Multitrophic functional diversity predicts ecosystem functioning in experimental assemblages of estuarine consumers. Ecology 96:2973-2983. doi: 10.1890/14-1977.1 
Legendre $P(2014)$ Interpreting the replacement and richness difference components of beta diversity: Replacement and richness difference components. Glob Ecol Biogeogr 23:1324-1334. doi: 10.1111/geb.12207

Littler MM, Littler DS (1980) The Evolution of Thallus Form and Survival Strategies in Benthic Marine Macroalgae: Field and Laboratory Tests of a Functional Form Model. Am Nat 116:25-44. https://doi.org/10.1086/283610

Loreau M, Mouquet N, Gonzalez A (2003) Biodiversity as spatial insurance in heterogeneous landscapes. Proc Natl Acad Sci 100:12765-12770 doi: 10.1073/pnas.2235465100

Lubchenco J (1980) Algal Zonation in the New England Rocky Intertidal Community: An Experimental Analysis. Ecology 61:333-344 doi: 10.2307/1935192

Macarthur R, Levins R (1967) The Limiting Similarity, Convergence, and Divergence of Coexisting Species. Am Nat 101:377-385 doi: 10.1086/282505

Madin JS, Hoogenboom MO, Connolly SR, Darling ES, Falster DS, Huang D, Keith SA, Mizerek T, Pandolfi JM, Putnam HM, Baird AH (2016) A trait-based approach to advance coral reef science. Trends Ecol Evol 31:419-428 doi: 10.1016/j.tree.2016.02.012.

Maechler M, Rousseeuw P, Struyf A, Hubert M, Hornik K (2019) cluster: Cluster Analysis Basics and Extensions. R package version 2.1.0.

Mason NWH, Mouillot D, Lee WG, Wilson JB (2005) Functional richness, functional evenness and functional divergence: the primary components of functional diversity. Oikos 111:112-118. doi: $10.1111 / \mathrm{j} .0030-1299.2005 .13886 . x$

Mauffrey ARL, Cappelatti L, Griffin JN (2019) Traditional functional groups capture limited variation in the trait space of macroalgae. bioRxiv 803965 doi: 10.1101/803965

Mauffrey ARL, Cappelatti L, Griffin JN (2020). Data from: Functional diversity of seaweeds revisited: confronting traditional groups with quantitative traits. Dryad, Dataset, https://doi.org/10.5061/dryad.nvx0k6dpn

Mcgill B, Enquist B, Weiher E, Westoby M (2006) Rebuilding community ecology from functional traits. Trends Ecol Evol 21:178-185 doi: 10.1016/j.tree.2006.02.002

Micheli F, Halpern BS (2005) Low functional redundancy in coastal marine assemblages. Ecol Lett 8:391-400 doi: 10.1111/j.1461-0248.2005.00731.x

Mokany K, Ash J, Roxburgh S (2008) Functional identity is more important than diversity in influencing ecosystem processes in a temperate native grassland: Determinants of ecosystem processes. J Ecol 96:884-893 doi: 10.1111/j.1365-2745.2008.01395.x

Mouillot D, Graham NAJ, Villéger S, et al (2013) A functional approach reveals community responses to disturbances. Trends Ecol Evol 28:167-177 doi: 10.1016/j.tree.2012.10.004

Mouillot D, Villeger S, Parravicini V, et al (2014) Functional over-redundancy and high functional vulnerability in global fish faunas on tropical reefs. Proc Natl Acad Sci 111:13757-13762 doi: 10.1073/pnas.1317625111

Muguerza N, Bustamante M, Díez I, et al (2020) Long-term surveys reveal abrupt canopy loss with immediate changes in diversity and functional traits. Mar Biol 167:61. doi: 10.1007/s00227-020-36751 
Pessarrodona A, Foggo A, Smale DA (2019) Can ecosystem functioning be maintained despite climatedriven shifts in species composition? Insights from novel marine forests. J Ecol 107:91-104. doi: 10.1111/1365-2745.13053

de los Santos CB, Onoda Y, Vergara JJ, Pérez-Lloréns et al (2016) A comprehensive analysis of mechanical and morphological traits in temperate and tropical seagrass species. Mar Ecol Prog Ser 551:81-94 doi: 10.3354/meps11717

Reich PB, DS Ellsworth, MB Walters, JM Vose, C Gresham, JC Volin, WD Bowman (1999) Generality of leaf trait relationships: a test across six biomes. Ecology 80:1955-1969.

Reynolds AP, Richards G, de la Iglesia B, Rayward-Smith VJ (2006). Clustering Rules: A Comparison of Partitioning and Hierarchical Clustering Algorithms. Journal of Mathematical Modelling and Algorithms, 5(4), 475-504. doi: 10.1007/s10852-005-9022-1.

Roderick ML, SL Berry, IR Noble (2000) A framework for understanding the relationship between environment and vegetation based on the surface area to volume ratio of leaves. Funct Ecol 14:423437

Rodriguez S, Martín AP, Sousa-Pinto I, Arenas F (2016) Biodiversity effects on macroalgal productivity: exploring the roles of richness, evenness and species traits. Mar Ecol Prog Ser 562:79-91. doi: 10.3354/meps11948

Rosenfeld JS (2002). Functional redundancy in ecology and conservation. Oikos 98: 156-162

Schellenberger Costa D, Gerschlauer F, Pabst H, et al (2017) Community-weighted means and functional dispersion of plant functional traits along environmental gradients on Mount Kilimanjaro. J Veg Sci 28:684-695 doi: 10.1111/jvs.12542

Schonbeck MW, Norton TA (1979) Drought-hardening in the upper-shore seaweeds fucus spiralis and pelvetia canaliculata. J Ecol 67:687 doi: 10.2307/2259120

Scrosati R, Heaven C (2007) Spatial trends in community richness, diversity, and evenness across rocky intertidal environmental stress gradients in eastern Canada. Mar Ecol Prog Ser 342:1-14 doi: $10.3354 /$ meps342001

Scrosati RA, Knox AS, Valdivia N, Molis M (2011) Species richness and diversity across rocky intertidal elevation gradients in Helgoland: testing predictions from an environmental stress model. Helgoland Marine Research 65: 91 doi: 10.1007/s10152-010-0205-4

Seger GDS, Cappelatti L, Gonçalves LO, et al (2017) Phylogenetic and functional structure of climbing plant assemblages in woody patches advancing over Campos grassland. Journal of Vegetation Science 28:1187-1197. doi: 10.1111/jvs.12568

Singer FD (2016) Ecology in Action. Cambridge University Press 719 p.

Smale DA, Burrows MT, Moore P, et al (2013) Threats and knowledge gaps for ecosystem services provided by kelp forests: a northeast Atlantic perspective. Ecol Evol 3:4016-4038. doi: 10.1002/ece3.774

Smith AB, Sandel B, Kraft NJB, Carey S (2013) Characterizing scale-dependent community assembly using the functional-diversity-area relationship. Ecology 94:2392-2402 doi: 10.1890/12-2109.1

Sol D, Trisos C, Múrria C, et al (2020) The worldwide impact of urbanisation on avian functional diversity. Ecol Lett 23:962-972. doi:10.1111/ele.13495 
Stachowicz JJ, Bruno JF, Duffy JE (2007) Understanding the effects of marine biodiversity on communities and ecosystems. Annu Rev Ecol Evol Syst 38:739-766. doi: 10.1146/annurev.ecolsys.38.091206.095659

Stachowicz JJ, Graham M, Bracken MES, Szoboszlai Al (2008) Diversity enhances cover and stability of seaweed assemblages: the role of heterogeneity and time. Ecology 89(11):3008-3019 doi: 10.1890/071873.1

Starko S, Claman BZ and Martone PT (2015) Biomechanical consequences of branching in flexible wave-swept macroalgae. New Phytologist, 206(1), 133-140. doi: 10.1111/nph.13182

Steneck RS, Dethier MN (1994) A Functional Group Approach to the Structure of Algal-Dominated Communities. Oikos 69:476 doi: 10.2307/3545860

Stephenson TA, Stephenson A (1949) The universal features of zonation between tidemarks on rocky shores. Journal of Ecology 38: 289-305

Stevens RD, Gavilanez MM (2015) Dimensionality of community structure: phylogenetic, morphological and functional perspectives along biodiversity and environmental gradients. Ecography 38:861-875. doi: 10.1111/ecog.00847

Stewart HL and Carpenter RC (2003) The effects of morphology and water flow on photosynthesis of marine macroalgae. Ecology, 84(11), 2999-3012.

Swenson N (2014) Functional and Phylogenetic Ecology in R. New York, Springer. 212 p.

Tait LW, Hawes I, Schiel DR (2014) Shining light on benthic macroalgae: mechanisms of complementarity in layered macroalgal assemblages. PLoS ONE 9:e114146. doi: 10.1371/journal.pone.0114146

Taylor PR, Hay ME (1984). Functional morphology of intertidal seaweeds: adaptive significance of aggregate vs. solitary forms. Marine Ecology Progress Series, 18, 295-302.

Teagle H, Hawkins SJ, Moore PJ, Smale DA (2017) The role of kelp species as biogenic habitat formers in coastal marine ecosystems. J Exp Mar Biol Ecol 492:81-98. doi: 10.1016/j.jembe.2017.01.017

Teixidó N, Gambi MC, Parravacini V et al. (2018) Functional biodiversity loss along natural $\mathrm{CO}_{2}$ gradients. Nat Commun 9: 5149. doi: 10.1038/s41467-018-07592-1

Tilman D (2001) Functional diversity. Encyclopaedia of biodiversity. Academic Press, San Diego, 109120

Thomsen MS, Wernberg T, Altieri A, et al (2010) Habitat Cascades: The Conceptual Context and Global Relevance of Facilitation Cascades via Habitat Formation and Modification. Integrative and Comparative Biology 50:158-175. doi: 10.1093/icb/icq042

Underwood AJ, Jernakoff $P$ (1984) The effects of tidal height, wave-exposure, seasonality and rockpools on grazing and the distribution of intertidal macroalgae in New South Wales. J Exp Mar Biol Ecol 75:71-96 doi: 10.1016/0022-0981(84)90024-8

Valdivia N, Segovia-Rivera V, Fica E, et al (2017) Context-dependent functional dispersion across similar ranges of trait space covered by intertidal rocky shore communities. Ecol Evol 7:1882-1891. doi: $10.1002 /$ ece3.2762

Vergés A, McCosker E, Mayer-Pinto M, et al (2019) Tropicalisation of temperate reefs: Implications for ecosystem functions and management actions. Funct Ecol 1365-2435.13310. doi: 10.1111/13652435.13310 
Villéger S, Mason NWH, Mouillot D (2008) New multidimensional functional diversity indices for a multifaceted framework in functional ecology. Ecology 89:2290-2301 doi: 0.1890/07-1206.1

Violle C, Navas ML, Vile, D et al. (2007). Let the concept of trait be functional! Oikos 116, 882-892

Wernberg T, Russell BD, Thomsen MS, et al (2011) Seaweed Communities in Retreat from Ocean Warming. Curr Biol 21:1828-1832 doi: 10.1016/j.cub.2011.09.028

Weykam G, Gómez I, Wiencke C et al. (1996) Photosynthetic characteristics and C:N ratios of macroalgae from King George Island (Antarctica). Journal of Experimental Marine Biology and Ecology, 204, 1-22

Zhang JT, Lihong F, Min L (2012) Functional diversity in plant communities: Theory and analysis methods. African Journal Biotechnology 11:1014-1022 doi: 10.5897/AJB11.3122

\section{List of appendices (given at the end of the thesis)}

Appendix 1. Sensitivity analyses of diversity metrics by excluding the zone-defining Phaeophytes. Includes Table S1 (Summary of main effects from the linear models with diversity metrics) and Fig. S1 (Standardised effect sizes - SES).

Appendix 2. Sampling effort across zones and habitats. Includes Fig. S2 (Species accumulation curves) and Table S2 (Observed and extrapolated species richness).

Appendix 3. Additional information regarding traits and PCoA: methods and trait correlations. Includes Table S3 (Pearson correlations (R) between all pairs of continuous traits), Table S4 (Correlation (R) between the first PCo axes and study traits), and Fig. S3 (Quality of the trait space with different numbers of PCo axes).

Appendix 4. Diversity metrics for each study site individually. Includes Fig. S4.

Appendix 5. Relationship between functional richness and species richness. Includes Fig. S5 (Relationships between functional diversity metrics and species richness).

Appendix 6. Results from the standardised effect sizes (SES) constrained within zones. Includes Figure S6 (SES from randomizations constrained within zones). 


\section{Chapter 4}

A phylogenetic perspective to the functional diversity of red seaweeds

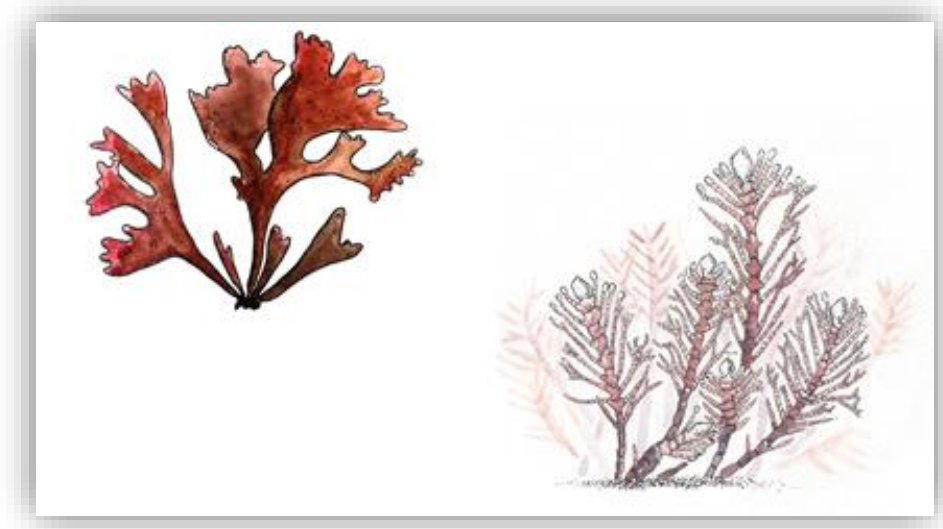

(C) Elizabeth Mills 


\begin{abstract}
Functional ecology sheds light on the patterns of diversity and composition of species in communities, based on their relevant characters. Combining phylogenetic approaches to functional ecology can improve our understanding of community assembly processes and the power to predict consequences of changes in the structure of assemblages. Here I investigate the potential of phylogenies to inform species-environment-trait relationships in red seaweed (Rhodophyta) assemblages, by exploring how closely evolutionary relationships between species reflect variability in traits. I assembled a phylogenetic tree with 45 species and used three functional traits related to photosynthetic capacity (specific leaf area), physical structure (thallus dry matter content), and space use (length), measured at the individual level. My questions were: 1) do these functional traits have a phylogenetic signal? 2) how well does phylogenetic diversity (and higher taxonomic levels) capture trait diversity? and 3) can phylogenetic diversity reveal hidden trait-environment relationships (i.e. unmeasured traits are more dependent on the environment)? I found that traits had different levels of phylogenetic signal, from the most labile thallus dry matter content to the most conserved length. Intraspecific variation in traits did not affect the detection of phylogenetic signal. In a community gradient example, I show that functional and phylogenetic diversities differed across intertidal zones, although phylogenetic diversity captured $72 \%$ of variation in traits across communities (1x1 m quadrats). These results suggest that the ability of a red algal phylogeny to capture species trait differences is scale- and trait- dependent. This study informs some of the relationships between red algae evolutionary history and their functional traits.
\end{abstract}

Key-words: Phylogenetic signal, functional traits, phylogenetic diversity, Rhodophyta 


\section{Introduction}

Functional traits are useful tools to infer community properties, predict ecosystem functions and elucidate drivers of species assembly across the environment. Methods that use the range of functional traits among coexisting species - functional diversity - allow us to scale from individual-level physiology to community-level multifunctionality (Gross et al. 2017; Cadotte 2017). Among highly diverse ecosystems, temperate rocky shores host rich assemblages of macroalgae, or seaweeds, which are habitat formers and dominate the standing biomass. However, research on algal functional ecology has remained largely restricted to functional groups defined by their gross morphology (Littler and Littler 1980; Steneck and Dethier 1994) and only recently work has emerged using continuous functional traits (e.g. Gómez and Huovinen 2011). For example, community-level traits can show functional patterns of assemblages across the intertidal gradient: traits representing a resource acquisitionconservation trade-off largely explain distinction between zone-dominant Phaeophytes (Cappelatti et al. 2019; chapter 1); across all algal groups, substitution of similar species between zones help maintain functional diversity despite species loss (Chapter 3). However, little is known about how continuous functional traits are related to evolutionary relationships in groups of seaweed.

Red algae (division Rhodophyta) are a monophyletic group of algae, which contains the oldest and largest number of algal species (Yoon et al. 2016). Red algae are widely distributed across the globe and can reach greater depths than other groups due to their highly efficient pigments. Although mostly small - compared to brown and green algae - their presence is noticeable across the whole rocky intertidal, in a diversity of habitats and habits (Lee 2018). Some species are reef building (e.g. Corallina) whereas some are economically important (e.g. Porphyra, "nori"). Because they are the most species-rich, morphologically 
diverse group of algae, and show a high ecological importance, in this chapter I will focus on Rhodophyta.

In addition to functional trait approaches, phylogenetic methods can give insights into community diversity and complement our understanding of ecological patterns (Swenson 2019). Although phylogenies cannot explain ecological mechanisms, they can inform the shared evolutionary history and therefore can be used to address how much species evolutionary similarities are reflected in their functional traits and how these relationships vary across communities (Webb et al. 2002; Losos 2011; Swenson 2019). This approach has been widely used in functional ecology, as genetic data and bioinformatic tools are increasingly available. While saving time and effort usually required to process traits, phylogenies should capture more traits than those which are feasible to measure, and therefore describe the general multivariate similarity between species (Webb 2000). Additionally, phylogenies can provide an estimation of species' original contributions to the overall phylogenetic diversity; phylogenetic originality can be informative for conservation measures and for the study of trait evolution within clades (Pavoine et al. 2005).

Shared ancestry among species suggests shared characters and is therefore a potential proxy for functional diversity: we can address how much species' evolutionary relatedness match their similarities on traits of interest. This approach can be useful when investigating community assembly across an environmental gradient, which can show different patterns. If functional and phylogenetic diversity (FD and PD henceforth) correlate, it is evidence that, for the traits and gradient of interest, PD can be a proxy for FD (although it will never be a true substitute). On the other hand, if PD relates to the environment more strongly than FD does, it suggests that the environment is acting upon unmeasured characteristics of the species in question (Cadotte et al. 2013). When FD relates to the environment more strongly, it indicates 
that the measured traits do not show a phylogenetic signal, while they respond to the environment. Because of the intrinsic association between phylogenetic and phenotypic relationships, methods to analyse these two components separately - decoupling - may reveal how much additional information there is to explain the diversity and composition of species in communities across gradients (Bello et al. 2017), which can stimulate a search for more functional traits to explain the ecological pattern of interest (Li et al. 2017). In addition to community assembly, PD can also predict ecosystem functions better than species diversity (e.g. productivity in vascular plants; Cadotte et al. 2009; Flynn et al. 2011).

The idea that species' relatedness could inform phenotypic / ecological similarities has been applied long before the arrival of phylogenetic methods (Darwin 1859). Taxonomic ratios (family: genus: species) have been used in studies of community assembly under the premise that a higher proportion of lower compared to higher taxonomic rankings reflected more similarity in community traits, as taxonomy is traditionally based on morphological characters (Enquist et al. 2002). Although this taxonomic approach has been replaced by a more informative phylogenetic method (as it integrates evolutionary history), it is still worthwhile to test how trait variability is captured by taxonomic hierarchies, thus providing an assessment of the power of using traits at levels other than species. For example, for a specific system of interest, we could use genus means when trait values are not available for all species. However, because of the potentially different diversification paths traits might take along the evolution of the group, this replacement should be tested with the closest relatives with available trait values. Furthermore, even within species there could be a trait variation large enough to compromise the use of species-level means (Albert et al. 2012).

The matching of PD and FD can be tested with dissimilarities derived from these two components (e.g. Mantel test) and will vary depending on how strongly related species tend to 
resemble each other. This pattern - trait similarity increases with evolutionary relatedness - is termed phylogenetic signal and it is relative to a Brownian motion model, where trait evolution is assumed to stem from linearly increasing variance (Wiener 1923). In other words, phylogenetic signal is the degree to which we can predict variation in trait values from species' evolutionary relationships (Swenson 2019). One way to measure phylogenetic signal is with Blomberg's K, where the absence of a phylogenetic signal indicates that most trait variability is within rather than between clades, which could be derived from convergent evolution or character displacement (Blomberg et al 2003). Consequently, under either strong phylogenetic signal (traits are more conserved than expected by Brownian motion), or the absence of phylogenetic signal (traits are labile), variation in traits cannot be predicted by phylogeny.

Here I explore what could be gained by incorporating a phylogenetic perspective to the study of macroalgal functional ecology. Using a phylogenetic tree of red algae species and a community survey along an environmental gradient, I aimed to answer the following questions: 1) do three functional traits, related to photosynthesis, structure and space use, have a phylogenetic signal? 2) how well does phylogenetic diversity (and higher taxonomic levels) capture trait diversity? and 3) can phylogenetic diversity reveal hidden trait-environment relationships (i.e. do unmeasured traits vary with the environment)? In the case that there is a phylogenetic signal, phylogenetic diversity should be similar to functional diversity across the environmental gradient. I expected little or no variation in diversity across the gradient unexplained by the three functional traits, since they cover the major ecological aspects of seaweeds - photosynthesis, structure, and space use.

\section{Methods}

\section{Data collection}


Species were sampled for traits at several locations in south UK: Oxwich Bay, Overton, Bracelet Bay, Rhossili (Wales); Portlooe and Portwrinkle (England). During walking surveys in the intertidal at spring tides, a minimum of six samples was collected for each species of erect algae I found, at least $10 \mathrm{~m}$ apart, to ensure a good estimation of trait averages. A total of 50 red algae species were sampled. They were brought in ice boxes to the laboratory at Swansea University, were several morphological traits were measured; however, for this study I selected three, largely uncorrelated traits, each describing an eco-physiological aspect (see chapter 2 for information on all traits). Traits selected here are, as follows: specific thallus area (STA; cm2 g-1), which represents photosynthetic ability, thallus dry matter content (TDMC; ratio) representing structure, and maximum length $(\mathrm{cm})$ representing space use. Methods for their measurement are described in the appendix for Chapter 1. A principal component analysis revealed the association of the three traits with the first three axes (Appendix 1). I also used the phylogeny to test autocorrelation between traits (explained below).

\section{Phylogenetic tree construction and comparative analyses}

I constructed multi-locus phylogenies using the genes encoding for the large subunit of the ribulose-bisphosphate carboxylase (rbcL) and the photosystem II protein D1 (psbA). I retrieved sequences for 45 of our sampled species from GenBank using the Entrez Direct tool (Kans 2013) (accessed on 26.12.2019). In the cases of species where more than one sequence was available for a given gene, these were aligned using MAFFT v7.429 (Katoh and Standley 2013) and the longer sequence was kept for downstream analyses. Representative sequences of each species were then aligned using MAFFT separately for each gene. Alignments were inspected manually and trimmed to remove terminal gaps. Finally, I concatenated the singlegene alignments to produce a multi-locus sequence alignment. I then generated a Maximum 
Likelihood tree with bootstrapping $(n=1000)$ in software MEGA (Kumar et al. 2018). Branch lengths represent number of substitutions per nucleotide.

To answer question 1 (do traits related to photosynthesis, structure and space use have a phylogenetic signal?) I calculated the phylogenetic signal for each trait, using Blomberg's K (Blomberg et al 2003). $\mathrm{K}$ is one of the best studied method and is superior to Mantel tests in identifying phylogenetic signal (Harmon and Glor 2010), but it can only be measured on individual traits. If $\mathrm{K}$ approaches 1 , traits are evolving as expected according to Brownian motion model; whereas $\mathrm{K}>1$ or $\mathrm{K}<1$ indicate that traits are more, or less, similar between closely related species than expected. Values close to zero indicate phylogenetic independence. Despite being sensitive to underlying evolutionary model, measuring phylogenetic signal is a useful tool to identify patterns of traits and proxies for functional similarities among species (Münkemüller et al. 2012). K values were calculated in R package phytools (Revell 2012). One species had a missing value for STA (Dumontia contorta), so I removed it from the test for this trait. To address data uncertainty due to measurement error, I also calculated $\mathrm{K}$ including standard errors of species' traits using package sensiPhy (Paterno et al. 2018).

I addressed question 2 in two parts: first, I investigated how much phylogenetic diversity can inform functional diversity (how well does phylogenetic diversity capture trait diversity?). To answer this question, I used a Mantel test, which quantifies the correlation between a functional and a phylogenetic distance matrix, thus allowing a multivariate (multitrait) assessment of phylogenetic signal. The phylogenetic distance matrix included pairwise distances among all 45 species, using the sum of branch lengths. This matrix was calculated with function distTips in package adephylo (Jombart and Dray 2008), which computes the shortest distance between all pairs of tips (here, species) of the phylogeny. The multivariate 
functional distance matrix was generated from Gower distances among species according to their standardized traits.

For the second part, I also asked how much higher taxonomic ranks (as a rough substitute of phylogenetic relationships) can inform diversity in functional traits. Using other taxonomic ranks instead of species can potentially be a simple and more accessible tool to estimate trait values than using phylogenetic methods per se. Using a method of nested variance partitioning, I tested how much each taxonomic level captures trait variability. I used function partvar in R package cati (Taudiere and Violle 2016), which is based on a decomposition of variance using restricted maximum likelihood (REML). Each taxonomic level, from species to orders, was a factor, and each trait was a dependent variable provided at the level of individual, to capture within-species variability.

With the trait data and the phylogeny, I also estimated the originality of species (i.e. how different from the rest they are) at both functional and phylogenetic levels. This allowed us to compare if species with the largest phylogenetic distance to the others have also the most distinct trait values. I used functions originality (R package ade4; Dray and Dufour (2007)) and distinctDis (R package adiv; Pavoine (2020)). Phylogenetic originality was calculated with the QE-based index (Pavoine et al. 2005), which calculates the average distance among species using branch lengths. Functional originality was calculated with nearest neighbour (NN; Pavoine et al. 2017), based on a Euclidean distance matrix of the log-transformed traits. I then ran a Spearman rank correlation between both measures of originality.

Testing the application of a phylogenetic approach to a macroalgal community

To test question 3 (can phylogenetic diversity inform hidden trait-environment relationships in macroalgae?), I used real community data, where I calculated functional diversity in red algae communities across the intertidal height gradient. The data is from the 
survey from four sites in south Wales, UK, described with detail in Chapters 2 and 3). During this survey, I sampled the low, middle, and upper intertidal zones, where abundances of all algal species were estimated within $1 \mathrm{~m}^{2}$ quadrats. I randomly selected quadrats with red algae, getting equal replication of zones (final number of quadrats $=120$ ). Each quadrat represents a community, subject to both local drivers (e.g. biotic interactions) and to the environmental stress gradient.

First, I ran a Mantel test between the functional distance matrix (Gower distance on standardized traits) and the phylogenetic distance matrix (branch lengths), to see how well they correlated among survey species. Then, for each community I estimated functional and phylogenetic diversity (FD and PD) as well as the decoupled phylogenetic diversity (decPD), i.e. based on the unique contribution of phylogenetic distances. This allowed me to compare patterns across the environment $a$ ) between FD and PD as well as $b$ ) between PD and decPD. Similarities in $a$ indicate how well PD can describe FD across the environmental gradient; differences in $b$ suggest that some environment-trait relationships are not captured by the measured traits. For all diversity metrics, I used mean pairwise distances (MPD), which is the average distance among all pairs of species within the community. MPD is sensitive to changes at distant taxa, useful when the phylogeny includes old clades (Rhodophyta have been diverging for $\sim 1$ billion years). MPD is also independent of species richness. To calculate MPD, I used R function melodic (de Bello et al 2016), giving weight according to species' abundances. MPD for both phylogenetic and functional components were derived from distance matrices, obtained with R function decouple (de Bello et al 2017), which calculates both shared and unique components of phylogenetic and functional distances among species. Finally, to observe how the different diversity metrics - FD, PD, decFD and decPD - varied along the environmental gradient, I used linear models with shore height as predictors. To compare coupled and decoupled metrics, I used Spearman rank correlations. 


\section{Results}

Do traits related to photosynthesis, structure and space use have a phylogenetic signal?

I found a strong phylogenetic signal for length $(K=1.39, \mathrm{p}=0.01)$ and for STA $(K=1.18$, $\mathrm{p}=0.02)$ and no signal for TDMC $(\mathrm{K}=0.49, \mathrm{p}=0.11)$. Results were consistent when including intraspecific variability, showing a reliable estimate of phylogenetic signal on species-level traits (Appendix 3). In other words, while length and STA are more similar among relatives than expected under the random walk evolution proposed by the Brownian model, TDMC is less so. Figure 1 illustrates how trait values are spread across the phylogeny, where it is possible to see which clades are more conserved. For example, orders Gigartinales and Corallinales show low values of STA, whereas Ceramiales had higher values. Within richer orders, closer species tended to have similar values of STA and length, such as Cystoclonium purpureum and Calliblepharis jubata in Gigartinales, or Polysiphonia fucoides and Vertabrata byssoides in Ceramiales. We can also observe distinct values among closely related species such as Bonnemaisonia hamifera and Asparagopsis armata for both length and STA (Fig. 1).

Another way to illustrate distribution of traits along the phylogeny is with ancestral trait reconstructions (Fig. 2), where it is possible to visualise at which part of the evolution of the group traits diverged. For STA, mostly basal clades diverged, although some more recent divergence also occurred. For length, divergence was more recent, although the major contrast is at the base, between Porphyra (the only species from Class Bangiophyceae) and the remaining species from Florideophyceae. Finally, TDMC diverged continuously throughout the evolution of the group, likely the reason for the absent (or weak) phylogenetic signal. Overall, these results indicate that length and STA (traits related to photosynthesis and space use) are better captured by phylogeny than TDMC (trait related to structure). 


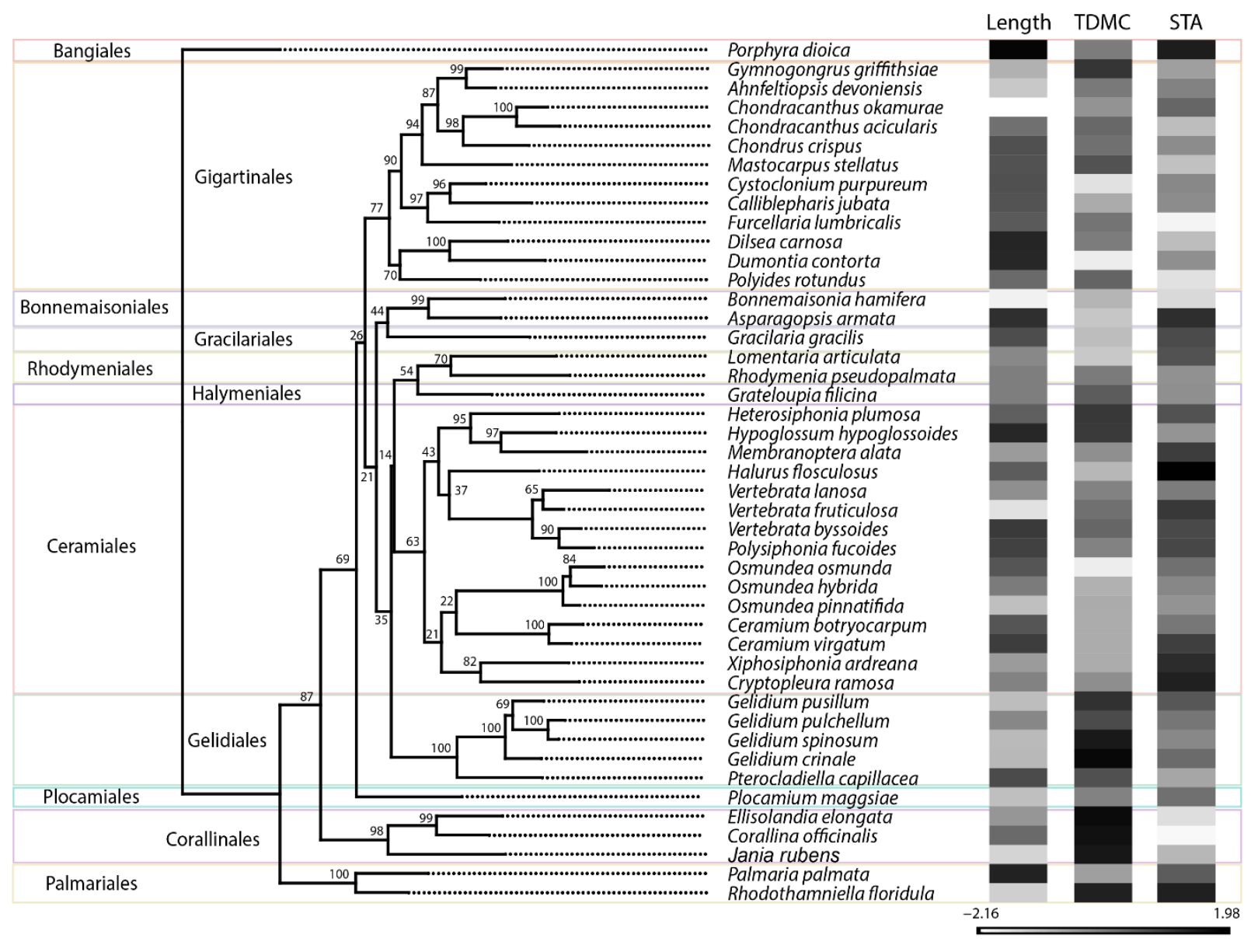

Figure 1. Heatmap of standardised trait values of total length, thallus dry matter content (TDMC) and specific thallus area (STA), of red algae species across a maximum likelihood phylogenetic tree. Taxonomic orders are shown in coloured background. Branch lengths are relative to the number of substitutions per nucleotide. 

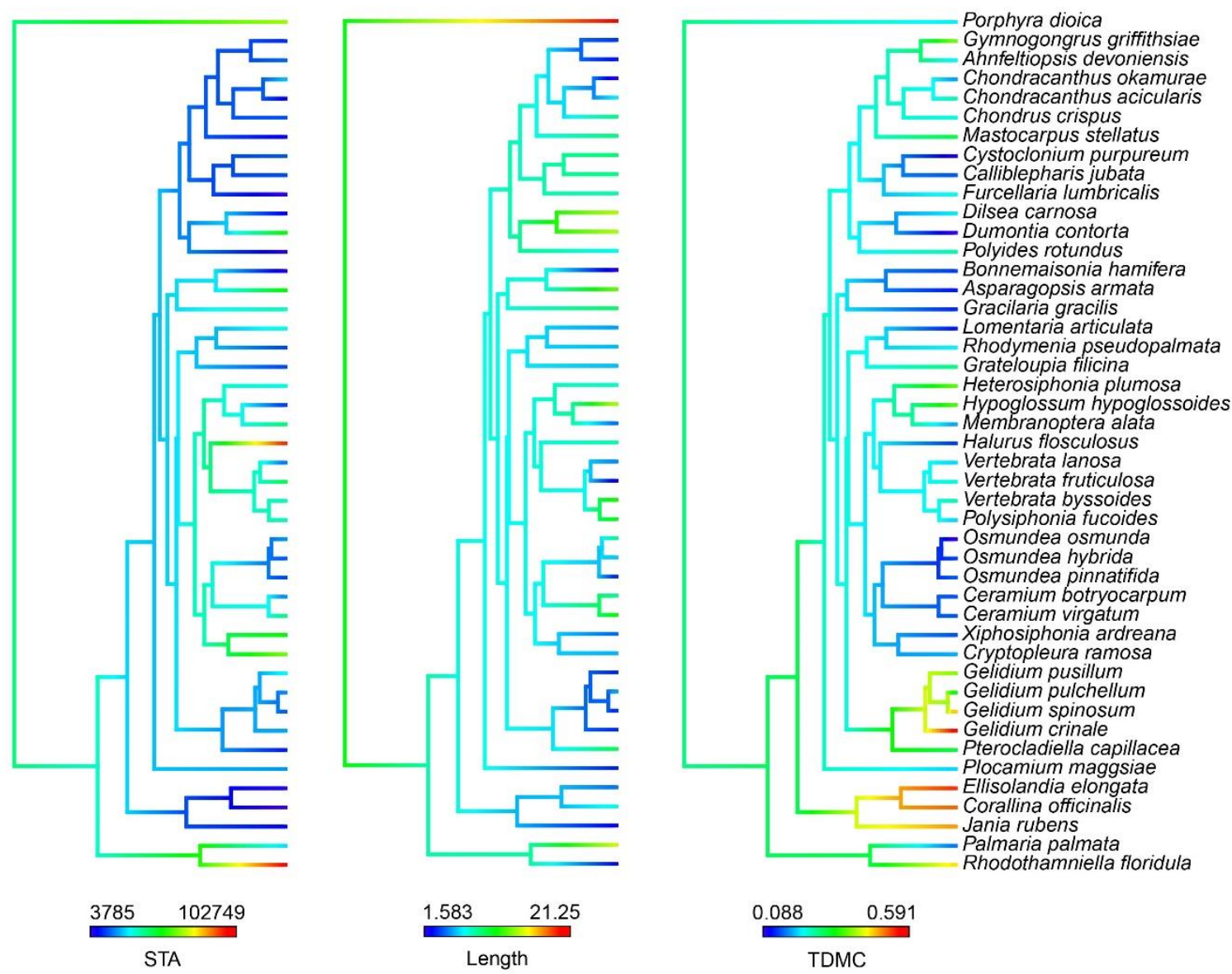

Figure 2. Ancestral trait reconstructions for STA, length and TDMC across a molecular phylogeny of 45 species of red algae found at the intertidal zone in the UK.

How well does phylogenetic diversity capture functional trait diversity?

To further test how much we can rely on phylogenies to estimate trait variability in red macroalgae, I compared phylogenetic and functional diversity metrics, including all three traits. This allowed us to have a more complete view of functional variation among species, as well as to estimate how much of species' differences is captured by the selected traits. The Mantel test between the Gower trait distance matrix (including all traits) and the cophenetic distance matrix (based on branch lengths of phylogeny) yielded a moderate correlation $(r=0.47, p=$ $0.001)$. 
The variation partitioning across taxonomic levels showed different results for each trait (Fig. 3). For STA, $40 \%$ of variability was captured by order alone, followed by species (23\%) and genus (17\%). There was a considerable variability within species as well (20\%). TDMC also varied largely among orders (41\%) and within species (27\%). For length, the pattern was the most different compared to the other traits: the major part of variance was explained by species (73\%), very little by genus $(5.4 \%)$ and the remaining by individual variation within species $(21 \%)$. It is important to note that this is a hierarchical partitioning, therefore if we only partition variance up to species level we would have, for example, STA with $20 \%$ of variance within species and $80 \%$ between species. This also means that genus level means could explain more than $50 \%$ of differences in STA and TDMC among individuals. These results indicate that, a) higher ranks may be useful to predict variance in STA and TDMC, to some extent; and b) the three traits had a substantial intraspecific variability, but always lower than higher ranks combined.

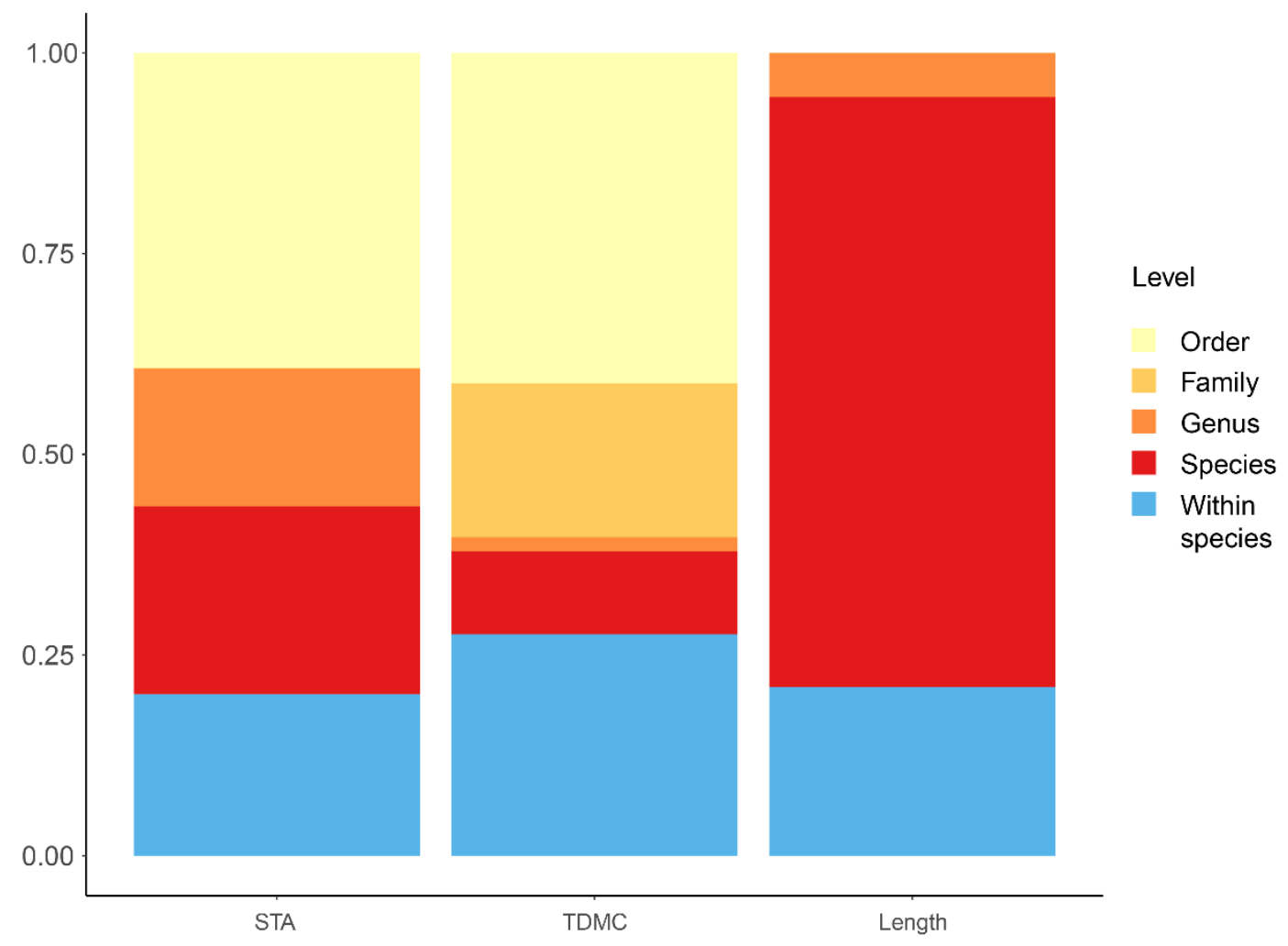


Figure 3. Nested variation partitioning (in percentage) among four taxonomic levels, and within species (individuals), for each study trait. STA: specific thallus area; TDMC: thallus dry matter content; Length: maximum length.

Species' phylogenetic and functional originality values had a low correlation $(\rho=0.18)$. The most phylogenetically original species was Porphyra dioica followed by Rhodothamniella floridula, Palmaria palmata and Jania rubens (Fig. 4). Only two of those were also among the most functionally original species: $R$. floridula and $P$. dioica. There are also some species with high mismatches in originalities, i.e. differences between the functional and phylogenetic originality: Bonnemaisonia hamifera and Vertebrata fruticulosa (functional > phylogenetic), and Porphyra dioica and Palmaria palmata (phylogenetic > functional). Additionally, I calculated the same originality analyses removing the distant Porphyra dioica, to observe if this species was skewing the correlation between the originality metrics. Indeed, correlation was even lower $(\rho=0.12)$. Generally, these results mean that, although there are some species which are both phylogenetically and functionally original, functional originality generally cannot be well predicted by phylogeny. 

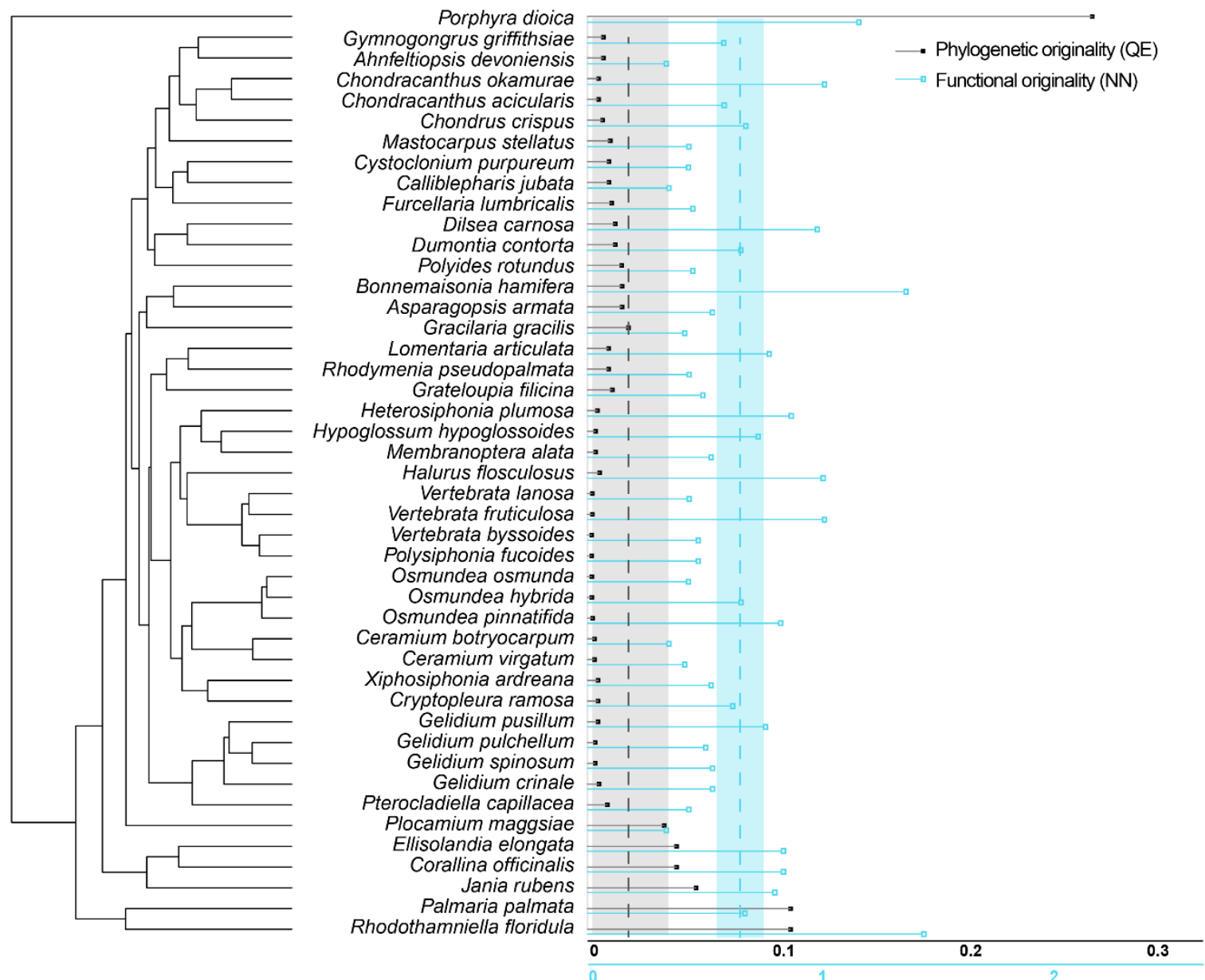

Figure 4. Phylogenetic and functional originality of $\mathbf{4 5}$ species of red algae. Phylogenetic originality was measured with the QE-based index (Pavoine 2005) and functional originality was calculated by the distance to the nearest neighbour (Pavoine et al. 2017). Dotted lines and bars indicate mean and standard error.

Can phylogenetic diversity reveal hidden trait-environment relationships in macroalgae?

I further decoupled functional and phylogenetic distances among all species, to reveal potentially hidden environment-trait relationships, i.e. those not shown by the selected traits. To test that, I used a community survey across intertidal zones (low, middle, and upper), where I estimated the unique (decoupled) and shared (coupled) contributions of functional and phylogenetic distances to community diversity across zones. There were 29 species of red algae in the survey, so I dropped the remaining species from the main tree for analyses. The number 
of species at the low, middle and upper shore were 25, 15 and 9. This time, the Mantel test between the functional and the phylogenetic distance matrices among all survey species revealed a high correlation $(\mathrm{r}=0.70, \mathrm{p}=0.001)$.

The correlation between coupled FD and PD (mean pairwise distances) was strong ( $\rho$ $=0.72$ ). However, linear models showed that the diversity patterns were different between the two metrics: communities did not significantly differ between zones for PD $(F=2.43 ; \mathrm{p}=$ 0.09), while FD was higher in the low shore compared to the other zones (Fig. 5).

Decoupling PD and FD (decPD, decFD) showed some differences to the coupled diversity metrics. Spearman correlations between PD and decPD were $\rho=0.58$, indicating an additional $42 \%$ of between-quadrat functional diversity differences not captured by the traits. However, the decoupled PD was still invariant to shore height $(F=0.29 ; \mathrm{p}=0.7)$. These results indicate that 1) STA, TDMC and length combined captured differences in the functional composition of communities, 2) the differences between PD and FD affected how mean pairwise differences changed across zones, and 3) decoupling the phylogenetic from the functional component of diversity did not change the relationships between PD and the environmental gradient (i.e. no additional information from the unique component of phylogenetic diversity). 
Functional level

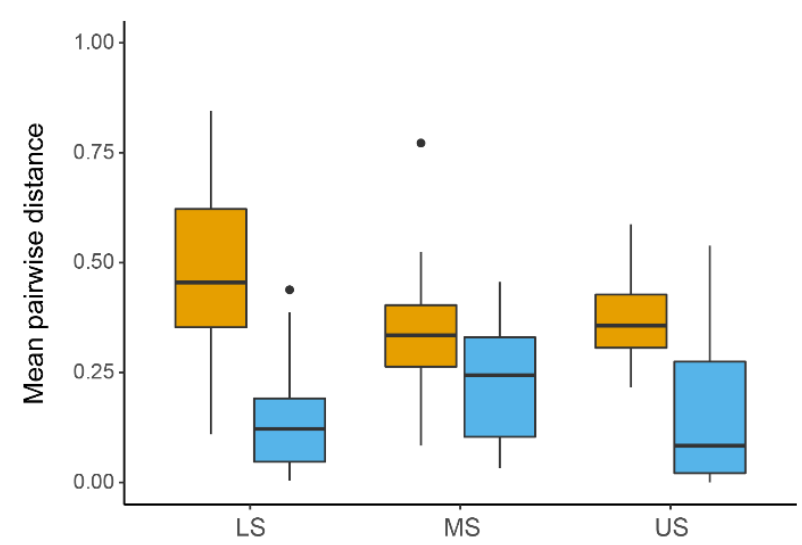

Phylogenetic level

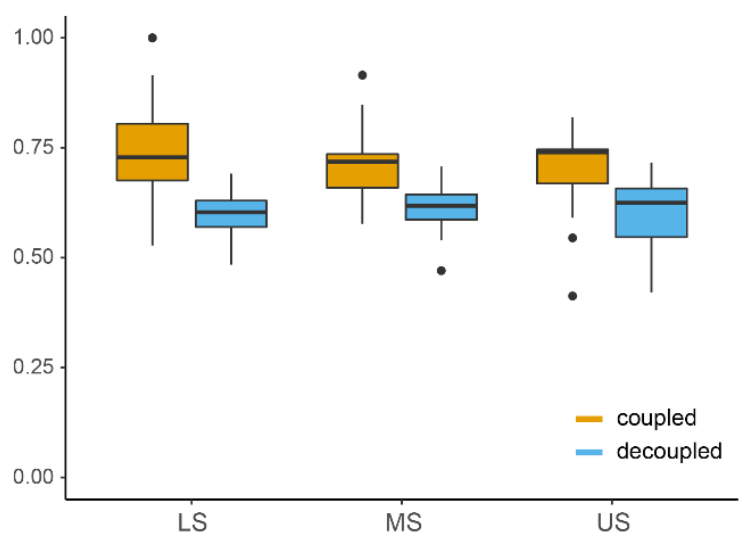

Figure 5. Functional diversity as mean pairwise distances and the effect of decoupling phylogenetic diversity on red algal communities across intertidal zones (LS = low shore; MS = middle shore; US = upper shore).

\section{Discussion}

Here I have combined a phylogenetic approach to the study of the functional ecology of red algae. I found that traits related to photosynthesis (STA) and space use (length) showed a significant phylogenetic signal, while the trait related to structure (TDMC) did not. On the taxonomic level, higher ranks explained a large part of variation in STA and TDMC. Although phylogenetic diversity (PD) explained about half of the diversity of these three traits combined, PD explained almost three-quarters of mean pairwise functional distances in intertidal communities. Moreover, decoupling PD from functional diversity (FD), i.e. the unique contribution of PD, did not show additional ("hidden") community-environment relationships.

Observing how traits are distributed across a phylogeny can inform how closely related species in similar environments share ecological strategies, and thus shed light into evolutionary history of a group of organisms. Two of the three traits selected for this study showed significant phylogenetic signal, both approaching $\mathrm{K}=1$. Blomberg's $\mathrm{K}$ for STA and length was strong (above 1), indicating that, under the Brownian motion model of trait 
evolution (random walk), trait values are more similar among close relatives than expected, i.e. conserved. In other words, similarities in the values of SLA and length among species approximately match their phylogenetic relatedness. In vascular plants, the equivalent to STA - specific leaf area - usually does not show phylogenetic signal (Gallagher 2012; Baraloto et al. 2012, Rios et al. 2014; Liu 2015; Wang et al 2017) and neither does height/length (Cadotte et al. 2009; Liu et al. 2015). The contrast between the phylogenetic signals between red algae and vascular plants suggests that these two evolutionarily distant producer groups had different evolutionary pathways for equivalent functional traits. For TDMC, the lack of phylogenetic signal suggests a convergence in trait values from distant species, possibly due to an adaptation to the environment only in some species of the set (Blomberg et al. 2003). The phylogenetic signal for STA and length reveals the potential of a red algae phylogeny to predict similarities of these traits among species. However, because $\mathrm{K}>1$, there is a risk of underestimating trait similarities and potentially overestimating functional diversity. Even so, a phylogeny could be a useful tool in studies where there is an interest in these traits but no trait values for all species.

An interesting finding was the explanatory power of higher taxonomic levels for individual-level traits, provided by the hierarchical variation partitioning. While STA and TDMC were more than $50 \%$ captured by genus, length was mostly captured by species. The result for length could indicate that its high phylogenetic signal is a result of a stronger conservation towards the base of the phylogeny, with the differentiation occurring more recently (towards the tips; also evident on the trait reconstruction tree). In practical terms, the genus average could be used for estimating STA, and for TDMC even family would be a suitable level. This approach is useful in the absence of some species' values or in the case where identifying individuals at the species level is difficult. However, length should be considered at the species level only, as genus only explains about $5 \%$ of individual values. This analysis also revealed that about a quarter of variation in traits is expressed within species, 
which is consistent with the analogous traits in vascular plants (specific leaf area, height, and leaf dry matter content; Siefert et al. 2015).

Although phylogenetic distances captured less than half of multi-trait differences among all species, in the community survey example there was a greater match between the phylogenetic and functional approaches. PD was strongly correlated with FD both in the overall species distance matrices and in the community diversity metrics (mean pairwise distances). However, when comparing diversity across intertidal zones, only FD showed a pattern of variation (i.e. higher diversity in the low shore). This result exemplifies that, even when a phylogeny has a good correlation with trait variation, it might not be a good predictor of environment-FD relationship (Bernard-Verdier et al. 2013). Nonetheless, while phylogeny did not reveal hidden zone-trait relationships, the remaining $30 \%$ of species differences not explained by the selected traits suggest that other traits might be important for different environmental variables (e.g. wave exposure). Furthermore, the range in PD among communities within zones was lower than that for FD, indicating that local factors (i.e. not related to shore height) such as competition and facilitation could be more important for functional than phylogenetic diversity.

Decoupling unique information contained in phylogenetic and functional differences among species provided further insight into community assembly patterns. There was an effect of decoupling FD and PD: FD did not vary across zones when the phylogenetic component was removed. This result means that the functional differences between species changed after accounting for phylogenetic relatedness, revealing the non-independence between traits and phylogeny (de Bello et al. 2017). However, this contrast was only observed in the low shore, implying a stronger relationship between the phylogenetic and functional structures of communities in that environment. For example, coexistence is promoted when seaweeds have 
different lengths to occupy distinct water layers during emersion, which is most prolonged in the low shore. Because length is highly dependent on species relatedness (strong phylogenetic signal), after accounting for the phylogeny effect there are no additional patterns observed between this trait and shore height. This result could suggest a potential phylogenetic bias in analyses of present species-environment relationships (Pagel 1999). However, phylogenetic relatedness is not necessarily a bias to be corrected, but a tool to help the interpretation of results from different aspects and evolutionary scales (de Bello et al. 2015). That is because phylogeny and ecology are not mutually exclusive; rather, they are different facets of the history of trait associations among species (Ackerly and Donoghue 1995).

I also found low correlations between species' functional and phylogenetic originalities, indicating that the most distant species do not necessarily have the most distinct trait combination. This result is similar to that found by Pavoine et al. (2017) for Carnivora species. When phylogenies can accurately inform species' functional differences, phylogenetic originality may provide information on species' potential contribution to ecosystem functioning - original species should make proportionally larger contributions to the diversity of functions - or even indicate priority for conservation measures (Isaac et al. 2007). In this study, I can point out some highly original species at both functional and phylogenetic levels (e.g. Porphyra dioica, Rhodothamniella floridula), but I cannot advocate the use of phylogenies of red algal species to inform species' unique functional contributions to communities. What is also interesting to observe with this originality metric is the species with a large mismatch between the functional and phylogenetic perspectives. Bonnemaisonia hamifera and Vertebrata fruticulosa were much more original in their trait values than in their phylogenetic distance, suggesting these species are contributing the most to the differences between the functional and phylogenetic distances among species. On the other hand, species with more originality in the phylogenetic than the functional level could be more original in 
traits not considered here, such as branching order or carbon : nitrogen ratio. Moving forward, it would be worth investigating the evolution of these "mismatched" species, which may show a fast (recent) divergence from their sister species, potentially due to competition or local adaptation.

In conclusion, the three functional traits selected here - specific leaf area, thallus dry matter content and length - have different patterns of distribution among species, as shown by their varying phylogenetic signals. In a real assemblage example, although phylogenetic diversity captured a large amount of variation in traits across communities, functional and phylogenetic diversities showed slightly different patterns across communities at different intertidal zones. These results suggest that the ability of phylogenetic differences among red algae to predict their overall trait differences is scale dependent. Moreover, since traits had different phylogenetic signals, these relationships might also be dependent on the selection of traits. I also found that the use of traits at higher taxonomic levels can be informative for STA and TDMC, but not length, appearing to be at least somewhat unrelated to their phylogenetic signal. Together these results inform some of the relationships between the evolutionary history and functional traits of red algae. Future trait-base studies on seaweeds may profit from including phylogenetic methods; for example, they can help identifying and testing hypotheses of how the evolutionary and ecological processes drove the present functional diversity of seaweeds in the rocky intertidal (Gerhold et al. 2015). Such an approach - combining functional and phylogenetic facets of seaweed diversity - will gain further strength and comparability if conducted at multiple scales, since community PD may vary across phylogenetic and spatial scales (Pavoine 2017, Swenson 2019). 


\section{References}

Ackerly DD, Donoghue MJ (1995) Phylogeny and Ecology Reconsidered. The Journal of Ecology 83:730. https://doi.org/10.2307/2261642

Albert CH, de Bello F, Boulangeat I, et al (2012) On the importance of intraspecific variability for the quantification of functional diversity. Oikos 121:116-126. https://doi.org/10.1111/j.16000706.2011.19672.x

Baraloto C, Hardy OJ, Paine CET et al. (2012) Using functional traits and phylogenetic trees to examine the assembly of tropical tree communities. Journal of Ecology 100(3): 690-701

Bernard-Verdier M, Flores O, Navas M-L, Garnier E (2013) Partitioning phylogenetic and functional diversity into alpha and beta components along an environmental gradient in a Mediterranean rangeland. J Veg Sci 24:877-889. https://doi.org/10.1111/jvs.12048

Blomberg SP, Garland T, Ives AR (2003). Testing for phylogenetic signal in comparative data: behavioral traits are more labile. Evolution, 57, 717-745. https://doi.org/10.1111/j.0014-3820.2003. tb00285.x

Cadotte M, Albert CH, Walker SC (2013) The ecology of differences: assessing community assembly with trait and evolutionary distances. Ecol Lett 16:1234-1244. https://doi.org/10.1111/ele.12161

Cadotte MW (2017) Functional traits explain ecosystem function through opposing mechanisms. Ecology Letters 20:989-996. https://doi.org/10.1111/ele.12796

Cadotte MW, Cavender-Bares J, Tilman D, Oakley TH (2009) Using Phylogenetic, Functional and Trait Diversity to Understand Patterns of Plant Community Productivity. PLoS ONE 4:e5695. https://doi.org/10.1371/journal.pone.0005695

Cappelatti L, Mauffrey ARL, Griffin JN (2019) Applying continuous functional traits to large brown macroalgae: variation across tidal emersion and wave exposure gradients. Mar Biol 166:145. https://doi.org/10.1007/s00227-019-3574-5

Darwin C (1859) On the origin of species by means of natural selection. John Murray, London.

de Bello F, Berg MP, Dias ATC, et al (2015) On the need for phylogenetic 'corrections' in functional trait-based approaches. Folia Geobot 50:349-357. https://doi.org/10.1007/s12224-015-9228-6

de Bello F, Carmona CP, Lepš J, Szaca-Kovats R, Partel M (2016) Functional diversity through the mean trait dissimilarity: resolving shortcomings with existing paradigms and algorithms. Oecologia 180 (4): 933-940. Doi: 10.1007/s00442-016-3546-0

de Bello F, Smilauer P, Diniz-Filho JAF et al. (2017) Decoupling phylogenetic and functional diversity to reveal hidden signals in community assembly. Methods Ecol Evol 8(10): 1200-1211. doi: 10.1111/2041-210X.12735

Dray S, Dufour A (2007). The ade4 Package: Implementing the Duality Diagram for Ecologists. Journal of Statistical Software 22(4), 1-20. doi: 10.18637/jss.v022.i04

10.18637/jss.v022.i04 (URL: https://doi.org/10.18637/jss.v022.i04).

Flynn DFB, Mirotchnick N, Jain M, et al (2011) Functional and phylogenetic diversity as predictors of biodiversity-ecosystem-function relationships. Ecology 92:1573-1581. https://doi.org/10.1890/101245.1 
Gallagher RV, Leishman MR (2012) A global analysis of trait variation and evolution in climbing plants. Journal of Biogeography 39(10):1757-1771

Gómez I, Huovinen P (2011) Morpho-functional patterns and zonation of South Chilean seaweeds: the importance of photosynthetic and bio-optical traits. Mar Ecol Prog Ser 422:77-91. https://doi.org/10.3354/meps08937

Gross N, Bagousse-Pinguet YL, Liancourt P, et al (2017) Functional trait diversity maximizes ecosystem multifunctionality. Nat Ecol Evol 1:0132. https://doi.org/10.1038/s41559-017-0132

Harmon LJ, Glor RE (2010) poor statistical performance of the mantel test in phylogenetic comparative analyses. Evolution. https://doi.org/10.1111/j.1558-5646.2010.00973.x

Isaac NJB, Turvey ST, Collen B, et al (2007) Mammals on the EDGE: Conservation Priorities Based on Threat and Phylogeny. PLoS ONE 2:e296. https://doi.org/10.1371/journal.pone.0000296

Jombart T, Dray S (2008) adephylo: exploratory analyses for the phylogenetic comparative method. Bioinformatics 26(15):1907-9. doi: 10.1093/bioinformatics/btq292

Kans J. Entrez Direct: E-utilities on the UNIX Command Line. 2013 Apr 23 [Updated 2019 Dec 16]. In: Entrez Programming Utilities Help [Internet]. Bethesda (MD): National Center for Biotechnology Information (US); 2010-. Available from: https://www.ncbi.nlm.nih.gov/books/NBK179288/

Katoh K, Standley DM, (2013) MAFFT Multiple Sequence Alignment Software Version 7: Improvements in Performance and Usability. Molecular Biology and Evolution 30(4): 772-780, https://doi.org/10.1093/molbev/mst010

Kumar S, Stecher G, Li M, Knyaz C, Tamura K (2018) MEGA X: Molecular Evolutionary Genetics Analysis across computing platforms. Molecular Biology and Evolution 35:1547-1549

Lee R (2018). Rhodophyta. In: Phycology (pp. 84-132). Cambridge: Cambridge University Press. doi:10.1017/9781316407219.008

Li D, Ives AR, Waller DM (2017) Can functional traits account for phylogenetic signal in community composition? New Phytol 214:607-618. https://doi.org/10.1111/nph.14397

Littler MM, Littler DS (1980) The Evolution of Thallus Form and Survival Strategies in Benthic Marine Macroalgae: Field and Laboratory Tests of a Functional Form Model. The American Naturalist 116:2544. https://doi.org/10.1086/283610

Liu H, Xu Q, He P, et al (2015) Strong phylogenetic signals and phylogenetic niche conservatism in ecophysiological traits across divergent lineages of Magnoliaceae. Sci Rep 5:12246. https://doi.org/10.1038/srep12246

Losos JB (2011) Seeing the Forest for the Trees: The Limitations of Phylogenies in Comparative Biology: (American Society of Naturalists Address). The American Naturalist 177:709-727. https://doi.org/10.1086/660020

Münkemüller T, Lavergne S, Bzeznik B, et al (2012) How to measure and test phylogenetic signal: How to measure and test phylogenetic signal. Methods in Ecology and Evolution 3:743-756. https://doi.org/10.1111/j.2041-210X.2012.00196.x

Pagel M (1999) Inferring the historical patterns of biological evolution. Nature 401:877-884. https://doi.org/10.1038/44766 
Paterno GB, Penone C, Werner GDA (2018) sensiPhy: An r-package for sensitivity analysis in phylogenetic comparative methods. Methods Ecol Evol 9(6): 1461-1467.

Pavoine S, Bonsall MB, Dupaix A, et al (2017) From phylogenetic to functional originality: Guide through indices and new developments. Ecological Indicators 82:196-205. https://doi.org/10.1016/j.ecolind.2017.06.056

Pavoine S, Ollier S, Dufour A-B (2005) Is the originality of a species measurable?: Originality of a species. Ecology Letters 8:579-586. https://doi.org/10.1111/j.1461-0248.2005.00752.x

Pavoine S (2020). adiv: Analysis of Diversity. $\mathrm{R}$ package version 2.0. https://CRAN.Rproject.org/package=adiv

Revel LJ (2011) phytools: an R package for phylogenetic comparative biology (and other things). Methods Ecol Evol 3(2):217-223.

Rios RS, Salgado-Luarte C, Gianoli E. (2014) Species divergence and phylogenetic variation of ecophysiological traits in lianas and trees. PLoS One. 2014;9(6):e99871. doi:10.1371/journal.pone.0099871

Siefert A, Violle C, Chalmandrier L, et al (2015) A global meta-analysis of the relative extent of intraspecific trait variation in plant communities. Ecology Letters 18:1406-1419. https://doi.org/10.1111/ele.12508

Steneck RS, Dethier MN (1994) A Functional Group Approach to the Structure of Algal-Dominated Communities. Oikos 69:476. https://doi.org/10.2307/3545860

Swenson NG (2019) Phylogenetic Ecology A History, Critique, and Remodeling. The University of Chicago Press

Taudiere A, Violle C (2016) cati: an R package using functional traits to detect and quantify multi-level community assembly processes. Ecography 39:699-708. https://doi.org/10.1111/ecog.01433

Wang R, Wang Q, Zhao N, Yu G, He N. (2017) Complex trait relationships between leaves and absorptive roots: Coordination in tissue $\mathrm{N}$ concentration but divergence in morphology. Ecol Evol. 7(8):2697-2705. doi: 10.1002/ece3.2895.

Wiener N (1923) Differential-Space. Studies in Applied Mathematics 2:131-174.

Webb CO (2000) Exploring the Phylogenetic Structure of Ecological Communities: An Example for Rain Forest Trees. The American Naturalist 156:145-155. https://doi.org/10.1086/303378

Webb CO, Ackerly DD, McPeek MA, Donoghue MJ (2002) Phylogenies and Community Ecology. Annu Rev Ecol Syst 33:475-505. https://doi.org/10.1146/annurev.ecolsys.33.010802.150448

Yoon HS et al. (2016) Rhodophyta. In: Archibald J. et al. (eds) Handbook of the Protists. Springer, Cham 


\section{List of appendices (given at the end of the thesis)}

Appendix 1. Figure S1. Biplot of the principal component analyses (PCA) of the three selected traits. Points are individual species. Smaller biplot shows trait associations to PC axes 1 and 3.

Appendix 2. Figure S2. Maximum likelihood tree of 45 species of red algae, indicating the bootstrap values per node.

Appendix 3. Table S2. Including measurement error in the estimation of phylogenetic signal (Blomberg's K) 


\section{Chapter 5}

\section{Functional diversity of seaweeds revisited: confronting traditional groups with quantitative traits}

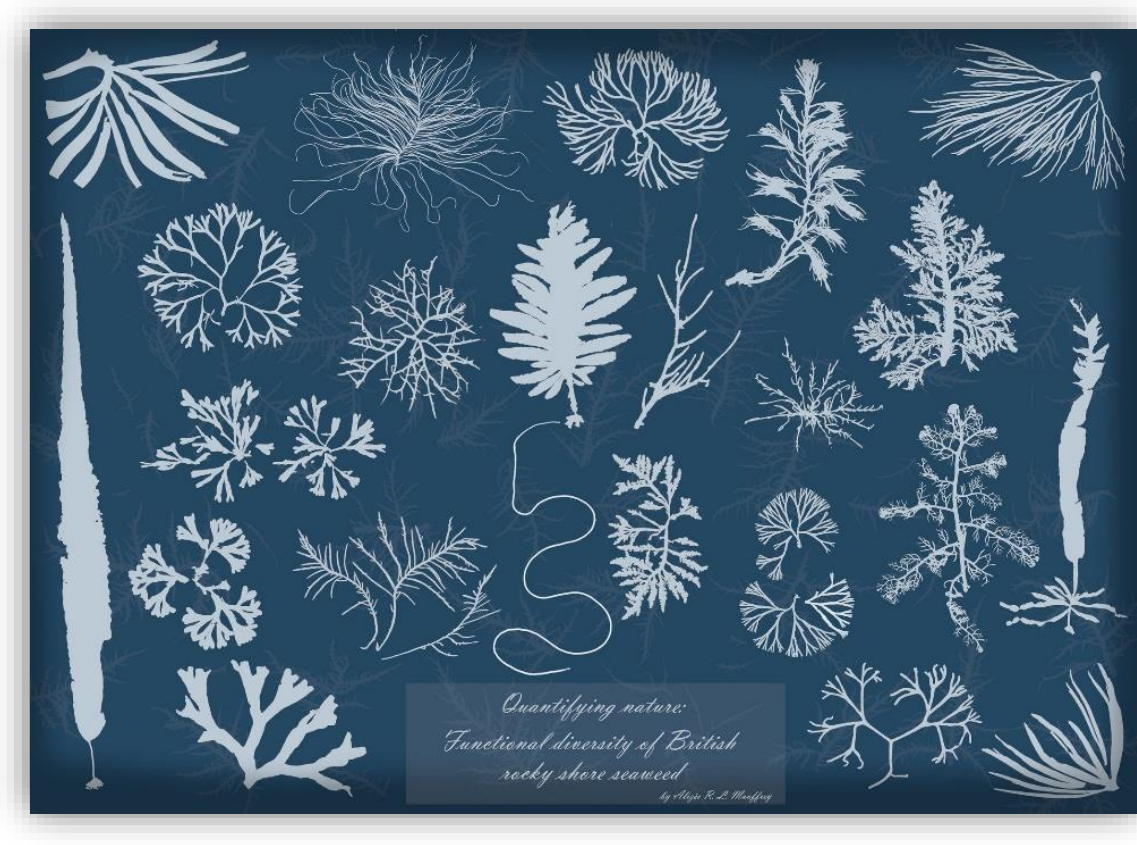

(C) Alizée Mauffrey

Disclaimer: This chapter was led by Alizée Mauffrey, with a co-autorship of John Griffin and Laura Cappelatti. It has been published at Journal of Ecology (doi: 10.1111/13652745.13460) 


\begin{abstract}
Macroalgal (seaweed) beds and forests fuel coastal ecosystems and are rapidly reorganising under global change, but quantifying their functional structure still relies on binning species into coarse groups on the assumption that they adequately capture relevant underlying traits. To interrogate this 'group gambit', we measured 12 traits relating to competitive dominance and resource economics across 95 macroalgal species collected from the UK and widespread on North-East Atlantic rocky shores. We assessed the amount of trait variation explained by commonly-used traditional groups - (i) two schemes based on gross morphology and anatomy and (ii) two categorisations of vertical space use - and examined species reclassification into emergent groups created from post hoc clustering of our dataset. We then offer an alternative, emergent grouping scheme of macroalgal functional diversity. (i) Morphology and anatomybased groups explained slightly more than a third of multivariate trait expression with considerable group overlap (i.e., low precision) and extensive mismatch with underlying trait expression (i.e., low accuracy). (ii) Categorisations of vertical space use accounted for about a quarter of multivariate trait expression with considerable group overlap. Nonetheless, turf species tended to display attributes of opportunistic forms. (iii) A nine-group emergent scheme provided a highly explanatory and parsimonious alternative to traditional functional groupings. Synthesis: Our analysis using a comprehensive dataset of directly measured functional traits revealed a general mismatch between traditional groups and underlying traits, highlighting the deficiencies of the group gambit in macroalgae. While existing grouping schemes may allow first order approximations, they risk considerable loss of information at the trait and, potentially, ecosystem levels. Instead, we call for further development of a trait-based approach to macroalgal functional ecology to capture unfolding community and ecosystem changes with greater accuracy and generality.
\end{abstract}

Keywords: Canopy; emergent groups; functional diversity; functional traits; Littler and Littler; seaweed; Steneck and Dethier; turfs 


\section{Introduction}

Macroalgae (seaweed) form extensive and productive beds in the coastal environment worldwide (Hurd et al. 2014). These phylogenetically and functionally diverse species fuel coastal ecosystems and provide a range of ecosystem services including food and natural products (Griffiths et al. 2016; McLachlan 1985), habitat for commercially important fish (Miranda et al. 2017), and blue carbon sequestration (Chung et al. 2011). Yet under accelerating anthropogenic forcing, macroalgal beds are experiencing major changes in community composition as, for instance, kelp retreat towards the poles while warmer-water and non-native species expand (Harley et al. 2012; Pessarrodona et al. 2019). Such community restructuring - and its ecosystem ramifications - is mediated by species' functional traits (Lavorel and Garnier, 2002; Suding et al. 2008; Trugman et al. 2019).

Traits hold the promise of more predictive ecology that goes beyond case studies of species or taxonomic groups towards a more general understanding (McGill et al. 2006). Functional traits are morphological, physiological or phenological characteristics of individuals that influence their response to the environment and/or effect on ecosystem properties and/or services (Díaz et al. 2013). Functional traits reflect adaptive strategies and underlying physiological trade-offs. In vascular plants, for example, functional trait variation largely reflects competitive dominance (plant size) and the leaf economics spectrum, which emerges from physiological trade-offs between structural integrity and growth potential (Díaz et al., 2016). As an alternative to direct use of functional trait values, so-called 'emergent' groups have been built through post hoc clustering of functional trait data on the premise that they represent trait variability more closely than traditional grouping approaches (Lavorel et al. 1997). In turn, functional traits or emergent groups explain species' contributions to ecosystem functions and services. For instance, plant specific leaf area and leaf nitrogen 
content have been linked to primary productivity and decomposition (Reich 2014; Shipley et al. 2006).

However, ecologists studying macroalgal beds and forests rarely directly measure functional traits and instead typically assign species to long-established form-based groups. Littler and Littler (1980) first proposed the 'functional-form model', categorising species into morpho-functional groups based on gross morphology and anatomical features. Over a decade later, Steneck and Dethier (1994) proposed a less subjective grouping scheme based on branching pattern, anatomy and degree of cortication. Macroalgal ecologists have also employed broad categorisations of vertical space use, such as the binary canopy vs. turf scheme, to infer ecosystem consequences of changing assemblage structure, particularly in light of the global rise of turfs over canopy-forming macroalgae (Feehan et al. 2019; FilbeeDexter and Wernberg 2018). Traditional grouping methods remain highly influential: for instance, Steneck and Dethier's paper has been cited over 1000 times, with 60 citations in 2018 alone (Google Scholar, accessed October 2019).

Using functional groups is more practical and less time consuming than carrying out direct trait measurements, but grouping carries implicit assumptions. Grouping approaches overlook within-group variability (Petchey and Gaston, 2006), can lead to subjective species allocation (Chapin et al. 1996; Díaz and Cabido 2001; Phillips et al. 1997), and disregard relative influences of specific traits and intraspecific variability (Hanisak et al. 1988; Padilla and Allen 2000; Violle et al. 2012). Perhaps most importantly from the ecosystem perspective, it is assumed that macroalgal groups capture relevant suites of functional traits and, in turn, ecological processes. For instance, turf and sheet-like species are expected to possess a high relative surface area, allowing fast nutrient acquisition and high productivity (Littler and Littler 1980; Steneck and Dethier 1994) while canopy-forming species typically display high 
structural integrity and complexity, thereby sustaining rich epibiota (Filbee-Dexter and Wernberg 2018; Teagle et al. 2017). Unlike among plant functional types (Thomas et al., 2019), the assumption that traditional macroalgal functional grouping schemes capture underlying interspecific trait variation remains untested. We call this 'the group gambit' (following the phylogenetic hypothesis in Mazel et al. 2018).

Here, we provide the first comprehensive test of the group gambit in macroalgae. Using direct measurements of traits related to two major aspects of ecological variation, competitive dominance and resource economics, we test the assumption that traditional grouping approaches accurately capture underlying trait expression across four commonly-used schemes: the form- (i.e., morphology- and anatomy-) based grouping approaches of Littler and Littler (1) and Steneck and Dethier (2), as well as two categorisations of macroalgal vertical space use (i.e., stature), the binary canopy vs. turf (3) and a three-level scheme adapted from Arenas, Sánchez, Hawkins, and Jenkins $(2006 ; 4)$. To do so, we quantify the extent of trait variation explained by each traditional grouping scheme and assess the accuracy of traditional groups by examining post hoc group reworking (i.e. species reclassification from traditional to emergent groupings). A strong correspondence between groups and the underlying functional traits would support their continued application and bolster ecological interpretation. However, substantial mismatch between groups and traits - as well as reclassification of species into emergent groups - would indicate a loss of information and underline the potential gains offered by direct trait measurements. Our study reveals the limitations of traditional grouping schemes and provides screened trait values as well as an alternative nine-group emergent scheme as a platform for further development of trait-based macroalgal ecology. 


\section{Materials and methods}

\section{Sampling}

We measured eleven continuous and one categorical functional traits (Table 1) at the individual level across 95 erect intertidal macroalgal species, which spanned a great variety of form and function and hence, traditional functional groups. Samples were collected from twelve rocky shores in the UK ranging from very sheltered to very exposed: six sites in South Wales, four sites in Orkney (Scotland) and two sites in Cornwall (England). The collected species are commonly found on North-East Atlantic rocky shores (Ar Gall et al. 2016; Araújo et al. 2006; Martínez et al. 2012; Martins et al. 2007), and include species restricted to the region ( $25 \%$ of species), more broadly distributed across multiple temperate regions $(\sim 35 \%)$, as well as cosmopolitan and non-native species ( 40\%). Sampling took place from May to September 2013 and 2015-2018. We collected an average of 6 replicates per species, ranging from 1 to 45 (mode and median =6, S.D. $=7.55)$. Such a large difference in replication was due to the rarity of some species and to our efforts in sampling abundant species across several sites to better capture natural variability. Replicates were sampled more than $2 \mathrm{~m}$ apart. Whenever possible, a replicate was made up of a single individual. However, when individuals were too small for the trait measurements, a sufficient quantity was collected for each replicate by pooling several individuals or tufts. Whenever distinguishing between individuals was not possible (e.g., for turfs), the samples were collected by isolating tufts. Replicates within species were sampled from a variety of microhabitats to better reflect natural variability, but belonged to the same life stage (e.g., the Trailliella intricata stage of Bonnemaisonia hamifera). Samples were kept in seawater in a cooler until brought back to the laboratory. They were then either screened fresh or frozen at $-18^{\circ} \mathrm{C}$ until processed. 


\section{Trait screening}

The functional traits measured are hypothesised to capture two fundamental aspects of primary producer variability, (1) the economics spectrum and (2) competitive dominance. We consider multiple indicators (or 'functional markers' sensu Garnier et al. 2004) to provide a more integrated estimation of ecological strategy and function. Here, we briefly summarise the ecological significance of the traits with regard to photosynthesis, structural integrity, space use and complexity (Table 1). The suite of economics-related traits indicates the relative investment in resource acquisition versus resistance to (a)biotic stress and therefore resource conservation, tying in with the $r$ - ('fast return') to $K$ - ('slow-return') selection continuum (Pianka (1970). Slow-return primary producers tend to display long lifespans, low maximum photosynthesis and productivity, reduced palatability, and slow decomposition (Littler and Littler 1980; Smart et al. 2017; Wright et al. 2004). Traits $a$-g relate to photosynthesis and/or structural integrity, and hence, position on the economics spectrum: Thallus Dry Matter Content (TDMC; a) is the ratio between dry and wet mass and represents the proportion of structural compounds and water-filled - and therefore mainly photosynthetically active tissues (Elger and Willby 2003; Littler and Littler 1981; Schonbeck and Norton 1979). Thickness (b) also increases with the amount of structural tissue, providing resistance to physical stress and herbivore grazing (Cappelatti et al. 2019; Littler and Littler 1980; Little et al. 1983); Carbon (C) content (c) and its ratio (C:N, d) with Nitrogen (N) content (e) more directly quantify recalcitrant structural compounds relative to N-rich photosynthetically-active tissues (Cornelissen et al. 2003; Weykam et al. 1996). Analogously to Specific Leaf Area (Wilson et al. 1999), Specific Thallus Area (STA; f), obtained by dividing surface area by dry mass, captures light- and nutrient- absorbing surfaces and increases with the extent of low density, water-filled, photosynthetically-active tissues relative to recalcitrant, structural compounds (Littler and Littler 1980). Finally, because macroalgae absorb nutrients through the 
blades, the surface-area-to-volume ratio, or SA:V $(\mathrm{g})$, is associated with nutrient acquisition (Littler and Littler 1980).

Traits $h-l$ are hypothesised to relate to space use and complexity, and hence, competitive dominance. Plant height is a major determinant of competitive dominance (Díaz et al. 2016). Its macroalgal analogue, maximum length (h), and by extension aspect ratio (i), or the ratio between maximum length and width, relate to the ability of macroalgae to outcompete surrounding individuals by taking the position of canopy and emerges from a trade-off between light capture and structural integrity (Carpenter 1990; Littler and Littler 1980). The presence of pneumatocysts (i.e., air bladders; $j$ ) is another important predictor of macroalgal competitive dominance through canopy occupancy (Dromgoole 1981). Branching order (k), or the degree of branching of a thallus, and the surface-area-to-perimeter ratio (SA:P; 1) relate to threedimensional complexity and resource acquisition, and hence, both competitive dominance and economics (Steneck and Dethier 1994; Veiga et al. 2014). High complexity allows individuals to maximise light exposure (Stewart and Carpenter 2003), provides greater nutrient and gas exchange, delays desiccation at low tide (Hay 1981; Padilla 1984; Taylor and Hay 1984) and reduces the impact of herbivory (Padilla 1984), but increases drag (Starko et al. 2015). We measured both traits at the whole individual level to capture the complexity of the whole thallus, since all thallus parts, from holdfast to fronds, are important habitats for epibiota and nekton (Teagle et al. 2017).

Large or structurally complex individuals were subsampled, ensuring that all thallus parts were included at representative proportions. Trait measurements are described in Chapter 1. 
Table 1. Functional traits and their physiological significance. "SLOW" and "FAST" indicate whether increasing trait values place macroalgae on the so-called slow and fast ends of the resource utilisation spectrum, respectively. "COMPETITIVE" indicates that increasing trait values entail increasing competitive dominance; a question mark indicates that the functional trait may not relate to any end of the competitive dominance spectrum in a straightforward way. References are given in superscript and are the following: 1. Carpenter (1990); 2. Cornelissen et al. (2003); 3. Dromgoole (1981); 4. Elger and Willby (2003); 5. Hay (1981); 6. Littler and Littler (1980); 7. Reich et al. (1999); 8. Roderick et al. (2000); 9. Steneck and Dethier (1994); 10. Taylor and Hay (1984); 11. Veiga et al. (2014); 12. Vile et al. (2005); 13. Weykam et al. (1996).

\begin{tabular}{|c|c|c|c|c|}
\hline $\begin{array}{c}\text { Functional } \\
\text { trait }\end{array}$ & Equation & Unit & Part & $\begin{array}{c}\text { Physiological and ecological significance; } \\
\text { weight (w) for PCoA }\end{array}$ \\
\hline $\begin{array}{l}\text { Thallus Dry } \\
\text { Matter Content } \\
\text { (TDMC) }\end{array}$ & $\begin{array}{l}\text { Dry mass. } \\
\text { fresh mass }{ }^{-1}\end{array}$ & None & Whole & $\begin{array}{l}\text { Structural versus photosynthetic tissues; } \\
\text { structural integrity }(\mathrm{SLOW})^{2 ; 4} ; \mathrm{w}=0.33\end{array}$ \\
\hline Thickness & $\mathrm{NA}$ & $\mathrm{mm}$ & Fronds & Structural integrity $(\mathrm{SLOW})^{7 ; 8 ; 12} ; \mathrm{w}=0.25$ \\
\hline $\begin{array}{l}\text { Maximum } \\
\text { (Max.) length }\end{array}$ & NA & $\mathrm{cm}$ & Whole & $\begin{array}{l}\text { Competition for light }(\text { COMPETITIVE })^{1 ; 6} \\
w=0.33\end{array}$ \\
\hline Aspect ratio & $\begin{array}{l}\text { Max. length. } \\
\text { Max. width }\end{array}$ & None & Whole & $\begin{array}{l}\text { Competition for light versus substrate use, } \\
\text { i.e., vertical space use versus horizontal } \\
(?)^{1 ; 6} ; w=0.33\end{array}$ \\
\hline $\begin{array}{l}\text { Specific Thallus } \\
\text { Area (STA) }\end{array}$ & ${ }_{1}^{\text {SA.dry mass }}{ }^{-}$ & $\mathrm{mm}^{2} \mathrm{~g}^{-1}$ & Fronds & $\begin{array}{l}\text { Photosynthetic versus structural tissues; } \\
\text { light capture (FAST) } ; \mathrm{w}=0.25\end{array}$ \\
\hline $\begin{array}{l}\text { Surface Area to } \\
\text { Volume (SA:V) }\end{array}$ & SA.volume ${ }^{-1}$ & $\mathrm{~mm}_{1}^{2} \mathrm{~mL}^{-}$ & Fronds & $\begin{array}{l}\text { Nutrient-absorbing versus structural tissues; } \\
\text { nutrient capture }(\text { FAST })^{6} ; \mathrm{w}=0.25\end{array}$ \\
\hline $\begin{array}{l}\text { Surface Area to } \\
\text { Perimeter } \\
\text { (SA:P) }\end{array}$ & SA.P. $P^{-1}$ & None & Whole & $\begin{array}{l}\text { Retention of resources (SLOW); structural } \\
\text { integrity but resistance to water movement, } \\
\text { encouraging breakage }(?)^{11} ; \mathrm{w}=0.5\end{array}$ \\
\hline Branching order & NA & None & Whole & $\begin{array}{l}\text { Retention of resources (SLOW); } \\
\text { desiccation and herbivory resistance } \\
\text { (COMPETITIVE); structural fragility but } \\
\text { less resistance to water movement, } \\
\text { preventing breakage }(?)^{5 ; 9 ; 10} ; \mathrm{w}=0.5\end{array}$ \\
\hline $\begin{array}{l}\text { Pneumatocysts } \\
\text { (YES/NO) }\end{array}$ & NA & None & Whole & Light capture (COMPETITIVE) $)^{3} ; \mathrm{w}=0.33$ \\
\hline $\begin{array}{l}\text { Carbon }(\mathrm{C}) \\
\text { content }\end{array}$ & NA & $\%$ & Whole & Structural integrity $(\mathrm{SLOW})^{2 ; 13} ; \mathrm{w}=0.33$ \\
\hline $\begin{array}{l}\text { Nitrogen }(\mathrm{N}) \\
\text { content }\end{array}$ & NA & $\%$ & Whole & Light capture $(\mathrm{FAST})^{2 ; 13} ; \mathrm{w}=0.25$ \\
\hline $\begin{array}{l}\text { Carbon to } \\
\text { Nitrogen }(\mathrm{C}: \mathrm{N})\end{array}$ & C. $\mathrm{N}^{-1}$ & None & Whole & $\begin{array}{l}\text { Structural versus photosynthetic tissues } \\
(\mathrm{SLOW})^{2 ; 13} ; \mathrm{w}=0.33\end{array}$ \\
\hline
\end{tabular}




\section{Categorisation of species into functional groups}

We allocated species to the groups defined by Littler and Littler as well as Steneck and Dethier based on a review of the literature. The species we screened belonged to five traditional groups: 'filamentous', 'sheet', 'coarsely branched', 'thick leathery' and 'articulate calcareous' for Littler and Littler's functional-form model, and five groups defined by Steneck and Dethier (1994), 'filamentous (S)', 'foliose', 'corticated', 'leathery' and 'articulated calcareous', in increasing order of cortication. Although both schemes contain groups with similar or identical names, they were originally defined using different approaches and are not assumed a priori to be analogous. We used two common categorisations of vertical space use: the binary canopy vs. turf scheme and a three-level canopy/subcanopy/turf scheme adapted from Arenas et al. (2006). Turfs were considered macroalgae with little to no three-dimensional structure (compared with kelp and other canopy-forming macroalgae) that form a dense layer of fine filaments, branches, or plumes on the substratum (Filbee-Dexter and Wernberg, 2018). This broad definition of turf macroalgae allowed categorisation of all species within our study. Vertical structure in the water column is somewhat community-dependent, so we categorised species into the three-level scheme based on what we judged was the most common scenario on the rocky shores screened.

\section{Data analysis}

We performed all analyses in R 3.5.3 (R Core Team, 2019) and plotted graphical results using ggplot2 (Wickham 2009) and ggpubr (Kassambara 2019). Prior to running analyses on species-level traits, a linear model confirmed that traits varied strongly at the species level; across continuous traits, species identity explained $82.3 \pm 7.6 \%$ (mean \pm S.D.) of individuallevel variance. Species trait averages were transformed to bring their distribution as close to 
normality as possible and to reduce differences in scale across traits. To examine the distribution of individual traits among traditional groups, smoothed density curves for each of the eleven continuous functional traits studied were drawn. To assess whether groups significantly differed from each other, we ran pairwise Wilcoxon rank sum tests on every group pair.

We imputed the four percent of average trait values that were missing from the dataset (function 'mice' in eponymous R package; (van Buuren and Groothuis-Oudshoorn 2011) to then reduce the dimensionality of the data using a Principal Coordinate Analysis (PCoA; function cmdscale in built-in R package 'stats'). We favoured a PCoA over a Principal Component Analysis because it allowed us to include pneumatocyst presence. The PCoA was run on a weighted Gower distance matrix (function daisy in cluster; Maechler et al. 2019), with equal weighting to traits associated with photosynthesis, structural integrity, space use, and complexity. In other words, an eco-physiological aspect (e.g. photosynthesis) was not overrepresented by having more traits than another aspect; we adjusted the contribution of traits so that each aspect added to 1 (Table 1). To assess the strength of association between the principal coordinates and each trait, we ran linear regressions between the scores of the first two PCoA axes and the twelve traits studied.

In order to assess how precisely traditional macroalgal grouping schemes capture underlying trait variation, we tested how much of the original trait variance (Gower distance matrix) they explained using PERMANOVAs (function adonis in vegan; Oksanen et al., 2019) We also compared the traditional groups' parsimony in explaining such trait variance with Akaike's Information Criterion (AIC; manually calculated) for each PERMANOVA model. We assessed the accuracy of the groups established by Littler and Littler's and Steneck and Dethier's (both five-group) schemes by comparing their species composition to five-group post 
hoc groupings emerging from the trait dataset. Extensive species reclassification - i.e., group reworking - would suggest substantial mismatch between traditional groups and underlying trait variation and hence, rather low accuracy of traditional groups. We created emergent groups from the weighted Gower matrix using $k$-medoids clustering ( $k$-medoids), a top-down clustering approach whereby species are assigned to a chosen number of groups based on multivariate distance from group medoids, making it rather robust to noise and outliers (Reynolds et al. (2006); using pam in package cluster; Maechler et al. 2019).

Clustering to generate emergent groups also provided a tool for generating a more functionally informative alternative to traditional functional groupings. To allow the data to inform not only the assignment of species to groups but also the number of groups, we used $k$ medoids (as described above) while allowing an increasing number of groups (from five upwards), searching for an emergent grouping scheme that maximised overall explanatory power and parsimony while maintaining statistically significant differences $(P<0.05)$ between all pairs of groups. Finally, to evaluate the robustness of the resulting grouping scheme to intraspecific trait variability, we assessed how randomly correcting the trait dataset with highest and lowest standard error (S.E.) influenced the explanatory power of the emergent grouping scheme. To do so, we computed the explanatory power $\left(R^{2}\right.$, based on PERMANOVA) of the emergent grouping scheme across 999 iterations while correcting randomly-selected thirds of species-level trait means with +1 S.E, - 1 S.E., and no correction.

\section{Results}

\section{Distributions of individual traits}

For both form-based grouping approaches, species-level trait distributions were generally not unimodal and were right-skewed, suggesting that their groups captured underlying trait variation with limited accuracy (Fig. 1 and 2). Under both schemes, group 
overlap was extensive across traits; from a possible 55 cases ( 11 continuous traits $\mathrm{x} 5$ groups), there were only 7 instances where a group was different from all others (pairwise Wilcoxon rank sum test; $P<0.05)$. None of the form-related groups were significantly different from all others for thickness, aspect ratio, branching order, SA:P, or C:N (pairwise Wilcoxon rank sum test; $P>0.05)$. However, under both schemes, there were differences between roughly half of all possible group pairs (pairwise Wilcoxon rank sum test; $P<0.05$ ), reflecting the position of groups along the continuum of trait variability (Fig. 1 and 2). Overall, '(thick) leathery' and 'articulate(d) calcareous' were the two most distinct functional groups (Figs 1, 2). 


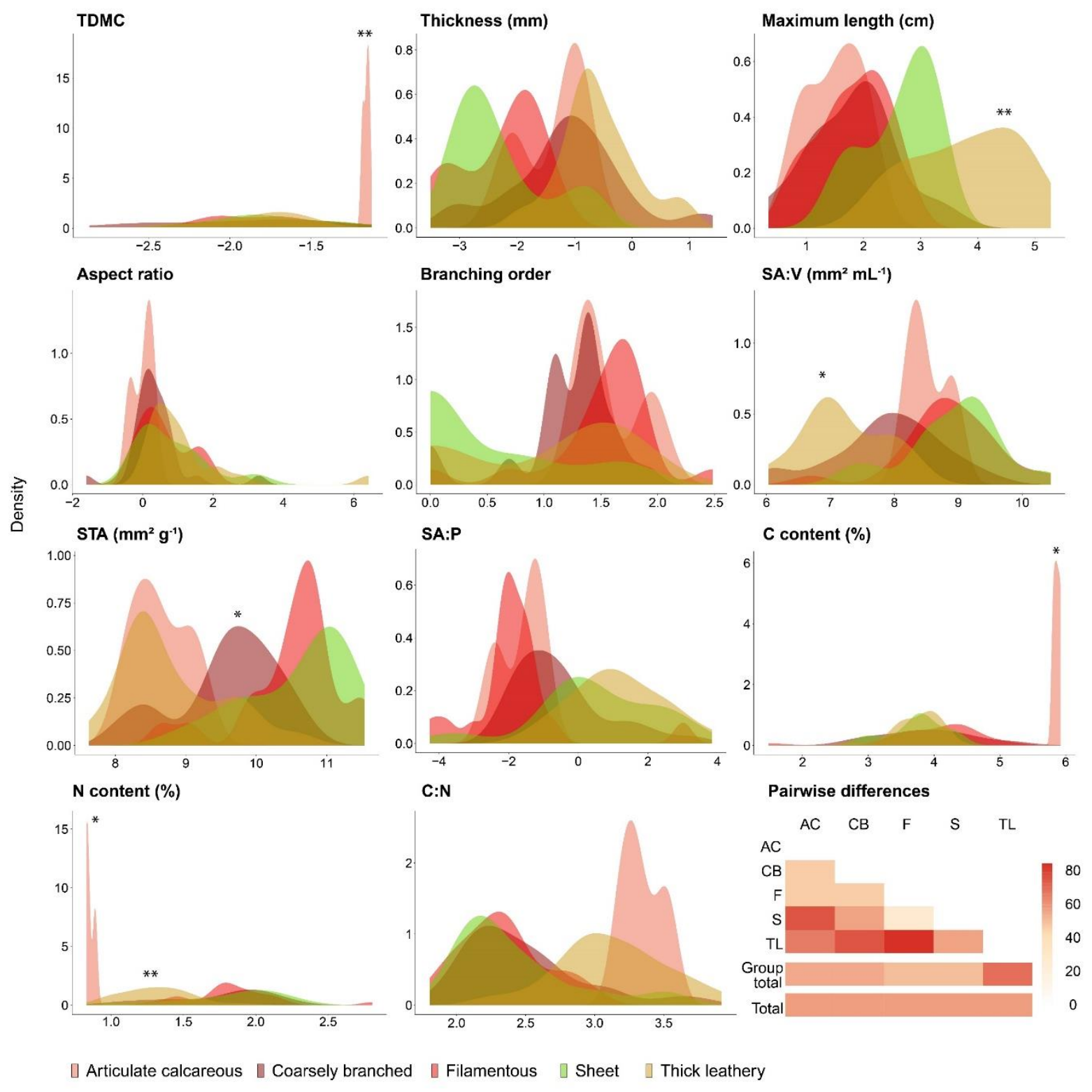

Figure 1. Distribution of species-level traits among Littler and Littler's groups. Values of the 11 continuous functional traits are transformed species-level means across the 95 macroalgal species screened. Groups that are significantly different from all others are marked by asterisks (pairwise Wilcoxon rank sum test; '*': $P<0.05$, '**': $P<0.01$; lowest common $P$ is shown). Heatmap (bottom right) shows the proportion of significant differences among pairwise comparisons for each group (group total) and overall (total; ' $\mathrm{AC}$ ' is for articulated calcareous, ' $\mathrm{CB}$ ' for coarsely branched, ' $\mathrm{F}$ ' for filamentous, ' $\mathrm{S}$ ' for sheet, and ' $\mathrm{TL}$ ' for thick leathery). 


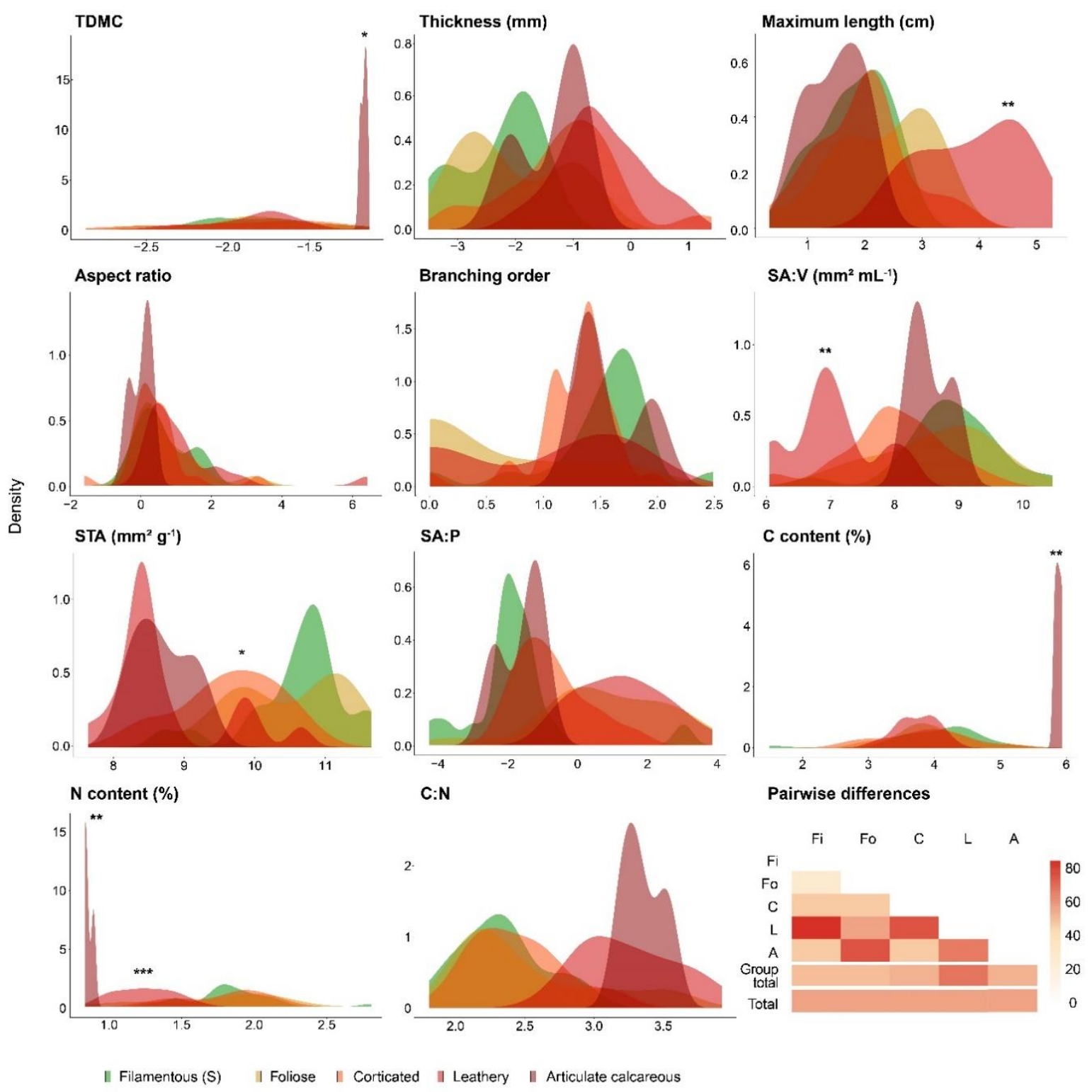

Figure 2. Distribution of species-level traits among Steneck and Dethier's groups. Values of the 11 continuous functional traits are transformed species-level means across the 95 macroalgal species screened. Groups that are significantly different from all others are marked by asterisks (pairwise Wilcoxon rank sum test; '*': $P<0.05$, '**': $P<0.01$, '***': $P<0.001$; lowest common $P$ is shown). Heatmap (bottom right) shows the proportion of significant differences among pairwise comparisons for each group (group total) and overall (total; 'Fi' stands for filamentous (S), 'Fo' for foliose, ' $\mathrm{C}$ ' for corticated, ' $\mathrm{L}$ ' for leathery, and ' $\mathrm{A}$ ' for articulated calcareous). 
Both categorisations of macroalgal stature (i.e., vertical structure in the water column) explained significant differences in most of the traits' distributions (pairwise Wilcoxon rank sum test, $P<0.05$; Fig. 3; see Fig. S1 for the three-level scheme). Specifically, in the canopy vs. turf scheme, canopy species had greater thickness, maximum length, aspect ratio and C:N, while turf species had greater SA:V, STA, C and N values. In the three-level scheme, groups differed in thickness, maximum length, SA:V and STA (pairwise Wilcoxon rank sum test, $P<$ 0.05). Canopy species also had lower values than turf for SA:P and $\mathrm{N}$, and greater values for C:N. Notwithstanding these differences, stature-based groups spanned wide ranges of trait values and, in most cases, displayed a high degree of overlap, suggesting limited precision. The prevalence of significant differences between groups, compared to the two form-based approaches, should be interpreted in light of the higher within-group sample sizes. 


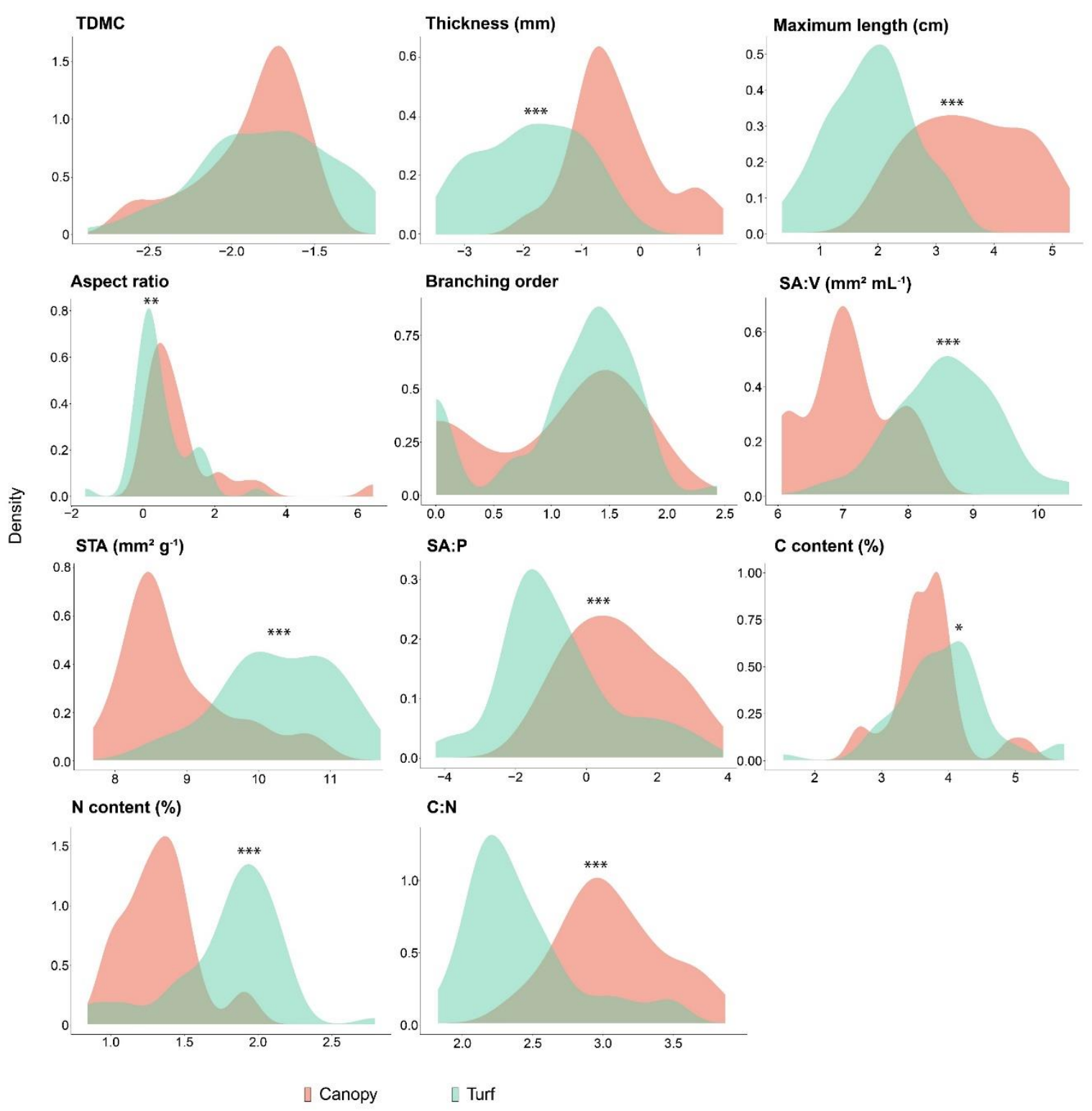

Figure 3. Distribution of species-level traits among a common binary categorisation of vertical space use. Values of the 11 continuous functional traits are transformed species-level means across the 95 macroalgal species screened. Groups that are significantly different from all others are marked by asterisks (pairwise Wilcoxon rank sum test; '*': $P<0.05$, '**': $P<$ 0.01 , '***': $P<0.001$; lowest common $P$ is shown). 


\section{Distributions in multivariate trait space}

Many of the functional traits were entrained along the first PCoA axis. Species positioned further along that axis had lower maximum length, $\mathrm{C}: \mathrm{N}$ ratio and thickness, and higher SA:V, STA and N content (Figs 4, 5). These trait attributes correspond to a less (light-) competitive but a faster (resource acquisitive) strategy. Meanwhile, branching order was clearly most strongly associated with the second PCoA axis. The first two principal coordinates accounted for $49.9 \%$ of inertia in the distance matrix, while the third (not shown) accounted for an additional $13 \%$.

Both Littler and Littler's and Steneck and Dethier's groups explained about $37 \%$ of multivariate species-level trait expression (Fig. 5; five-cluster PERMANOVA, $R^{2}=0.37, P<$ 0.001) with a similar level of parsimony (AIC $=-367.01$ for Littler and Littler's scheme; AIC $=-366.99$ for Steneck and Dethier's scheme; $\Delta \mathrm{AIC}=0.02$ ) but considerable group overlap in trait space (i.e., rather low precision). Littler and Littler's and Steneck and Dethier's groups were in roughly the same locations of the trait space (Fig. 5). Species categorised under (thick) leathery displayed a wide array of trait values and were split between those characterised by high SA:P and maximum length on the one hand, and high thickness and C:N on the other (Figs 1, 2, 4, 5). Calcareous species displayed high $\mathrm{C}$ content and branching order, and stood out from the rest of the species. Coarsely branched/corticated species were scattered across most of the trait space. The filamentous groups mainly gathered species with high SA:V and branching order. Finally, the 'sheet'/'foliose' group principally represented species with low C:N and high STA (Figs 1, 2, 4, 5).

Classifications of vertical space use explained the least multivariate trait expression and were the least parsimonious of all traditional schemes $(\mathrm{AIC}=-357.94$ for canopy/turf and AIC $=-356.84$ for canopy/subcanopy/turf, each representing a $\Delta \mathrm{AIC}$ of 9.07 and 10.17 versus Littler 
and Littler's scheme; Fig. 5. The binary canopy vs. turf scheme explained about $26 \%$ of multivariate trait expression (two-cluster PERMANOVA, $R^{2}=0.26, P<0.001$ ) and - despite containing an extra group - the three-level scheme explained roughly the same amount of trait variation, ca. $27 \%$ (three-cluster PERMANOVA, $R^{2}=0.27, P<0.001$ ).

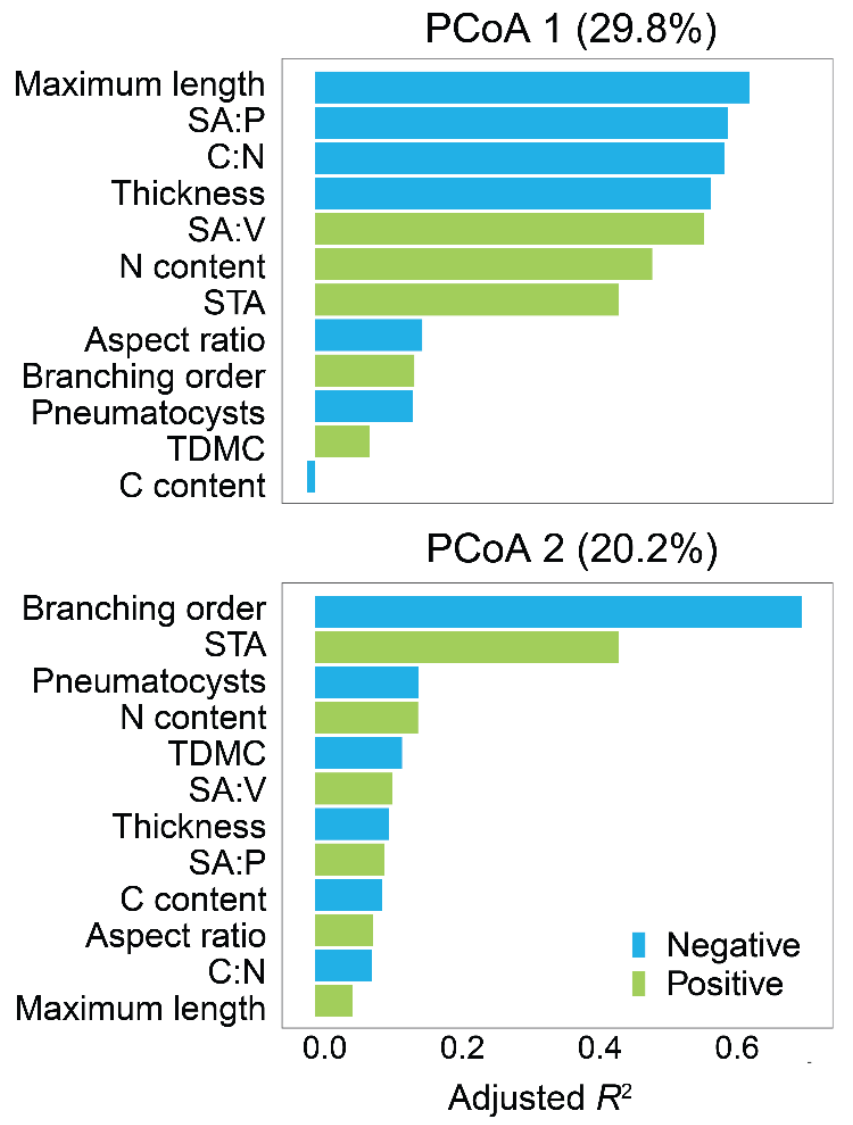

Figure 4. Associations between functional traits and principal coordinate axes. Associations were assessed by a series of linear regressions based on the sample size of 95 species. The strength and direction of trait-axis association are indicated, respectively, by the coefficients of determination $\left(R^{2}\right)$ and colour of the bars. Proportion of inertia accounted for by each axis is given in parenthesis. 

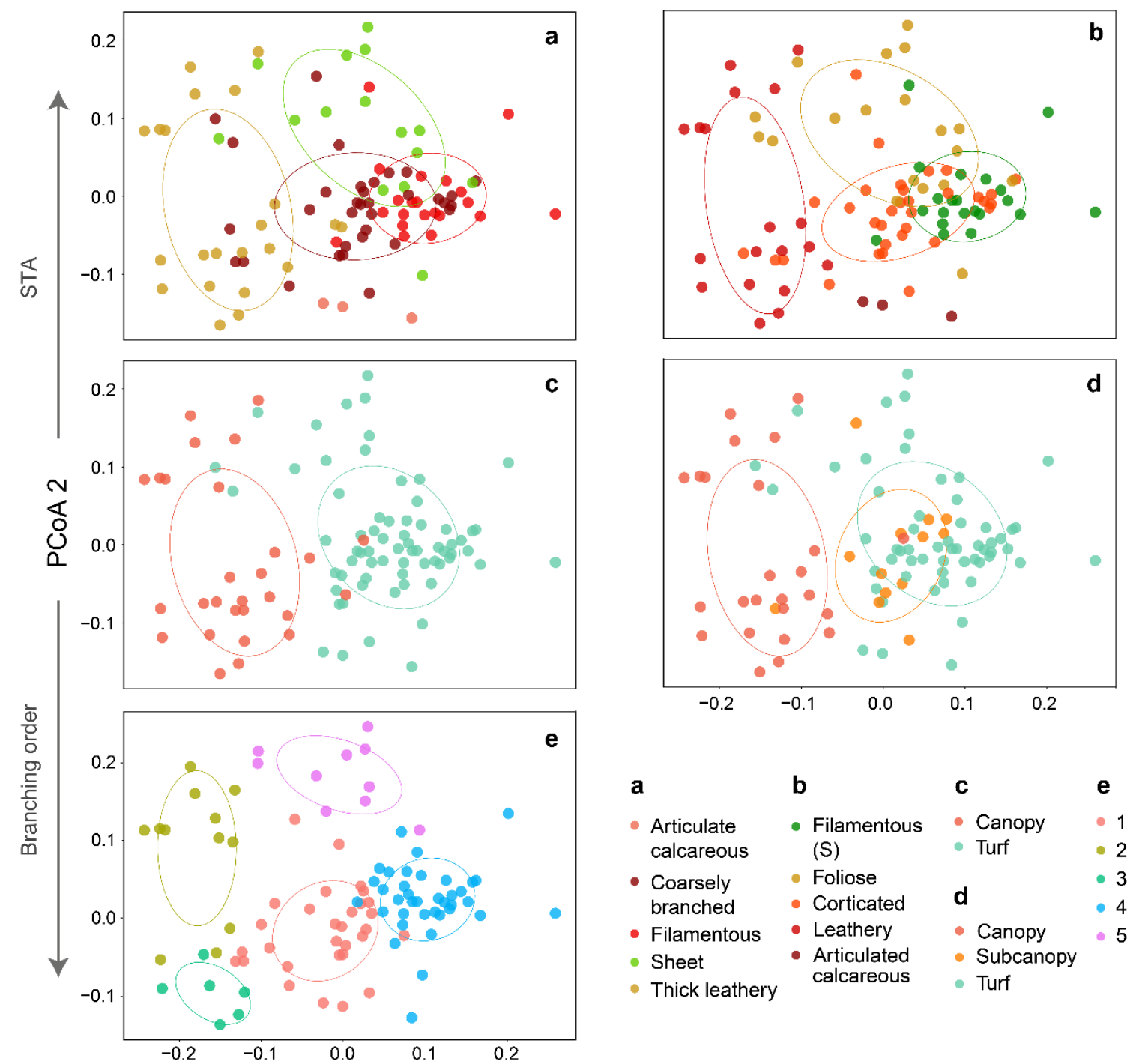

- Articulate calcareous

- Coarsely branched

- Filamentous

- Sheet

- Thick leathery

b

- Filamentous (S)

- Foliose

- Corticated

- Leathery

- Articulated calcareous c

- Canopy

- Turf

d

- Canopy

- Subcanopy

- Turf

Figure 5. Distribution of functional grouping schemes in macroalgal trait space. Group distribution in macroalgal functional trait space as yielded by the first two axes of a Principal Coordinate Analysis (PCoA) is given for: (a) Littler and Littler's 'functional-form' model (ordered alphabetically), (b) Steneck and Dethier's scheme (ordered by degree of cortication), (c) canopy vs. turf, (d) canopy/subcanopy/turf, and (e) emergent groups yielded by post hoc clustering of the species using the divisive $k$-medoids method. Confidence ellipses (50\%) are represented, assuming a multivariate normal distribution. Arrows indicate most strongly related functional traits to each PCoA axis (trait-axis relationships are given in Fig. 4). 


\section{Reclassification across grouping approaches}

To evaluate how species are classified under different approaches (including emergent groups), the group membership of individual species can be traced across the grouping schemes (Fig. 6). Despite the less subjective basis of Steneck and Dethier's scheme, largely the same sets of species remained grouped together compared to Littler and Littler's earlier scheme. Correspondences were evident between groups: the 'filamentous' group of Littler and Littler's model corresponded to 'filamentous (S)' in Steneck and Dethier's scheme, 'sheet' to 'foliose', 'coarsely branched' to 'corticated', 'thick leathery' to 'leathery', and 'articulate calcareous' to 'articulated calcareous'. All of the mismatches in species allocation between the two schemes were due to Littler and Littler's groups 'coarsely branched' and 'thick leathery' being reclassified by Steneck and Dethier's approach (Fig. 6). The addition of an extra category to the canopy vs. turf scheme, to form canopy/subcanopy/turf, led to the reclassification of larger turf species into the subcanopy group (11\% of all species reclassified). These reclassified species were primarily coarsely branched under Littler and Littler's scheme.

To assess whether traditional groupings schemes accurately capture underlying trait expression, we examined species reclassification - i.e., group reworking - from five-group traditional to emergent groupings. Most species were vastly reworked in their group allocation, with only a few tight nuclei of species left unchanged. Notably, (thick) leathery species became split into two different clusters (Fig. 5 and 6). The first cluster, emergent group 2, corresponded to species typically displaying high maximum length and SA:P. The second cluster, emergent group 3, mostly represented species with high C:N and thickness. Most species belonging to the much spread out 'coarsely branched' and the corresponding 'corticated' groups were reallocated across all emergent groups, leaving a tight nucleus of species unchanged (emergent group 1; Fig. 5 and 6). Filamentous species tended to be grouped together regardless of the 
clustering approach (emergent group 4), corresponding mainly to high-SA:V species. The low degree of overlap between traditional and trait-based, emergent functional groups reveals substantial mismatch between traditional groups and macroalgal trait values and underlines the low functional accuracy of traditional schemes. This suggests that current grouping approaches are far from optimal solutions to capture species' dispersion in trait space, while trait-based, post hoc emergent groupings have the potential to better capture macroalgal functional expression.

\section{A proposed nine-group emergent scheme}

In order to identify an alternative, trait-based grouping scheme emerging from our dataset, we ran $k$-medoids with an increasing number of groups. While we observed a monotonic increase in the extent of trait variation explained as well as parsimony, a nine-group emergent scheme maximised explanatory power and parsimony while maintaining significant differences between all groups. This scheme explained about two thirds of multivariate trait expression (PERMANOVA, $R^{2}=0.69, P<0.001$ ), and all emergent groups were significantly different from each other (pairwise PERMANOVA, $P<0.05$ ). The scheme's explanatory power remained substantial even when we conducted resampling to allow for intraspecific variability in species' traits (PERMANOVA, $R^{2}=0.57 \pm 0.02[$ mean \pm S.D.]). The species composition of the groups emerging from our trait data is largely uncoupled from macroalgal general appearance (i.e., gross morphology, anatomy, and stature; Fig. 7). Emergent groups 2 and 3 (thick leathery), 4 (coarsely branched), and 6 (articulate calcareous) gather species belonging to a single morpho-functional group; still, all traditional groups but articulate(d) calcareous were broken down into more fine-tuned functional units (e.g., [thick] leathery species are spread over groups 1, 2, 3 and 5). Group composition appeared to be partly driven by taxonomic identity and underlying phylogenetic relationships: group 1 gathered all - but 
not exclusively - kelps (i.e., orders Laminariales and Tilopteridales), group 4 consisted entirely of the two unusually thick, low-TDMC Codium fragile subspecies, and group 6 gathered all calcified species. Presence of pneumatocysts emerged as an important predictor of group composition, as all pneumatocyst-bearing species were allocated to group 3. This nine-group emergent scheme provides a more functionally informative alternative compared to traditional seaweed groups.

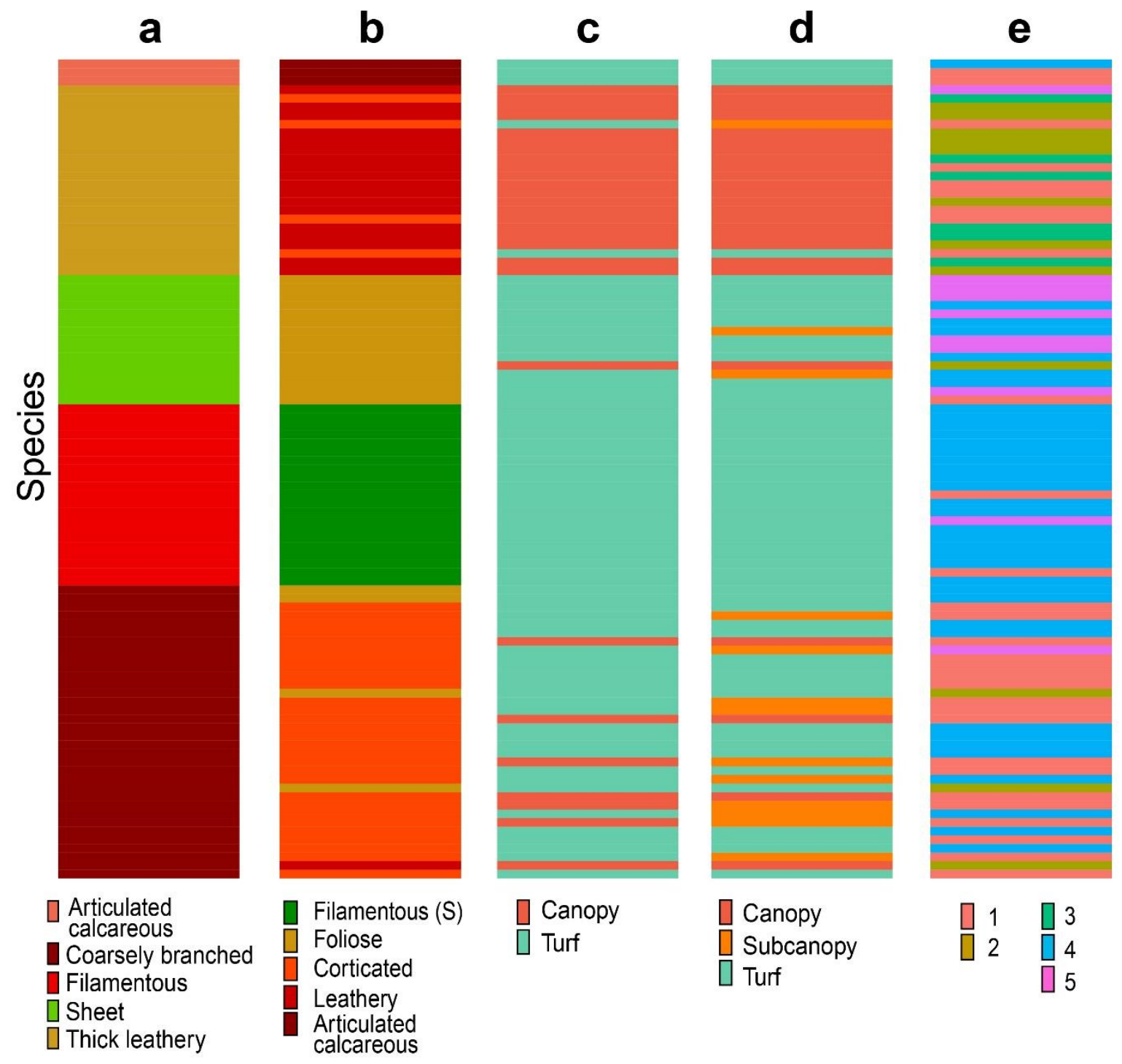

Figure 6. Species reclassification across grouping schemes. Species allocation to groups is given for (a) Littler and Littler's functional-form model (species are ordered alphabetically within group), (b) Steneck and Dethier's scheme, (c) the binary canopy vs. turf and (d) the three-level canopy/subcanopy/turf categorisations of vertical space use, and (e) emergent 
groups created by post hoc clustering of our data using the divisive $k$-medoids method. Within each grouping scheme, stacked horizontal bars correspond to individual species. The order of individual species remains consistent across columns and is initially ordered according to Littler and Littler's groups. Tracking individual species from left to right shows reclassification across grouping schemes.

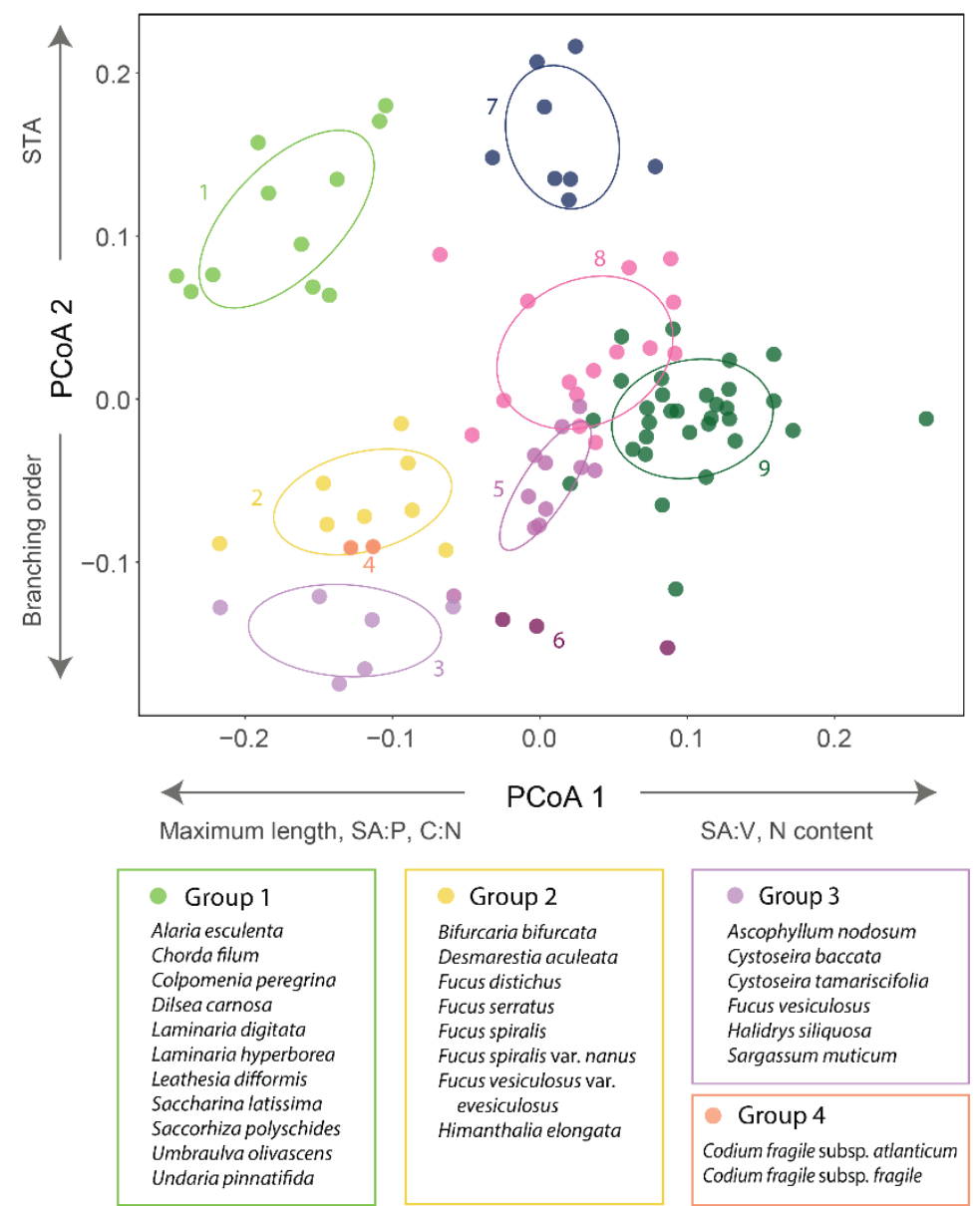

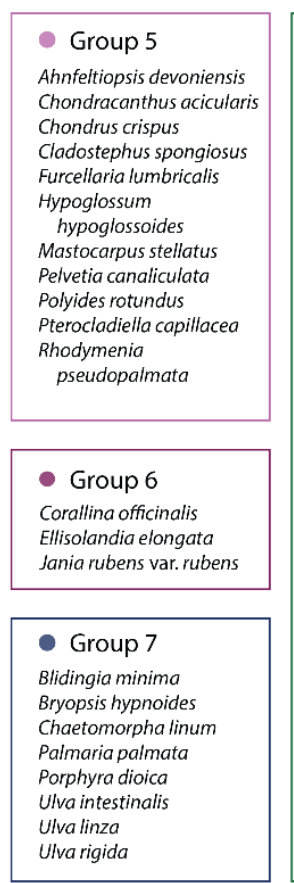

- Group 9

Asparagopsis armata Bonnemaisonia hamifera

(Trailliella intricata)

Bostrychia scorpioides

Callithamnion tetricum

Catenella caespitosa

Ceramium botryocarpum

Ceramium nodulosum

Chondracanthus okamurae

Cladophora rupestris

Cladophora sericea

Dictyota sp.

Gelidium crinale

Gelidium crinale

Gelldium pulchellum

Gelidium pusilium

Gelidium spinosum

Grateloupia filicina

Gymnogongrus griffithsiae

Halopteris scoparia

Halurus flosculosus

Heterosiphonia plumosa

Lomentaria articulato

Plocamium sp.

Plocamium maggsiae

Rhodothamniella floridula

Taonia atomaria

Ulva lactuca

Vertebrata byssoides

Vertebrata fruticulos

Vertebrata fucoides

Vertebrata lanosa

Xiphosiphonia ardreano

- Group 8

Asperococcus fistulosus

Calliblepharis jubata

Chordaria flagelliformis

Chylocladia verticillate

Cryptopleura ramosa

Cystoclonium purpureum

Eudesme virescens

Gracilaria gracilis
Halurus equisetifolius Membranoptera alato Osmundea hybrida Osmundea osmunda Osmundea pinnatifida Rhodymenia holmes Ulva compressa

Figure 7. A proposed nine-group emergent scheme. Group composition and locations in macroalgal functional trait space are shown. The divisive $k$-medoids clustering method was used to create the emergent groups based on post hoc clustering of the trait data. Confidence ellipses (50\%) are represented, assuming a multivariate normal distribution. Arrows indicate most strongly related functional traits to each PCoA axis (trait-axis relationships are given in Fig. 4).

\section{Discussion}

As rapid global change dramatically alters community composition, it is imperative that functional schemes - across all major producer groups - are fit-for-purpose. We assessed 
whether common categorisations of form and stature explained trait differences across macroalgae collected from rocky shores with, to our knowledge, the largest set of macroalgal traits assembled to date. Despite their convenience and prevalence in macroalgal ecology, the traditional grouping schemes all left substantial amounts of interspecific trait variation unexplained. These results highlight the need for a re-evaluation of macroalgal grouping approaches and an increased focus on underlying functional trait variation.

Traditional groups are incomplete representatives of underlying physiological and ecological variation

Groups established by Littler and Littler (1980) and Steneck and Dethier (1994) were built on the premise that morphology and anatomy capture interspecific differences in physiology and function. Our finding of limited precision, accuracy, and stability of such groups suggests that anatomy (mainly, cortication) and morphology (gross form and branching order) alone fail to reliably capture variation in functional traits among species. Assuming functional traits are more direct proxies of physiology and potential contributions to ecosystem functions, Littler and Littler's and Steneck and Dethier's schemes do not provide a strong link between form and function.

In seeming contrast to our results, traditional grouping schemes have been reported to account for functional properties, from photosynthetic rates to susceptibility to grazing (e.g., Littler and Littler, 1980, 1984; Steneck and Dethier, 1994). However, closer examination of these studies reveals that large overlap between groups is common and inferences are often drawn from differences between extreme groups, such as jointed calcareous or encrusting against remaining groups (Littler and Arnold 1982; Littler and Littler 1984; Littler et al. 1983). Moreover, previous qualitative review found a general mismatch between functional groups and ecological responses and effects across ecosystems (Padilla and Allen 2000). Our findings 
also echo work on vascular plants showing that growth form does not accurately represent underlying evolutionary trade-offs between photosynthetic rates, construction costs, and longevity and hence, fails to capture global patterns of plant functional traits, nutrient cycling, and primary productivity (Díaz et al. 2016; Shipley et al. 2006).

Notwithstanding the overall inadequacy of form-based grouping schemes of macroalgal form in capturing underlying functional trait expression, some of their groups fared worse than others. The groups '(thick) leathery' and 'coarsely branched'/'corticated' were particularly spread out in trait space and were extensively reworked across the groups of the five-group emergent scheme, highlighting their lack of functional distinction. The '(thick) leathery' group was split up between two main emergent groups: an isolated one that consisted entirely of (thick) leathery species, representing what may be considered 'true' (thick) leathery macroalgae (emergent group 3), and one that associated with other morphologies (emergent group 2). In fact, the latter mixed some sheet/foliose and coarsely branched/corticated species with native kelps (orders Laminariales and Tilopteridales). The non-native kelp Undaria pinnatifida got clustered with sheet-like species (emergent group 5), suggesting substantial functional differences with native kelps and in accordance with recent findings (reviewed in Teagle et al., 2017). Emergent group 3 gathered species with varied morphology and mainly consisted of high-thickness, high-C:N fucophycids (subclass Fucophycidae, orders Fucales and Chordales). These species also had pneumatocysts, which seems to be a strong determinant of group allocation among leathery macroalgae. Conversely, the filamentous group appeared to be the most stable across form-based traditional and emergent grouping schemes. This suggests that filamentous species tend to display rather specific suites of traits that translate into precise anatomical and morphological features and hence, that are well-captured by the schemes of Littler and Littler and Steneck and Dethier. These findings underline that traditional form-based groups vary in their functional accuracy. 
Common categorisations of vertical space use provide coarse assessments of the ecological impacts of fast-paced changes in macroalgal assemblages

Categorisations of vertical space use are widely used because of their convenience in accounting for changes in macroalgal community composition (Filbee-Dexter and Wernberg, 2018). These were the least parsimonious of traditional approaches, accounted for the least multivariate trait expression, and showed a high degree of overlap for individual traits. Accordingly, species turnover within these groups - besides canopy to turf transitions - will have different ecological consequences depending on species traits. Recent focused comparative work on two kelp (canopy) species supports this point: along the southern coast of Britain under ocean warming, replacement of Laminaria hyperborea with L. ochroleuca results in ecologically significant changes in supported biodiversity and ecosystem processes (Pessarrodona et al. 2019; Smale et al. 2015). Moreover, various definitions of turfs have been employed, resulting in a lack of generality across ecosystems (Connell et al. 2014). Our findings imply that coarse categorisations of macroalgal stature will hinder explanatory power and the generality of global synthesis when assessing the ecological impacts of environmentmediated changes in macroalgal assemblages.

Nevertheless, categorisations of macroalgal stature can remain insightful when applied to ecosystem functioning. Perhaps aided by greater within-group sample sizes, both categorisations of vertical space use explained significant differences for most individual functional traits. The trait differences entailed in canopy-to-turf shifts, such as reduced C:N and higher STA, correspond to contrasts between 'slower', longer-lived species, and 'faster' opportunistic forms (Airoldi 1998; Littler and Littler 1980, 1981). These differences may partially explain the global rise of turfs with altered environmental conditions (Feehan et al. 2019; Filbee-Dexter and Wernberg 2018) as well as the consequences of canopy-to-turf shifts 
for carbon flow and habitat provisioning (Copertino et al. 2005; Filbee-Dexter and Wernberg 2018). Therefore, despite risking substantial loss of information and lack of generality, broad categorisations of macroalgal stature may offer quick first-order assessments of the ecological impacts of fast-paced changes in macroalgal assemblages.

Functional traits and emergent groups offer more ecologically informative alternatives to traditional macroalgal groups

Although traditional functional groups can allow practical and rapid assessments of macroalgal assemblages, functional trait values - as the closest proxies of primary producer functional variation and ecological roles (Díaz et al. 2016; Vile et al. 2006) - provide a more ecologically-informative alternative. Our study provides a fresh perspective on the functional differentiation and diversity of seaweed species and the accompanying trait data provides a platform for researchers to more accurately capture functional identity and diversity (Boyé et al. 2019; Villéger et al. 2008) and therefore more strongly connect changes in community structure to ecosystem processes (Cadotte 2017; Gagic et al. 2015).As an alternative to direct use of trait values, we also provide a nine-group emergent scheme, potentially simplifying field and analytical methods, while still allowing meaningful measurements of functional diversity (Chapin et al. 1996; Chen et al. 2017; Díaz and Cabido 2001). Although intraspecific variation was relatively small in our dataset - and in a previous study where large brown seaweeds were sampled across sites of contrasting wave exposure (Cappelatti et al. 2019) - care should be taken when applying the trait data at sites with unusual conditions (e.g., very sheltered sea loughs) or in regions distant from the UK (e.g., other regions of the NW Atlantic). There are additional considerations before applying emergent groups: they make the simplifying assumption that species are equivalent within groups, can force outlying species into groups, and can be somewhat sensitive to the clustering method. Therefore, while emergent groups 
have the potential to more accurately capture macroalgal functional diversity compared to traditional groups, we recommend the direct use of functional traits wherever possible.

Our study on UK rocky shores highlights the continuous nature of macroalgal trait expression and underlines the usefulness of functional traits as direct, continuous measures of macroalgal functional variation. Yet, more broadly unleashing the potential of trait-based approaches to macroalgal ecology will require trait data covering other regions and a much greater proportion of the world's seaweed taxa. This could be achieved by geographically distributed research groups undertaking trait-screening using standardised methods and curating data within open access databases. Because trait screening demands substantial resources, a key challenge is to identify a manageable set of - ideally orthogonal - ecologically relevant traits before embarking on globally coordinated efforts. Here, maximum length, branching order, and surface area to volume ratio $(\mathrm{SA}: \mathrm{V})$ emerge as contenders because, collectively, these traits are highly associated with orthogonal axes of variation and relate to both competitive dominance and resource economics. Prioritising abundant or otherwise functionally important species (e.g., "foundation species") would further reduce the burden of trait screening.

\section{Conclusion}

Our analysis using a comprehensive dataset of directly measured functional traits revealed substantial limitations to the group gambit of macroalgae. Despite accounting for up to more than a third of trait expression, traditional groups appeared to inadequately capture macroalgal functional variation: we found substantial group overlap (i.e., low precision) and mismatch between traditional groups and underlying traits values (i.e., low accuracy). Therefore, gross morphology and anatomy as well as vertical position in the canopy are incomplete representatives of macroalgal functional identity. Conversely, post hoc emergent 
grouping schemes such as that proposed herein have the potential to more accurately capture macroalgal trait expression than traditional groups while retaining the convenience of species grouping. Ultimately, functional traits are the closest proxies of macroalgal functional variation and hence, should provide the strongest assessments of macroalgal roles under global change. Studies like ours, which emphasise the potential of direct use of functional traits in capturing macroalgal form and function, can act as an incentive to build large, coordinated datasets spanning all main aspects of macroalgal eco-physiology.

\section{Acknowledgements}

We would like to thank A. Raduan, S. Ball, J. Hunt, P. Deacon, O. Smith, E. Milne, G. Burton, M. Georgiev, O. Koppel, L. Wójcik, J. Mutter, F. Guillen Ezcurra, G. Blow, D. de Battisti, and T. Fairchild, for the invaluable help with sampling and trait screening. We thank M. Wilkinson for his help during the 2017 British Phycological Society Seaweed Field Meeting in Orkney. 


\section{References}

Airoldi, L. (1998). Roles of Disturbance, Sediment Stress, and Substratum Retention on Spatial Dominance in Algal Turf. Ecology, 79(8), 2759-2770. doi: 10.1890/00129658(1998)079[2759:RODSSA]2.0.CO;2.

Ar Gall, E., Le Duff, M., Sauriau, P.-G., de Casamajor, M.-N., Gevaert, F., Poisson, E., ... Miossec, L. (2016). Implementation of a new index to assess intertidal seaweed communities as bioindicators for the European Water Framework Directory. Ecological Indicators, 60, 162-173. doi: 10.1016/j.ecolind.2015.06.035.

Araújo, R., Sousa-Pinto, I., Bárbara, I., \& Quintino, V. (2006). Macroalgal communities of intertidal rock pools in the northwest coast of Portugal. Acta Oecologica, 30(2), 192-202. doi: 10.1016/j.actao.2006.04.002.

Arenas, F., Sánchez, I., Hawkins, S. J., \& Jenkins, S. R. (2006). The invasibility of marine algal assemblages: role of functional diversity and identity. Ecology, 87(11), 2851-2861.

Bates, C. R. (2009). Host taxonomic relatedness and functional-group affiliation as predictors of seaweed-invertebrate epifaunal associations. Marine Ecology Progress Series, 387, 125-136.

Boyé, A., Thiébaut, É., Grall, J., Legendre, P., Broudin, C., Houbin, C., ... Gauthier, O. (2019). Traitbased approach to monitoring marine benthic data along $500 \mathrm{~km}$ of coastline. Diversity and Distributions, 25(12), 1879-1896. doi: 10.1111/ddi.12987.

Cadotte, M. W. (2017). Functional traits explain ecosystem function through opposing mechanisms. Ecology Letters, 20(8), 989-996. doi: 10.1111/ele.12796.

Cappelatti, L., Mauffrey, A. R. L., \& Griffin, J. N. (2019). Applying continuous functional traits to large brown macroalgae: variation across tidal emersion and wave exposure gradients. Marine Biology, 166(11), 145. doi: 10.1007/s00227-019-3574-5.

Carpenter, R. C. (1990). Competition Among Marine Macroalgae: A Physiological Perspective. Journal of Phycology, 26(1), 6-12. doi: 10.1111/j.0022-3646.1990.00006.x.

Chapin, F. S., Bret-Harte, M. S., Hobbie, S. E., \& Zhong, H. (1996). Plant functional types as predictors of transient responses of arctic vegetation to global change. Journal of Vegetation Science, 7(3), 347358. doi: $10.2307 / 3236278$.

Chen, J., Luo, Y., Xia, J., Wilcox, K. R., Cao, J., Zhou, X., .. Wang, R.-W. (2017). Warming Effects on Ecosystem Carbon Fluxes Are Modulated by Plant Functional Types. Ecosystems, 20(3), 515-526. doi: 10.1007/s10021-016-0035-6.

Chung, K. I., Beardall, J., Mehta, S., Sahoo, D., \& Stojkovic, S. (2011). Using marine macroalgae for carbon sequestration: a critical appraisal. Journal of Applied Phycology, 23(5), 877-886. doi: 10.1007/s10811-010-9604-9.

Connell, S. D., Foster, M. S., \& Airoldi, L. (2014). What are algal turfs? Towards a better description of turfs. Marine Ecology Progress Series, 495, 299-307. doi: 10.3354/meps10513.

Copertino, M., Connell, S. D., \& Cheshire, A. (2005). The prevalence and production of turf-forming algae on a temperate subtidal coast. Phycologia, 44(3), 241-248. doi: 10.2216/00318884(2005)44[241:TPAPOT]2.0.CO;2. 
Cornelissen, J. H. C., Lavorel, S., Garnier, E., Díaz, S., Buchmann, N., Gurvich, D. E., ... Poorter, H. (2003). A handbook of protocols for standardised and easy measurement of plant functional traits worldwide. Australian Journal of Botany, 51, 335-380.

de los Santos, C. B., Onoda, Y., Vergara, J. J., Pérez-Lloréns, J. L., Bouma, T. J., Nafie, Y. A. L., ... Brun, F. G. (2016). A comprehensive analysis of mechanical and morphological traits in temperate and tropical seagrass species. Marine Ecology Progress Series, 551, 81-94. doi: 10.3354/meps11717.

Díaz, S, \& Cabido, M. (2001). Vive la différence: plant functional diversity matters to ecosystem processes. Trends in Ecology and Evolution, 16, 646-655.

Díaz, Sandra, Kattge, J., Cornelissen, J. H. C., Wright, I. J., Lavorel, S., Dray, S., ... Gorné, L. D. (2016). The global spectrum of plant form and function. Nature, 529(7585), 167-171. doi: 10.1038/nature16489.

Díaz, Sandra, Purvis, A., Cornelissen, J. H. C., Mace, G. M., Donoghue, M. J., Ewers, R. M., ... Pearse, W. D. (2013). Functional traits, the phylogeny of function, and ecosystem service vulnerability. Ecology and Evolution, 3(9), 2958-2975. doi: 10.1002/ece3.601.

Dromgoole, F. I. (1981). Form and Function of the Pneumatocysts of Marine Algae. I. Variations in the Pressure and Composition of Internal Gases. Botanica Marina, 24, 257-266. doi: 10.1515/botm.1981.24.5.257.

Elger, A., \& Willby, N. J. (2003). Leaf dry matter content as an integrative expression of plant palatability: the case of freshwater macrophytes. Functional Ecology, 17, 58-65.

Feehan, C. J., Grace, S. P., \& Narvaez, C. A. (2019). Ecological feedbacks stabilize a turf-dominated ecosystem at the southern extent of kelp forests in the Northwest Atlantic. Scientific Reports, 9(1), 110. doi: 10.1038/s41598-019-43536-5.

Filbee-Dexter, K., \& Wernberg, T. (2018). Rise of Turfs: A New Battlefront for Globally Declining Kelp Forests. BioScience, 68(2), 64-76. doi: 10.1093/biosci/bix147.

Gagic, V., Bartomeus, I., Jonsson, T., Taylor, A., Winqvist, C., Fischer, C., ... Bommarco, R. (2015). Functional identity and diversity of animals predict ecosystem functioning better than species-based indices. Proceedings of the Royal Society B: Biological Sciences, 282(1801), 20142620. doi: 10.1098/rspb.2014.2620.

Garnier, E., Cortez, J., Billès, G., Navas, M.-L., Roumet, C., Debussche, M., ... Toussaint, J.-P. (2004). Plant functional markers capture ecosystem properties during secondary succession. Ecology, 85(9), 2630-2637.

Gómez, I., \& Huovinen, P. (2011). Morpho-functional patterns and zonation of South Chilean seaweeds:: the importance of photosynthetic and bio-optical traits. Marine Ecology Progress Series, $422,77-91$.

Google Scholar. (n.d.). Retrieved October 10, 2019, from https://scholar.google.co.uk/.

Griffiths, M., Harrison, S. T. L., Smit, M., \& Maharajh, D. (2016). Major Commercial Products from Micro- and Macroalgae. In F. Bux \& Y. Chisti (Eds.), Algae Biotechnology: Products and Processes (pp. 269-300). doi: 10.1007/978-3-319-12334-9_14.

Hanisak, M. D., Littler, M. M., \& Littler, D. S. (1988). Significance of macroalgal polymorphism: intraspecific tests of the functional-form model. Marine Biology, 99, 157-165. 
Harley, C. D. G., Anderson, K. M., Demes, K. W., Jorve, J. P., Kordas, R. L., Coyle, T. A., \& Graham, M. H. (2012). Effects of Climate Change on Global Seaweed Communities. Journal of Phycology, 48(5), 1064-1078. doi: 10.1111/j.1529-8817.2012.01224.x.

Hay, M. E. (1981). The functional morphology of turf forming seaweeds: persistence in stressful marine habitats. Ecology, 62, 739-750.

Hurd, C. L., Harrison, P. J., Bischof, K., \& Lobban, C. S. (2014). Seaweed Ecology and Physiology. Cambridge University Press.

Kassambara, A. (2019). ggpubr: "ggplot2" Based Publication Ready Plots (Version 0.2.1) [R, R ( $\geq$ 3.1.0), ggplot2, magrittr]. Retrieved from https://cloud.r-project.org/web/packages/ggpubr/index.html.

Lavorel, S., \& Garnier, E. (2002). Predicting changes in community composition and ecosystem functioning from plant traits: revisiting the Holy Grail. Functional Ecology, 16, 545-556.

Lavorel, S., McIntyre, S., Landsberg, J., \& Forbes, T. D. A. (1997). Plant functional classifications: from general groups to specific groups based on response to disturbance. Trends in Ecology and Evolution, 12, 474-478.

Littler, M M. (1980). Morphological form and photosynthesis performances of marine macroalgae: tests of a functional/form hypothesis. Botanica Marina, 22, 161-165.

Littler, M M, \& Arnold, K. E. (1982). Primary productivity of marine macroalgal functional-form groups from Southwestern North America. Journal of Phycology, 18, 307-311.

Littler, M M, \& Littler, D. S. (1980). The evolution of thallus form and survival strategies in benthic marine macroalgae: field and laboratory tests of a functional form model. American Naturalist, 116(1), $25-44$.

Littler, M M, \& Littler, D. S. (1981). Intertidal macrophyte communities from Pacific Baja California and the upper gulf of California: relatively constant vs. environmentally fluctuating systems. Marine Ecology Progress Series, 4, 145-158.

Littler, M M, \& Littler, D. S. (1984). Relationships between macroalgal functional form groups and substrata stability in a subtropical rocky-intertidal system. Journal of Experimental Marine Biology and Ecology, 74(1), 13-34.

Littler, M M, Littler, D. S., \& Taylor, P. R. (1983). Evolutionary strategies in a tropical barrier reef system: functional-form groups of marine macroalgae. Journal of Phycology, 19, 229-237.

Littler, Mark M., Taylor, P. R., \& Littler, D. S. (1983). Algal resistance to herbivory on a Caribbean barrier reef. Coral Reefs, 2(2), 111-118. doi: 10.1007/BF02395281.

Maechler, M., Rousseeuw, P., Struyf, A., Hubert, M., \& Hornik, K. (2019). cluster: Cluster Analysis Basics and Extensions (Version 2.1.0) [R, $\mathrm{R}(\geq 3.3 .0)]$. Retrieved from https://cran.rproject.org/web/packages/cluster/index.html.

Martínez, B., Viejo, R. M., Carreño, F., \& Aranda, S. C. (2012). Habitat distribution models for intertidal seaweeds: responses to climatic and non-climatic drivers. Journal of Biogeography, 39(10), 1877-1890. doi: 10.1111/j.1365-2699.2012.02741.x.

Martins, G. M., Hawkins, S. J., Thompson, R. C., \& Jenkins, S. R. (2007). Community structure and functioning in intertidal rock pools: effects of pool size and shore height at different successional stages. Marine Ecology Progress Series, 329, 43-55. doi: 10.3354/meps329043. 
Mazel, F., Pennell, M. W., Cadotte, M. W., Díaz, S., Riva, G. V. D., Grenyer, R., ... Pearse, W. D. (2018). Prioritizing phylogenetic diversity captures functional diversity unreliably. Nature Communications, 9(1), 1-9. doi: 10.1038/s41467-018-05126-3.

McGill, B. J., Enquist, B. J., Weiher, E., \& Westoby, M. (2006). Rebuilding community ecology from functional traits. Trends in Ecology and Evolution, 21(4), 178-185.

McLachlan, J. (1985). Macroalgae (seaweeds): industrial resources and their utilization. Plant and Soil, 89, 137-157.

Miranda, M., Lopez-Alonso, M., \& Garcia-Vaquero, M. (2017). Macroalgae for Functional Feed Development: Applications in Aquaculture, Ruminant and Swine Feed Industries. In Veterinary Medicine Research Collection. Seaweeds: Biodiversity, Environmental Chemistry and Ecological Impacts (NOVA science publishers). Retrieved from https://researchrepository.ucd.ie/handle/10197/9045.

Oksanen, J., Blanchet, F. G., Friendly, M., Kindt, R., Legendre, P., McGlinn, D., ... Wagner, H. (2019). vegan: Community Ecology Package (Version 2.5-5) [R, R ( $\geq 3.4 .0$ ), permute ( $\geq 0.9-0)$, lattice]. Retrieved from https://cran.r-project.org/web/packages/vegan/index.html.

Padilla, D. K. (1984). The importance of form: differences in competitive ability, resistance to consumers and environmental stress in an assemblage of coralline algae. Journal of Experimental Marine Biology and Ecology, 79, 105-127.

Padilla, D. K., \& Allen, B. J. (2000). Paradigm lost: reconsidering functional form and group hypotheses in marine ecology. Journal of Experimental Marine Biology and Ecology, 250, 207-221.

Pessarrodona, A., Foggo, A., \& Smale, D. A. (2019). Can ecosystem functioning be maintained despite climate-driven shifts in species composition? Insights from novel marine forests. Journal of Ecology, 107(1), 91-104. doi: 10.1111/1365-2745.13053.

Petchey, O. L., \& Gaston, K. J. (2006). Functional diversity: back to basics and looking forward. Ecology Letters, 9(6), 741-758. doi: 10.1111/j.1461-0248.2006.00924.x.

Phillips, J. C., Kendrick, G. A., \& Lavery, P. S. (1997). A test of a functional group approach to detecting shifts in macroalgal communities along a disturbance gradient. Marine Ecology Progress Series, $153,125-138$.

Pianka, E. R. (1970). On r- and K-Selection. The American Naturalist, 104(940), 592-597. doi: $10.1086 / 282697$.

R Core Team. (2019). R: A Language and Environment for Statistical Computing (Version 3.5.3) [R]. Retrieved October 10, 2019, from http://www.R-project.org/.

Reich, P B, Ellsworth, D. S., Walters, M. B., Vose, J. M., Gresham, C., Volin, J. C., \& Bowman, W. D. (1999). Generality of leaf trait relationships: a test across six biomes. Ecology, 80(6), 1955-1969.

Reich, P. B. (2014). The world-wide 'fast-slow' plant economics spectrum: a traits manifesto. Journal of Ecology, 102(2), 275-301. doi: 10.1111/1365-2745.12211.

Reynolds, A. P., Richards, G., de la Iglesia, B., \& Rayward-Smith, V. J. (2006). Clustering Rules: A Comparison of Partitioning and Hierarchical Clustering Algorithms. Journal of Mathematical Modelling and Algorithms, 5(4), 475-504. doi: 10.1007/s10852-005-9022-1. 
Roderick, M. L., Berry, S. L., \& Noble, I. R. (2000). A framework for understanding the relationship between environment and vegetation based on the surface area to volume ratio of leaves. Functional Ecology, 14, 423-437.

Roos, R. E., Zuijlen, K. van, Birkemoe, T., Klanderud, K., Lang, S. I., Bokhorst, S., ... Asplund, J. (2019). Contrasting drivers of community-level trait variation for vascular plants, lichens and bryophytes across an elevational gradient. Functional Ecology, 33(12), 2430-2446. doi: 10.1111/13652435.13454 .

Schneider, C. A., Rasband, W. S., \& Eliceiri, K. W. (2012). NIH Image to ImageJ: 25 years of image analysis. Nature Methods, 9(7), 671-675. doi: 10.1038/nmeth.2089.

Sánchez, Í., \& Fernández, C. (2006). Resource availability and invasibility in an intertidal macroalgal assemblage.

Schonbeck, M. W., \& Norton, T. A. (1979). Drought-Hardening in the Upper-Shore Seaweeds Fucus Spiralis and Pelvetia Canaliculata. Journal of Ecology, 67(2), 687-696. doi: 10.2307/2259120.

Shipley, B., Lechowicz, M. J., Wright, I., \& Reich, P. B. (2006). Fundamental trade-offs generating the worldwide leaf economics spectrum. Ecology, 87(3), 535-514.

Smale, D. A., Wernberg, T., Yunnie, A. L. E., \& Vance, T. (2015). The rise of Laminaria ochroleuca in the Western English Channel (UK) and comparisons with its competitor and assemblage dominant Laminaria hyperborea. Marine Ecology, 36(4), 1033-1044. doi: 10.1111/maec.12199.

Smart, S. M., Glanville, H. C., Blanes, M. del C., Mercado, L. M., Emmett, B. A., Jones, D. L., ... Hodgson, J. G. (2017). Leaf dry matter content is better at predicting above-ground net primary production than specific leaf area. Functional Ecology, 31(6), 1336-1344. doi: 10.1111/13652435.12832 .

Starko, S., Claman, B. Z., \& Martone, P. T. (2015). Biomechanical consequences of branching in flexible wave-swept macroalgae. New Phytologist, 206(1), 133-140. doi: 10.1111/nph.13182.

Steneck, R. S., \& Dethier, M. N. (1994). A functional group approach to the structure of algaldominated communities. Oikos, 69, 476-498.

Stewart, H. L., \& Carpenter, R. C. (2003). The effects of morphology and water flow on photosynthesis of marine macroalgae. Ecology, 84(11), 2999-3012.

Suding, K. N., Lavorel, S., Chapin, F. S. I., Cornelissen, J. H. C., Díaz, S., Garnier, E., ... Navas, M.L. (2008). Scaling environmental change through the community-level: a trait-based response-andeffect framework for plants. Global Change Biology, 14, 1125-1140. doi: 10.1111/j.13652486.2008.01557.x.

Taylor, P. R., \& Hay, M. E. (1984). Functional morphology of intertidal seaweeds: adaptive significance of aggregate vs. solitary forms. Marine Ecology Progress Series, 18, 295-302.

Teagle, H., Hawkins, S. J., Moore, P. J., \& Smale, D. A. (2017). The role of kelp species as biogenic habitat formers in coastal marine ecosystems. Journal of Experimental Marine Biology and Ecology, 492, 81-98. doi: 10.1016/j.jembe.2017.01.017.

Thomas, H. J. D., Myers-Smith, I. H., Bjorkman, A. D., Elmendorf, S. C., Blok, D., Cornelissen, J. H. C., ... van Bodegom, P. M. (2019). Traditional plant functional groups explain variation in economic but not size-related traits across the tundra biome. Global Ecology and Biogeography, 28(2), 78-95. doi: $10.1111 /$ geb.12783. 
Trugman, A. T., Anderegg, L. D. L., Wolfe, B. T., Birami, B., Ruehr, N. K., Detto, M., ... Anderegg, W. R. L. (2019). Climate and plant trait strategies determine tree carbon allocation to leaves and mediate future forest productivity. Global Change Biology, 25(10), 3395-3405. doi: 10.1111/gcb.14680.

van Buuren, S., \& Groothuis-Oudshoorn, K. (2011). mice: Multivariate Imputation by Chained Equations. Journal of Statistical Software, 45(3), 1-67.

Veiga, P., Rubal, M., \& Sousa-Pinto, I. (2014). Structural complexity of macroalgae influences epifaunal assemblages associated with native and invasive species. Marine Environmental Research, $101,115-123$.

Vile, D, Garnier, E., Shipley, B., Laurent, G., Navas, M.-L., Roumet, C., ... Wright, I. J. (2005). Specific leaf area and dry matter content estimate thickness in laminar leaves. Annals of Botany, 96, 1129-1136.

Vile, D., Shipley, B., \& Garnier, E. (2006). A Structural Equation Model to Integrate Changes in Functional Strategies During Old-Field Succession. Ecology, 87(2), 504-517. doi: 10.1890/05-0822.

Villéger, S., Mason, N. W. H., \& Mouillot, D. (2008). New Multidimensional Functional Diversity Indices for a Multifaceted Framework in Functional Ecology. Ecology, 89(8), 2290-2301. doi: 10.1890/07-1206.1.

Violle, C., Enquist, B. J., McGill, B. J., Jiang, L., Albert, C. H., Hulshof, C., .. Messier, J. (2012). The return of the variance: intraspecific variability in community ecology. Trends in Ecology and Evolution, 27(4), 244-252. doi: 10.1016/j.tree.2011.11.014.

Weykam, G., Gómez, I., Wiencke, C., Iken, K., \& Klöser, H. (1996). Photosynthetic characteristics and C:N ratios of macroalgae from King George Island (Antarctica). Journal of Experimental Marine Biology and Ecology, 204, 1-22.

Wickham, H. (2009). ggplot2: Elegant Graphics for Data Analysis (2nd ed., Vols. 1-1). Springer International Publishing.

Wilson, P., Thompson, K., \& Hodgson, J. G. (1999). Specific leaf area and leaf dry matter content as alternative predictors of plant strategies. New Phytologist, 143, 155-162.

Wright, I. J., Reich, P. B., Westoby, M., Ackerly, D. D., Baruch, Z., Bongers, F., .. Villar, R. (2004). The worldwide leaf economics spectrum. Nature, 428(6985), 821-827. doi: 10.1038/nature02403. 


\section{Chapter 6}

\section{General Discussion}

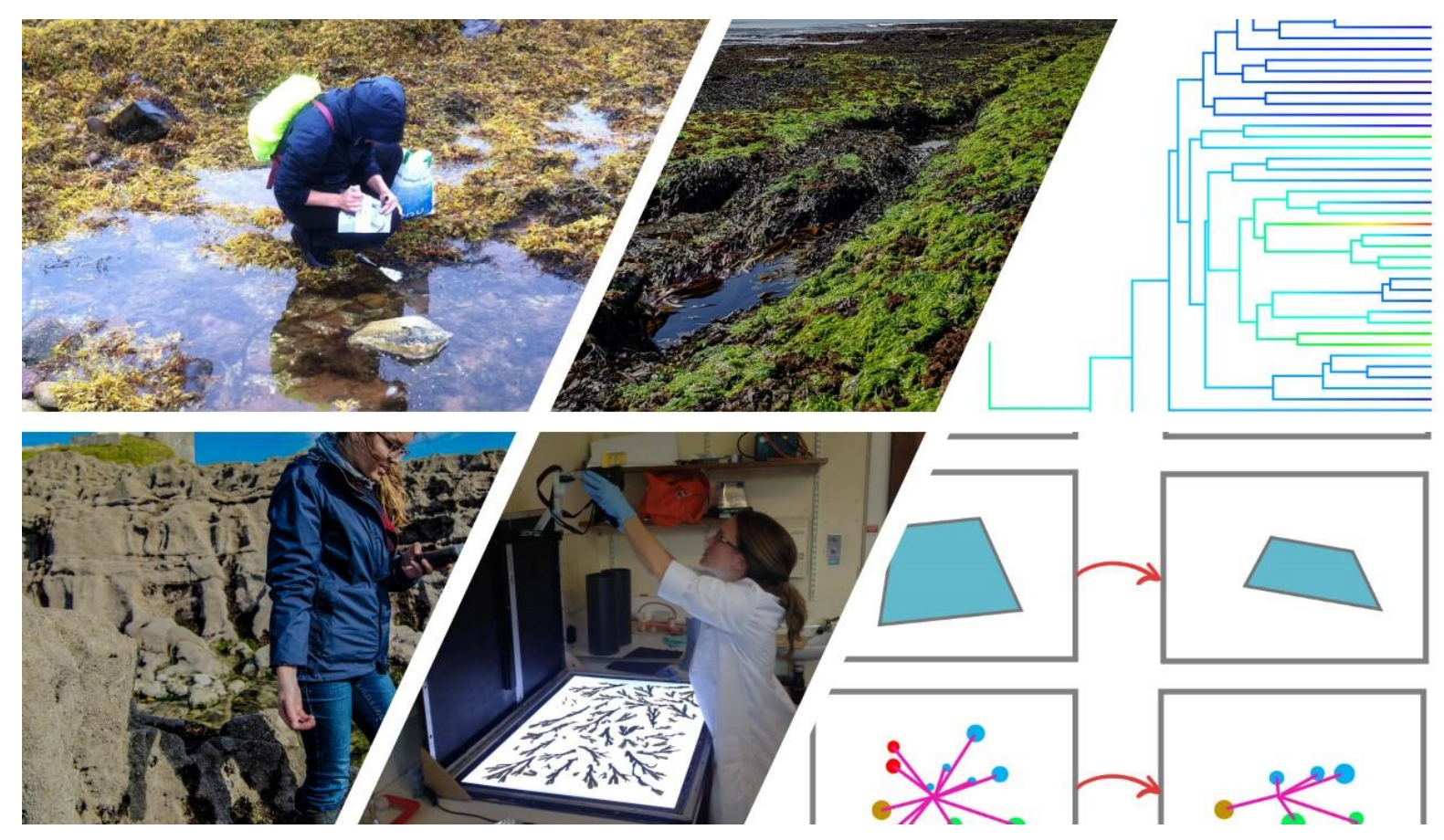


Seaweeds in British rocky shores display a remarkable diversity. From large kelps to turf mats, many seem so distinct that it is hard to believe they share any similarities. However, under the functional lens, it is possible not only to quantify their differences, but also to contextualise these differences, with a range of methods that aim to interpret the causes and effects of these differences on the environment. Over the course of my $\mathrm{PhD}$, I was able to explore the diversity of functional traits in a set of almost one hundred species of macroalgae, from south Wales to north Scotland. Many showed different strategies according to their environment; a few stood out. I will here discuss the main findings of my project and provide some outstanding questions.

\section{Dimensionality of macroalgae diversity}

Back in the 1980's, phycologists classified seaweeds into major groups based on their gross morphology (Littler and Littler 1980). Such grouping approaches have been used ever since, some phycologists have proposed more detailed groups (Steneck and Dethier 1994), and generally groups provided a deeper insight into seaweed diversity than taxonomy. For example, studies have established links between environmental variables and seaweed functional-form groups (Sousa-Dias and Melo 2008) and shown that assemblages with higher group diversity are better able to capture photosynthetic light via complementarity (Tait et al. 2014). However, these groups carry the assumption that variability among groups is larger than within them, and the often-subjective species' allocations may lead to a loss of inferential power (Díaz and Cabido 2001; Petchey and Gaston 2006). With continuously variable, morphological and chemical, traits across species ranging all these traditional morpho-functional groups, we obtain a finer resolution of differences, between and within species.

The multidimensional diversity of traits of the studied seaweeds can be summarised by principal components, where species' coordinates reflect their combination of trait values and 
the traits have varying levels of association with the axes. In Chapter 2 I found that variability in dominant Phaeophyte species can be captured largely by two axes: the first, analogous to the 'leaf economics' axis in plants, represents resource acquisition vs. conservation/stress tolerance trade-off. The second axis was associated with a gradient of competitive dominance, where dominant species are able to capture more light while also needing more investment in anchorage and blade resistance. In Chapter 3, I assessed a larger group of species from all major lineages, this time with a few additional traits. The higher variety of traits should capture differences among many species in a better resolution. The main similarity between this and the analyses with only Phaeophytes was that the first trait axis also related to a resource acquisition - conservation gradient, while the second axis related to traits linked to space use but not to length; therefore in this case the second axis is less clearly related to competitive strategy. Although there are differences between the trait dimensions of chapters 2 and 3 due to the number of species and the traits considered, we can observe a similarity in the main ecophysiological trade-offs: highly productive vs. resistant vs. competitive.

A caveat of these studies is that I did not measure ecological strategies such as competition or construction costs; these links between traits and strategies are based on what has been shown by other studies, with both seaweeds and (mostly) vascular plants. However, the pragmatic choice of using established knowledge on what traits represent allowed me to explore the connection between traits and strategies on a larger scale: how a large variety of coexisting species are positioned on different parts of the trait space. Following that, analysing community-level patterns of functional traits can provide some initial insights into the drivers of species assembly and the consequences for ecosystem functioning (Griffin et al. 2009; Lefcheck and Duffy 2015). 


\section{Community patterns}

The functional traits $\mathrm{I}$ used through my $\mathrm{PhD}$ revealed how communities are differentiated across intertidal macroalgae from a functional perspective. In chapter 2 I addressed how morphological differences at both intra-and interspecific levels affected the distribution of intertidal fucoids and kelp. I found that species' positions on the shore broadly reflect their position on the trait axes, which indicated a relationship between the vertical emersion gradient, from low to high intertidal, and the traits of the dominant species of algae. Functional traits allowed me to translate the well-known species turnover into axes of functional variation. One interesting finding was that the linear relationship between shore height and traits was disrupted by the mid-shore species Ascophyllum nodosum, a commonly dominant species in sheltered sites, with a resource-conservative strategy (Topinka et al. 1981, Vadas et al. 1990, Sundene 1973). It is interesting that the kelp Laminaria digitata, which has an opposing, "fast" strategy (sitting on the other side of the resource acquisition - conservation axis), is positioned closely to A. nodosum along the second trait axis (competitive dominance). Therefore, these two distinct species which dominate separate intertidal zones, are doing so via traits relating mostly to the trade-off between fast growth and long life.

Functional traits can also be used to test hypothesis of community assembly. In chapter 3, I incorporated all groups of macroalgae - red, green and brown - scaling from taxonomic to functional turnover along the intertidal gradient, to test the hypothesis that the increasing emersion period towards the upper shore would filter out community trait values and decrease functional diversity. I found that the diversity in functional traits was largely maintained despite the loss of species diversity towards higher zones. This maintenance was possible owing to the representation of most of the trait space by the remaining or new species, from one zone to the other. Although I did not find functional under-dispersion indicative of environmental filtering 
in the upper shore, there was an overdispersion observed in the low shore, indicated by the null models holding richness constant. This trait dispersion (more than expected at random) suggests biotic factors at play, likely competition for resources, expected in the absence of environmental stressors (Edwards and Connell 2012), and facilitation of functionally diverse understory species (Smale et al. 2013). These results suggest that tidal height has a stronger indirect, rather than direct, effect on functional diversity of seaweed communities: biotic interactions appear to drive trait differentiation more strongly in the low shore. Similarly, increasing tidal height has been demonstrated to drive the positive effect of algal canopies on associated invertebrates (Bertness et al. 1999).

An extra analysis with the community level traits with all algae groups provided a more complete view of community assembly (see Appendix of the General Discussion for method and result). Towards the upper shore, seaweed communities displayed, on average, higher TDMC and lower STA, while length remained the same, although with a lower maximum (Fig. S1). For TDMC, the pattern was maintained across communities of brown and red algae, but only red algae showed a decrease in community STA. Differently to the other groups, which decreased in length with height, green algae showed an increase in length. These results show that different algae groups (which have varying species richness) drive community-level traits in distinct ways. It is important to note that here, the browns include 13 species, not just the dominant ones considered in Chapter 2. In summary, STA seems to be more important for red algae to determine which zones species will occupy, whereas TDMC was determinant for both red and brown algae, and length was the only trait that varied for all groups (although not in the same direction). Overall, these traits are complimentary in explaining seaweed intertidal zonation and demonstrate how the three major groups of algae, which are evolutionarily distant, contribute in both similar and opposing ways to community-level, dominant traits. 


\section{Ecosystem functioning}

Traits can reflect response strategies to, but also effects on, the environment. Translating the zonation of fucoids and kelp into ecological functions, the more conservative and smaller high shore species are related to longer frond lifespans and therefore less material available for biomass and less wave attenuation (Smale et al. 2013). On the other hand, these species provide shelter from desiccation to epiphytes and epibiota and provide long-term carbon storage (Chung et al. 2011). Meanwhile in the low shore, longer and fast-growing species provide high productivity - contributing to blue carbon - and wave attenuation. These relationships were dependent on the level of wave exposure, being clearer on the most sheltered sites. Overall, I observed that, although these dominant algae are differentiated in the functional trait space, the level of wave exposure - and potentially factors I did not account for, such as substrate types - obfuscate the relationships between the emersion gradient and ecosystem functioning.

Investigating functional traits across communities can also reveal how changes in species richness lead to shifts or contractions in functional diversity. Among all macroalgal groups, functional $\beta$-diversity captured changes in the locations of species in trait space and thus potential consequences for ecosystem functioning. These analyses showed that, despite the increasing stress associated with the emersion period, ecosystem functioning is largely maintained in the higher parts of the shore, although the lower redundancy and functional breath implies a higher vulnerability to environmental changes. These results demonstrate the importance of looking at how functional diversity changes across environmental contexts: it reveals not only ecological strategies of species but how the effect of their turnover can be dependent on the degree of functional differentiation between species. 


\section{Applying phylogeny to the study of functional diversity of macroalgae}

Functional approaches are essentially a representation of the underlying relationships between organisms and environments, and among species, but there are other methods which attempt to do so. I also explored these relationships via the phylogenetic approach, not as an alternative to the functional approach, but rather as a complement. That idea stemmed from the fact that these two approaches are interconnected, and therefore I could not avoid addressing phylogenetic ecology on my studies of functional ecology. I tried to provide a useful basis for strengthening the connection between seaweed functional and phylogenetic ecology, which is underdeveloped. I will now discuss some of the findings from chapter 4.

One of the most common utilities of incorporating phylogenetic diversity to functional ecology is that is adds evolution as factor to explore dynamics of communities. With the premise that evolutionary distance reflects distinction in phenotypes, phylogenies allow the detection of cases where traits did not evolve neutrally and point towards further research directions (Lean and Maclauring 2016). In my study with a group of Rhodophyta (red algae),

I found that individual traits relating to different aspects of algae ecology have different distributions across the clades. In combination with the community trait data, this could raise new hypotheses regarding the evolution of algae, since different groups may have adapted to coexist in the same environment via different pathways, in a convergent manner (Littler and Littler 1980).

Another use of phylogenetic approaches in ecology is as surrogates for similarities in features among species - including functional traits, species interactions, ecosystem functions (Faith 1992; Forest et al. 2007). However, the main criticism for using phylogenies as a proxy for functional differences among species is that the premise of close relatives sharing more trait values is often not true or reliable (Swenson 2019). Therefore a priori tests of the matching 
between traits and evolutionary relationships are needed to test these assumptions. My goal was to provide some evidence of how much a phylogeny would be able to predict trait diversity of red algae, to inform future studies that may share some, but not all, species with the ones in my study (i.e. species for which traits are available in the data set). Using a phylogenetic tree of 45 species of red algae, I found that, indeed, phylogeny was a poor predictor of multi-trait variation, mainly because the traits selected (STA, TDMC, length) did not show a pattern of change consistent with a constant, neutral evolution (Brownian motion). However, this does not invalidate the approach completely, as I will discuss next.

Following this question, the second aim of this study was to access how much more information we can obtain from including a phylogenetic approach. The idea behind this question is that phylogenies should hold information on all differences among species (features) and therefore potentially include relevant unmeasured traits. By "relevant" I mean traits which respond to, or affect, the environment or ecosystem of interest. To test that, I applied a phylogenetic approach to the community study across an environmental gradient (intertidal emersion period, as given by shore height). Interestingly, in the smaller set of species $(n=29)$, phylogenetic distances between species highly matched their functional distances, also capturing well the variability in diversity metrics between communities. However, the predictive power of phylogeny was not useful in the analyses of communities across the environmental gradient, since phylogenetic diversity did not capture between-zone differences as did functional diversity. These results suggest that, while phylogeny can be a good predictor of functional diversity, it may not be enough to pick up on some trait-environment relationships.

Phylogenies can also be useful in conservation studies (Faith 1992; Isaac et al. 2007), under the assumption that a higher diversity of distinct clades provides more diversity in 
ecological functions. It can also be used to set priorities for conservation of species, considering species are not equally different, therefore some may be considered unique, or distinct. This kind of metric was first implemented by Vane-Wright et al. (1991), using taxonomic hierarchies, giving a higher distinctness value species with fewer internal nodes. Afterwards, branch lengths of phylogenetic trees started to be used to inform in more detail species distinctness, by summing evolutionary history in an assemblage (Faith 1992). More recently, other metrics have been developed which measure branch lengths, such as evolutionary distinctness (ED). ED is used by the Edge of Existence Programme (Zoological Society of London), which dedicates conservation efforts to species that are both endangered and phylogenetically distinct. On my study I used "originality” sensu Pavoine et al. (2005) using a quadratic entropy-based index, a metric which considers branch lengths to indicate the number of features shared between species. In other words, originality increases when a species adds new features to the community, therefore representing species' contributions to complementarity. Phylogenetic originality poorly correlated to functional originality, partly due to some species having large mismatches between both originality values. These "mismatched" original species call for special attention as they may be key components to understand the evolutionary divergence of the clade (e.g. Bonnemaisonia hamifera, Vertebrata fruticulosa, Palmaria palmata).

Contrasting to the use of phylogenetic originality or uniqueness measures, it has been argued that maximizing PD may not reliably capture FD. A study by Mazel et al. (2018) with vertebrates has shown that when only one of two closely related species might be selected in prioritization schemes in an area, it often happens that close relatives have distinct traits, which reduces the volume of the "protected" functional space. In my example, there were many close relatives with divergent traits such as Palmaria palmata and Rhodothamniella floridula, with the latter being one of the most functionally original species. The mismatch I found between 
species' relatedness and functional differences (both in traits and originalities) points towards the same direction - that maximizing PD might not be a good surrogate to conserve the most FD in seaweeds. However, any conservation effort for macroalgae will surely involve all groups of algae, whereby including the evolutionarily distant brown and green algae will likely translate into a better (coarse scale) matching between PD and FD. In the UK, an initial assessment of seaweeds following IUCN criteria has found $1 \%$ of species were in critical status, and $5 \%$ were vulnerable, but $34 \%$ of species were data-deficient, so more distribution data is needed (Wilbraham et al. 2013).

\section{Considering within-species trait variation}

We may see variability as a continuum, scaling from genes to phylogenies, to ultimately be quantified as dissimilarity between individuals (Swenson 2019). In this sense, at the other end of the axis from interspecific phylogenetic differences is intraspecific genetic diversity. The causes and consequences of intraspecific variation to communities has been broadly explored in plant systems (Albert et al. 2010; Hulshof et al. 2013; Burton et al. 2017), but not in seaweeds, although it is known that they can be highly plastic (Demes and Pruitt 2019). I first looked at trait variation within species in chapter 2, with large brown macroalgae, to test if environment-driven differences in traits affects our capacity to understand ecological patterns captured by functional diversity. I found that these species are making adjustments to their environment (where the main difference among sites is wave exposure), as has been previously observed (Blanchette 1997; Wing et al. 2007), but that these changes in morphology do not affect major between-species differences and their consequences to community-level trait means.

Comparing intra- to inter-specific trait variation is important for many aspects of community ecology. Intraspecific variation can have direct and indirect effects on the 
community (Bolnick et al. 2011). Among direct effects, are biotic interactions: variation alters niche breadths, changing the strength of species interactions (Vellend 2006; Pachepsky et al. 2007). The indirect effects include adaptive eco-evolutionary dynamics via heritable (genetic) trait variation which allows rapid evolution (Yoshida et al. 2003). Therefore, even when intraspecific variation is small, changes within species are likely to have important roles in population maintenance. Furthermore, traits with a high intraspecific variation due to plasticity may be more cryptic (e.g. secondary metabolite production, nutrient allocation). Seaweed ecology has much to benefit from studies addressing the causes and consequences of intraspecific variation at different biological levels and across scales (Demes and Pruitt 2019).

\section{Seaweed traits vs. functional groups}

Historically, functional groups have been used by seaweed ecologists more broadly than functional traits. In one hand, grouping approaches they allow practical and rapid assessments of assemblages and serve as surrogate for morphological (and ecological) similarity (Littler and Littler 1980; Steneck and Dethier 1994). In the other hand, functional traits can reflect adaptive strategies and physiological trade-offs in more detail, often in a multidimensional way. In chapter 5, I explored different grouping approaches to test how much they capture the functional traits I have measured (this chapter was led by Alizée Mauffrey).

The main results from this study show that morphology and anatomy-based groups (e.g. sheet, thick leathery, finely branched) explained about a third of multivariate traits, which was better than categorisations of vertical space use (canopy x turf grouping accounted for about a quarter trait expression). By plotting species in a trait space, we found considerable overlap between groups in all grouping approaches. By using emergent groups - a posteriori grouping based on traits - we could observe, for example, the split within the group of "thick leathery" algae into two groups, highlighting how even seemingly distinct groups can hold a high 
variability within them. The relevance of findings such as this is, for example, for conservation and invasion ecology. One of the most invasive species of seaweed is the kelp wakame (Undaria pinnatifida), which was not grouped with other kelp in our a posteriori groups. This suggests that the impacts of the establishment of this species - and perhaps substitution of other kelps - may be poorly predicted if based only on the functional group to which this species belong. The fact that kelps can be largely different, however, is not new (Teagle et al. 2017), but this case exemplifies the potential oversight by groupings based on gross morphology.

Functional traits and emergent groups offer more ecologically informative alternatives to traditional macroalgal groups; however, when time or resources are scarce, measuring a range of functional traits and species can be impossible. In such cases, grouping approaches are still useful, but we provide evidence that they may underestimate functional diversity. We then proposed that, if researchers make a practical choice of grouping species, they use our nine-group emergent scheme. Alternatively, as we made the trait data set available, researchers can still use the emergent grouping approach on their focus species, to reduce trait information; this method would still provide a more explanatory alternative to traditional functional groupings. It is important to note that our nine-group emergent scheme is not a fixed group, where new species can be easily assigned to an existing group based on their morphology. Emergent groups are, by definition, based on underlying, directly measured traits, therefore they are not analogous to the morpho-functional groups, but a method to simplify multivariate trait information. For example, in chapter 3, I used emergent groups to describe functional redundancy.

\section{Seaweeds and traits in the Anthropocene}

As the species diversity and composition of marine species and communities rapidly changes in the Anthropocene (Harley 2011; Blowes et al. 2019), elucidating responses of 
functional diversity becomes a priority. Among anthropogenic effects on biodiversity, canopy loss has been reported worldwide, as a result from water pollution and increasing storms, for example (Mangialajo et al. 2008; Valdivia 2012). Canopy-forming seaweeds (large brown macroalgae: fucoids and kelp) were generally distant to each other in the functional space. Although it is known that the disappearance of canopy species from ecosystems has large impacts on primary production, food webs and possibly coastal defence (Smale et al. 2013), the lack of redundancy among canopy-forming species indicates that the functions they individually perform are also susceptible to changes in community composition. For example, Ascophyllum nodosum is projected to decrease in abundance with rising temperatures and wave energy (Hawkins et al. 2009). There are no other mid-shore canopy-forming species with similar trait values, or any other species at the whole intertidal positioned as far up the first trait axis, which relates to all the three main eco-physiological aspects mentioned - photosynthesis, structure and space use. Thus, we can expect a loss of A. nodosum to have disproportional effects on important coastal ecosystem services, including productivity, carbon storage, and habitat provision.

Another consequence of anthropogenic climate change is ocean acidification; along natural gradients at volcanic $\mathrm{CO}_{2}$ vents, studies have demonstrated diversity loss of macroalgae with increasing acidification in benthic (Teixidó et al. 2018) and rocky shore communities (Hall-Spencer et al. 2008). Among the species lost with decreasing $\mathrm{pH}$ are calcifying algae (e.g. Corallina spp. and Ellisolandia spp.). Although there is an ongoing debate on whether calcifying organisms are a carbon source or sink, carbonate has as role in the consolidation of organic carbon deposits (see Macreadie et al. 2019) which have a high longevity, thus contributing to long term carbon storage (van der Heijden and Kamenos 2015). Added to the high abundance of coralline algae across the intertidal, we can expect their reduction or extinction to be of significant ecological impact, with potential cascading effects in these 
coastal ecosystems. Therefore, future studies would greatly benefit from using the functional approach (with continuous traits) along gradients such as coastal development, ocean acidification (volcanic vents), and climate change-driven species loss or turnover.

\section{Future directions and challenges}

During my $\mathrm{PhD}$ I have explored the bases of seaweed functional traits, comparing variability across individuals, species, clades, and environments. I have found that continuously measured traits can inform many aspects of macroalgal ecology, which allowed me to explore different dimensions of intertidal communities. The results I found and the trait data itself can help future investigations of coastal ecology. Among future directions, empirically testing the proportional and interacting role of biotic and environmental drivers on trait variation will allow scaling from short-term individual response to long-term ecosystem functioning. Another avenue I believe is important to take is to increase the spatial scale and project changes to functional diversity of seaweed assemblages across the globe as a consequence of anthropogenic changes. Some progress has been made on predicting distribution of key seaweed species under different future scenarios (Martínez et al. 2012); including functional traits should improve or understanding of how species have responded (Pacifici et al. 2017) and will respond (Pessarrodona et al. 2019) to accelerating changes in their habitats.

Functional traits may be of great use in ecological monitoring schemes of water systems, such as the EU Water Framework Directive (WFD). One of the assessment tools of the WFD is the macroalgal index based on shore surveys, which includes species' life-history characteristics (e.g. perennial, opportunists) and their algal group. Undoubtedly these are practical and informative guides, accessible to non-specialists. However, including the continuous functional traits $\mathrm{I}$ used in my $\mathrm{PhD}$ could provide a deeper assessment of the 
ecological status of the British shores and water bodies. For example, surveys across a temporal scale would indicate whether changes in species composition are causing alterations to ecosystem functioning.

Finally, a goal worth pursuing is coordinated trait screening initiatives that will expand our data on seaweed traits, following efforts in terrestrial plants (Díaz et al. 2016). This will allow functional diversity of seaweed to be resolved across more species and environments around the world.

\section{Overall conclusions}

My attempts to position macroalgae species in a continuous and multidimensional space provided some detail into the functional diversity of these organisms. Functional traits varied between and within species, across intertidal zones and sites of different wave exposure, illustrating how they can be used to ask different ecological questions. Different metrics provided complementary perspectives on how these changes in species-level functional traits scaled to community structure: for example, functional richness showed varying range of available traits across intertidal zones; community weighted means showed shifts in trait values and therefore potential for shifts in functions. While traits were associated to axis of variation among species, parts of the functional space showed distinct levels of redundancy. Some species deserve more attention in the conservation of ecological functions, although all species appear to contribute to the diversity of ecosystem functions, whether by being distinct or redundant.

Functional, continuously measured, trait data require a lot of effort and are timeconsuming, but they allow the elucidation of community patterns in a way that taxonomy-based studies cannot: traits are the mechanistic link between organisms and their environment. Moreover, unified trait screening efforts should lead us to a widely available data base of 
seaweed traits, which will facilitate studies of functional diversity. Under the "functional lens" we can improve our understanding of coastal ecology and provide tools for ecological monitoring, which will contribute to the conservation of these important, but understudied, organisms.

\section{References}

Albert CH, Thuiller W, Yoccoz NG, et al (2010) Intraspecific functional variability: extent, structure and sources of variation. Journal of Ecology 98:604-613. https://doi.org/10.1111/j.13652745.2010.01651.x

Bertness MD, Leonard GH, Levine JM, et al (1999) Testing the relative contribution of positive and negative interactions in rocky intertidal communities. 80:16

Blanchette CA (1997) Size and survival of intertidal plants in response to wave action: a case study with Fucus gardneri. Ecology 78:1563-1578. https://doi.org/10.1890/00129658(1997)078[1563:SASOIP]2.0.CO;2

Blowes SA, Supp SR, Antão LH, et al (2019) The geography of biodiversity change in marine and terrestrial assemblages. Science 366:339-345. https://doi.org/10.1126/science.aaw1620

Bolnick DI, Amarasekare P, Araújo MS, et al (2011) Why intraspecific trait variation matters in community ecology. Trends in Ecology \& Evolution 26:183-192. https://doi.org/10.1016/j.tree.2011.01.009

Boyé A, Thiébaut É, Grall J, et al (2019) Trait-based approach to monitoring marine benthic data along $500 \mathrm{~km}$ of coastline. Divers Distrib ddi.12987. https://doi.org/10.1111/ddi.12987

Burton JI, Perakis SS, McKenzie SC, et al (2017) Intraspecific variability and reaction norms of forest understorey plant species traits. Funct Ecol 31:1881-1893. https://doi.org/10.1111/1365-2435.12898

Chappuis E, Terradas M, Cefalì ME, et al (2014) Vertical zonation is the main distribution pattern of littoral assemblages on rocky shores at a regional scale. Estuarine, Coastal and Shelf Science 147:113122. https://doi.org/10.1016/j.ecss.2014.05.031

Chung IK, Beardall J, Mehta S, et al (2011) Using marine macroalgae for carbon sequestration: a critical appraisal. J Appl Phycol 23:877-886. https://doi.org/10.1007/s10811-010-9604-9

Demes KW, Pruitt JN (2019) Individuality in seaweeds and why we need to care. J Phycol 55:247-256. https://doi.org/10.1111/jpy.12845

Díaz S, Cabido M (2001) Vive la différence: plant functional diversity matters to ecosystem processes. Trends in Ecology \& Evolution 16:646-655. https://doi.org/10.1016/S0169-5347(01)02283-2

Edwards MS and Connell SD (2012) Competition, a Major Factor Structuring Seaweed Communities. In: Wienke C and Bischof K (eds.) Seaweed Biology: Novel Insights into Ecophysiology, Ecology and Utilization. Springer-Verlag Berlin.

Faith DP (1992) Conservation evaluation and phylogenetic diversity. Biological Conservation 61:1-10. https://doi.org/10.1016/0006-3207(92)91201-3 
Forest F, Grenyer R, Rouget M, et al (2007) Preserving the evolutionary potential of floras in biodiversity hotspots. Nature 445:757-760. https://doi.org/10.1038/nature05587

Griffin JN, Méndez V, Johnson AF, et al (2009) Functional diversity predicts overyielding effect of species combination on primary productivity. Oikos 118:37-44. https://doi.org/10.1111/j.16000706.2008.16960.x

Hall-Spencer JM, Rodolfo-Metalpa R, Martin S, et al (2008) Volcanic carbon dioxide vents show ecosystem effects of ocean acidification. $454: 4$

Harley CDG (2011) Climate Change, Keystone Predation, and Biodiversity Loss. Science 334:11241127. https://doi.org/10.1126/science.1210199

Hawkins S, Sugden H, Mieszkowska N, et al (2009) Consequences of climate-driven biodiversity changes for ecosystem functioning of North European rocky shores. Marine Ecology Progress Series 396:245-259. https://doi.org/10.3354/meps08378

Hulshof CM, Violle C, Spasojevic MJ, et al (2013) Intra-specific and inter-specific variation in specific leaf area reveal the importance of abiotic and biotic drivers of species diversity across elevation and latitude. Journal of Vegetation Science 24:921-931. https://doi.org/10.1111/jvs.12041

Isaac NJB, Turvey ST, Collen B, et al (2007) Mammals on the EDGE: Conservation Priorities Based on Threat and Phylogeny. PLoS ONE 2:e296. https://doi.org/10.1371/journal.pone.0000296

Jenkins M (2003) Prospects for Biodiversity. Science 302:1175-1177. https://doi.org/10.1126/science.1088666

Lean C and Maclauring J (2016) The value of phylogenetic diversity. Pellens R and Grandcolas P (eds.) In: Biodiversity Conservation and Phylogenetic Systematics. Springer International Publishing AG Switzerland.

Lefcheck JS, Duffy JE (2015) Multitrophic functional diversity predicts ecosystem functioning in experimental assemblages of estuarine consumers. Ecology 96:2973-2983. https://doi.org/10.1890/141977.1

Littler MM, Littler DS (1980) The Evolution of Thallus Form and Survival Strategies in Benthic Marine Macroalgae: Field and Laboratory Tests of a Functional Form Model. The American Naturalist 116:2544. https://doi.org/10.1086/283610

Macreadie PI, Anton A, Raven JA, et al (2019) The future of Blue Carbon science. Nat Commun 10:3998. https://doi.org/10.1038/s41467-019-11693-w

Mangialajo L, Chiantore M, Cattaneo-Vietti R (2008) Loss of fucoid algae along a gradient of urbanisation, and structure of benthic assemblages. Mar Ecol Prog Ser 358:63-74. https://doi.org/10.3354/meps07400

Martínez B, Viejo RM, Carreño F, Aranda SC (2012) Habitat distribution models for intertidal seaweeds: responses to climatic and non-climatic drivers: Distribution models for intertidal seaweeds in north-western Iberia. J Biogeogr 39:1877-1890. https://doi.org/10.1111/j.1365-2699.2012.02741.x

Pachepsky E, Bown JL, Eberst A, et al (2007) Consequences of intraspecific variation for the structure and function of ecological communities Part 2: Linking diversity and function. Ecological Modelling 207:277-285. https://doi.org/10.1016/j.ecolmodel.2007.05.005

Pacifici M, Visconti P, Butchart SHM, et al (2017) Species' traits influenced their response to recent climate change. Nature Clim Change 7:205-208. https://doi.org/10.1038/nclimate3223

Pavoine S, Ollier S, Dufour A-B (2005) Is the originality of a species measurable?: Originality of a species. Ecology Letters 8:579-586. https://doi.org/10.1111/j.1461-0248.2005.00752.x 
Pessarrodona A, Foggo A, Smale DA (2019) Can ecosystem functioning be maintained despite climatedriven shifts in species composition? Insights from novel marine forests. J Ecol 107:91-104. https://doi.org/10.1111/1365-2745.13053

Petchey OL, Gaston KJ (2006) Functional diversity: back to basics and looking forward. Ecol Letters 9:741-758. https://doi.org/10.1111/j.1461-0248.2006.00924.x

Smale DA, Burrows MT, Moore P, et al (2013) Threats and knowledge gaps for ecosystem services provided by kelp forests: a northeast Atlantic perspective. Ecol Evol 3:4016-4038. https://doi.org/10.1002/ece3.774

Sousa-Dias A, Melo RA (2008) Long-term abundance patterns of macroalgae in relation to environmental variables in the Tagus Estuary (Portugal). Estuarine, Coastal and Shelf Science 76:2128. https://doi.org/10.1016/j.ecss.2007.05.039

Steneck RS, Dethier MN (1994) A Functional Group Approach to the Structure of Algal-Dominated Communities. Oikos 69:476. https://doi.org/10.2307/3545860

Sundene O (1973) Growth and reproduction in Ascophyllum nodosum (Phaeophyceae). Norwegian J. of Botany, 20, 249-255.

Tait LW, Hawes I, Schiel DR (2014) Shining Light on Benthic Macroalgae: Mechanisms of Complementarity in Layered Macroalgal Assemblages. PLoS ONE 9:e114146. https://doi.org/10.1371/journal.pone.0114146

Teagle H, Hawkins SJ, Moore PJ, Smale DA (2017) The role of kelp species as biogenic habitat formers in coastal marine ecosystems. Journal of Experimental Marine Biology and Ecology 492:81-98. https://doi.org/10.1016/j.jembe.2017.01.017

Teixidó N, Gambi MC, Parravacini V, et al (2018) Functional biodiversity loss along natural CO2 gradients. Nat Commun 9:5149. https://doi.org/10.1038/s41467-018-07592-1

Topinka J, Tucker L, Korjeff W (1981) The Distribution of Fucoid Macroalgal Biomass Along Central Coastal Maine. Botanica Marina, 24 (6), 311-320. doi:10.1515/botm.1981.24.6.311

Vadas RL, Wright WA, Miller SL (1990) Recruitment of Ascophyllum nodosum: wave action as a source of mortality. Mar. Ecol. Prog. Ser., 61, 263-272.

Valdivia N (2012) Stressed but Stable: Canopy Loss Decreased Species Synchrony and Metabolic Variability in an Intertidal Hard-Bottom Community. PLoS ONE 7:10

van der Heijden LH, Kamenos NA (2015) Calculating the global contribution of coralline algae to carbon burial. Biogeosciences Discuss 12:7845-7877. https://doi.org/10.5194/bgd-12-7845-2015

Vane-Wright RI, Humphries CJ., Williams PH (1991). What to protect? - Systematics and the agony of choice. Biol. Conserv. 55: 235-254

Vellend M (2006) The consequences of genetic diversity in competitive communities. Ecology 87:304311. https://doi.org/10.1890/05-0173

Wilbraham J, Brodie J and Pottas J (2013) Towards a Red List for UK seaweeds. Conference: British Phycological Society Annual Meeting. doi: 10.13140/RG.2.2.11532.31361

Wing SR, Leichter JJ, Perrin C, et al (2007) Topographic shading and wave exposure influence morphology and ecophysiology of Ecklonia radiata (C. Agardh 1817) in Fiordland, New Zealand. Limnology and Oceanography 52:1853-1864. https://doi.org/10.4319/lo.2007.52.5.1853

Yoshida T, Jones LE, Ellner SP, et al (2003) Rapid evolution drives ecological dynamics in a predatorprey system. Nature 424:303-306. https://doi.org/10.1038/nature01767 
Supplementary material 
Appendices for Chapter 2: "Applying continuous functional traits to large brown macroalgae: variation across tidal emersion and wave exposure gradients."

\section{Appendix 1.}

Water nutrient analysis: We collected three $50 \mathrm{~mL}$ samples of seawater at each site, on three occasions (September 2017, April and July 2018). Samples were filtered and frozen prior to analysis (XY2 Autosampler, Seal Analytical Ltd., Southampton, UK). The results are shown in Table S1.

Water salinity: We collected samples for salinity measurement in August 2018. The aim of this analysis was to confirm that the site located in the ria (Angle Bay, Pembrokeshire), into which several rivers flow, had salinity values representative of fully marine conditions and comparable to those of Gower sites. On the same day, six replicates were collected at Angle Bay and six at Oxwich (a site chosen to represent the Gower sites as it is the mid-site geographically) and analysed with a portable probe (Hanna Instruments, Woonsocket, RI, US). Results are given in Table S1.

Water temperature: We did not expect any differences in water temperature at these sites due to their similar latitudes. Nevertheless, to confirm this, during the first 10 days of October 2018, we deployed temperature loggers (HOBO Pendant, Onset Computer Co., Bourne, MA, US) at each study site on exposed rock on the middle shore and away from the seaweed canopy. Values were averaged from measurements taken at 10-minute intervals during four hours of daytime high tide. Results are shown in Table S1.

Table S1. Averages of seawater nutrient concentrations, salinity, and temperature. TON: Total Oxidized Nitrogen. Standard deviations are given in parenthesis.

\begin{tabular}{|c|c|c|c|c|c|c|c|}
\hline \multirow{2}{*}{ Sites } & \multicolumn{5}{|c|}{ Nutrients $\left(\mu \mathrm{mol} \mathrm{L} L^{-1}\right)$} & \multirow{2}{*}{$\begin{array}{r}\text { Salinity } \\
\text { (ppt) }\end{array}$} & \multirow{2}{*}{$\begin{array}{r}\text { Water temp. } \\
\left({ }^{\circ} \mathrm{C}\right)\end{array}$} \\
\hline & TON & $\mathrm{NH}_{4}$ & $\mathrm{NO}_{2}$ & $\mathrm{PO}_{4}$ & $\mathrm{SiO}_{3}$ & & \\
\hline Angle Bay & $3.02(1.9)$ & $2.98(1.3)$ & $0.21(0.3)$ & $1.37(0.4)$ & $5.77(3.8)$ & $33.4(0.1)$ & $20.4(1.3)$ \\
\hline Bracelet Bay & 3.77 (3.2) & $3.10(2.3)$ & $0.24(0.4)$ & $1.30(0.3)$ & $4.41(5.7)$ & & $20.1(0.3)$ \\
\hline Oxwich & $1.44(0.2)$ & $3.23(1.9)$ & $0.23(0.3)$ & $1.18(0.3)$ & $5.35(6.7)$ & $32.22(2.4)$ & $19.9(0.4)$ \\
\hline Rhossili & $3.22(2.4)$ & $3.98(2.4)$ & $0.23(0.3)$ & $1.53(0.4)$ & $3.90(3.5)$ & & $20.7(1.3)$ \\
\hline
\end{tabular}




\section{Appendix 2.}

\section{PCA tests}

Imputation of missing trait values. Of the 167 samples, some had missing values for a trait, which were imputed so we could perform the ordination with all the traits without removing entire samples due to one or two missing values. The total missing values for each trait were: STA ( $n=4)$, SAV (35), thickness (2) and holdfast ratio (17). To make sure this imputation did not affect our conclusions, we ran another PCA after removing individuals with missing values instead of imputing them. The contributions of each trait to the first three axes are shown in Table S2, together with contributions of traits with imputed values. The only change was a shift in the order of importance in the loadings of PC2 from holdfast ratio to length. Fig. S2 shows the PCA plot with the samples with missing values removed.

Removing the trait $S A V$. We had a concern over the potential effect of two correlated traits on the principal component. Those were STA and SAV, with a correlation of $r=0.76$. So, we performed a PCA without SAV to observe any differences with the main PCA with all six traits. We then correlated the coordinates of the individuals between both methods, on the PCA axes 1 and 2, and found a high correlation of 0.97 for both axes. Therefore, we were confident to keep SAV on the analyses.

Table S2. Contributions of each trait to the first three PCA axes, on all eight study species. On the left, as used for the PCA on main text; on the left, after rows were removed when there was a missing value for one or more traits. Variation explained is given below each axis, in italic. Values are percentages. Main contributions highlighted in bold.

\begin{tabular}{lrrrrrr}
\hline & \multicolumn{3}{c}{ Missing values imputed } & \multicolumn{3}{c}{ Missing values removed } \\
\cline { 2 - 7 } & Axis 1 & Axis 2 & Axis 3 & Axis 1 & Axis 2 & Axis 3 \\
& 46.1 & 21.5 & 16.7 & 48.4 & 21.6 & 16 \\
\hline Thickness & 15.99 & $\mathbf{2 6 . 4 1}$ & 1.03 & 14.05 & $\mathbf{2 9 . 8 7}$ & 2.62 \\
TDMC & $\mathbf{2 2 . 0 8}$ & 12.27 & 0.26 & $\mathbf{2 3 . 3}$ & 7.75 & 0.23 \\
STA & $\mathbf{3 5 . 4 7}$ & 0.04 & 0.00 & $\mathbf{3 2 . 4 3}$ & 0.01 & 0.04 \\
Length & 4.73 & 17.97 & $\mathbf{5 0 . 7 5}$ & 4.3 & $\mathbf{2 7 . 2}$ & $\mathbf{4 5 . 9}$ \\
SAV & $\mathbf{1 7 . 7 9}$ & 15.74 & 4.06 & $\mathbf{1 9 . 9 8}$ & 12.85 & 2.15 \\
Holdfast ratio & 3.94 & 27.55 & $\mathbf{4 3 . 8 8}$ & 5.9 & 22.3 & $\mathbf{4 9 . 0 5}$ \\
\hline
\end{tabular}




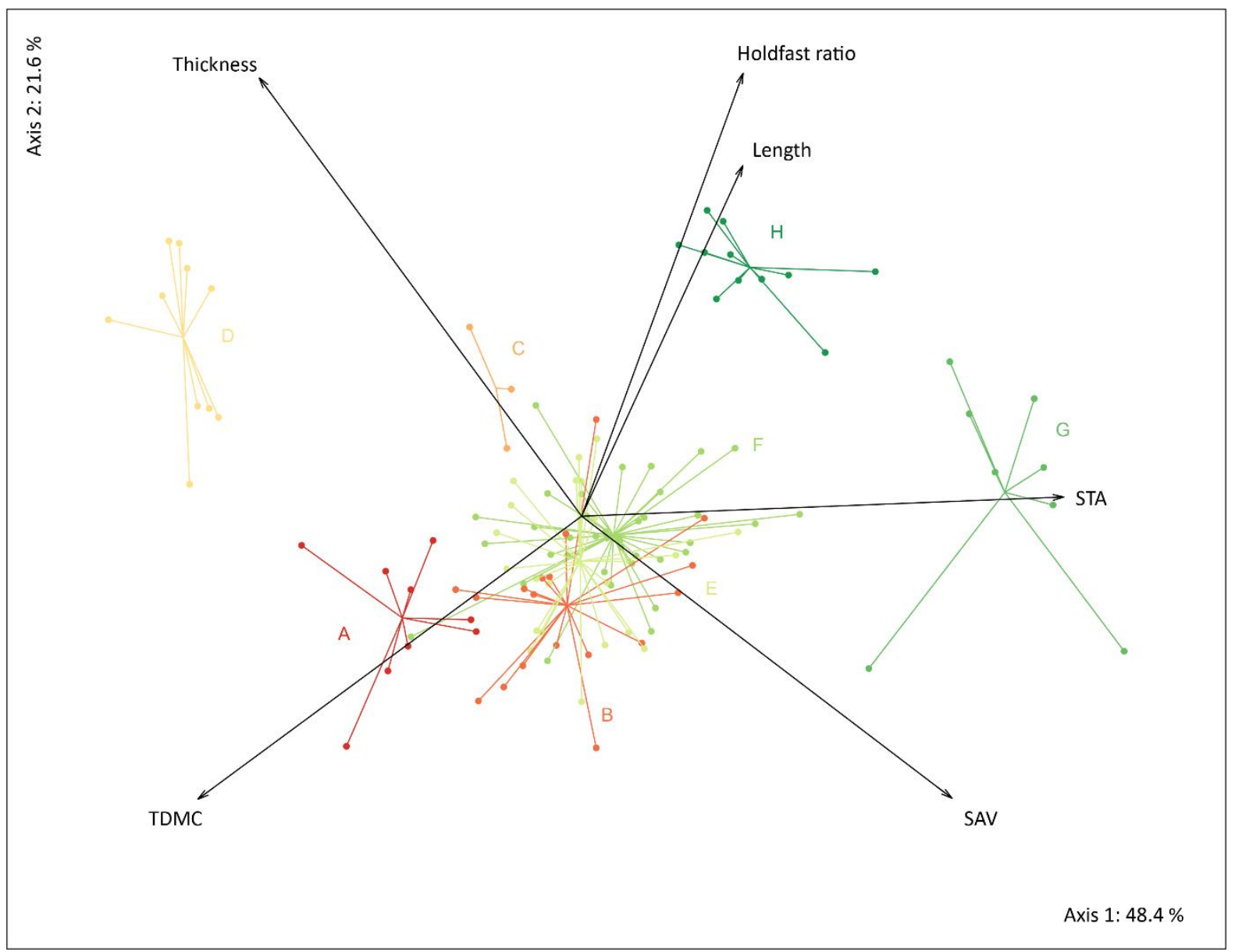

Figure S2. First two PCA axes (samples with missing values removed) of large brown macroalgae species and functional traits at all study sites in south Wales, UK. All eight sampled species are included, and, with the exception of H. siliquosa and S. latissima were found in at least three of the four sites (see main text in Methods and Results for more information on species occurrences and use in analyses). A: Pelvetia canaliculata; B: Fucus spiralis; C: Halidrys siliquosa; D: Ascophyllum nodosum; E: F. vesiculosus; F: F. serratus; G: Saccharina latissima; and H: Laminaria digitata. 


\section{Appendix 3.}

Species traits as response to tidal height. To further investigate intraspecific variability, for each trait we checked if, after accounting for site and species differences (ANOVA with site and species interaction), residual variability could be attributed to variation in tidal height of collected samples. The results are shown in Table S3.

Table S3. Summary of analysis with residuals of each trait from site*species analysis, with relative height as independent variable.

\begin{tabular}{lrrrr}
\hline Species & Estimate & Std. error & T value & P value \\
\hline Thickness & 0.00 & 0.05 & 0.15 & 0.87 \\
TDMC & 0.06 & 0.06 & 0.99 & 0.32 \\
STA & -0.04 & 0.07 & -0.5 & 0.6 \\
Length & 0.02 & 0.17 & 0.09 & 0.92 \\
SAV & 0.06 & 0.11 & 0.55 & 0.58 \\
Holdfast ratio & -0.29 & 0.29 & -1.02 & 0.31 \\
\hline
\end{tabular}



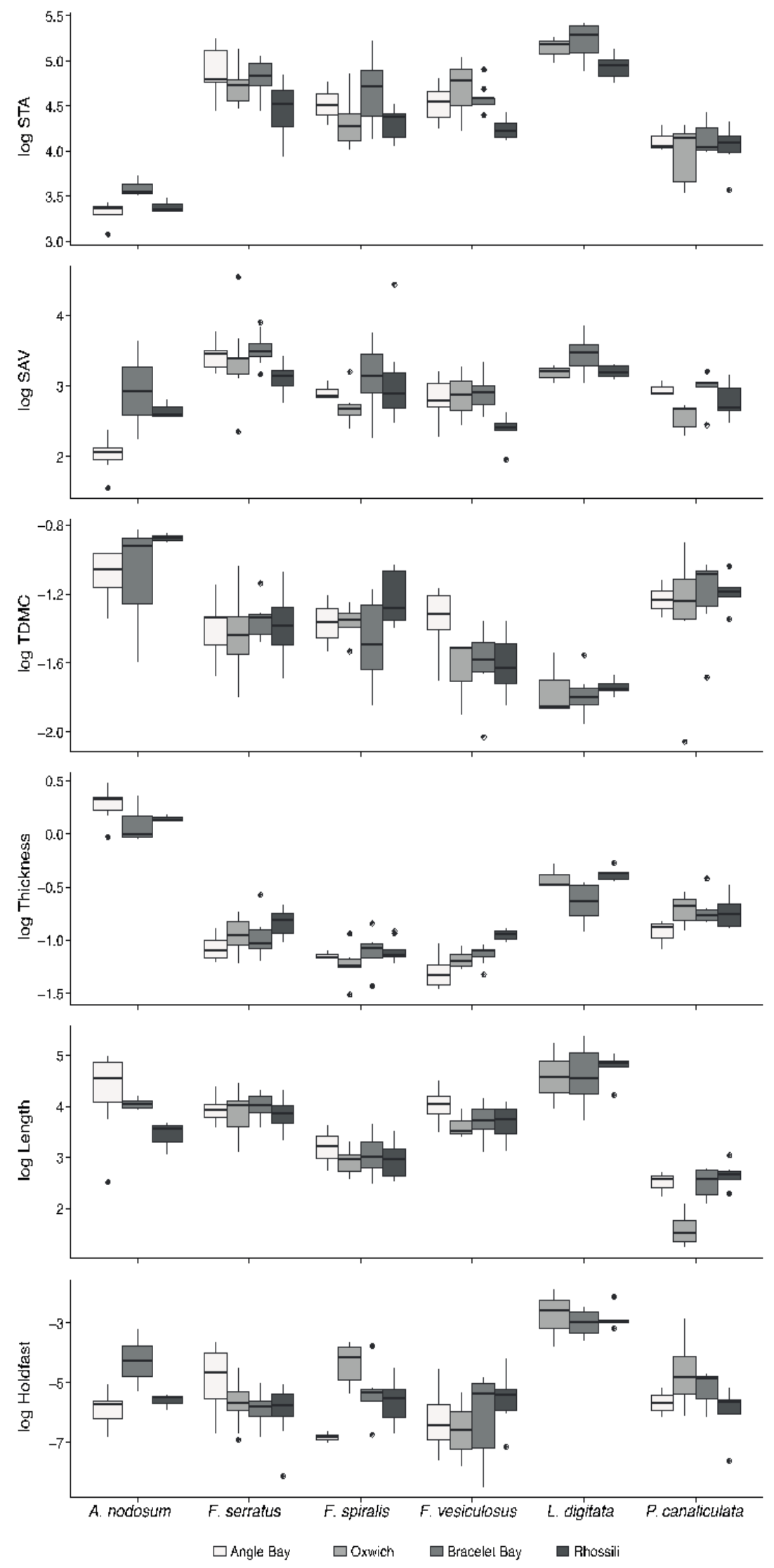

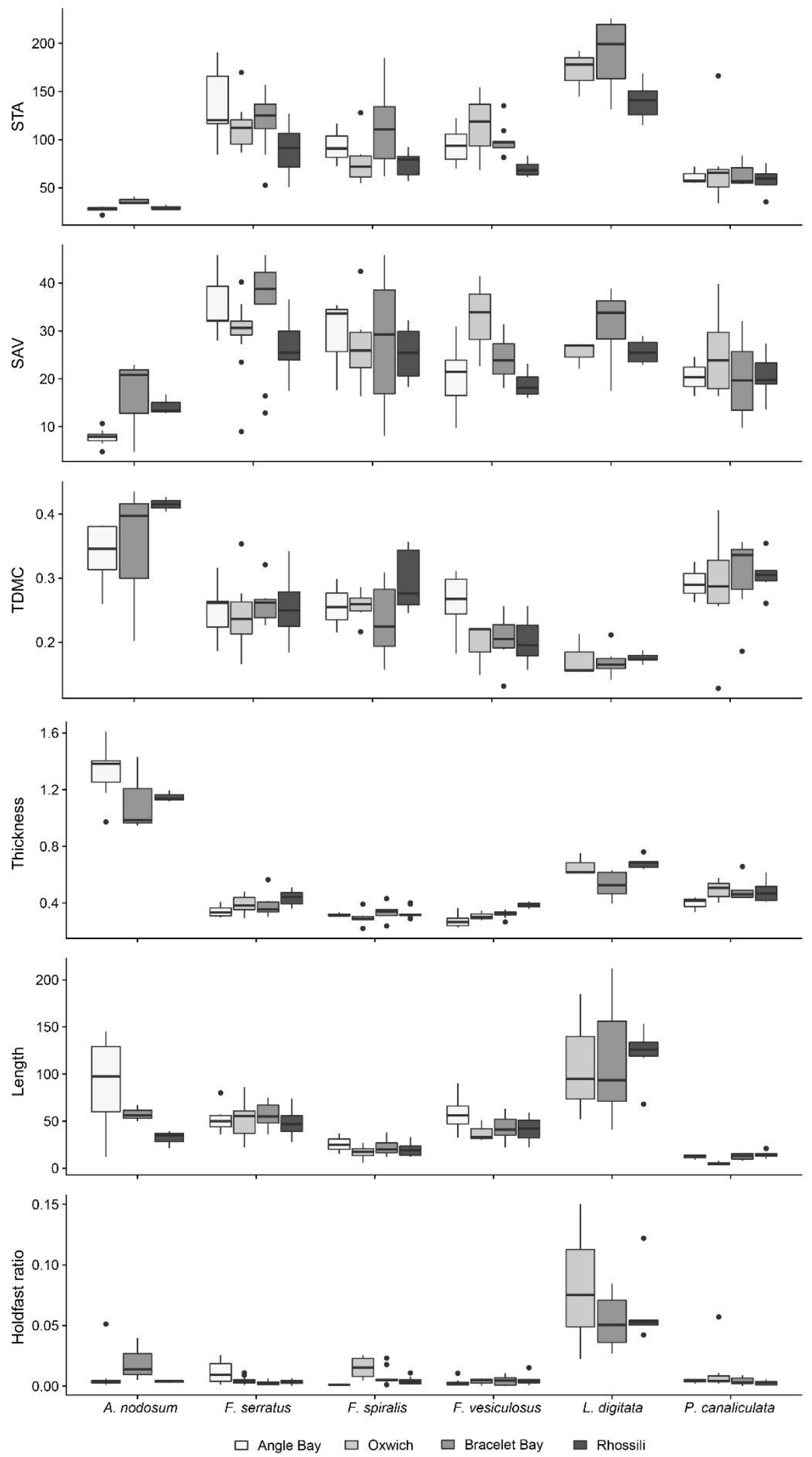

Figure S1 (previous and current pages). Boxplots of species traits (log-transformed above, original below) across the four study sites, for the six species found at more than one site. Grey hue indicates intensity of wave exposure. 


\section{Appendix 4.}

Table S4. Result of the PERMANOVA including all six traits, individual level, for the six species that occurred at more than one site. Degrees of freedom (df), and test statistics (sum of squared differences, mean of squared differences, F-value and $\mathrm{P}$ value) are given, as well as an estimated variance explained (Partial $\mathrm{R}^{2}$ ).

\begin{tabular}{lrrrrrr}
\hline & df & Sum sq & Mean SS & F & $\begin{array}{r}\text { Partial } \\
\mathbf{3 R}^{\mathbf{2}}\end{array}$ & P value \\
\hline Site & 3 & 31.92 & 10.64 & 9.61 & 0.067 & $\mathbf{0 . 0 0 1}$ \\
Species & 5 & 251.09 & 50.22 & 45.69 & 0.529 & $\mathbf{0 . 0 0 1}$ \\
Site $*$ Species & 13 & 44.57 & 3.43 & 3.12 & 0.094 & $\mathbf{0 . 0 0 1}$ \\
Residuals & 134 & 147.29 & 1.10 & & 0.310 & \\
\hline
\end{tabular}

\section{Appendix 5.}

Table S5. Mean and standard deviation of relative height $(\mathrm{RH})$ where each species occurred, at all four study sites, from the 2017 trait survey and the 2018 abundance survey.

\begin{tabular}{lcr}
\hline Species & Mean (SD) RH & \\
\hline & Trait survey & Abundance survey \\
\hline Ascophyllum nodosum & $0.49(0.12)$ & $0.45(0.12)$ \\
Fucus serratus & $0.35(0.15)$ & $0.26(0.12)$ \\
Fucus spiralis & $0.71(0.05)$ & $0.64(0.11)$ \\
Fucus vesiculosus & $0.45(0.15)$ & $0.43(0.10)$ \\
Halidrys siliquosa & $0.58(0.00)$ & NA \\
Laminaria digitata & $0.11(0.04)$ & $0.21(0.10)$ \\
Pelvetia canaliculata & $0.75(0.05)$ & $0.74(0.04)$ \\
Saccharina latissima & $0.30(0.00)$ & $0.31(0.00)$ \\
\hline
\end{tabular}


Appendices for Chapter 3: "Functional diversity of seaweeds declines scale-dependently across an environmental stress gradient."

\section{Appendix 1.}

Additional information regarding traits and Principal coordinate axes. Description of traits used in the study and the methods to collect them; correlations among traits (Table S1) and between traits and PCo axes (Table S2).

List of traits: a) surface area to volume ratio (SA:V); b) specific thallus area (STA); c) surface area to perimeter ratio (SA:P); d) thallus dry matter content (TDMC); e) thickness; f) length; g) branching order, h) Carbon to Nitrogen ratio $(\mathrm{C}: \mathrm{N})$.

Trait measurement methods: To obtain specific thallus area, for traits $a-c$, we scanned the fresh, clean blades, then multiplied by two, as both sides are photosynthetically active. Some species have no distinction of thallus parts (holdfast, stipe and fronds), in which case they were considered in their entirety (thallus), otherwise we took the area of the fronds. To obtain dry mass needed for traits $b$ and $d$, we cleaned and oven-dried the respective fronds/thalli for a week. For $e$, we used an electronic thickness gauge; some species are very fine and delicate, so we measured their thickness under a microscope, with a micrometric scale. For $f$ we used a tape measure or, again for small species, the microscope. $g$ was obtained by counting the number of times the main axis of the thallus divided in two and then calculating the average of five different measurements. Carbon and Nitrogen for $h$ were measured on dry ground samples in an elemental analyser. 


\section{Appendix 1. Sensitivity analyses of diversity metrics by excluding the zone-defining Phaeophytes}

To test any possible bias caused by the species we used to define the zones (dominant Phaeophytes; fucoids and kelp) on the diversity metrics, we ran additional tests removing these species from analyses. Results were largely consistent with the main analyses, i.e. we still observe an effect of zone on all metrics except the SES of Functional richness (Table S1; Fig. S1). However, one change is that the effect of rock pool on the observed functional richness in no longer significant $(\mathrm{p}=0.06$; Table $\mathrm{S} 1)$. For the SES analyses, we observed additional deviance from expected for functional dispersion in the MS+RP-absent and the US communities; for functional richness, instead of LS+RP present, it is LS+RP-absent which shows deviance from null (Fig. S1). Despite these small differences, since we are describing whole communities (including the dominant Phaeophytes) these results should only serve as an indication that the non-expected patterns described in the main text are not strongly biased by the zone-defining species.

Table S1. Summary of main effects from (generalised) linear models ((G)LMs) with diversity dimensions ( $\alpha$-diversity) without zone-defining Phaeophytes, and shore zone and presence of rock pool (RP). For species and emergent group richness we used generalised linear models (family: quasipoisson); for functional richness and dispersion we used general linear models. Significant values are in bold. $\mathrm{RPa}=\mathrm{RP}$ absent; $\mathrm{RPp}=\mathrm{RP}$ present.

\begin{tabular}{|c|c|c|c|c|}
\hline GLMs & Deviance & Res. deviance & F value & P value \\
\hline \multicolumn{5}{|l|}{ Species richness } \\
\hline Zone & 66.955 & 96.078 & 28.299 & $<0.001$ \\
\hline $\mathrm{RP}$ & 10.043 & 86.034 & 8.489 & $<0.001$ \\
\hline Zone * RP & 0.118 & 85.916 & 0.050 & 0.95 \\
\hline \multicolumn{5}{|l|}{ Emergent group richness } \\
\hline Zone & 8.373 & 21.05 & 16.942 & $<0.001$ \\
\hline $\mathrm{RP}$ & 1.463 & 19.587 & 5.920 & 0.017 \\
\hline Zone * RP & 0.215 & 19.371 & 0.436 & 0.648 \\
\hline LMs & Sum of Squares & Mean SSq & F value & P value \\
\hline \multicolumn{5}{|l|}{ Functional richness } \\
\hline Zone & 51.25 & 25.626 & 5.523 & 0.006 \\
\hline $\mathrm{RP}$ & 16.59 & 16.588 & 3.575 & 0.063 \\
\hline Zone * RP & 10.26 & 5.129 & 1.105 & 0.337 \\
\hline \multicolumn{5}{|l|}{ Functional dispersion } \\
\hline Zone & 3.276 & 1.638 & 4.015 & 0.022 \\
\hline $\mathrm{RP}$ & 2.526 & 2.526 & 6.193 & 0.015 \\
\hline Zone * RP & 0.31 & 0.155 & 0.38 & 0.685 \\
\hline \multicolumn{5}{|l|}{ SES Functional richness } \\
\hline Zone & 2.31 & 1.155 & 1.55 & 0.219 \\
\hline $\mathrm{RP}$ & 0.00 & 0.001 & 0.002 & 0.965 \\
\hline
\end{tabular}




\begin{tabular}{lrrrr} 
Zone * RP & 2.56 & 1.280 & 1.717 & 0.187 \\
\hline SES Functional & & & & \\
dispersion & & & & \\
\hline Zone & 10.57 & 5.287 & 3.002 & $\mathbf{0 . 0 5 6}$ \\
RP & 6.76 & 6.761 & 3.839 & $\mathbf{0 . 0 5 4}$ \\
Zone * RP & 0.33 & 0.167 & 0.095 & 0.909 \\
\hline
\end{tabular}
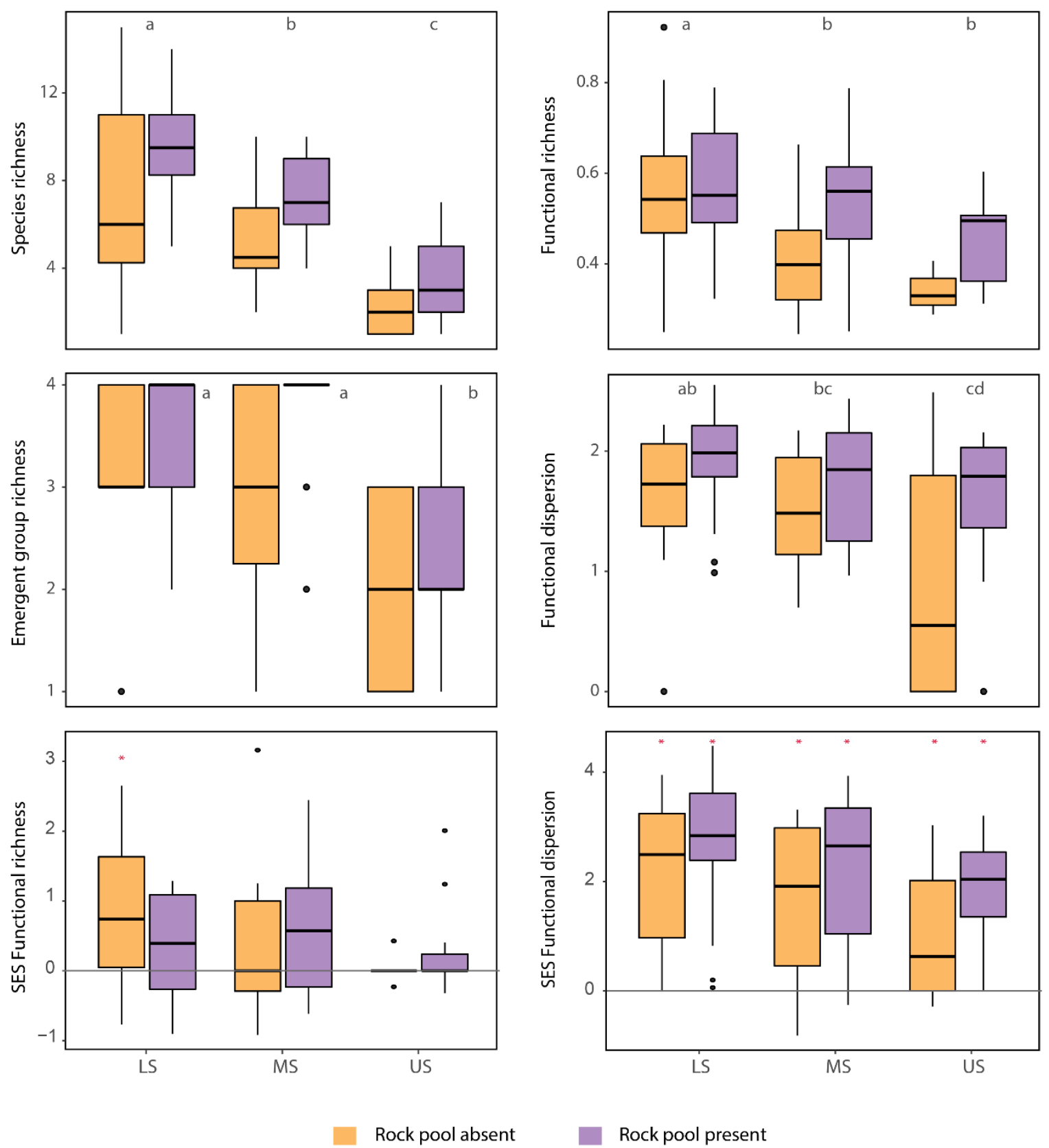

Rock pool present

Figure S1. Observed and SES values of species' and functional $\alpha$-diversity without zone-defining Phaeophytes. Boxplots show values across shore zones $(\mathrm{LS}=$ low shore, $\mathrm{MS}=$ middle shore and US $=$ upper shore), in quadrats with and without rock pools. Functional richness is scaled to the potential maximum (details in Methods). For observed values, different letters on top of boxes indicate zones are 
significantly different. For SES, values above or below the lines indicate deviance from null models, i.e. greater or lower than expected at random (asterisks indicate significance of difference, obtained from one-sample $t$ test, or Wilcoxon rank test when data distribution was not normal).

\section{Appendix 2. Sampling effort across zones and habitats.}

After randomly selecting quadrats to have an equal representation of zone and habitat type $(n=84)$, to test if we adequately sampled the three shore zones among the two habitat categories, we plotted species accumulation curves and extrapolated species richness per community (Chao1 index). We used functions specaccum and specpool, respectively, on vegan package (Oksanen et al. 2019). Accumulation curves started to stabilize, but did not fully reach an asymptote, indicating that more sampling would still add to the list of species (Fig. S2). In general, the richness in the upper shore was better sampled (Table S2), and at least $79 \%$ of each community was estimated, compared to the extrapolated richness values. Despite the small underestimation of the lower/middle shore, we still observed higher alpha diversity and SES values in the lower zones, therefore we can be safe that these results are not a product of a sampling bias - at worst they are an underestimation of low-shore richness and diversity.

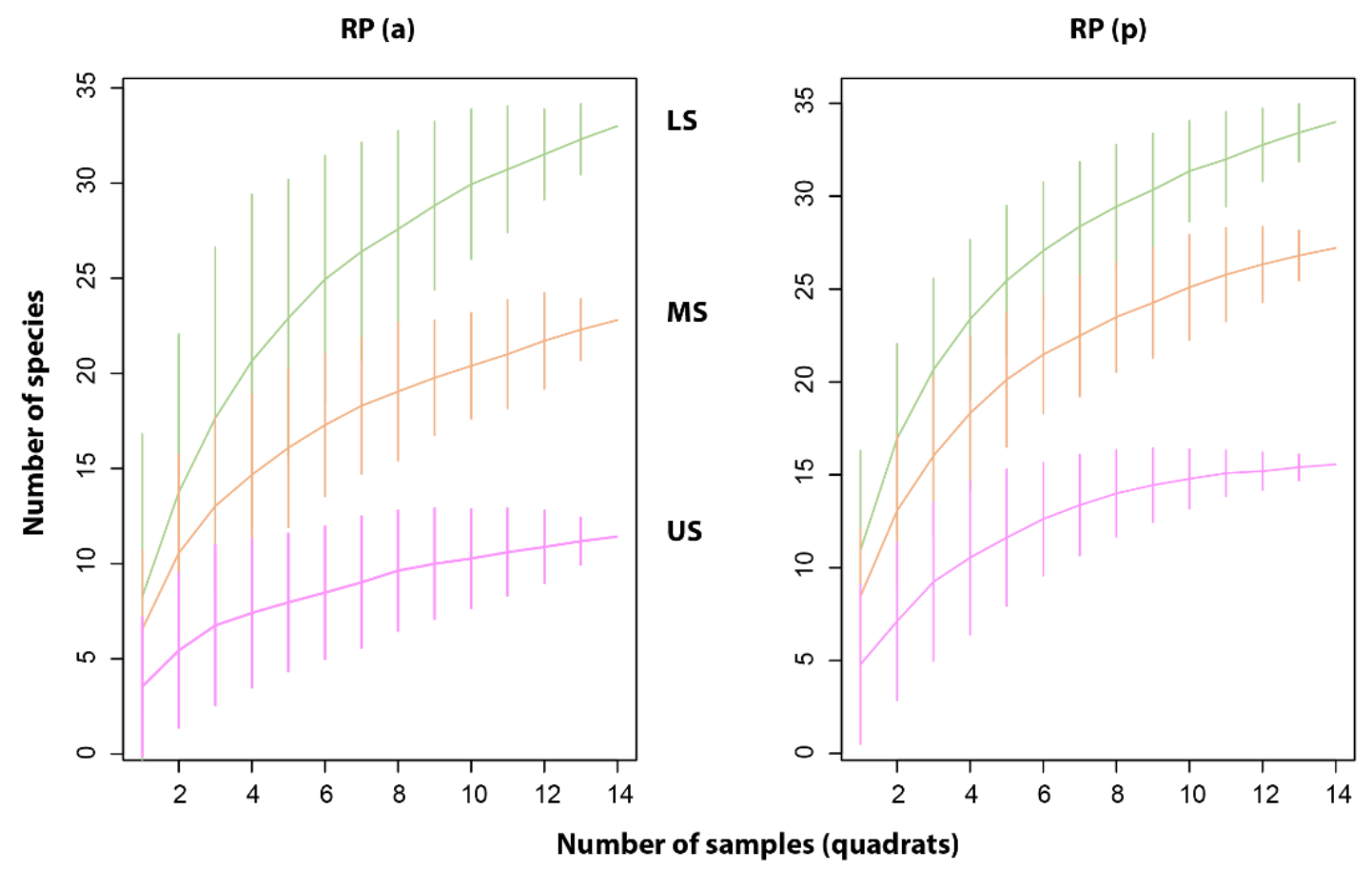

Figure S2. Species accumulation curves for the three shore zones (LS=low shore, MS=middle shore and US=upper shore), for the two habitat categories $(\mathrm{RP}(\mathrm{a})=$ rock pool absent and $\mathrm{RP}(\mathrm{p})=$ rock pool present). 
Table S2. Observed and extrapolated species richness. Number of species (incidence-based) with method Chao, by each zone overall and among habitat categories $(\mathrm{RP}(\mathrm{a})=$ rock pool-absent, $\mathrm{RP}(\mathrm{p})=$ rock pool-present). $\%=$ how much of estimated richness was sampled, in percentage.

\begin{tabular}{|c|c|c|c|c|}
\hline Community & Category & Low shore & Middle shore & Upper shore \\
\hline Observed & \multirow{3}{*}{ overall } & 41 & 31 & 18 \\
\hline Extrapolated & & 49 & 37 & 19 \\
\hline$\%$ & & 84 & 84 & 95 \\
\hline Observed & \multirow{3}{*}{$\mathrm{RP}(\mathrm{a})$} & 33 & 23 & 11 \\
\hline Extrapolated & & 39 & 30 & 18 \\
\hline$\%$ & & 85 & 77 & 61 \\
\hline Observed & \multirow{3}{*}{$\mathrm{RP}(\mathrm{p})$} & 34 & 27 & 15 \\
\hline Extrapolated & & 46 & 37 & 15 \\
\hline$\%$ & & 74 & 73 & 100 \\
\hline
\end{tabular}

\section{Appendix 3. Additional information regarding traits and Principal coordinate analysis.}

List of traits: a) surface area to volume ratio $(\mathrm{SA}: \mathrm{V})$; b) specific thallus area (STA); c) surface area to perimeter ratio (SA:P); d) thallus dry matter content (TDMC); e) thickness; f) length; g) branching order, h) Carbon to Nitrogen ratio (C:N).

Trait measurement methods: To obtain specific thallus area, for traits $a-c$, we scanned or photographed the fresh, clean samples. Individuals were scanned on an Epson Perfection V600, V39, (Suwa, Japan) or photographed directly (Pentax K3 digital camera, SMC DA L 18-55 mm, Tokyo, Japan) on a lightbox (MiniSun A1, Manchester, UK). Finer samples were photographed with an imaging microscope (Leica S8AP0, Wetzlar, Germany, affixed with GT Vision GXCAM-H3, Sudbury, UK). Some species have no distinction of thallus parts (holdfast, stipe, and fronds), in which case they were considered in their entirety (thallus), otherwise we took the area of the fronds. Area and perimeter of samples were calculated using the software ImageJ (Schneider et al. 2012). Surface area was multiplied by two, as both sides are photosynthetically active.

To obtain dry mass needed for traits $b$ and $d$, we cleaned and oven-dried the respective fronds/thalli for a week. For $e$, we used an electronic thickness gauge (Digital Micrometers Ltd, DTG03 0.005, DML3032 $0.001 \mathrm{~mm}$, Sheffield, UK); some species are very fine and 
delicate, so we measured their thickness under the microscope, with a micrometric scale. For $f$ we used a tape measure or the microscope. $g$ was obtained by counting the number of times the main axis of the thallus divided in two and then calculating the average of five different measurements. Carbon and Nitrogen for $h$ were measured on dry ground samples in an elemental analyser (PDZ Europa 2020 isotope ratio mass spectrometer interfaced with an ANCA GSL elemental analyser and calibrated with acetanilide).

Table S3. Pearson correlations (R) between all pairs of continuous traits.

\begin{tabular}{|l|c|c|c|c|c|c|c|c|}
\hline & SAV & STA & SA:P & TDMC & Thick & Length & Branch & C:N \\
\hline SAV & 1 & 0.8 & -0.22 & 0.12 & -0.75 & -0.39 & -0.18 & -0.47 \\
\hline STA & & 1 & -0.06 & -0.25 & -0.7 & -0.3 & -0.23 & -0.61 \\
\hline SA:P & & & 1 & -0.23 & 0.17 & 0.52 & -0.21 & 0.29 \\
\hline TDMC & & & & 1 & -0.16 & -0.19 & 0.06 & -0.27 \\
\hline Thick & & & & & 1 & 0.48 & 0.1 & 0.46 \\
\hline Length & & & & & 1 & -0.31 & 0.51 \\
\hline Branch & & & & & & & 1 & 0.15 \\
\hline C:N & & & & & & & & 1 \\
\hline
\end{tabular}

\section{Details on the PCoA and its derived metrics}

The functional space of our study species was reduced via a Gower distance-based PCoA (dbFD; Villéger et al. 2008). We then used the first two dimensions of the PCoA to calculate community-level indices of functional richness and dispersion. To test the quality of the two-dimensional representation of the functional space, we used a function described and created by Maire et al. (2015), which computes the mean squared deviation between the initial functional distance (in this case, Gower) and the standardised distance in the functional space, based on functional dendrograms. It is then possible to choose from several dimensions. Although more dimensions are better, we confirmed that the first two dimensions are in congruence with the initial distance (Fig. S3) and therefore a good representation of the functional space among our study species. 

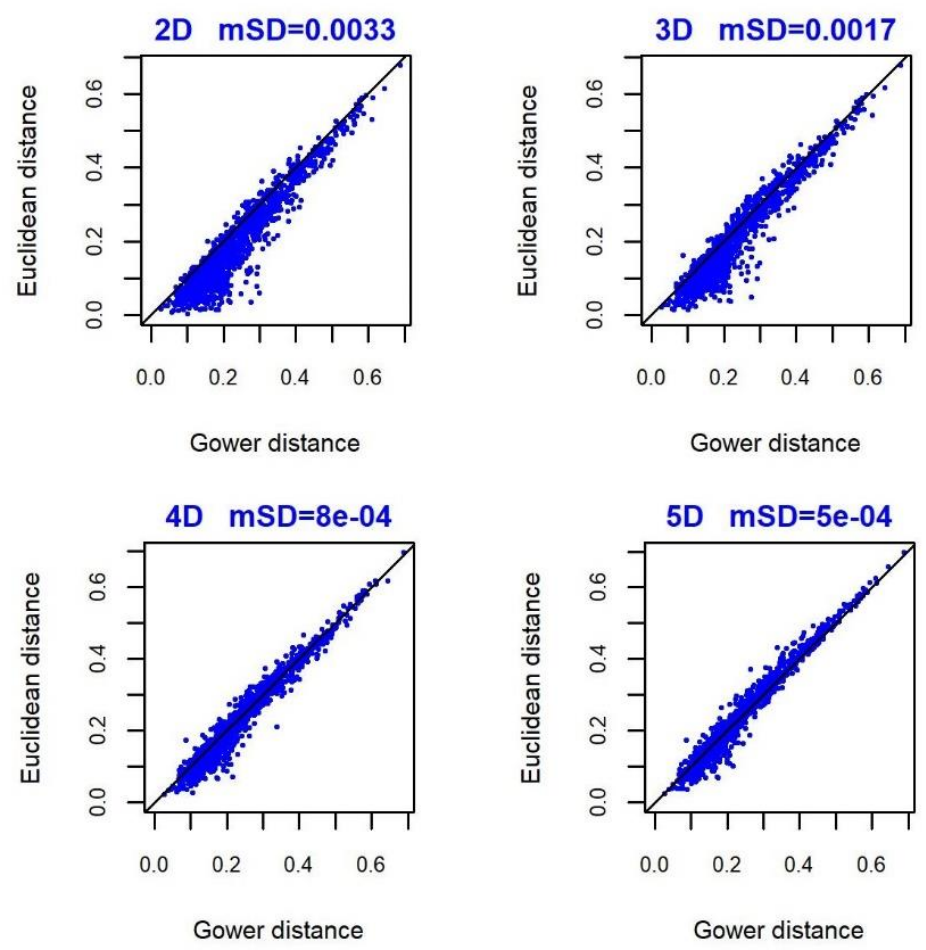

Figure S3. Graphical representation of the quality of functional representation for two to five dimensions. Panels illustrate quality of each n-dimensional functional space built from a principal coordinate analysis, showing correlation of species pairs between initial (Gower) and reduced (Euclidean) functional distances.

At the small scale, only PCo axes 1-2 were kept to meet the requirement of species > traits per community; at the large scale we included one more axis to more faithfully represent the underlying trait variation among species (PCo axes 1-2 and 1-3 explained 60.9\% and 71.6\% of inertia). Note that sampling curves (Fig. S2) indicate that we underestimated total zone-level species richness. The upper zone is closer to estimated asymptotic richness levels than the low or middle zones, indicating that declines in species richness and functional richness (sensitive to species richness) between lower zones and the upper zone are likely to be conservative estimates. Importantly, however, qualitative richness differences across zones were not scaledependent (the sample-based species accumulation curves do not overlap). 
Table S4. Correlation (R) between the first three PCo axes and study traits. ANOVA was used for the categorical trait pneumatocysts (abbreviated as "Pneum."). Strongest associations are highlighted in bold and negative correlations in red.

\begin{tabular}{cccccccccc}
\hline PCo axis & STA & SAV & TDMC & Thickness & Length & SAP & Branching & C:N & Pneum. \\
\hline 1 & $\mathbf{- 0 . 8 5}$ & $\mathbf{- 0 . 8 3}$ & 0.04 & $\mathbf{0 . 8 1}$ & $\mathbf{0 . 6 4}$ & 0.35 & 0.13 & $\mathbf{0 . 7 9}$ & $\mathbf{0 . 4 3}$ \\
2 & 0.34 & -0.01 & $\mathbf{- 0 . 7 9}$ & 0.06 & 0.51 & $\mathbf{0 . 6 1}$ & $\mathbf{- 0 . 4 2}$ & -0.18 & 0 \\
3 & -0.16 & -0.39 & $\mathbf{- 0 . 4 8}$ & 0.35 & -0.29 & -0.36 & $\mathbf{0 . 4 1}$ & -0.36 & 0 \\
\hline
\end{tabular}

Appendix 4. Diversity metrics for each study site individually.
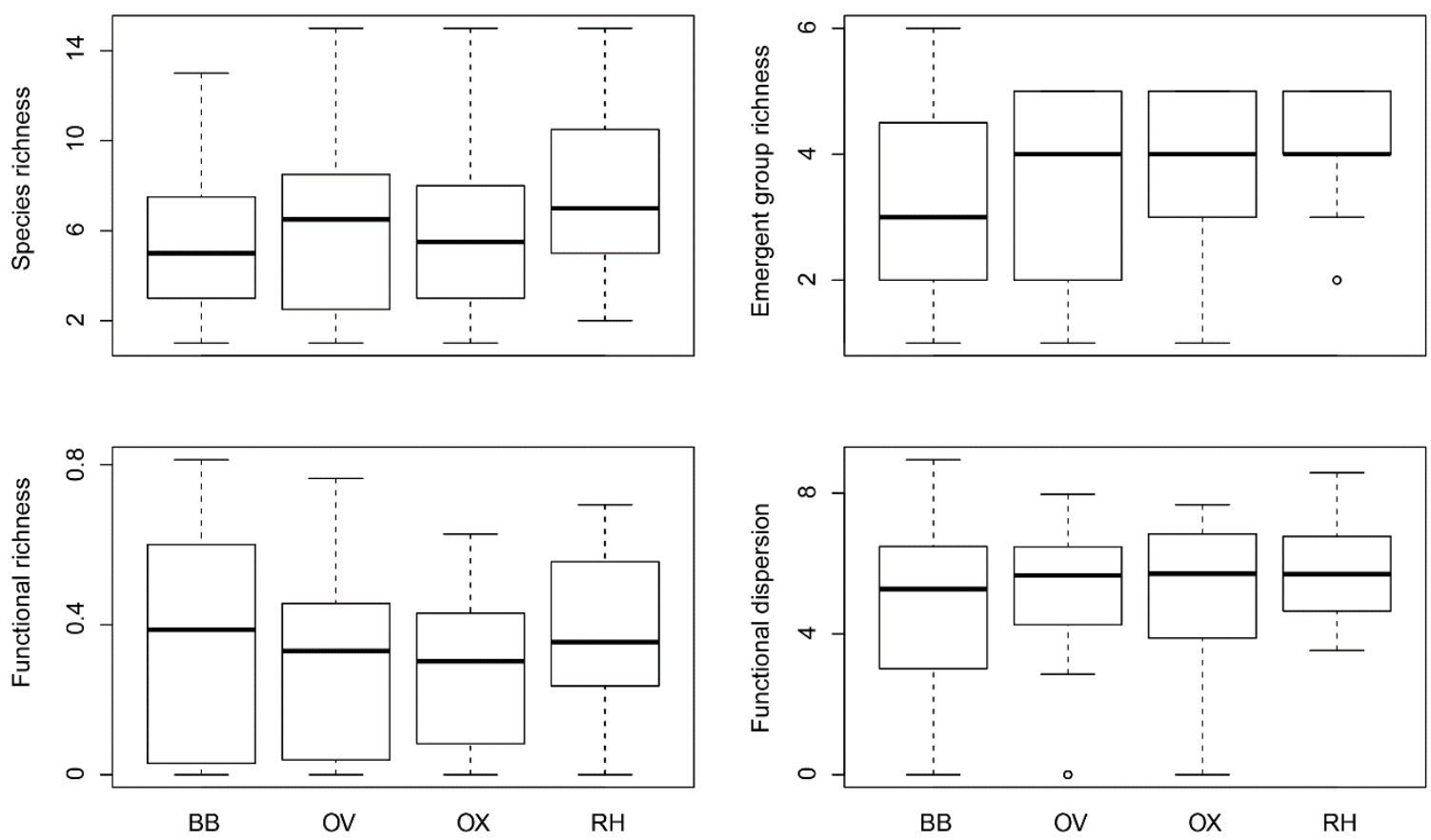

Figure S4. Comparing diversity metrics across sites. Diversity metrics (alpha diversity) measured across all study sites in the Gower peninsula, Wales, UK. Functional richness is scaled to potential maximum (see Methods in main). $\mathrm{BB}=$ Bracelet Bay; $\mathrm{OV}=$ Overton; $\mathrm{OX}=$ Oxwich; $\mathrm{RH}=$ Rhossili. 


\section{Appendix 5. Relationship between functional richness and species richness.}
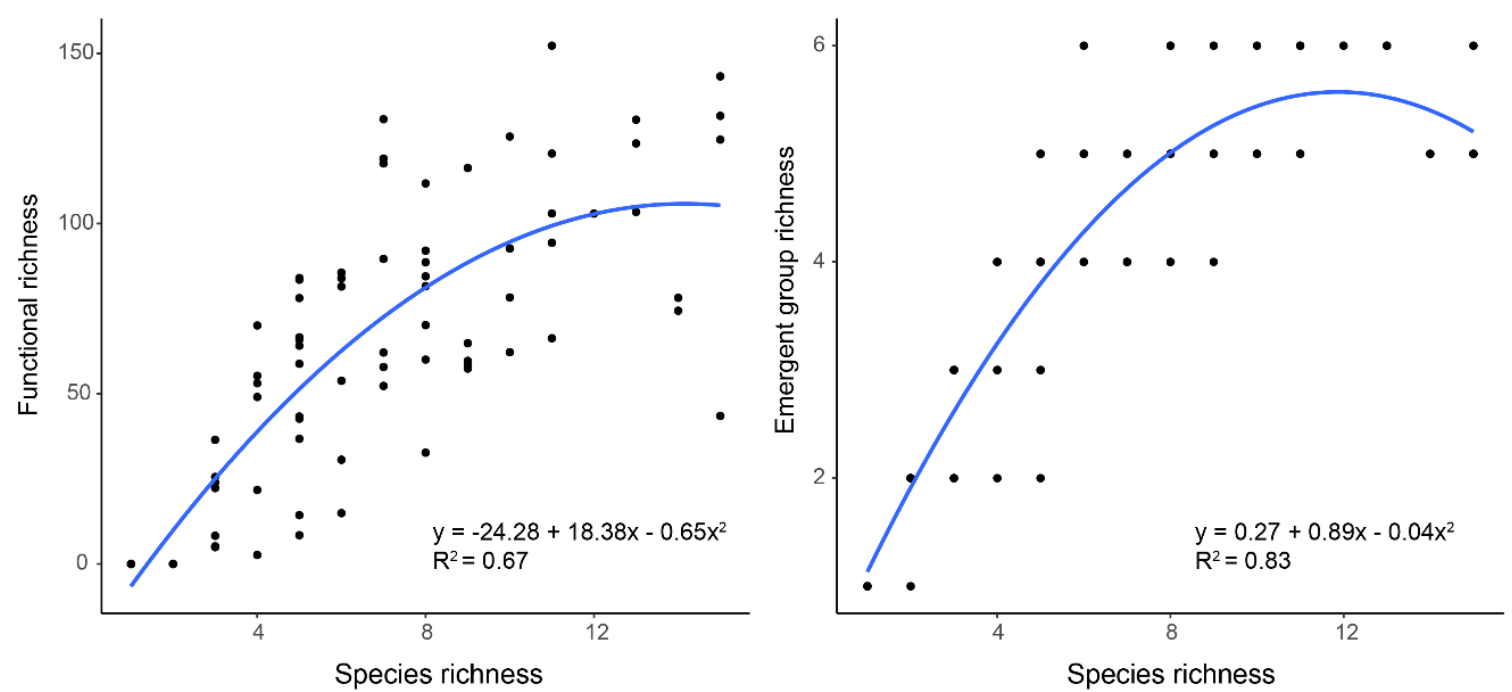

Figure S5. Relationships (quadratic regression) between functional richness and species richness, and correlation between emergent group richness and species richness, across intertidal macroalgae communities. 


\section{Appendix 6. Results from standardised effect sizes (SES) constrained within zones.}

We ran additional null models to isolate the effect of factors within zones from the large effect of the intertidal gradient. We did that by constraining randomizations within species found in each zone. Results were consistent with the main SES tests (Fig. S6).

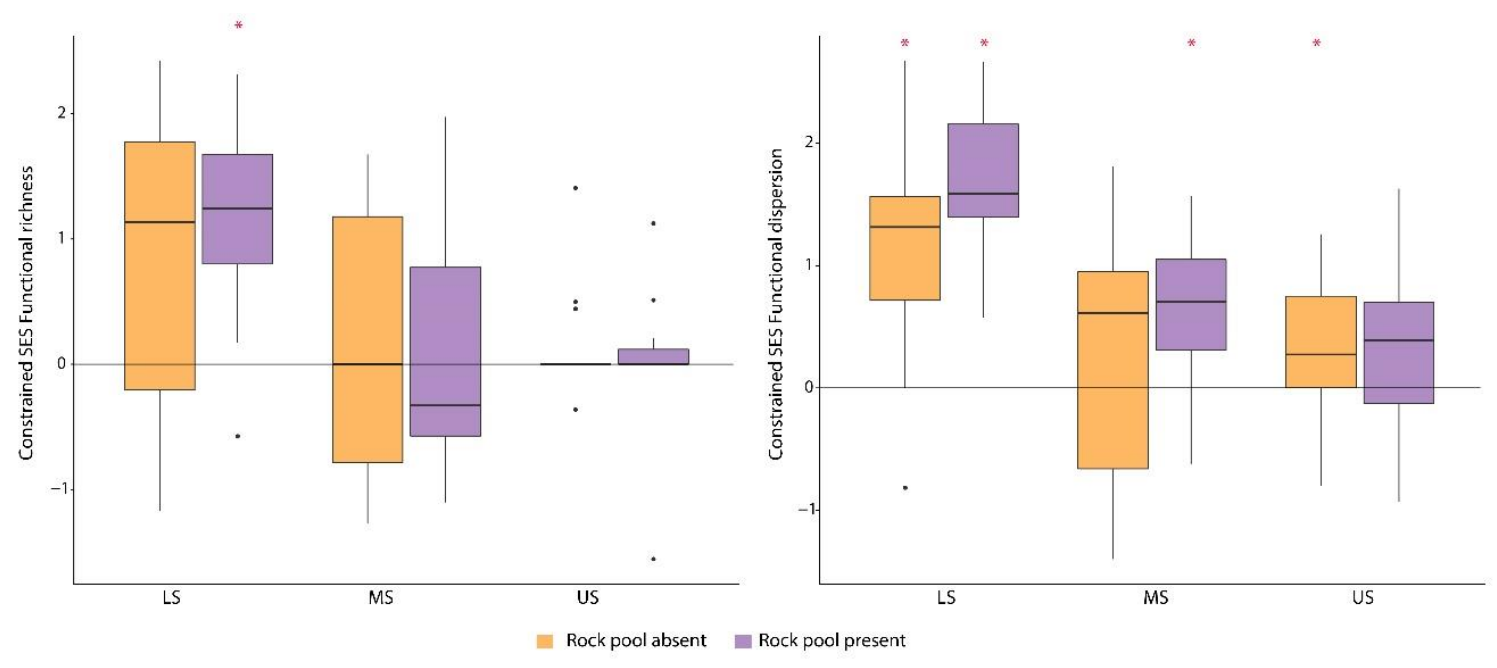

Figure S6. Standardised effect sizes (SES) from randomizations constrained within zones. Boxplots show SES values of functional dispersion across shore zones (LS=low shore, MS=middle shore and US=upper shore). Values not touching the lines indicate deviance from null models, i.e. above or below expected at random. Asterisks indicate significant difference from zero (obtained from onesample $t$ test, or Wilcoxon rank test when data distribution was not normal).

\section{References}

Maire E, Grenouillet G, Brosse S, Villéger S (2015). How many dimensions are needed to accurately assess functional diversity? A pragmatic approach for assessing the quality of functional spaces: Assessing functional space quality. Global Ecology and Biogeography 24:728-740. doi: 10.1111/geb.12299

Oksanen J et al (2019). vegan: Community Ecology Package. R package version 2.5-4. https://CRAN.R-project.org/package=vegan

Schneider C A, Rasband WS, Eliceiri KW (2012). NIH Image to ImageJ: 25 years of image analysis. Nature Methods, 9(7), 671-675. doi: 10.1038/nmeth.2089.

Villéger S, Mason NWH, Mouillot D (2008) New Multidimensional Functional Diversity Indices for a Multifaceted Framework in Functional Ecology. Ecology 89:2290-2301 
Appendices for Chapter 4: "A phylogenetic perspective to the functional diversity of red seaweeds."

\section{Appendix 1.}

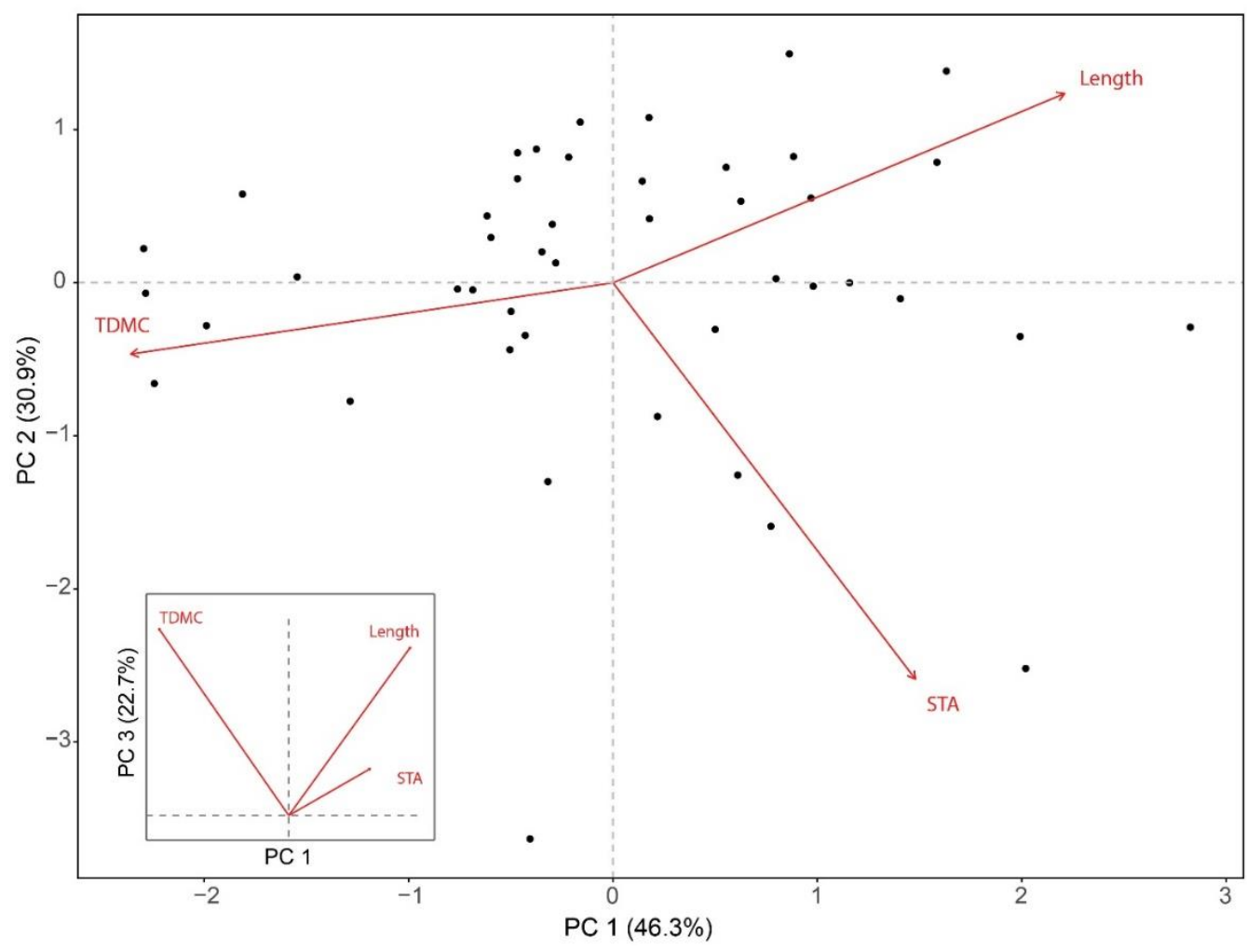

Figure S1. Biplot of the principal component analyses (PCA) of the three selected traits. Points are individual species. Smaller biplot shows trait associations to PC axes 1 and 3.

\section{Appendix 2.}

Table S2. Including measurement error in the estimation of phylogenetic signal (Blomberg's K).

\begin{tabular}{lcc}
\hline Trait & $\mathrm{K}$ & $\mathrm{P}$ value \\
\hline Length & 1.37 & 0.01 \\
STA & 1.13 & 0.02 \\
TDMC & 0.45 & 0.15
\end{tabular}


Appendix for Chapter 5: "Functional diversity of seaweeds revisited: confronting traditional groups with quantitative traits"
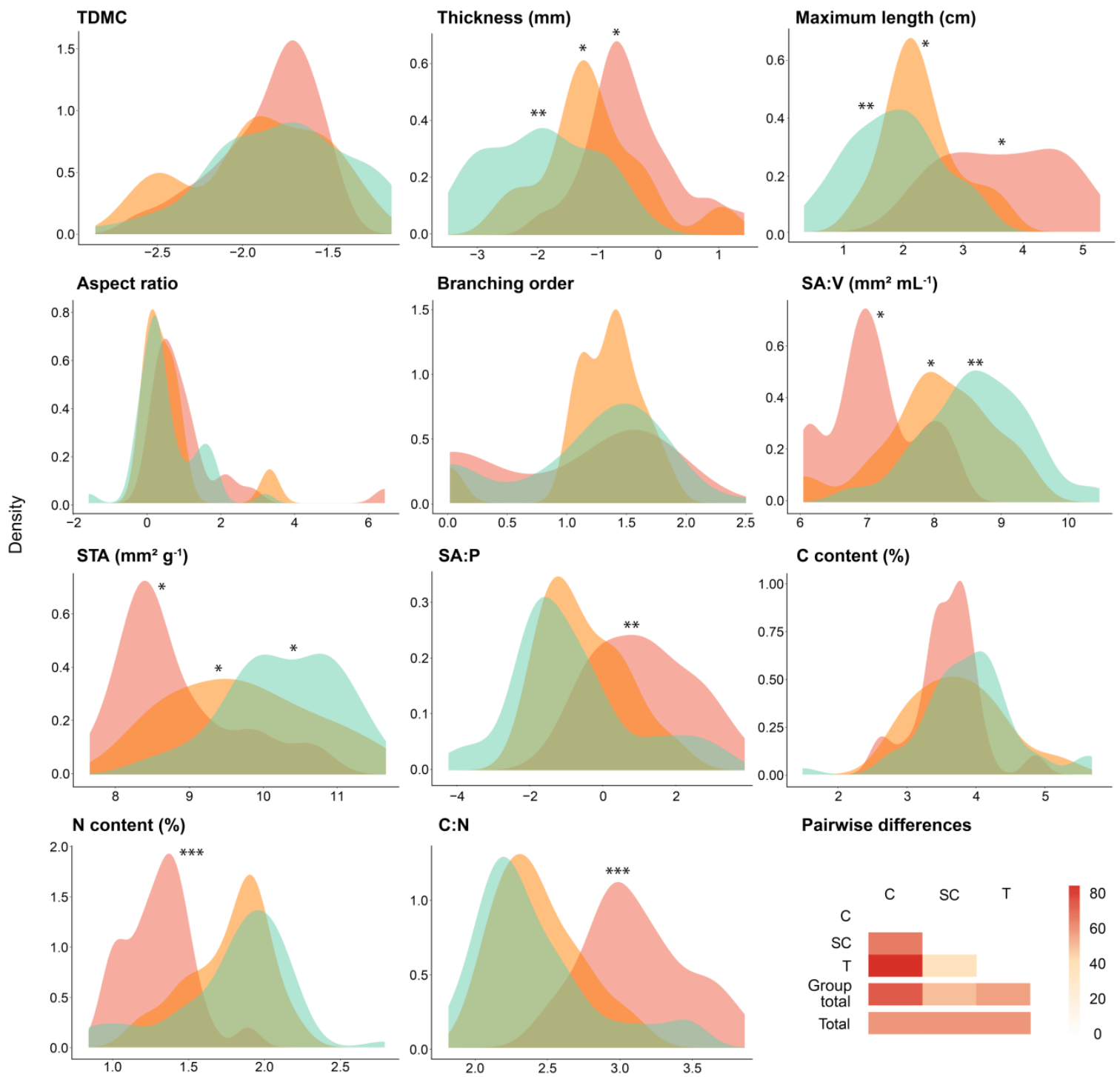

Pairwise differences

$\square$ Canopy $\square$ Subcanopy $\square$ Turf

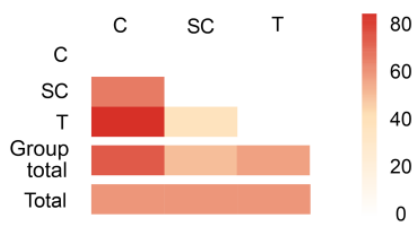

Figure S1. Distribution of species-level traits among a common three-level categorisation of vertical space use. Values of the 11 continuous functional traits are transformed species-level means across the 95 macroalgal species screened (Table S4). Groups that are significantly different from all others are marked by asterisks (pairwise Wilcoxon rank sum test; '*': $P<0.05$, '**': $P<0.01$, '***': $P<0.001$; lowest common $P$ is shown). Heatmap (bottom right) shows the proportion (\%) of significant differences among pairwise comparisons for each group (group total) and overall (total; ' $\mathrm{C}$ ' stands for canopy, ' $\mathrm{SC}$ ' for subcanopy, and ' $\mathrm{T}$ ' for turf). 


\section{Appendix for the General Discussion}

Extra analysis: community weighted means of all algae groups, along the main intertidal zones

Aim and method: To combine all chapters and provide a more general assessment of how traits vary with intertidal height, I calculated community weighted means (CWM) across zones considering all species together and separated by algae groups. For simplicity, I used the three traits selected on chapter 4 - TDMC, STA and length - which represent distinct ecophysiological strategies. CWM were calculated the same way as on Chapter 2, but across the 120 quadrats selected on Chapter 4.

Results: Towards the upper shore, seaweed communities displayed, on average, higher TDMC, driven by communities of brown and red algae (Fig. 1). Contrarily, average STA decreased with height, driven by red algae only. Average length remained constant (although with a lower range), driven positively by green algae and negatively by the other two groups.

Summary: Trait - environment relationships differed among the three major algae groups. STA was more important for red algae assembly across zones, whereas TDMC was determinant for both red and brown algae, and length varied for all groups (but not in the same direction). 


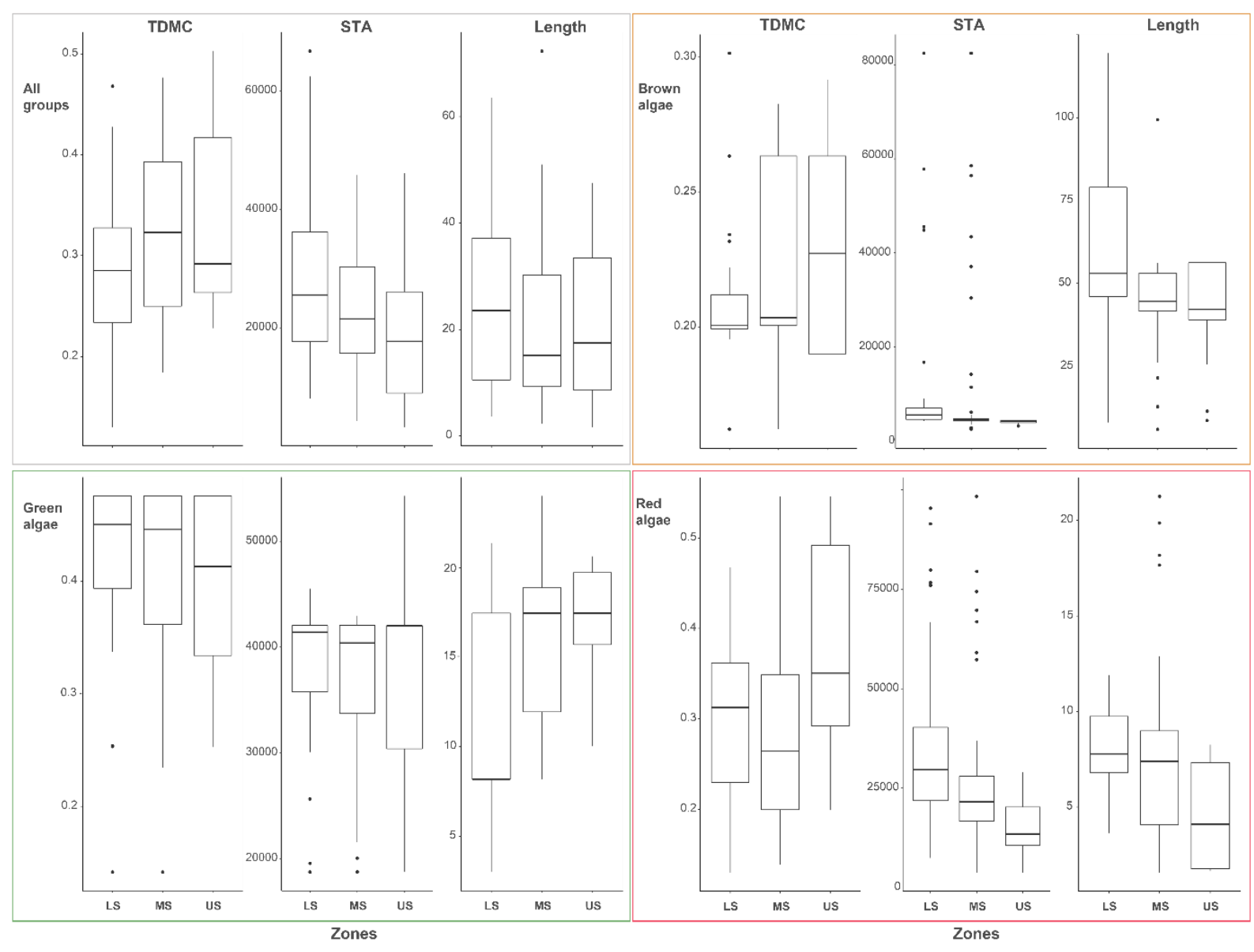

Figure S1. Community weighted means across intertidal zones for all algae groups and separated by group. TDMC: thallus dry matter content; STA: specific thallus area. Number of species for each group: browns $=13$; greens $=7$; reds $=42$. 


\section{Glossary}

Community assembly: how species are organised in a community, comprising their composition, abundances, frequencies and distribution across space.

Convex hull: a construct from computational geometry, which provides a multidimensional measure of the volume of trait space occupied by species in a community.

Ecosystem functioning: The process through which the constituent living and non-living elements of ecosystems change and interact (as defined by IUCN*).

Ecosystem services: goods and services provided by healthy ecosystems, including medicinal plants, clean water and air, and protection from extreme natural events (as defined by $\left.\mathrm{IUCN}^{*}\right)$.

Epibiota: mobile or non-mobile organisms living in association with the focus species.

Frond: main photosynthetic part of a macroalga; equivalent to the leaves in a plant.

Holdfast: attachment structure of macroalgae.

Stipe: supporting structure found in some species of macroalgae; equivalent to a stem in a plant.

Thallus: whole of a macroalga. Divided into (not necessarily): holdfast, stipe and frond.

*https://www.iucn.org/downloads/en_iucn_glossary_definitions.pdf 